Ivanildo Barbosa

\title{
AVALIAÇÃO DO IMPACTO DE ACIDENTES DE TRÂNSITO NO TRÁFEGO DE VIAS URBANAS A PARTIR DE VALORES DE VELOCIDADE
}

Tese de Doutorado

Tese apresentada ao Programa de Pós-Graduação em Informática da PUC-Rio como requisito parcial para obtenção do título de Doutor em Informática.

Orientador: Prof. Marco Antonio Casanova 


\section{Avaliação do impacto de acidentes de trânsito no tráfego de vias urbanas a partir de valores de velocidade}

Tese apresentada ao Programa de Pós-Graduação em Informática da PUC-Rio como requisito parcial para obtenção do título de Doutor em Informática. Aprovada pela Comissão Examinadora abaixo assinada.

Prof. Marco Antonio Casanova

Orientador

Departamento de Informática - PUC-Rio

Prof. Antonio Luz Furtado

Departamento de Informática - PUC-Rio

Prof. Helio Côrtes Vieira Lopes

Departamento de Informática - PUC-Rio

Prof. José Antonio Fernandes de Macêdo Departamento de Ciência da Computação - UFC

Profa. Marta Lima de Queirós Mattoso Programa de Engenharia de Sistemas/COPPE - UFRJ

Prof. José Eugênio Leal

Coordenador Setorial do Centro Técnico Científico - PUC-Rio

Rio de Janeiro, 27 de março de 2015 
Todos os direitos reservados. É proibida a reprodução total ou parcial do trabalho sem autorização da universidade, da autora e do orientador.

\section{Ivanildo Barbosa}

Graduou-se em Engenharia Cartográfica pelo Instituto Militar de Engenharia (IME) em 2001. Trabalha com Sistemas de Informações Geográficas desde 2002. Professor do Instituto Militar de Engenharia (IME) desde 2007. Concluiu o Mestrado em Engenharia Cartográfica na área de Modelagem e Representação Terrestres pelo Instituto Militar de Engenharia (IME) em 2006.

Ficha Catalográfica

Barbosa, Ivanildo
Avaliação do impacto de acidentes de trânsito no
tráfego de vias urbanas a partir de valores de velocidade /
Ivanildo Barbosa; orientador: Marco Antonio Casanova. -
2015.
$175 \mathrm{f} . ; 30 \mathrm{~cm}$
Tese (Doutorado em Informática) - Pontifícia
Universidade Católica do Rio de Janeiro, Departamento de
Informática, 2015.
Inclui bibliografia.
1. Informática - Teses. 2. Sistemas de transporte
inteligentes. 3. Modelagem de tráfego. 4. Série temporais.
5. Propagação espacial de fenômenos. I. Casanova, Marco
Antonio. II. Pontifícia Universidade Católica do Rio de
Janeiro. Departamento de Informática. III. Título.




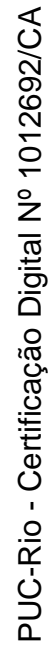

A Deus, pelas oportunidades, e à minha esposa,

Sarah Queiroz de Moraes Barbosa, pelo grande apoio, incentivo e carinho. 


\section{Agradecimentos}

A Deus, que criou as oportunidades quando, aos olhos humanos, parecia improvável.

À minha esposa, Sarah, pela paciência, pelo incentivo e pelo companheirismo.

Aos meus pais, pelo incentivo durante toda a minha vida.

Aos meus companheiros da Seção de Engenharia Cartográfica pela motivação, em especial, ao Dr. Leonardo, que se empenhou de forma excepcional para que o curso acontecesse.

Ao meu orientador prof. Marco Antonio Casanova, pela dedicação, estímulo e paciência. Sou especialmente grato por acreditar em mim mesmo quando nem eu mesmo acreditava, mostrando sempre um horizonte que me motivava a seguir em frente. Sua conduta me fez refletir sobre meu papel como professor e orientador, sendo um aprendizado à parte para a vida.

Aos colegas que fiz durante as aulas, pelo incentivo constante.

Aos professores que lecionaram durante esse período, me mostrando um mundo desconhecido que me inspirou e que continuará me inspirando por muitos e muitos anos.

A gli amici da CNR per farmi imparare italiano ed anche conoscere meglio il KDD, il SQL/PostGIS (grazie, Lorenzo) e la Gelateria De' Coltelli. Chiara Renso, grazie per l'attenzione ed per farmi sentire bene lontano mi cità. Sei una bella inpirazione professionale per me.

A todos os funcionários do Departamento de Informática da PUC-Rio, pela presteza e pela cordialidade no atendimento às demandas solicitadas.

A todos os amigos dentro e fora da PUC que, de uma forma ou de outra, me estimularam ou me ajudaram. 


\section{Resumo}

Barbosa, Ivanildo; Casanova, Marco Antonio (Orientador). Avaliação do impacto de acidentes de trânsito no tráfego de vias urbanas a partir de valores de velocidade. Rio de Janeiro, 2015. 175p. Tese de Doutorado Departamento de Informática, Pontifícia Universidade Católica do Rio de Janeiro.

Uma das preocupações das grandes cidades é a minimização dos efeitos do aumento da quantidade de veículos em circulação e dos acidentes que, consequentemente, tendem a ocorrer com maior frequência. Com a popularização e a miniaturização dos receptores GPS, a disponibilidade de valores de velocidade observados nas vias urbanas e a publicação de ocorrências de trânsito georreferenciadas em redes sociais, é agora possível avaliar as condições do trânsito quanto às reduções de velocidade. Contudo, é necessário filtrar os dados de tal forma a minimizar incertezas temáticas, espaciais e temporais. Esta tese propõe uma metodologia para a avaliação do impacto de acidentes de trânsito, empregando valores de velocidade. Para tanto, considera metodologias auxiliares para: (1) processamento de rotas rastreadas com GPS para identificar vias com maior circulação, calcular estatísticas das velocidades observadas e estimar o tráfego em vias de mão dupla, pela análise das direções do movimento; (2) representação do comportamento do tráfego a partir dos valores de velocidade registrados nas vias; (3) extração e seleção dos dados sobre acidentes extraídos do Twitter para identificar os possíveis efeitos desses acidentes nos valores de velocidade. As contribuições desta tese são: (1) avaliação do tráfego, em condições normais e após a ocorrência de acidentes, com base em valores de velocidade, de aquisição mais simples do que os valores de fluxo e concentração de tráfego; (2) emprego de publicações de eventos em redes sociais, permitindo rápido acesso à informação; (3) aplicação das avaliações em vias urbanas, em lugar de rodovias, o que implica em levar em consideração as interferências no tráfego inerentes às interseções, sinais de trânsito e fluxo de pedestres; e (4) uma metodologia para extração de estatísticas de velocidade a partir de dados GPS, enfatizando as possíveis fontes de erro existentes nos processos de map matching e classificação temporal. 


\section{Palavras-chave}

Sistemas de Transporte Inteligentes; Modelagem de Tráfego; Séries Temporais; Propagação espacial de fenômenos; Twitter. 


\section{Abstract}

Barbosa, Ivanildo; Casanova, Marco Antonio (Advisor). Assessment of the impact of traffic accidents on the flow of urban roads based on speed values. Rio de Janeiro, 2015. 175p. D.Sc. Thesis - Departamento de Informática, Pontifícia Universidade Católica do Rio de Janeiro.

A major concern in large cities is to minimize the effects of the increasing quantity of vehicles in circulation and, consequently, of the accidents that tend to occur more frequently. Due to the popularization and miniaturization of GPS receivers, the availability of large volumes of data about vehicle speed in urban roads and the large number of traffic-related messages published in social networks, it is now possible to collect enough input data to model traffic conditions based on the observed reduction in speed values. However, it is necessary to filter the data to minimize thematic, spatial and temporal uncertainties. This thesis proposes a methodology to assess the impact of traffic accidents by analyzing speed values. To achieve this goal, it also proposes auxiliary methodologies, aiming at: (1) processing GPS-tracked routes to compute speed statistics and estimate traffic in two-way streets, by performing direction analysis; (2) representing traffic behavior based on the observed speed values; (3) extracting and selecting accident-related data by mining Twitter posts for later identification of the likely effects on speed values. The main contributions of this thesis are: (1) the assessment of traffic conditions based on speed values, which are easier to acquire than data about traffic volume and concentration; (2) the use of posts from social networks, which provide timely access to traffic events; (3) the assessment of urban roads instead of freeways or roads, which require modeling intersections, traffic lights and pedestrian flow; and (4) a methodology designed to extract speed statistics from raw GPS data, which handles likely error sources related to both map matching process and temporal classification.

\section{Keywords}

Intelligent Transportation Systems; Traffic Modelling; Temporal series; Spatial propagation; Twitter. 


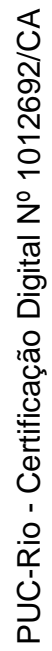

"Nenhum vento sopra a favor de quem não sabe para onde ir."

Sêneca (04 a.C. - 65) 


\section{Sumário}

1 Introdução 17

$\begin{array}{lr}\text { 1.1. Motivação } & 17\end{array}$

$\begin{array}{ll}\text { 1.2. Objetivo } & 18\end{array}$

1.3. Trabalhos Relacionados 19

1.4. Organização da Tese 21

2 Descrição do Tráfego 23

2.1. Variáveis Macroscópicas do Tráfego 24

2.2. Formação de Congestionamentos 28

đิ 2.3. Classificação hierárquica das vias 29

2.3.1. Vias de trânsito rápido 30

2.3.2. Vias arteriais 32

$\begin{array}{ll}\text { 2.3.3. Vias coletoras } & 34\end{array}$

$\begin{array}{ll}\text { 2.4. Conclusões } & 35\end{array}$

3 Dados de Trânsito Publicados na Web 37

$\begin{array}{ll}\text { 3.1. Portais Oficiais } & 37\end{array}$

3.2. Dados publicados pelo Maplink 39

3.3. Dados publicados pelo Google $\quad 41$

3.4. Dados publicados pelo Twitter 42

3.5. Conclusão 43

4 Qualidade da Informação Geoespacial Relativa a Trânsito 44

4.1. Acurácia Temática 44

4.2. Acurácia Espacial 45

4.3. Acurácia Temporal $\quad 47$

4.4. Métricas de confiabilidade dos dados 48 
4.5.1. Acurácia Temática 49

4.5.2. Acurácia Espacial 50

4.5.3. Acurácia Temporal 52

4.5.4. Confiabilidade dos dados $\quad 52$

4.6. Conclusões 53

5 Estimação de estatísticas de velocidade de uma malha viária com base em rotas rastreadas com GPS $\quad 54$

5.1. Introdução $\quad 54$

5.2. Cenário $\quad 55$

5.3. Metodologia 57

5.3.1. Map Matching 58

5.3.2. Classificação temporal 62

5.3.3. Cálculo das Estatísticas 63

5.4. Experimentos 63

5.4.1. Aplicação com dados reais 63

$\begin{array}{ll}\text { 5.4.2. Estimação de tempo de viagem } & 67\end{array}$

$\begin{array}{ll}\text { 5.5. Trabalhos relacionados } & 68\end{array}$

$\begin{array}{ll}\text { 5.6. Conclusão } & 69\end{array}$

6 Descrição do tráfego com base na velocidade 72

6.1. Modelo de Dados Empregado nas Análises 72

6.1.1. Malha viária da cidade do Rio de Janeiro 72

6.1.2. Medições de velocidade 73

6.2. Revisão conceitual $\quad 74$

6.2.1. Detecção de outliers $\quad 75$

6.2.2. Detecção de agrupamentos de valores $\quad 77$

6.2.3. Métricas de similaridade entre distribuições de valores $\quad 79$

6.3. Metodologia para análise de amostras de velocidade 81

6.3.1. Detecção de outliers 82 
6.3.2. Detecção de agrupamentos de valores 84

6.3.3. Métricas de similaridade entre distribuições de valores 84

6.4. Conclusão 86

7 Avaliação das variações das velocidades após acidentes $\quad 89$

7.1. Metodologia $\quad 89$

7.1.1. Seleção de Dados $\quad 89$

7.1.2. Ordenação dos pontos 92

7.1.3. Avaliação dos valores de velocidade 92

7.1.4. Identificação de propagação do congestionamento 93

7.2. Experimentos Realizados 94

$\begin{array}{ll}\text { 7.3. Conclusão } & 101\end{array}$

8 Conclusões 104

$\begin{array}{lll}\text { 8.1. Resumo } & 104\end{array}$

8.2. Contribuições 105

$\begin{array}{ll}\text { 8.3. Limitações } & 106\end{array}$

$\begin{array}{ll}\text { 8.4. Trabalhos Futuros } & 107\end{array}$

9 Referências Bibliográficas $\quad 109$

Apêndice 1: Dicionário de Dados $\quad 115$

$\begin{array}{ll}\text { Apêndice 2: Tweets Analisados } & 120\end{array}$

Apêndice 3: Descrição dos Pontos de Medição de Velocidade 147 


\section{Lista de figuras}

Figura 1 - Gráficos relacionando variáveis macroscópicas do trafego. Extraído de da Silva (2007)

Figura 2 - Exemplo de diagrama Fluxo-Concentração 27

Figura 3 - Exemplo de diagrama Fluxo-Velocidade 27

Figura 4 - Exemplo de diagrama Concentração-Velocidade 28

Figura 5 - Trecho de uma via classificada como expressa. Extraído de Google Street View.

Figura 7 - Trecho de uma via classificada como arterial secundária.

Extraído de Google Street View.

Figura 8 - Trecho de uma via classificada como coletora. Extraído de Google Street View.

Figura 9 - Registro de acidente feito por usuário do aplicativo Olhos da Cidade.

Figura 10 - Distribuição dos pontos de medição de velocidade da empresa Maplink pela cidade do Rio de Janeiro (base cartográfica Open Street Maps).

Figura 11 - Conteúdo do Google Maps gerado por usuários do aplicativo Waze.

Figura 12 - Postagem com link para página com maior detalhamento da ocorrência.

Figura 13 - Exemplos de generalização cartográfica. Extraído de IBGE (2004).

Figura 14 - Exemplo de discrepância entre o local de registro da postagem e o conteúdo da mensagem.

Figura 15 - Etapas de processamento propostas para agregar estatísticas de velocidade à malha viária.

Figura 16 - Distribuição de valores de azimutes de pontos orientados.

Figura 17 - Exemplos de pontos contidos em mais de uma zona de vizinhança. 
Figura 18- Exemplo da distribuição de pontos GPS ao longo das vias da cidade.

Figura 19 - Exemplos de estatísticas de velocidade ao longo da semana.

Figura 20 - Opções de rotas propostos pelo Google Maps.

Figura 21 - Extrato da página da empresa Maplink com informações sobre o tráfego no corredor Linha Amarela.

Figura 22 - Gráficos com valores de velocidade obtidos entre $7 \mathrm{~h}$ e $8 \mathrm{~h}$ de (a) segundas-feiras e (b) terças-feiras.

Figura 23 - Histogramas referentes aos valores de velocidade obtidos às (a) segundas-feiras e (b) terças-feiras.

Figura 24 - Observações de velocidade às segundas feiras entre 10h e 11h: (a) distribuição dos valores e (b) Histograma com intervalos de $5 \mathrm{~km} / \mathrm{h}$.

Figura 25 - Limites superior e inferior de outliers observados nos pontos 2354 e 2355 em função da hora do dia, em diferentes dias da semana.

Figura 26 - Quantidade de agrupamentos detectados em função da hora do dia.

Figura 27 - Valores de similaridade entre as distribuições de velocidade, em função da hora do dia, nos pontos 2354 e 2355.

Figura 28 - Valores de similaridade entre as distribuições de velocidade, em função da hora do dia, nos pontos 2356 e 2357

Figura 29 - Localização e posicionamento relativo entre os pontos 2356 e 2357.

Figura 30 - Distribuição geográfica das ocorrências por

palavra-chave (base cartográfica Open Street Maps).

Figura 31 - Distribuição das ocorrências por palavra-chave e por hora do dia.

Figura 32 - Distribuição total das ocorrências por hora do dia.

Figura 33 - Amostras de velocidade extraídas em locais vizinhos ao local de ocorrência do tweet \#539728870866300929.

Figura 34 - Amostras de velocidade extraídas em locais vizinhos ao 
local de ocorrência do tweet \#539728870866300929.

Figura 35 - Distribuições de probabilidades de velocidades nos PMV (a) \#1272 e (b) \#1309.

Figura 36 - Distribuições de probabilidades de velocidades nos trechos definidos pelos PMV (a)\#1273 - \#1272 - \#1271 e (b) \#1312 - \#1311 - \#1310 - \#1309.

Figura 37 - Amostras de velocidade extraídas em locais vizinhos ao local de ocorrência do tweet \#534379856176246784.

Figura 38 - Distribuições de probabilidades de velocidades nos trechos definidos pelos PMV \# 1486, \#1485 e \#1484. 


\section{Lista de Tabelas}

Tabela 1 - Capacidades das vias arteriais e coletoras. Extraído de Rio de Janeiro (2005). 36

Tabela 2 - Dados sobre os resultados de processamento. 65

Tabela 3 - Dados adicionais sobre os resultados de processamento. 65

Tabela 4 - Tempos de viagem estimados com base nos valores de velocidade média calculados previamente 68

Tabela 5 - Valores de similaridade e distância entre os valores de velocidade observados

Tabela 6 - Exemplo de frequências relativas das velocidades observadas em PMV 


\section{Introdução}

Este capítulo apresenta a motivação para a tese, os objetivos do trabalho e como a tese está organizada.

\subsection{Motivação}

Um dos maiores desafios dos gestores das cidades é a diminuição do tempo gasto diariamente pela população no transporte urbano. Cidades como o Rio de Janeiro tem investido para fornecer à população novas opções de transporte de massa para, consequentemente, diminuir a quantidade de carros nas ruas. São expansões das linhas de metrô, investimentos nos trens urbanos que integram a região metropolitana, corredores expressos de ônibus e veículos leves sobre trilhos, entre outras iniciativas. Contudo, automóveis pessoais ainda são a escolha de muitas pessoas pelo conforto e pela flexibilidade dos deslocamentos.

Os tempos de deslocamento nos percursos urbanos são naturalmente consequência das velocidades desenvolvidas pelos veículos ao longo das vias e das distâncias percorridas. A velocidade de um veículo em uma rodovia depende, além da habilidade do motorista e da qualidade do veículo, de cinco condições: características técnicas da rodovia, atrito lateral, volume e composição do tráfego, condições do tempo e limitações legais, frequentemente impostas por dispositivos de controle de tráfego. O efeito desses fatores geralmente é interrelacionado, embora alguns deles possam ser dominantes (DNIT, 2009).

Com a miniaturização e a popularização dos rastreadores GPS, juntamente com a crescente oferta de Internet móvel, a quantidade de dados de velocidade gerada por estes sensores permite a construção de uma ampla base de dados. Serviços disponibilizados por empresas como o Google e a Maplink já usam dados de velocidade produzidos por seus usuários para diagnosticar as condições do tráfego em tempo real.

Por outro lado, a proposta de inclusão de conteúdo na Web, produzido pelos seus usuários, deu origem a iniciativas, cada vez mais presentes na vida cotidiana, 
como os blogs, e serviços como Wikipedia, Youtube, Flick, e o Waze ${ }^{l}$, entre outros. Exemplos adicionais de iniciativas colaborativas no mapeamento viário incluem o OpenStreetMap ${ }^{2}$ e o TrackSource ${ }^{3}$, oferecendo dinamismo na produção e na atualização das bases cartográficas com precisão compatível à visualização em navegadores. Aplicativos como o próprio Waze e o Olhos da Cidade , $^{\text {, }}$ disponibilizado pela Prefeitura do Rio de Janeiro, permitem ao usuário inserir dados sobre ocorrências de trânsito e acompanhar o estado do trânsito em tempo real. A integração dos serviços do Google Maps com os dados produzidos pelos usuários do aplicativo Waze demonstra o valor das iniciativas colaborativas.

A publicação de dados em perfis de redes sociais fornece insumos para análises em diversas áreas do conhecimento. A mineração de dados a partir de postagens do Twitter, por exemplo, é empregada em iniciativas como o Observatório da $\mathrm{Web}^{5}$ e em trabalhos como os publicados por McGee et al (2011), Alonso (2014), MacEachren (2011), Sakaki et al (2010), Albuquerque (2012), Redlich (2013), entre outros.

Apesar de as publicações referentes a condições do tráfego poderem conter informações de caráter técnico, produzidas por instituições especializadas, existem aquelas que contém comentários e desabafos sobre ocorrências vividas por usuários leigos. Alguns trabalhos relacionados à mineração de dados de trânsito publicados no Twitter serão citados no capítulo 4 .

Portanto, a abundância da oferta de dados contendo valores de velocidade pode ser um importante recurso para avaliar o comportamento do tráfego a fim de identificar tendências, padrões e relacionamentos. Em conjunto com uma base de dados que contenha registros de ocorrências de trânsito, é possível avaliar a influência de tais ocorrências no tráfego urbano cotidiano.

\subsection{Objetivo}

O objetivo desta tese é extrair conhecimento a partir da análise de velocidade em vias urbanas, utilizando rotas rastreadas com GPS, dados obtidos por sensores

\footnotetext{
${ }^{1} \mathrm{https}: / /$ www.waze.com/

${ }^{2}$ https://www.openstreetmap.org

${ }^{3}$ http://tracksource.org.br/

${ }^{4}$ http://www .rio.rj.gov.br/web/guest/exibeconteudo?id=4997234

${ }^{5} \mathrm{http}$ ://observatorio.inweb.org.br/
} 
fixos e dados sobre acidentes ocorridos no período, extraídos de postagens no Twitter.

Espera-se, mais especificamente, responder às seguintes perguntas:

- Quais as precauções necessárias para utilizar rotas rastreadas com GPS, dados obtidos de sensores fixos e dados extraídos do Twitter como fontes de dados de trânsito?

- Como os valores de velocidade se distribuem ao longo das vias e ao longo de períodos de tempo (ao longo de um dia, ao longo de uma semana, etc)?

- Como os efeitos dos acidentes podem ser percebidos ao longo de uma via e nas vias próximas, especialmente no que se refere a valores de velocidade?

\subsection{Trabalhos Relacionados}

Antes de enumerar as contribuições, é necessário mencionar alguns trabalhos publicados sobre a descoberta de conhecimento relacionado ao comportamento do tráfego de veículos em vias urbanas. Estes trabalhos poderão voltar a ser mencionados nos capítulos relacionados aos temas abordados, juntamente com outros trabalhos relacionados aos temas específicos de cada capítulo.

É possível distinguir diferentes abordagens sobre o assunto. A primeira consiste na avaliação da qualidade da rede viária, seja no tocante à capacidade das vias, à sua conformação geométrica ou à conectividade existente entre elas. Como exemplo de trabalho baseado nessa abordagem pode ser mencionado Demšar et al. (2008), que apresenta uma metodologia de identificação vulnerabilidades em redes espaciais, isto é, o potencial dos danos causados à conectividade da rede com a eliminação de um componente. Outro trabalho que pode ser mencionado sobre o assunto é Wu et al (2009), onde a análise da rede de tráfego visa a identificar potenciais de congestionamento, empregando árvores geradoras mínimas (AGM) a partir da rede viária para identificar cruzamentos com menor capacidade de fluxo. A principal vantagem desta abordagem é a independência de medições de variáveis do tráfego, com grande importância em simulações. Contudo, a avaliação de valores reais das variáveis de tráfego permite elaborar diagnósticos mais realísticos. 
A segunda abordagem está relacionada à identificação de demanda de tráfego a partir da análise de rotas coletadas por receptores GPS (Global Positioning System) instalados em frotas. Um exemplo é Rinzivillo et al (2012), onde as rotas rastreadas são processadas a fim de identificar os limites da mobilidade urbana entre cidades, comparando esses limites com os limites administrativos municipais. Furtado et al (2012) também emprega rotas rastreadas com GPS, porém com o intuito de identificar pontos de interesse que possuem maior atratividade em uma região, ou seja, onde a demanda de tráfego aumenta devido ao acesso a esses pontos. O emprego de rotas obtidas por rastreamento com GPS para obtenção de velocidades pode ser exemplificado em Wang et al (2013). Foram utilizadas rotas de taxi da cidade de Beijing para extrair valores de velocidade, associadas às vias pelo processo de map matching. Os valores são organizados em função do tempo e são codificados por cores em função da velocidade média registrada em cada via. A vantagem desta abordagem é a possibilidade de aumentar a base de dados à medida que os receptores GPS tendem a fornecer dados cada vez mais precisos por quantias mais acessíveis. Uma das principais desvantagens dessa abordagem é que os valores de velocidade são calculados a partir de coordenadas de pontos consecutivos, de modo que esse resultado nem sempre coincide com o valor registrado no velocímetro. Outra desvantagem é que o tamanho da amostragem depende da quantidade de usuários que possui o equipamento e que disponibiliza os dados rastreados.

A terceira abordagem se caracteriza pela extração de conhecimento a partir de contadores de loop (loop detectors) fixados em locais pré-definidos. Alguns desses equipamentos permitem quantificar fluxo, densidade e velocidade (ver capítulo 2) enquanto outros medem apenas fluxo e densidade. Cabe salientar que o Highway Capacity Manual (TRB, 2000), principal referência no que tange a estudos de tráfego no Brasil, apresenta a velocidade de fluxo, a densidade do fluxo e o atraso (ou delay) como medidas de desempenho para rodovias. O atraso descrito no HCM se refere ao tempo perdido em função do controle de tráfego em interseções. Knoop (2009), Chung e Recker (2012) e Medeiros et al (2010) são exemplos de trabalhos baseados nas observações contadores de loop.

Knoop (2009) propôs um método para quantificar a quantidade de motoristas que mudam de estrada ao se deparar com um congestionamento provocado por um acidente. Nos experimentos descritos, as estradas avaliadas 
foram equipadas com contadores a cada 500 metros, armazenando a cada 1 minuto, em um banco de dados, a velocidade e a quantidade de carros. A métrica usada é baseada na variação dos valores de fluxo em cada via analisada em comparação com os fluxos medidos nas vias consideradas alternativas.

Chung e Recker (2012) apresenta uma metodologia para estimar as extensões espacial e temporal dos atrasos ocasionados por acidentes ocorridos em vias expressas. Neste trabalho, a via é segmentada em seções delimitadas por sensores de tráfego ${ }^{6}$ e o tempo é dividido em subintervalos de 5 minutos ao longo de um ano. São observadas as velocidades médias em cada trecho e em cada intervalo de tempo, de modo que seja possível distinguir os valores observados após a ocorrência de um acidente daqueles medidos em situações normais.

Medeiros et al (2010) emprega dados de fluxo e densidade medidos por contadores posicionados ao longo da malha viária durante 3 anos, armazenados a cada 3 minutos. Assim, o diagnóstico de congestionamento não é baseado em valores de velocidade. Também são empregados no trabalho grafos de propagação, grafos direcionados onde os nós representam os sensores, os arcos representam a propagação de comportamentos atípicos e os pesos dos arcos representam a probabilidade de propagação. A vantagem desta abordagem é a possibilidade de analisar fluxo, densidade e, dependendo do equipamento, velocidade do número total de veículos que passa por ele, de modo que os resultados obtidos com esses equipamentos não são baseados em amostras, mas em todo o conjunto de objetos. A desvantagem dessa abordagem é que o custo de instalação impede que tais equipamentos estejam disponíveis em toda a rede viária.

\subsection{Organização da Tese}

A tese é composta pelos seguintes capítulos.

Os Capítulos 2, 3 e 4 tratam de aspectos gerais de dados sobre trânsito. O Capítulo 2 apresenta conceitos relacionados à descrição do tráfego, à formação de congestionamentos e descreve as características das vias existentes, com base em especificações oficiais, citando a legislação brasileira inerente ao assunto. O

\footnotetext{
${ }^{6}$ Os equipamentos empregados neste trabalho apenas medem fluxo e densidade, de modo que os valores de velocidade são computados posteriormente.
} 
Capítulo 3 cita fontes de dados e serviços Web destinados a fornecer informações relevantes ao tráfego tais como valores de velocidade, dados sobre acidentes ocorridos recentemente, roteamento, entre outros. O Capítulo 4 descreve os elementos da qualidade geoespacial, de acordo com o padrão internacional ISO 19157 (ISO, 2013), e coerentemente com os conceitos propostos por Barbosa e Casanova (2011). Os dados obtidos das fontes citadas no capítulo 3 são avaliados de maneira simplificada segundo essa classificação. Estes capítulos ilustram os conceitos com dados da Cidade do Rio de Janeiro.

O Capítulo 5 descreve uma metodologia para processar um conjunto de rotas rastreadas com GPS para calcular estatísticas das velocidades observadas e estimar o tráfego em vias de mão dupla pela análise das direções do movimento. Este capítulo distingue-se dos demais por utilizar rotas rastreadas com GPS na região da cidade de Pisa, Itália.

O Capítulo 6 aborda o comportamento do tráfego a partir da avaliação das variações das velocidades. São abordados conceitos para identificação de valores anormais (outliers), de padrões de distribuição de valores ao longo do tempo, assim como a avaliação da variação da velocidade entre pontos pertencentes a uma mesma via pela comparação das distribuições de velocidade.

O capítulo 7 propõe uma metodologia para avaliação dos valores de velocidade após a ocorrência de acidentes de trânsito, visando à identificação dos possíveis efeitos desses acidentes nos valores de velocidade. Os dados sobre acidentes são extraídos do Twitter e avaliados conforme os conceitos apresentados no Capítulo 4. Os Capítulos 6 e 7 voltam a utilizar dados da Cidade do Rio de Janeiro como estudo de caso.

Por fim, o capítulo 8 resume os resultados obtidos na tese e apresenta trabalhos futuros visando à continuidade das pesquisas apresentadas. 


\section{Descrição do Tráfego}

Tráfego, segundo a ABNT (1983), é “o estudo da passagem de pedestres, animais e veículos, de qualquer natureza, por vias terrestres, aquáticas e aéreas, abertas ao trânsito público”. Trânsito, segundo o Código Nacional de Trânsito (Brasil, 2004), é “a utilização das vias por pessoas, veículos e animais, isolados ou em grupos, conduzidos ou não, para fins de circulação, parada, estacionamento e operação de carga ou descarga". Portanto, nesta tese será empregada a terminologia Trânsito para denotar a movimentação dos veículos nas vias de uma cidade enquanto a terminologia Tráfego será empregada para descrever analiticamente as regras inerentes ao trânsito. Neste capítulo, por exemplo, serão abordados conceitos próprios para descrever como os veículos se movimentam pelas vias. No capítulo 3, entretanto, serão abordados dados e serviços relacionados a fatos ocorridos no trânsito em vias urbanas.

Existem diferentes formas de abordar o comportamento do tráfego, adotadas conforme a necessidade específica que se deseja atender: a macroscópica, que descreve as correntes de tráfego; a microscópica, que analisa as interações entre veículos consecutivos em uma corrente de tráfego; e a mesoscópica, que avalia o comportamento de grupamentos de veículos formados ao longo da malha viária (da Silva, 2007).

No contexto deste trabalho, entende-se que, ao tentar modelar a expansão de congestionamentos em uma rede viária, a abordagem mais apropriada seja a macroscópica, uma vez que os impactos serão refletidos como alterações na corrente de tráfego sem avaliar as variações instantâneas dos veículos individualmente. Portanto, serão apresentadas as variáveis macroscópicas do tráfego e a relação matemática entre eles.

Serão também abordadas as condições para a formação de congestionamentos em vias urbanas, seguidas dos critérios de classificação hierárquica dessas vias de acordo com especificações técnicas e na legislação de trânsito brasileira em vigor. Como exemplos das classificações hierárquicas, serão indicadas vias localizadas na cidade do Rio de Janeiro. 


\subsection{Variáveis Macroscópicas do Tráfego}

Para compreender a abordagem macroscópica para análise do comportamento do tráfego, é necessário conhecer algumas definições (da Silva, 2007):

a) Demanda (D): quantidade de veículos que devem passar por uma determinada seção da via. Compreende tanto os veículos que conseguem passar pelas vias disponíveis quanto aqueles que formam filas aguardando a oportunidade de passar;

b) Fluxo (ou Volume, q): variável temporal que representa a quantidade de veículos que passa pela seção de uma via em um intervalo de tempo $\Delta t$ (por exemplo, veículos/hora).

c) Capacidade $(C)$ : fluxo máximo que pode normalmente atravessar uma seção em condições existentes de tráfego, geometria e controle, num dado período.

d) Concentração (ou densidade, $k$ ): grandeza espacial que representa a quantidade de veículos presentes ao longo de uma determinada seção de uma via em um instante $t$ (por exemplo, veículos $/ \mathrm{km}$ ).

e) Velocidade ( $(v)$ : representa a velocidade que os veículos podem desenvolver ao trafegar pela via. Numa situação em que não há alteração nos valores das variáveis $q$ e $k$, a velocidade $v$, comum a todos os veículos ao longo da via e ao longo do tempo, é simplesmente dada pela razão entre fluxo e densidade;

f) Velocidade de fluxo livre $\left(v_{f}\right)$ : corresponde à média das velocidades desejadas pelos motoristas dos veículos numa corrente de tráfego. Neste trabalho, será adotado o valor da velocidade nominal máxima permitida para a via em questão (ver Seção 2.3 sobre hierarquia de vias);

g) Concentração máxima $\left(k_{J}\right)$ : correspondente à situação de completo congestionamento (jam, em inglês);

h) Velocidade 'ótima' $\left(v_{0}\right)$ : correspondente ao ponto em que a capacidade da via é alcançada;

i) Concentração 'ótima' $\left(k_{0}\right)$ : correspondente ao ponto em que a capacidade da via é alcançada. 
Existem modelos que relacionam essas grandezas, entre os quais se destacam os modelos logarítmicos de velocidade-concentração e fluxoconcentração (Underwood, de 1961 e Greenberg, de 1959), além dos modelos parabólicos de fluxo-concentração e de fluxo-velocidade (Greenshields, de 1935). O modelo de Greenberg demonstra boa aderência para fluxos congestionados, mas não é satisfatório para baixas concentrações. Por outro lado, o modelo de Underwood apresenta boa aderência para baixas concentrações, mas não para altas.

A Fig. 1a apresenta o gráfico de um modelo logarítmico fluxo-concentração enquanto o gráfico da Fig. 1b refere-se a um modelo parabólico fluxo-velocidade.

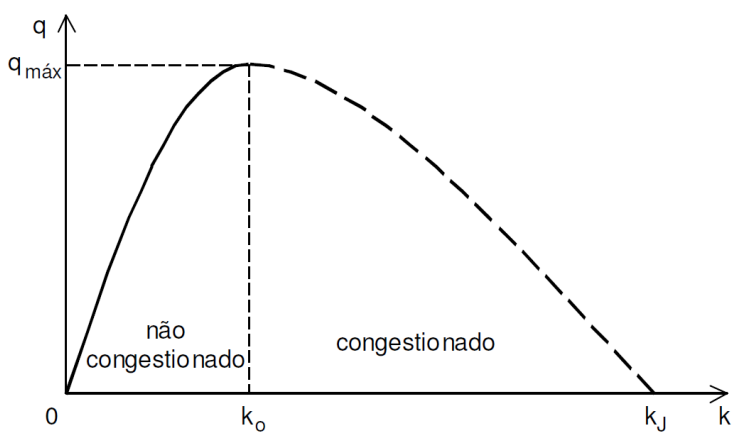

(a)

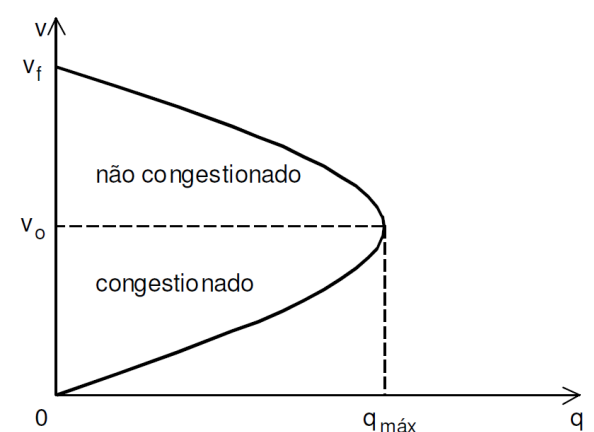

(b)

Figura 1 - Gráficos relacionando variáveis macroscópicas do trafego. Extraído de da Silva (2007)

Em casos de tráfego denso e ininterrupto, aplica-se ao tráfego formulação análoga à do escoamento de um fluido em um duto (eq. 1) de modo que $x$ é a distância considerada em relação a uma dada origem e $c$ é uma constante, chamada de parâmetro da via.

$$
\frac{d q}{d t}=-\frac{c^{2}}{k} \frac{\partial k}{\partial x}
$$

A partir de Eq. 1, deduz-se a equação geral do tráfego, que indica o fluxo $q$ em tráfego ininterrupto em função da densidade (eq. 2).

$$
q=c k \ln \frac{k_{J}}{k}
$$

Como o processo de contagem de veículos não é viável na maioria das vezes, os valores de $c, k$ e $k_{J}$ não estão disponíveis para uma rede de tráfego. 
Contudo, a partir de algumas premissas, é possível especificar tais valores a fim de completar a modelagem da rede viária:

a) o comprimento médio $l_{v}$ dos veículos, em metros, que trafegam pela via;

b) a concentração $k_{J}$, dada pela divisão de 1.000 (mil) metros pelo comprimento médio multiplicado por uma margem de segurança;

c) a velocidade ótima,tomada como a velocidade máxima permitida na via;

A Eq. 3 é obtida a partir da Eq. 2, isolando o valor da concentração em função dos valores da velocidade observada e da concentração máxima. Resta, porém, obter o parâmetro da via.

$$
\begin{gathered}
v=c \ln \left(\frac{k_{J}}{k}\right) \\
\frac{v}{c}=\ln \left(\frac{k_{J}}{k}\right) \\
\frac{k_{J}}{k}=e^{v / c} \\
k=\frac{k_{J}}{e^{v / c}}=k_{J} e^{-v / c}
\end{gathered}
$$

Considerando a situação em que a capacidade da via foi atingida, é possível identificar o valor da concentração ótima $k_{0}$ pela derivação da Eq. 2 em função da concentração $k$. Comparando este valor com aquele obtido pela Eq. 3, conclui-se que o parâmetro da via é numericamente igual a $v_{0}$, especificado inicialmente. Consequentemente é possível calcular a equação do fluxo em função da velocidade observada (Eq. 4).

No caso de baixas concentrações de tráfego, essas 4 equações, baseadas no modelo de Greenberg, não apresentam boa aderência com a realidade observada.

$$
\begin{gathered}
q_{\text {máx }}=\operatorname{máx}\left[k c \ln \left(\frac{k_{J}}{k_{0}}\right)\right] \\
\frac{\partial q}{\partial k}=c\left[\ln \left(\frac{k_{J}}{k_{0}}\right)-k_{0} \frac{k_{0}}{k_{J}}\left(\frac{-k_{J}}{k_{0}^{2}}\right)\right]=0 \\
k_{0}=\frac{k_{J}}{e}=k_{J} e^{-v_{0} / c} \\
e^{-1}=e^{-v_{0} / c} \\
c=v_{0} \\
q=v k_{J} e^{-v / v_{0}}
\end{gathered}
$$


O modelo de Underwood, mais indicado nestes casos, preconiza que a velocidade é obtida em função da velocidade de fluxo e dos valores de concentração ótima e observada (Eq. 5). Consequentemente, o fluxo é calculado como o produto da concentração pela respectiva velocidade observada.

$$
v=v_{f} e^{-k / k_{0}}
$$

A fim de adequar os modelos apresentados à realidade geral das vias, optouse por empregar um modelo misto, empregando o modelo de Greenberg para altas concentrações e o modelo de Underwood para baixas concentrações. A transição se dá na concentração ótima segundo o modelo de Greenberg, onde a velocidade observada é a velocidade nominal da via.

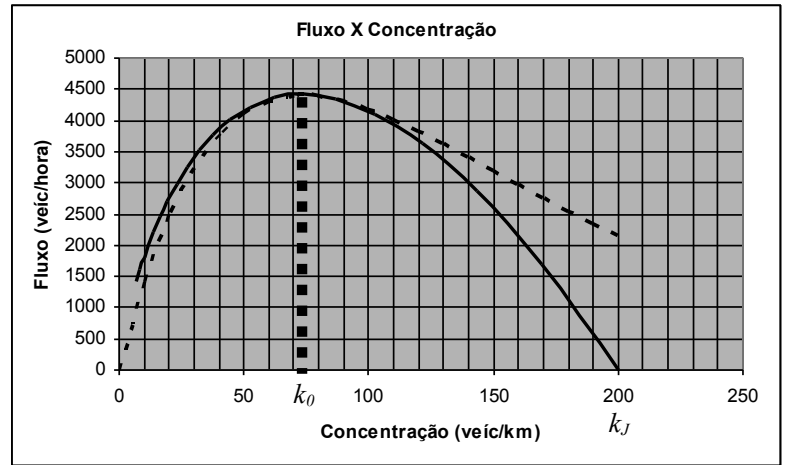

Figura 2 - Exemplo de diagrama Fluxo-Concentração

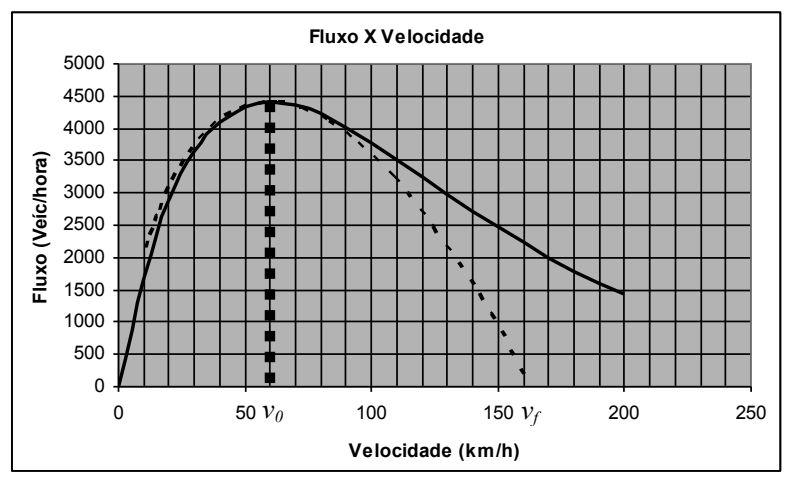

Figura 3 - Exemplo de diagrama Fluxo-Velocidade 


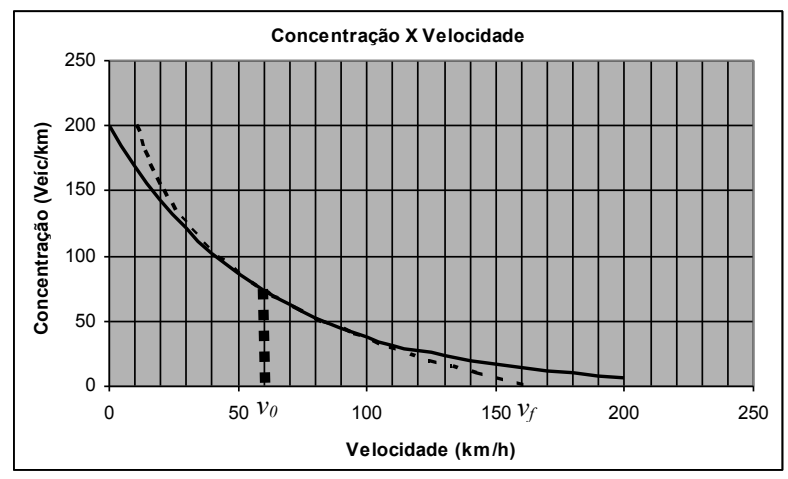

Figura 4 - Exemplo de diagrama Concentração-Velocidade

Os gráficos ilustrados nas Fig. 2, 3 e 4 referem-se, respectivamente, aos diagramas de fluxo-concentração, fluxo-velocidade e de velocidade-concentração, considerando $v_{0}=60 \mathrm{~km} / \mathrm{h}$ e $l_{v}=5 \mathrm{~m}$. As linhas contínuas representam os valores calculados pelo modelo de Greenberg, enquanto as linhas tracejadas representam os valores calculados pelo modelo de Underwood.

\subsection{Formação de Congestionamentos}

Conforme visto na seção 2.1.1, a capacidade de uma via é expressa como o número máximo horário de veículos que se estima poder passar por uma dada seção ou trecho homogêneo de uma rodovia, durante certo período de tempo, segundo determinadas condições existentes da rodovia e do tráfego (Brasil, 2009) ou, de acordo com o Highway Capacity Manual (HCM, 2000), é a taxa horária máxima na qual se espera, de forma razoável, que pessoas ou veículos possam atravessar um ponto ou uma seção uniforme de uma faixa ou pista de tráfego durante um determinado tempo em condições normais de via, tráfego e controle.

Congestionamentos representam restrições ou interferências no fluxo normal do tráfego. À medida que o fluxo se aproxima da capacidade, pequenos distúrbios provocam paradas sucessivas na corrente de tráfego e consequente redução do fluxo. Congestionamentos também podem ser causados por reduções temporárias da capacidade da via, seja pela interdição de uma faixa de rolamento para manutenção ou pela ocorrência de um acidente.

Knoop (2009) apresenta estatísticas sobre a redução da capacidade das vias expressas americanas e holandesas em consequência de interdições parciais de vias. A redução da capacidade do tráfego com a indisponibilidade de uma de três 
faixas varia de 47 a $65 \%$ enquanto varia de 73 a $83 \%$ quando duas de três faixas são bloqueadas. Os valores foram obtidos de estudos e manuais americanos e holandeses, em períodos entre 1971 e 2007, indicando maior redução nos documentos recentes. Apesar da melhoria da tecnologia empregada na construção das estradas, dos traçados mais velozes, o comportamento dos motoristas influencia diretamente o fluxo de veículos. Não foram encontrados valores de referência em estradas brasileiras, muito menos em áreas urbanas.

Tanto a redução de capacidade quanto o aumento do fluxo pioram o nível de serviço ao ponto de aumentar a concentração do tráfego e reduzir a velocidade dos veículos. Persistindo o desequilíbrio entre o volume e a capacidade, formam-se as filas, ou seja, outros trechos alcançam a concentração crítica e a velocidade também é reduzida.

É possível identificar as vias candidatas ao congestionamento pela análise da rede viária, que nada mais é que um grafo direcionado, empregando o caminhamento em largura. Porém, nem todas as vias possuem a mesma probabilidade de serem afetadas, uma vez que o tráfego que passa por elas é inferior ao de vias de maiores capacidades, de hierarquia superior (ver Seção 2.3). Outro aspecto importante é a ocorrência de acidentes em locais habitualmente congestionados, de modo que não é possível observar o aumento da concentração $k$ pois já possui um valor elevado. O reflexo pode acontecer no aumento da fila, a menos que avisos e desvios no tráfego possam mitigar esse efeito.

Em resumo, a redução dos valores de velocidade ao longo da via está intimamente relacionada à redução de capacidade provocada por um distúrbio no trânsito.

\subsection{Classificação hierárquica das vias}

A análise do comportamento do tráfego está diretamente associada aos fluxos de veículos que entram e que saem da via, assim como de sua capacidade nominal. Como foi visto anteriormente, a mensuração do fluxo em todas as vias demanda custos que podem não compensar, em virtude das características das vias. Em contrapartida, é possível modelar uma relação entre o fluxo de veículos e a velocidade média desenvolvida em um trecho de via. 
Segundo Brasil (2009), a velocidade de um veículo em uma rodovia depende, além da habilidade do motorista e da qualidade do veículo, de cinco condições: características técnicas da rodovia, atrito lateral, volume e composição do tráfego, condições do tempo, limitações legais e as impostas pelos dispositivos de controle de tráfego. As características técnicas das rodovias são especificadas em projeto e visam a atender finalidades específicas, principalmente no que diz respeito à velocidade diretriz da via, ou seja, a maior velocidade com que pode ser percorrido um trecho viário com segurança e em condições aceitáveis de conforto, mesmo com pavimento molhado, quando o veículo estiver submetido apenas às limitações impostas pelas características geométricas, sem influência do tráfego (Brasil, 2009). Nesta tese, estão sendo equiparados os termos velocidade diretriz e velocidade de fluxo livre (seção 2.1.1).

O inciso I do art. 60 do Código Brasileiro de Trânsito classifica as vias urbanas em vias de trânsito rápido, arteriais, coletoras e locais (Brasil, 2004). A classificação apresentada em Brasil (2009) é mais detalhada, acrescentando aspectos técnicos como largura da via, quantidade de faixas, nível de acesso, entre outros. O Plano Diretor de Transporte Urbano da Região Metropolitana do Rio de Janeiro classifica as vias da cidade como Expressas, Arteriais Principais, Arteriais Secundárias, Coletoras e Locais (Rio de Janeiro, 2005).

As vias locais atendem, principalmente, a viagens mais curtas, tendo como principal função o acesso às propriedades. Não necessitam de grande mobilidade e elevados níveis de serviço e, por isso, essas vias não serão consideradas nas análises descritas nesta tese. Espera-se, com isso, simplificar as análises, eliminando trechos com baixa probabilidade de escolha por parte dos motoristas. Nas seções seguintes serão apresentados detalhes dos outros tipos de via.

\subsubsection{Vias de trânsito rápido}

O Código Brasileiro de Trânsito descreve as Vias de trânsito rápido como aquelas caracterizadas por acessos especiais com trânsito livre, sem interseções em nível, sem acessibilidade direta aos lotes lindeiros $^{7}$ e sem travessia de pedestres em nível.

\footnotetext{
${ }^{7}$ Lotes lindeiros são aqueles situados ao longo das vias urbanas ou rurais e que com elas se limita.
} 
As especificações contidas em Brasil (2009) apresentam o conceito de vias expressas em duas categorias: as primárias, de elevada capacidade e altas velocidades, com duas pistas separadas por canteiro central, com pelo menos duas faixas de tráfego em cada sentido, com controle total de acesso e interseções em desnível; e as secundárias, e capacidade e velocidade algo restritas, por ação de eventuais interseções em nível e permissão de acesso a determinados tipos de uso do solo.

As vias expressas primárias possuem as mesmas características e funções das chamadas freeways americanas, com controle total de acesso e todas as interseções em desnível, destinando-se a atender grandes fluxos de tráfego. Proporcionam continuidade às principais rodovias interurbanas, quer atravessando ou contornando as áreas urbanas. Porém, de modo geral, elas não proporcionam conexões diretas com os principais geradores de tráfego ou com o centro da cidade, uma vez que a distribuição do tráfego se faz através de outras vias componentes dos sistemas arteriais que se conectam com as vias expressas.

Já as vias expressas secundárias possuem características e funções semelhantes às expressways americanas. Podem ter interseções em nível com algumas vias transversais e apresentar critérios operacionais e de projeto ligeiramente inferiores às vias expressas primárias. De um modo geral, não proporcionam acesso às propriedades adjacentes.

Como visam a atender ao maior número de veículos por quilômetro e às maiores distâncias relativas de viagem na área urbana, a velocidade diretriz básica recomendada para o projeto geométrico de vias expressas primárias (e de vias expressas secundárias que possam vir a ter a função de primárias em tempo previsível) é de $110 \mathrm{~km} / \mathrm{h}$. Nos trechos de transição para uma via de padrão inferior, a velocidade diretriz poderá descer até $80 \mathrm{~km} / \mathrm{h}$. Se não houver perspectiva de transformação de vias expressas secundárias em primárias, em consequência das condições locais, devem ser adotadas velocidades diretrizes inferiores, de preferência $90 \mathrm{~km} / \mathrm{h}$ ou, como mínimo absoluto, $60 \mathrm{~km} / \mathrm{h}$.

$\mathrm{O}$ tráfego em vias expressas é objeto de contínua pesquisa, devido à baixa influência do tráfego de pedestres, do uso do solo adjacente e de vias de tráfego com velocidade muito inferior. Além disso, a análise do comportamento do tráfego torna-se linear, restrita a uma única via, em um único sentido, minimizando a demanda pela instalação de equipamentos de medição de 
velocidade. Como exemplo de trabalho desenvolvido em vias dessa natureza, podem ser citados Knoop (2009) e Chung e Recker (2012).

No Rio de Janeiro, são exemplos de vias expressas a Avenida Governador Carlos Lacerda (Linha Amarela), Avenida Brasil (pista central) e Túnel Rebouças. A Figura 5 ilustra uma seção de uma via expressa, um trecho da Linha Amarela.

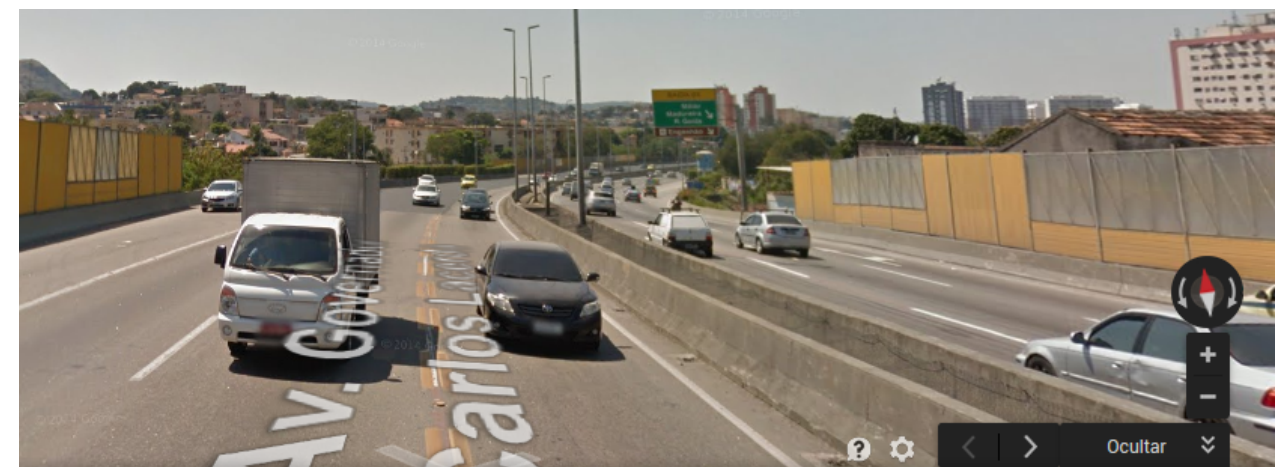

Figura 5 - Trecho de uma via classificada como expressa. Extraído de Google Street View.

\subsubsection{Vias arteriais}

As vias arteriais são caracterizadas no Código Brasileiro de Trânsito por interseções em nível, geralmente controladas por semáforo, com acessibilidade aos lotes lindeiros e às vias secundárias e locais, possibilitando o trânsito entre as regiões da cidade.

As especificações contidas em pelo Departamento Nacional de Infraestrutura de Transporte, o DNIT (Brasil, 2009), classifica as vias arteriais como primárias e secundárias. As vias arteriais primárias possuem capacidade e velocidade menores que as vias expressas, com traçado sensivelmente contínuo e interseções predominantemente em nível, atendendo principalmente à mobilidade do tráfego, podendo, contudo, ser permitido o acesso a propriedades adjacentes. Essas vias redistribuem o tráfego das vias expressas para os seus destinos, até o nível das arteriais secundárias. Estas, por sua vez, complementam e interconectam as vias do sistema arterial principal, com menor nível de mobilidade que as vias arteriais primárias.

Vias arteriais primárias atendem principalmente ao tráfego direto, geralmente em percurso contínuo, mas a maioria das interseções é em nível e as restrições de acesso às propriedades adjacentes não são absolutas. Isso significa 
que essas vias estão mais sujeitas às interferências mútuas com as áreas urbanizadas da cidade. As velocidades diretrizes recomendadas para essas vias depende do nível de desenvolvimento da região onde se encontra, caracterizado pela interferência de pedestres e do uso do solo adjacente.

As vias arteriais secundárias se interconectam com o Sistema Arterial Principal e o suplementa, atendendo aos percursos de viagens com extensões intermediárias, em níveis de serviço inferiores àqueles que são típicos das vias arteriais primárias. Atende às viagens com grau de mobilidade um pouco inferior ao do Sistema Arterial Principal e distribui o tráfego por áreas menores do que as atendidas pelo sistema principal.

Em ambos os casos, recomenda-se a velocidade diretriz de $80 \mathrm{~km} / \mathrm{h}$ para arteriais em áreas urbanas pouco desenvolvidas, de $60 \mathrm{~km} / \mathrm{h}$ para áreas de interferência intermediária e $50 \mathrm{~km} / \mathrm{h}$, em áreas de desenvolvimento intenso.

Na Cidade do Rio de Janeiro, o Plano Diretor de Transporte adota nomenclatura diferente para as vias arteriais: principais e secundárias. São exemplos de vias arteriais principais a Avenidas Presidente Vargas (Figura 6), a Avenida Brasil (pista lateral) e a Avenida Borges de Medeiros, enquanto são exemplos de vias arteriais secundárias a Avenida Armando Lombardi, a Avenida Geremário Dantas (Figura 7) e Estrada do Galeão.

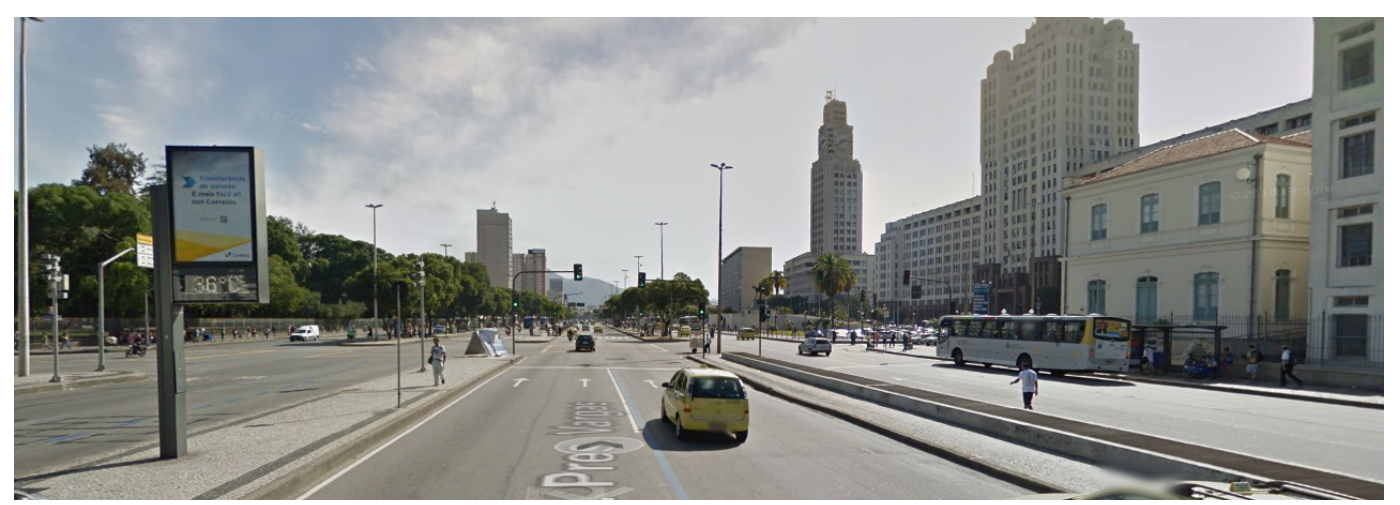

Figura 6 -- Trecho de uma via classificada como arterial primária. Extraído de Google Street View. 


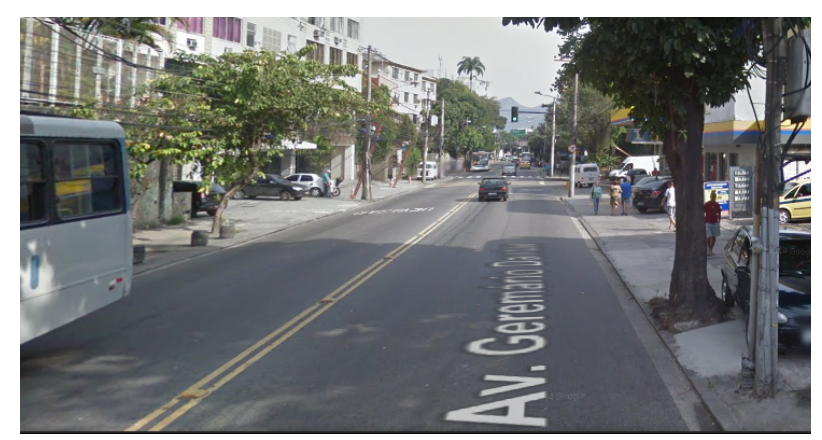

Figura 7 - Trecho de uma via classificada como arterial secundária. Extraído de Google Street View.

\subsubsection{Vias coletoras}

Vias coletoras são destinadas a coletar e distribuir o trânsito que tenha necessidade de entrar ou sair das vias de trânsito rápido ou arteriais, possibilitando o trânsito dentro das regiões da cidade. Em outras palavras, conecta as vias arteriais às vias locais e vice-versa. Ao contrário das vias arteriais, vias coletoras podem penetrar nas vizinhanças residenciais, distribuindo o tráfego das vias arteriais, através da área, até seus destinos finais. Os eventuais cruzamentos com outras vias coletoras ou vias locais devem ser controlados por semáforos ou sinais de parada obrigatória na via local que interceptar ou, no caso de interseção com outra coletora, na via de menor tráfego.

Não há referências explícitas à velocidade diretriz, dado que sua função implica a redução da velocidade desenvolvida nessas vias. Portanto, espera-se menor fluxo de veículos. São exemplos de vias coletoras a Avenida Padre Leonel Franca (Figura 8), a Avenida Ministro Ivan Lins e a Autoestrada Lagoa-Barra.

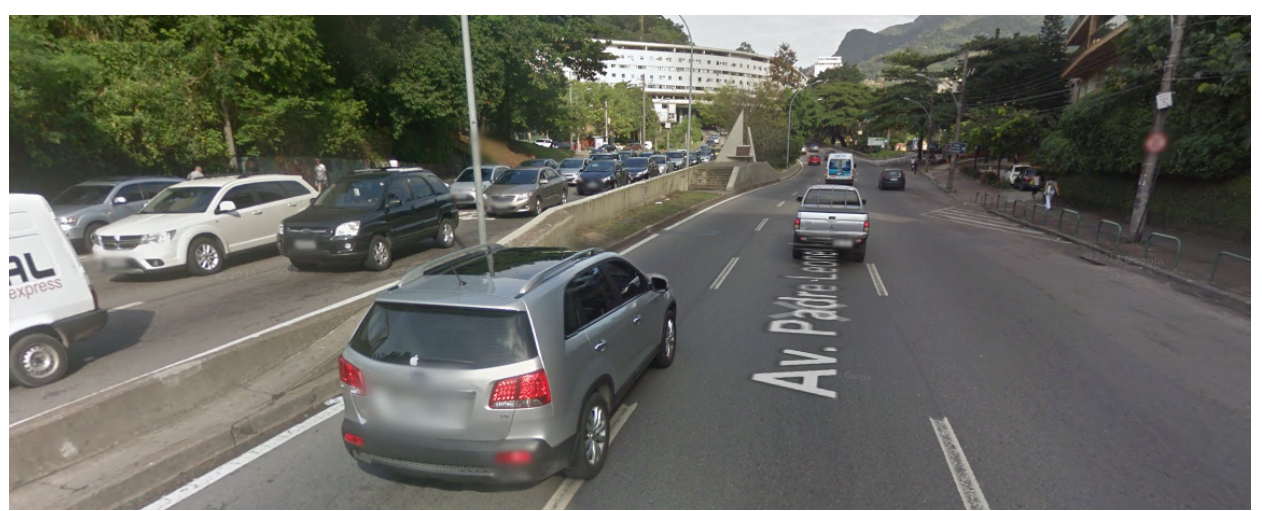

Figura 8 - Trecho de uma via classificada como coletora. Extraído de Google Street View. 


\subsection{Conclusões}

Congestionamentos representam restrições ou interferências no fluxo normal do tráfego. À medida que o fluxo se aproxima da capacidade, pequenos distúrbios provocam paradas sucessivas na corrente de tráfego e consequente redução do fluxo.

A metodologia de medição da capacidade indicada pelo HCM foi empregada para obter os dados da Tabela 1 (Rio de Janeiro, 2005). Ou seja, é possível quantificar a capacidade nominal das vias de acordo com suas especificações técnicas. Contudo, os valores de fluxo não podem ser medidos em todas as vias.

Sabendo que há relação matemática entre os valores de velocidade e de fluxo, a estimação do fluxo a partir de valores médios de velocidade permitirá avaliar o equilíbrio no tráfego. Outra possibilidade é a avaliação das condições do tráfego diretamente a partir dos valores de velocidade. 
Tabela 1 - Capacidades das vias arteriais e coletoras. Extraído de Rio de Janeiro (2005).

\begin{tabular}{|c|c|c|c|}
\hline Característica da Ligação & $\begin{array}{c}\text { Capacidade } \\
\text { Teórica } \\
\text { Horária Por } \\
\text { Sentido (veq/ } \\
\text { htv) }\end{array}$ & $\begin{array}{l}\text { Capacidade } \\
\text { Prática Horária } \\
\text { Por Sentido- } \\
\text { Via Urbana } \\
\text { Exceto } \\
\text { Expressa (veq / } \\
\text { htv) }\end{array}$ & $\begin{array}{c}\text { Capacidade } \\
\text { Prática Horária } \\
\text { Por Sentido- } \\
\text { Rodovias (veq / } \\
\text { htv) }\end{array}$ \\
\hline Uma faixa em um único sentido & 900 & 540 & 900 \\
\hline Uma faixa em cada sentido (via com duas faixas) & 900 & 540 & 900 \\
\hline Duas faixas em um único sentido & 1800 & 1080 & 1800 \\
\hline $\begin{array}{l}\text { Duas faixas em um único sentido com } \\
\text { estacionamento (uma faixa útil) }\end{array}$ & 900 & 540 & n.a. \\
\hline Duas faixas em cada sentido (via com quatro faixas) & 1800 & 1080 & 1800 \\
\hline $\begin{array}{l}\text { Duas faixas em cada sentido com estacionamento } \\
\text { (duas faixas úteis sendo uma em cada sentido) }\end{array}$ & 900 & 540 & n.a. \\
\hline Três faixas em um único sentido & 2700 & 1620 & 2700 \\
\hline $\begin{array}{l}\text { Três faixas em um único sentido com } \\
\text { estacionamento em duas faixas (uma faixa útil) }\end{array}$ & 900 & 540 & n.a. \\
\hline $\begin{array}{l}\text { Três faixas em um único sentido com } \\
\text { estacionamento em uma faixa (duas faixas úteis) }\end{array}$ & 1800 & 1080 & n.a \\
\hline Três faixas em cada sentido (via com seis faixas) & 2700 & 1620 & 2700 \\
\hline $\begin{array}{l}\text { Três faixas em cada sentido com estacionamento } \\
\text { em uma faixa (quatro faixas úteis sendo duas em } \\
\text { cada sentido) }\end{array}$ & 2700 & 1620 & n.a \\
\hline Quatro faixas em um único sentido & 3600 & 2160 & 3600 \\
\hline $\begin{array}{l}\text { Quatro faixas em um único sentido com } \\
\text { estacionamento em duas faixas (duas faixas úteis) }\end{array}$ & 1800 & 1080 & 1800 \\
\hline $\begin{array}{l}\text { Quatro faixas em um único sentido com } \\
\text { estacionamento em uma faixa (três faixas úteis) }\end{array}$ & 2700 & 1620 & 2700 \\
\hline Quatro faixas em cada sentido (via com oito faixas) & 3600 & 2160 & 3600 \\
\hline Cinco faixas em um único sentido & 4500 & 2700 & 4500 \\
\hline $\begin{array}{l}\text { Cinco faixas em um único sentido com } \\
\text { estacionamento em duas faixas (três faixas úteis) }\end{array}$ & 2700 & 1620 & 2700 \\
\hline $\begin{array}{l}\text { Cinco faixas em um único sentido com } \\
\text { estacionamento em uma faixa (quatro faixas úteis) }\end{array}$ & 3600 & 2160 & 3600 \\
\hline Cinco faixas em cada sentido (via com dez faixas) & 4500 & 2700 & 4500 \\
\hline $\begin{array}{l}\text { Seis faixas em um único sentido com } \\
\text { estacionamento em duas faixas (quatro faixas úteis) }\end{array}$ & 3600 & 2160 & 3600 \\
\hline Oito faixas em um único sentido & 7200 & 4320 & 7200 \\
\hline Calçadão (trecho sem circulação de veículos) & 0 & 0 & 0 \\
\hline Faixa reversivel & 900 & 540 & 900 \\
\hline Pista em leito natural - uma faixa em cada sentido & 450 & 270 & 450 \\
\hline
\end{tabular}




\section{Dados de Trânsito Publicados na Web}

Este capítulo descreve as bases de dados disponibilizadas na Web e que servirão como subsídio para análises do comportamento do tráfego. Não estão sendo consideradas bases de dados de aplicativos de tráfego que não podem ser descarregadas, interpretadas e nem mesmo acessadas por APIs com documentação aberta para os usuários. São dados de interesse a velocidade média dos veículos nos trechos, alguma indicação qualitativa do tráfego (intenso, congestionado ou livre), assim como eventos que possam causar alterações no tráfego, tais como acidentes, colisões e veículos enguiçados.

Embora os exemplos refiram-se aos dados usados nos experimentos na Cidade do Rio de Janeiro, descritos em detalhe na Seção 6.1, as observações aplicam-se a cenários urbanos típicos de uma grande cidade.

\subsection{Portais Oficiais}

Em virtude das crescentes demandas por transparência nas ações governamentais e diante das possibilidades de aplicação dos dados produzidos pelo Poder Público, alguns gestores públicos têm aberto seus dados de modo a permitir ao cidadão que assim o desejar usufruir dos dados produzidos pelos governos e até avaliar o desempenho dos serviços públicos. Iniciativas governamentais como a Lei de Acesso à Informação (Brasil, 2011) e a Infraestrutura Nacional de Dados Espaciais (Brasil, 2008) explicitam essa promoção da publicidade dos dados públicos.

Por outro lado, a crescente onda de grandes eventos realizados na Cidade do Rio de Janeiro nos últimos anos e a expectativa por mais eventos fez a cidade aderir às tecnologias de cidades inteligentes (smart cities), permitindo a disseminação de dados para o desenvolvimento de soluções para cidadãos e turistas.

Neste contexto, a Prefeitura da Cidade do Rio de Janeiro disponibilizou um portal de dados abertos, destinado a desenvolvedores de aplicativos para benefício 
dos cidadãos, empresários e turistas. Segundo consta no portal, tal iniciativa "proporciona ao cidadão um melhor entendimento do governo municipal, no acesso aos serviços públicos, no controle das contas públicas e na participação no planejamento, desenvolvimento das políticas públicas e melhor conhecimento da cidade" (Rio de Janeiro, 2014). O W3C Brasil considera como dados abertos aqueles que "podem ser livremente usados, reutilizados e redistribuidos por qualquer pessoa - sujeitos, no máximo, à exigência de atribuição da fonte e compartilhamento pelas mesmas regras." (Open Knowledge Foundation, 2014).

Os dados disponibilizados pela Prefeitura do Rio de Janeiro referentes a transporte e mobilidade incluem pontos de parada e de percurso de barcas, trens, metrô e ônibus. Além disso, o portal disponibiliza pontos rastreados por GPS instalados em ônibus que circulam na cidade (em tempo real) e um histórico das ocorrências de trânsito registradas.

Além do Portal de Dados Abertos, a Prefeitura do Rio de Janeiro - Instituto Pereira Passos mantém um geoportal, onde são disponibilizados dados como a malha viária da cidade, hidrografia, limites administrativos e localização de instituições públicas como delegacias e unidades de saúde municipais. Esta aplicação permite ao usuário a extração de bases de dados geográficas em diferentes formatos. Enquanto os dados abertos são disponibilizados em formato CSV (Comma Separated Values), os dados do Geoportal são disponibilizados em formatos próprios para aplicativos de geoprocessamento, dentre os quais destacase o formato shapefile para arquivos vetoriais, suportado pela maioria dos aplicativos de geoprocessamento e de documentação aberta (ESRI, 1998).

Outra iniciativa da Prefeitura do Rio de Janeiro de interesse para a geração e disponibilização de dados sobre trânsito é o aplicativo Olhos da Cidade, mencionado na Seção 1.1. A Figura 9 ilustra um acidente registrado no aplicativo pelo usuário Anonymous com uma sucinta descrição do ocorrido e a suposta localização da colisão. Devido ao caráter meramente informativo do aplicativo (para o usuário), são representados poucos detalhes na tela.

Para fins de análise de trânsito, podem ser aproveitados os dados sobre ônibus, as ocorrências de trânsito e a malha viária. Contudo, nesta tese, esses dados não foram empregados pelos seguintes motivos:

- Os ônibus possuem mobilidade reduzida devido às necessidades de parada, às suas dimensões e às restrições legais quanto à velocidade máxima permitida. 
Por outro lado, a adoção de corredores expressos para ônibus permite que desenvolvam maior velocidade em alguns horários e trechos, descaracterizando o comportamento do tráfego em geral;

- As ocorrências de trânsito disponíveis referem-se a um período anterior à extração de valores de velocidade, o que inviabiliza a comparação dos efeitos das ocorrências no trânsito;

- A malha viária disponibilizada não se encontra estruturada no formato de rede, o que inviabiliza as tarefas de roteamento, úteis para a análise. Além disso, os arquivos referem-se à malha viária da cidade em 2006, ou seja, obsoleta face às alterações ocorridas na última década.

Os dados que não puderam ser obtidos dos órgãos públicos podem ser recuperados a partir de iniciativas de empresas especializadas em serviços baseados na geolocalização, tais como a Maplink e o Google.

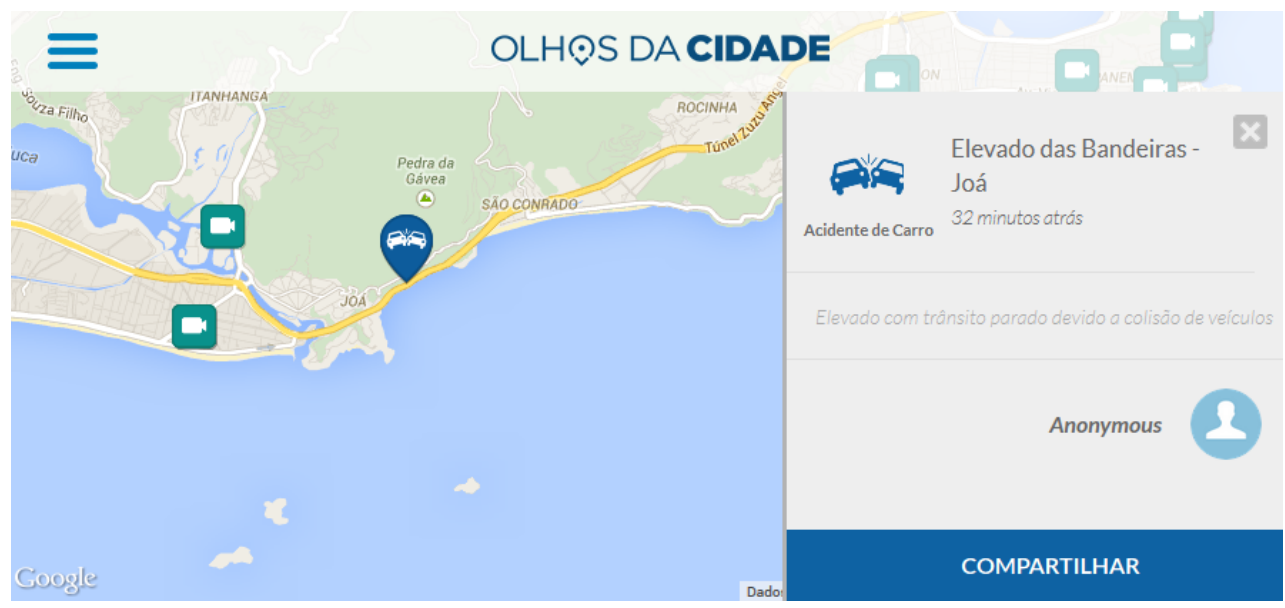

Figura 9 - Registro de acidente feito por usuário do aplicativo Olhos da Cidade.

\subsection{Dados publicados pelo Maplink}

Maplink é uma empresa direcionada a soluções de geolocalização, informações de trânsito, apoio ao controle de frotas, entre outras atividades. A empresa disponibiliza serviços Web para acesso aos dados produzidos. Os serviços são acessíveis através do protocolo SOAP (Simple Object Access Protocol) e as mensagens trocadas entre o requisitante e o serviço adotam o padrão de formato de mensagens em XML (Extensible Markup Language). O acesso aos dados é permitido mediante a indicação de um token fornecido pela empresa aos seus 
clientes, sendo que os não clientes podem solicitar um token temporário para acesso por até 15 dias (Maplink, 2015b).

A página na Web, entretanto, fornece dados sobre os principais corredores das cidades abrangidas pela empresa, atualizados a cada 15 minutos. No caso da Cidade do Rio de Janeiro, são indicadas vias expressas e outras consideradas importantes, devido à quantidade de fluxo que passa por elas ou à sua relação com vias importantes. No total, são 101 corredores e, em cada um deles, são distribuídos pontos de medição de velocidade (PMV), normalmente em cruzamentos relevantes, totalizando 602 valores de velocidade distribuídos pelas principais vias da Cidade do Rio de Janeiro (Figura 10). Os critérios de classificação da importância dos corredores e do posicionamento dos PMV não foram encontrados documentação fornecida pela empresa em sua página Web. Detalhes sobre a localização de PMV são apresentados no Anexo 3.

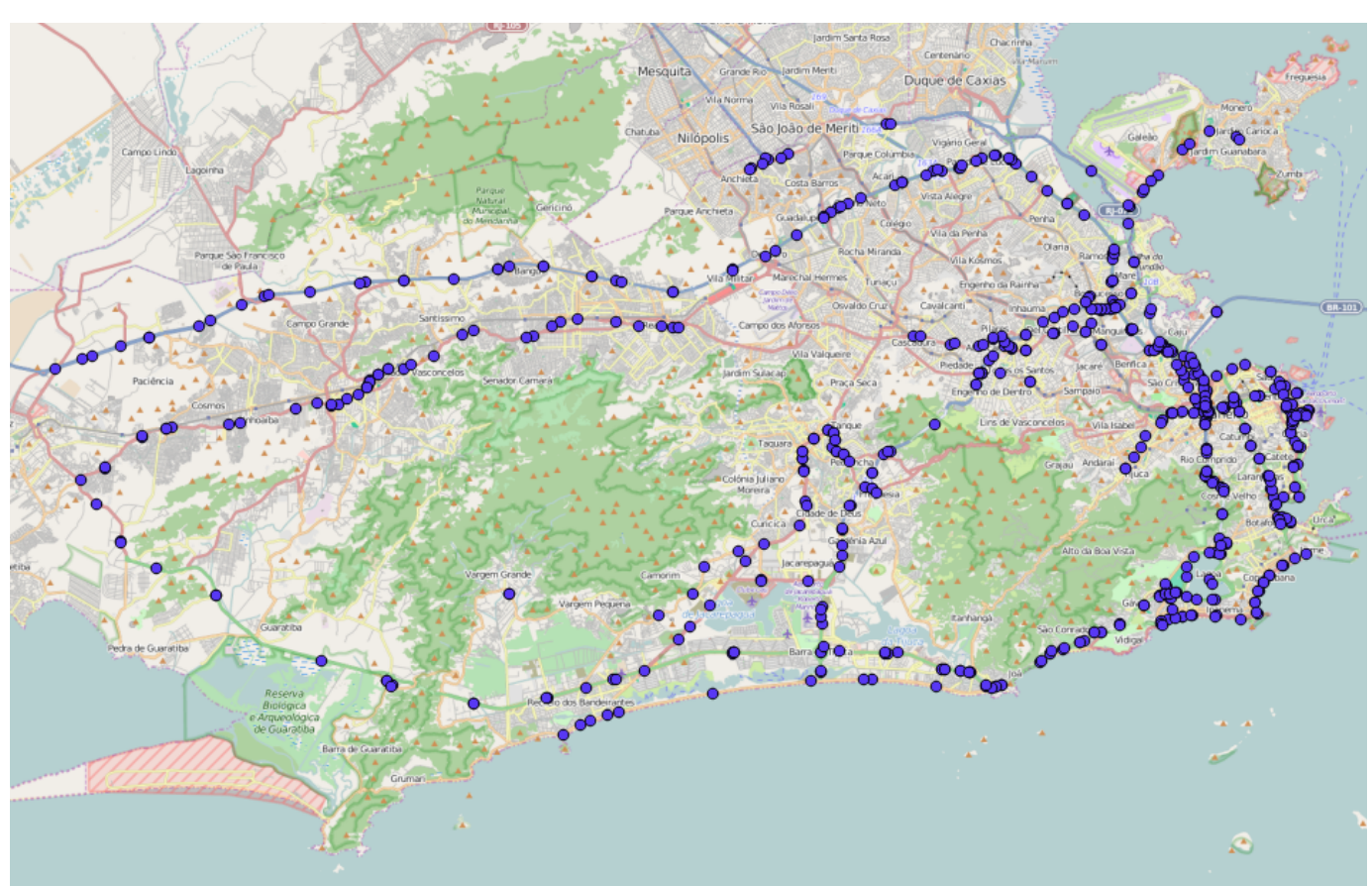

Figura 10 - Distribuição dos pontos de medição de velocidade da empresa Maplink pela cidade do Rio de Janeiro (base cartográfica Open Street Maps).

Segundo a empresa, as informações de trânsito apresentadas são calculadas a partir das posições anônimas de veículos, resultando em dados como latitude, longitude, velocidade e azimute. Posteriormente, são computadas as velocidades médias de deslocamento desses veículos dentro da base cartográfica (Maplink, 2015a). 
Observando o código fonte da página que contém as informações dos corredores, é possível identificar os dados cada PMV: coordenadas geográficas ${ }^{8}$, velocidade média observada $(\mathrm{em} \mathrm{km} / \mathrm{h})$ e tempo estimado para passar pelo ponto (em minutos). Portanto, a interpretação do código fonte permite extrair dados de velocidade instantâneos, processo que pode ser automatizado para posterior armazenamento dos valores em um banco de dados.

\subsection{Dados publicados pelo Google}

Um dos ramos de atuação da empresa Google é a disponibilização de serviços baseados em localização, tais como geocodificação (transformação de endereço em coordenadas geográficas e vice-versa), roteamento e renderização de mapas estáticos. O Google disponibilizou, também, diversas API para esses serviços (Google, 2013a), de modo que desenvolvedores possam explorar parte das funcionalidades com algumas restrições, como a quantidade de solicitações diárias ou as dimensões máximas de um mapa renderizado. Os mapas do Google podem ser renderizados como uma camada em um aplicativo de geoprocessamento, exibido em páginas Web como um bitmap ou salvos em arquivos como uma imagem simples, sem georrefenciamento. Cada modificação na visualização (mover ou variação de escala) implica uma nova requisição e um novo mapa estático é carregado.

Uma funcionalidade bastante útil, disponibilizada pela empresa, é a indicação qualitativa do tráfego em diversas vias: normal, intenso, lento e parado. Segundo a empresa, os dados são coletados a partir de informações anônimas transmitidas por usuários de aplicativos da empresa que concordaram em compartilhar suas localizações (Google, 2009). Contudo, não há forma de recuperar os dados usados na renderização do mapa, disponibilizado como um bitmap simples, sem estruturação ou georreferenciamento. Além do mais, não ficou claro se é possível distinguir dados de usuários em ônibus (vários registros em um único veículo), andando ou parado na calçada (dados de pedestres ao invés de dados de veículos).

\footnotetext{
${ }^{8}$ Apesar de não haver indicação do sistema de referência espacial, presume-se que seja WGS84, original do GPS e indicado pelo IETF (2010).
} 
Com a aquisição da empresa desenvolvedora do aplicativo Waze (Google, 2013b), foram incorporados aos mapas os registros de ocorrências criados pelo usuário do aplicativo (Figura 11). Até o presente momento, não foi disponibilizada uma API para recuperar essa nova camada de informação senão na forma de mapa estático.

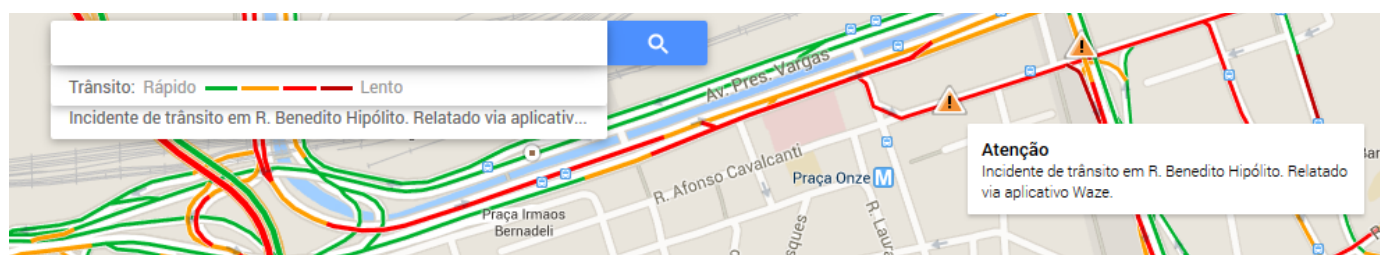

Figura 11 - Conteúdo do Google Maps gerado por usuários do aplicativo Waze.

\subsection{Dados publicados pelo Twitter}

Cada publicação no Twitter permite o registro de informações como a identificação (ID) da mensagem, usuário, texto, idioma, local (cidade), coordenadas e hora da criação (timestamp baseado no horário universal - UTC), entre outras. Todos esses elementos podem ser empregados como parâmetros de seleção de mensagens conforme a API REST disponibilizada para desenvolvedores. O acesso é limitado a 180 consultas a cada 15 minutos por usuário, identificado por tokens fornecidos pela empresa mediante cadastro (Twitter, 2014).

A consulta pela localização geográfica ainda é restritiva, uma vez que essa informação não é obrigatória para publicação da mensagem. Portanto, a consulta combinada por palavras-chave no texto e por usuários de alta reputação é uma alternativa apropriada para a seleção de postagens relevantes à analise desejada.

No contexto de trânsito, o emprego de palavras-chave como colisão, (veículo) enguiçado e retenções fornecerão boa aproximação ao contexto, ao contrário de termos abrangentes como acidente, que remete a acidentes passados, gestações indesejadas, incidentes domésticos, entre outros contextos.

Quanto à reputação dos usuários, é comum encontrar perfis corporativos de entidades públicas e privadas especializadas na operação e na divulgação de informações referentes ao tráfego nas cidades. No Rio de Janeiro, destaca-se o usuário@OperacoesRio, do Centro de Operações da cidade, que divulga dados relevantes sobre ocorrências de trânsito. Também é possível obter dados 
confiáveis por meio da imprensa, muitas vezes acompanhada de uma reportagem detalhada do evento e de possíveis implicações no tráfego à volta.

Um recurso empregado pelos usuários corporativos é a indicação de um hyperlink resumido, apontando para uma página com uma reportagem ou um relatório relacionado ao incidente (Figura 12).

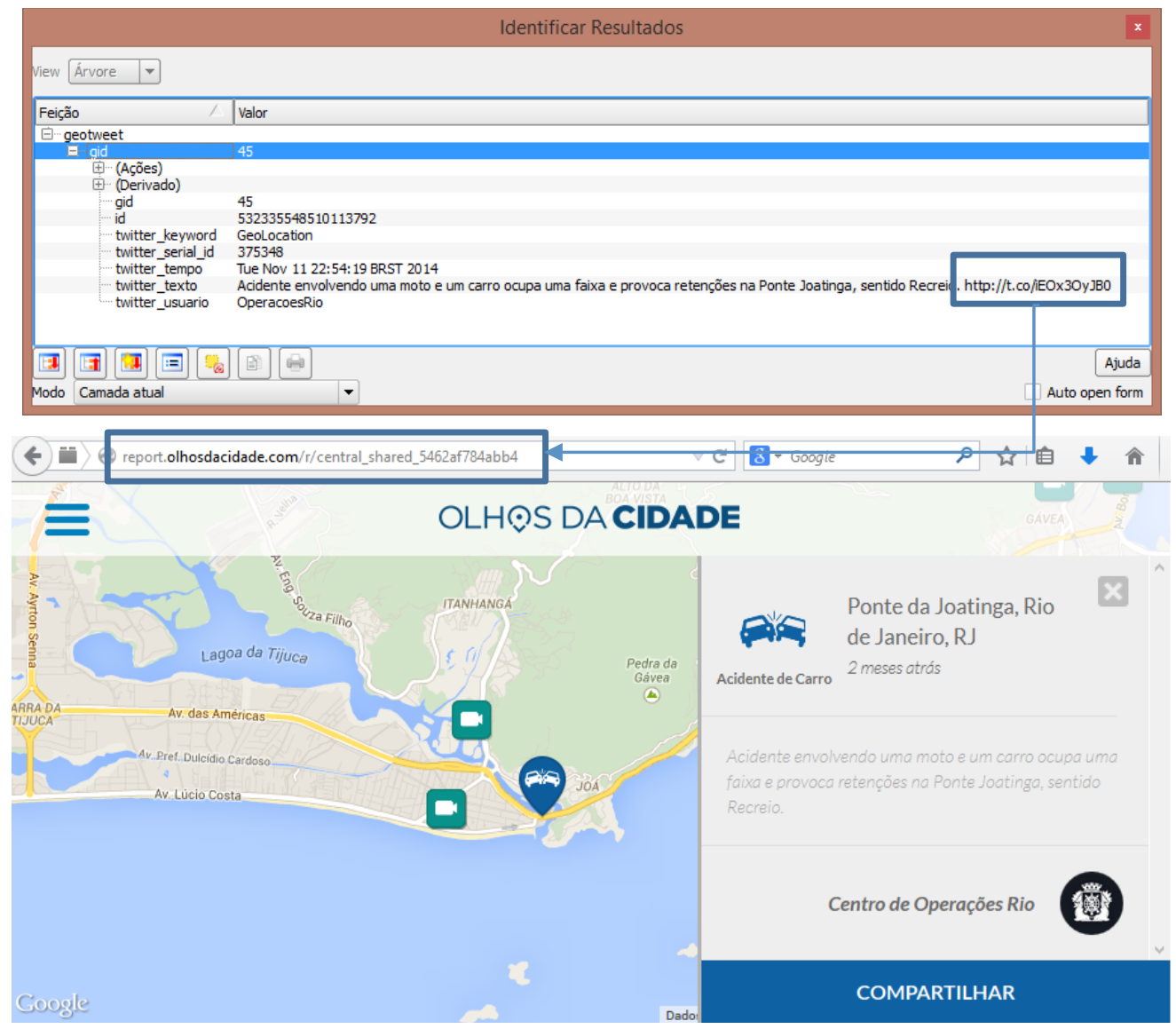

Figura 12 - Postagem com link para página com maior detalhamento da ocorrência.

\subsection{Conclusão}

Ao longo deste capítulo foram citadas diversas, mas não todas, modalidades de fontes de dados relacionados às condições de tráfego, sem detalhar aquelas que não permitem a recuperação das bases de dados pelo usuário. Os dados referentes ao trânsito da cidade do Rio de Janeiro, obtidos a partir das fontes enumeradas neste Capítulo, serão empregados nos Capítulos 6 e 7.

A aplicação dos dados extraídos dependerá, contudo, da avaliação prévia da qualidade dos dados, sob os pontos de vista temático, espacial e temporal, a fim de incrementar a confiabilidade das análises especificadas nesta tese. 


\section{Qualidade da Informação Geoespacial Relativa a Trânsito}

De acordo com a ISO 19157 (2013), são cinco os elementos de qualidade de dados espaciais: Completude, Consistência Lógica, Acurácias Posicional, Temporal e Temática. A quantificação desses elementos visa a orientar os usuários quanto à escolha dos dados que mais se adequam às suas necessidades e indicar o grau de incerteza inerente aos dados.

No contexto de tráfego, o foco desta tese, considera-se como premissa o fato de que as bases empregadas estejam completas e, de igual maneira, será considerada satisfatória a avaliação quanto à consistência lógica dos dados. As seções seguintes abordarão os aspectos referentes às acurácias temática, espacial e temporal, utilizando para os exemplos os conjuntos de dados da Cidade do Rio de Janeiro já citados no Capítulo 3.

\subsection{Acurácia Temática}

O conceito de acurácia temática refere-se à exatidão dos atributos quantitativos e à corretude dos atributos não quantitativos e das classificações das feições e seus relacionamentos (ISO, 2013). Trata-se da avaliação da corretude dos atributos qualitativos, como um nome de rua ou sua classificação hierárquica, e da acurácia dos atributos quantitativos, como o valor da velocidade medida em um determinado horário. Em ambos os casos, não estão sendo consideradas nem a localização nem a indicação de tempo.

É possível abordar este assunto sob as seguintes vertentes: o conteúdo registrado deve ser compatível com o evento correspondente e é possível recuperar referências espaciais implícitas.

Exemplos do primeiro caso são comuns no caso de classificação de imagens, onde os números digitais registrados são associados a fenômenos como uso do solo. Metodologias de classificação supervisionada fornecem amostras de imagens de um local conhecido e buscam na imagem padrões semelhantes. 
Contudo, ainda é possível que algumas regiões da imagem sejam atribuídas a classes equivocadas, na maioria das vezes por influência dos pixels vizinhos.

No segundo caso, pode-se dar como exemplo a geocodificação, processo que atribui coordenadas de locais a partir de seus endereços postais, em geral, logradouro e número. Ruas de mesmo nome podem indicar locais distantes milhares de quilômetros entre si. Além disso, a denominação dos logradouros, oficial ou alternativas, e o seu tipo (estrada, avenida, rua, etc.) podem não estar registrados com exatidão: variações como abreviaturas e nomes parciais podem ser encontradas, assim como nomes antigos e denominações populares, sem que deixem de representar a mesma via.

Nos casos em que as coordenadas não estão disponíveis, a referência vaga (como próximo a, na altura de, no quilômetro tal, esquina com, entre outras) permite maior acurácia do que simples referências ao nome da via. Albuquerque et al (2012a) propõem uma solução baseada em Inteligência Artificial usando técnicas de processamento de linguagem natural e aprendizado de máquina para extrair os fatos de interesse e seus respectivos locais de ocorrência a partir de postagens no Twitter. O texto da mensagem foi estruturado para identificar os eventos e as referências viárias. Em Albuquerque (2012b) foi apresentada uma metodologia para inferir de forma mais acurada a localização de eventos ocorridos no trânsito pela análise de dados recuperados de fontes dinâmicas na Web. A estruturação das mensagens postadas no Twitter por usuários especializados, empregando um dicionário de termos correlatos, permitiu incrementar o processo de geocodificação.

Redlich (2013) apresenta um modelo de dados sobre notícias de trânsito que padronize os dados publicados na internet (em especial, no Twitter) com atributos relevantes para a análise dos mesmos. Esse modelo se propõe a processar notícias publicadas pelos mais diversos veículos e usuários diferentes, em linguagem natural, de tal maneira que possam ser pesquisados eventos acontecidos no trânsito e as consequências que estes acarretaram em cada localidade.

\subsection{Acurácia Espacial}

O conceito de acurácia espacial está relacionado à proximidade de um valor observado com um valor de referência, aceito como verdadeiro. Errar um metro 
no posicionamento de um veículo enguiçado em uma estrada pode não fazer diferença para o socorro, pois o próprio veículo possui dimensões maiores. Entretanto, errar um metro ao estacionar o veículo em uma vaga de garagem pode acarretar prejuízos ao motorista e a terceiros.

O processo de representação cartográfica já descarta detalhes de dimensões menores que o limite da percepção humana: $0,25 \mathrm{~mm}$ na escala de representação, de acordo com a Swiss Society of Cartography (João, 1998). Além disso, os princípios de generalização cartográfica suprimem camadas de informação que dificultam a legibilidade do documento. A Figura 13 ilustra o processo de generalização cartográfica aplicado na representação de uma cidade. Pode-se observar que o arruamento é representado de maneira simplificada nas escalas maiores (1:50.000 e 1:100.000) e suprimido nas escalas menores. Na escala de 1:1.000.000, toda a cidade passa a ser representada apenas por um ponto.

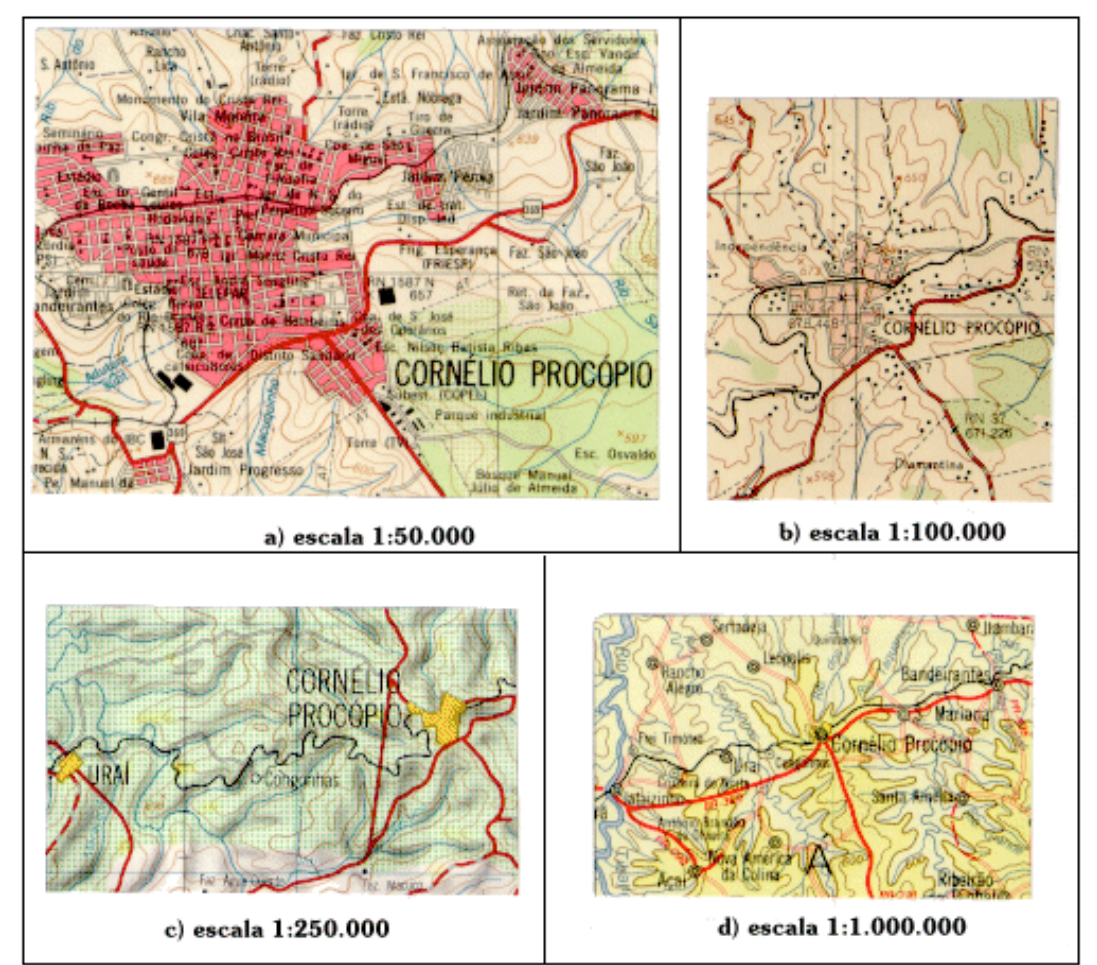

Figura 13 - Exemplos de generalização cartográfica. Extraído de IBGE (2004).

Outro fator que prejudica a acurácia de um conjunto de dados é a transformação de sistemas de referência geodésica (WGS84, SIRGAS 2000, SAD69, por exemplo) e de sistemas de coordenadas (geográficas ou projetadas: UTM, pseudoMercator, policônica, por exemplo). Tal fator é mais explícito 
quando é necessário integrar bases de dados de diferentes sistemas e é necessário representa-los em um mesmo sistema. Cada transformação é uma função matemática aplicada aos valores das coordenadas, implicando distorções nas dimensões e na posição dos objetos representados (IBGE, 2004).

O conhecimento desses conceitos é necessário para que o emprego de conjuntos de dados cartográficos de diferentes origens não prejudique a análise conjunta. Em especial, quando se trata de documentos em escalas detalhadas, onde os erros relacionados a transformações de coordenadas possuem a mesma ordem de grandeza dos fenômenos analisados.

Entretanto, estas não são a única fonte de inconsistências nas referências espaciais. A forma de aquisição dos dados também pode embutir erros de posicionamento na informação registrada. Um exemplo é o emprego de receptores GPS (Global Positioning System) em veículos ou mesmo em aparelhos celulares, que fornecem a posição com precisão da ordem de 10 metros. As posições obtidas a partir das informações das antenas de telefonia celular possuem precisões da ordem de centenas de metros. O capítulo 5 aborda com mais detalhes as incertezas existentes nas coordenadas obtidas com GPS.

\subsection{Acurácia Temporal}

De acordo com a ISO 19157, a acurácia temporal quantifica três fatores: a acurácia de uma medida de tempo (corretude da referência temporal de um item), a consistência temporal (corretude do ordenamento de eventos, ou seja, o correto sequenciamento de eventos) e a validade temporal (validade do dado referente ao tempo). No contexto avaliado nesta tese, destaca-se o primeiro valor.

De acordo com a classificação apresentada por Dias et al (2005), um Sistema Gerenciador de Bancos de Dados (SGBD) por tempo de transação registra o instante da inserção de dados no banco. Neste caso, o registro não permite determinar o instante em que ocorreu o evento. Um exemplo a ser dado são as postagens do Twitter. Consequentemente, os efeitos de uma determinada ocorrência podem ser observados antes do instante da publicação.

Além disso, o reflexo de um fenômeno registrado em um banco de dados tende a ser observado mais rapidamente em locais mais próximos. Isso significa que os efeitos de uma determinada ocorrência podem ser observados após o 
instante do registro da transação, de acordo com o tempo decorrido entre a ocorrência e a sua publicação e com a distância entre os locais avaliados.

\subsection{Métricas de confiabilidade dos dados}

Embora haja especificações para avaliar a qualidade, os resultados obtidos não são suficientes para assegurar a confiabilidade dos dados. Esta seção propõe critérios complementares para avaliar a confiabilidade de um conjunto de dados geoespaciais em um contexto especificado, como o planejamento de atividades em um determinado local (publicados originalmente em Barbosa e Casanova, 2011).

O primeiro critério indicado foi a cobertura espacial, que compara a extensão espacial do conjunto de dados com a área de aplicação. A interseção parcial ou inexistente implica a inexistência parcial ou total de dados, respectivamente, o que se traduz em incertezas nos resultados das análises em que o conjunto de dados é empregado. Além da extensão geográfica, são avaliados a completude (conforme especificado pela ISO 19157) e a escala equivalente, que indica o nível de generalização cartográfica com que os dados foram produzidos. A escala equivalente é um fator relevante pois, conforme abordado na seção 3.2 , a generalização cartográfica indica o menor nível de detalhamento na representação dos objetos, a alteração da simbologia e até a supressão de camadas de informação que possam atrapalhar a representação e a legibilidade dos mapas.

O segundo critério sugerido pelos autores foi a completude dos dados, relacionados à integridade temática da representação dos objetos. Este critério busca quantificar os campos não preenchidos ou preenchidos com o valor padrão (quando especificado), visando às consultas que empregam esses dados. Nesses casos, existe o risco de rejeitar resultados que atendam às condições especificadas ou aceitar resultados não confiáveis.

O terceiro critério indicado foi a proveniência dos dados, enfatizando fatores como a expertise e a aderência a especificações técnicas. Em suma, espera-se maior confiabilidade em dados produzidos por instituições de mapeamento do que em dados produzidos por usuários leigos, empregando equipamentos de precisão incompatível com a aplicação desejada. Afinal, existem aplicações que não poderão contar com dados produzidos por instituições governamentais e grandes 
empresas, mas que contam com a iniciativa colaborativa de usuários na produção e na disponibilização de dados geográficos, como o projeto Tracksource ${ }^{9}$.

O quarto critério indicado é o tempo de vida útil do conjunto de dados. Dias et al (2005) define vida como o conjunto das mudanças de características de um geo-objeto durante sua existência, caracterizada pela sua identidade. A noção de utilidade está associada semanticamente ao contexto de aplicação do dado, ou seja, a identidade pode permanecer, mas a validade do conteúdo pode deixar de ser relevante para o contexto aplicação. Em outras palavras, o dado é considerado válido enquanto forem observadas conjuntamente as acurácias temporal e temática. Dados geográficos relacionados a feições naturais (relevo e hidrografia, por exemplo) tendem a ser mais duráveis do que feições sujeitas à atuação humana (geometria das redes de transporte, acidentes de trânsito e edificações, por exemplo). O dado não precisa ser destruído por ter chegado ao término da vida útil, mas pode ser considerado válido para outras aplicações.

\subsection{Avaliação da Qualidade de Dados de Trânsito}

No contexto dos problemas de trânsito urbano tratados nesta tese, são empregados três conjuntos principais de dados: a malha viária da cidade; registros de velocidade; e registros de ocorrências que possam influenciar o trânsito. As seções seguintes visam a avaliar esses conjuntos de dados à luz dos conceitos enunciados neste capítulo.

Novamente, os exemplos referem-se aos dados usados nos experimentos na Cidade do Rio de Janeiro: o Google Maps fornece a malha viária; os registros de velocidade são extraídos da página da empresa Maplink; e os registros de ocorrências são extraídos do Twitter.

\subsubsection{Acurácia Temática}

No tocante à malha urbana, são atributos relevantes os sentidos permitidos em cada trecho. A troca de sentido implica falsos positivos ou ignorar trechos de interesse para a análise. A denominação das vias, oficiais e alternativas, e o tipo (estrada, avenida, rua, etc.) também são atributos que devem estar registrados com

\footnotetext{
${ }^{9}$ http://tracksource.org.br/sobre-o-projeto/
} 
exatidão. Variações como abreviaturas e nomes parciais podem ser encontradas, principalmente em tweets de usuários não corporativos, por exemplo.

No tocante aos pontos de medição de velocidade, é importante explicitar que trata-se de uma estatística computada sobre uma amostragem que está sujeita a flutuações estocásticas naturais do tráfego. A empresa alerta os usuários desses dados que "não pode garantir a qualidade, exatidão, completude, adequação, efetividade, confiabilidade ou utilidade dos mapas, endereços, estabelecimentos, pedágios, câmeras e radares de trânsito, vias públicas, pontos públicos e rotas, imagens, notícias, informações a eles relacionados ou de qualquer outro conteúdo do serviço” (Maplink, 2010). Portanto, será considerado como premissa o fato de que os valores de velocidade fornecidos são reais.

No que diz respeito aos tweets sobre ocorrências de trânsito, o principal atributo a ser avaliado é o próprio conteúdo da mensagem, dado que os demais itens são preenchidos automaticamente. A análise semântica do corpo da mensagem é importante, principalmente quando o usuário não é especialista no assunto e a palavra-chave empregada na consulta pode ser empregada em outros contextos diversos. Como exemplo, usar a palavra acidente na busca por mensagens que mencionem acidentes de trânsito retorna postagens referentes a acidentes de trânsito passados, acidentes aéreos, acidentes domésticos e pessoais. Usando a palavra colisão, as postagens encontradas apresentam maior correlação com eventos relacionados a trânsito.

\subsubsection{Acurácia Espacial}

Os fatores apresentados na Seção 1.2 acarretam algum nível de incerteza na posição em que os objetos são representados, sendo considerados como sistemáticos, dado que são inerentes do processo de representação dos dados e estarão contidos em todos dados de mesma origem. Ajustes nas configurações dos sistemas de coordenadas e de projeção podem minimizar boa parte dos deslocamentos e distorções na representação dos conjuntos de dados. Os erros que mais preocupam são os chamados erros grosseiros, onde os dados são inseridos ou representados enganosamente.

Usando o exemplo das postagens do Twitter que armazenam a localização do dispositivo no momento da publicação, observa-se a inconsistência entre o 
local da publicação e o local da ocorrência do evento relatado no texto por diversas razões: o usuário, no trânsito, publica a mensagem antes ou depois do local da ocorrência ou comenta o ocorrido após chegar em casa, ou republica uma mensagem lida, entre outras. A Figura 14 ilustra um caso em que a referência empregada encontra-se a aproximadamente 450 metros do local onde foi publicada a mensagem. Dependendo do contexto da via, tal diferença não interfere em uma análise qualitativa (a situação do trânsito é a mesma nos dois pontos e não há referências relevantes mais próximas), mas se as quantidades são relevantes na análise, recomenda-se avaliar tais discrepâncias.

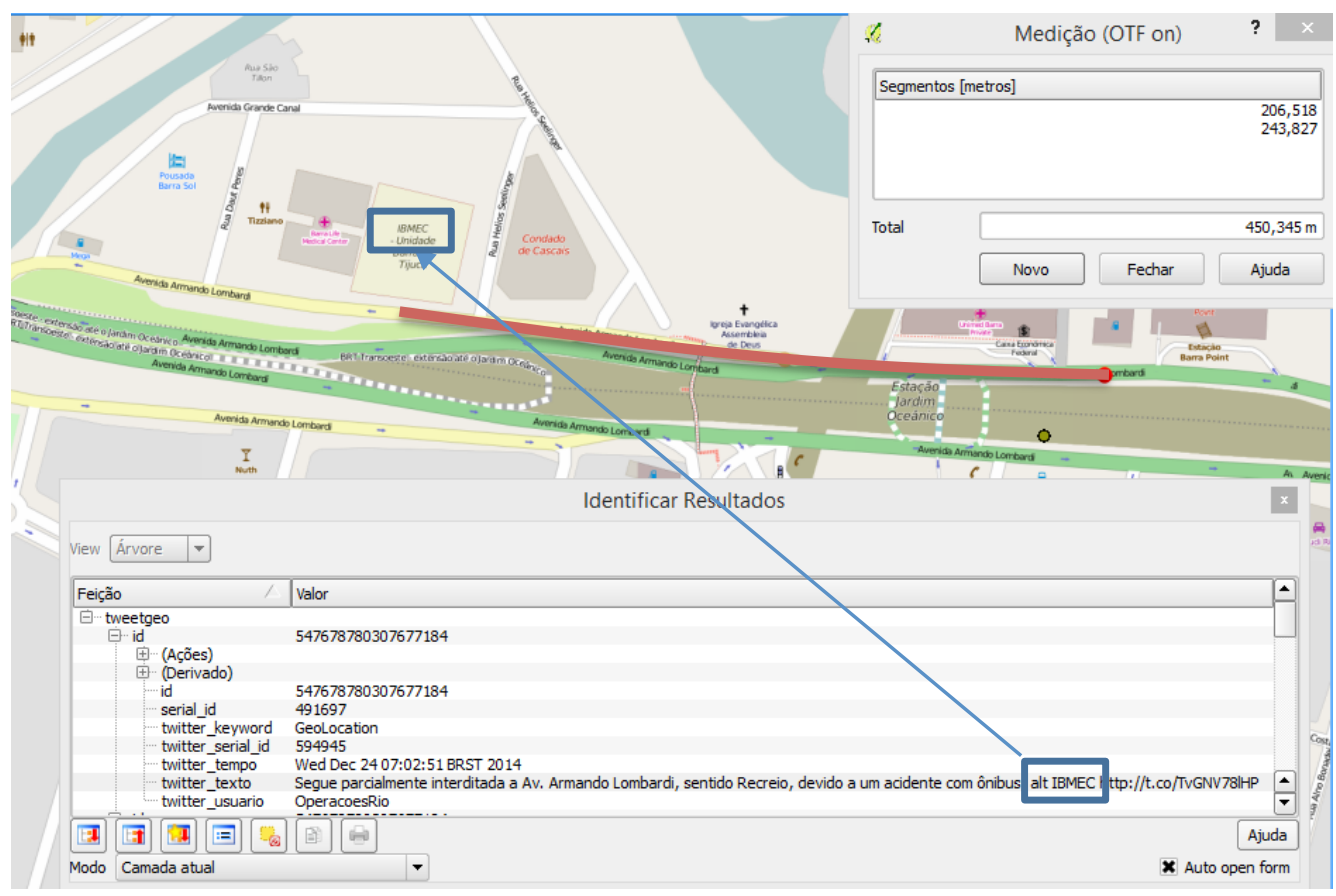

Figura 14 - Exemplo de discrepância entre o local de registro da postagem e o conteúdo da mensagem.

Nos casos em que as coordenadas não estão disponíveis, a referência vaga (como próximo a, na altura de, no quilômetro tal, esquina com, entre outras) permite maior acurácia do que simples referências ao nome da via. Entretanto, tais referências ainda são insuficientes para o posicionamento acurado da ocorrência. Se um evento ocorre antes ou depois de um cruzamento, por exemplo, os efeitos no tráfego podem se estender a outras regiões. Tweets nessas condições devem ser analisados com cautela. 


\subsubsection{Acurácia Temporal}

No que tange aos conjuntos de dados oriundos da empresa Maplink, assume-se como premissa que os dados temporais de velocidade disponibilizados estejam compatíveis com a real condição do tráfego no intervalo considerado no momento da extração. Considera-se também como premissa a acurácia temporal dos dados empregados pelos serviços do Google. Os dados do Twitter estão sujeitos às incertezas inerentes a um banco de dados por tempo de transação (seção 4.3).

\subsubsection{Confiabilidade dos dados}

Considerando como exemplo os dados sobre tráfego na Cidade do Rio de Janeiro, o critério de cobertura espacial pode ser considerado atendido. Quanto à escala equivalente, considera-se como premissa que a precisão das posições obtidas pelo GPS é compatível com as dimensões das vias urbanas da Cidade do Rio de Janeiro.

Quanto à completude dos dados, pode se considerar como premissa que as bases de dados utilizadas pelo Google estejam completas. Quanto aos dados oriundos da empresa Maplink, podem faltar dados de alguns PMV em alguns horários em virtude de falhas durante o processo de extração, indisponibilidade temporária do serviço ou devido à descontinuidade do serviço em vias fechadas pelo Poder Público. Os metadados dos tweets empregados foram extraídos com sucesso, exceto aqueles relacionados à geolocalização, publicados por usuários que não habilitaram suas posições. Como são considerados atributos temáticos, pode-se considerar que os dados extraídos do Twitter estão completos.

No que diz respeito à proveniência dos dados, a reputação dos serviços de roteamento e de renderização de mapas do Google Maps é alta em grandes cidades. Entretanto, alguma cautela é necessária em cidades como o Rio de Janeiro devido a alterações temporárias do trânsito como interdições, faixas reversíveis, e mudanças de sentido em algumas vias. Como já foi exposto, os dados extraídos da página da empresa Maplink podem "não retratar fielmente a situação real em que se encontrem ou a sua efetiva condição de uso ou funcionamento". Quanto aos usuários do Twitter, existe distinção entre a confiabilidade das postagens publicadas pelo Centro de Operações da Prefeitura e de usuários domésticos. Usuários relacionados à imprensa podem ser uma boa 
referência, contudo não é possível generalizar esse conceito. Foram utilizados os tweets publicados pelos usuários@OperacoesRio e@odia24horas, com boa reputação na publicação de informações sobre o trânsito na cidade do Rio de Janeiro (Albuquerque et al, 2012a).

Quanto ao critério de vida útil, os dados do Twitter e do MapLink não precisam ser descartados uma vez que a aplicação em questão se trata de uma análise retrospectiva. Como são premissas as acurácias temática e temporal da base de dados do Google Maps, pode-se considerar que essa base confiável segundo o critério da vida útil.

\subsection{Conclusões}

Ao longo deste capítulo foram apresentados critérios de acurácia (temática, temporal e espacial) e de confiabilidade (cobertura, completude, proveniência e vida útil) de dados relacionados ao estado do tráfego, disponibilizados pelas fontes de dados mencionadas no Capítulo 3. Tais critérios podem ser empregados na avaliação de quaisquer conjuntos de dados georreferenciados, removendo os registros em que foram detectadas incorreções e que, consequentemente, influenciarão os resultados de consultas e análises sobre essa base de dados.

Entre os problemas que podem ser encontrados na avaliação da qualidade dos dados empregados é a incerteza embutida nas referências espaciais e temporais quando esses dados são extraídos de textos em linguagem natural ou quando faltam valores para atributos temáticos, espaciais ou temporais. 


\section{Estimação de estatísticas de velocidade de uma malha viária com base em rotas rastreadas com GPS}

\subsection{Introdução}

As grandes cidades se deparam atualmente com o desequilíbrio entre a demanda de tráfego e a capacidade atual de suas redes viárias. Como foi abordado na seção 2.2, sempre que essa demanda excede a capacidade da via, formam-se filas, as velocidades médias diminuem, caracterizando-se o congestionamento, que implica viagens mais demoradas, um aspecto relevante a considerar.

Conhecer as condições de tráfego é um fator relevante no planejamento de rotas para otimização no emprego dos recursos disponíveis. Ao escolher o caminho mais curto, presume-se que as velocidades de deslocamento sejam as mesmas em todas as vias da rede. Porém, diferentes demandas de tráfego, normalmente dependentes do tempo, levam a flutuações no valor da velocidade média esperada para cada via. Isso significa que o menor caminho nem sempre é a opção mais rápida.

O tempo de viagem pode ser estimado a partir da velocidade média e do comprimento das vias, sendo esse valor empregado em aplicações com prazos predefinidos para deslocamentos como referência para monitoramento de veículos: baixos valores de velocidade podem indicar que é necessário refazer o planejamento ou que aconteceu algum tipo de emergência que precisa ser sanada (Albuquerque et al., 2012c).

Valores de velocidade podem ser calculados a partir das coordenadas de dois locais consecutivos em uma mesma trajetória rastreada por um receptor GPS independente ou instalado em um telefone celular. Dados provenientes de telefones celulares devem ser filtrados com cautela, uma vez que tais dispositivos podem estar no interior de edifícios, parados ou andando devagar pelas calçadas em vez de considerar apenas os usuários que estão, de fato, no trânsito. Além disso, dentro de um único ônibus podem estar vários usuários, o que atribui peso maior à velocidade desse ônibus no cálculo da média. A alternativa do receptor GPS individual facilita, em princípio, a coleta de dados em qualquer ponto da rede 
viária com baixo custo. Além disso, um receptor GPS instalado em um veículo em movimento permite rastrear sua trajetória. A principal desvantagem desse método é o tamanho da amostra necessário para modelar as condições reais de tráfego, o que pode ser resolvido aumentando seja taxa de rastreamento, espacial (um ponto a cada $n$ metros) ou temporal (um ponto a cada $n$ segundos) seja o número de veículos dotados de receptores, aptos a fornecer dados.

Este capítulo propõe uma metodologia para incrementar a base de dados de uma malha viária com estatísticas de velocidade a partir da análise das trajetórias adquiridas por veículos que circulam em uma cidade. As estatísticas calculadas consistem de média e desvio-padrão de velocidade, além do tamanho das amostras empregadas nos cálculos, organizadas por via e intervalos de tempo. A média das velocidades podem ser empregadas na estimação dos tempos de viagem para veículos ao longo de opções de rotas a fim de avaliá-las quanto à rapidez. As oscilações dos valores ao longo do tempo também são consideradas.

Para atingir o objetivo proposto, a metodologia prevê três principais fases: (1) map-matching, (2) classificação temporal dos pontos GPS e (3) cálculo de estatísticas e incremento da base de dados.

Após esta introdução, a Seção 5.2 descreve o problema proposto e o modelo empregado na solução desse cenário. A Seção 5.3 descreve a metodologia adotada para extração das estatísticas a partir dos conjuntos de dados utilizados. A Seção 5.4 apresenta os resultados experimentais de uma aplicação com dados reais da região de Pisa, Itália. A Seção 5.5 apresenta trabalhos relacionados. Por fim, a Seção 5.6 contém as conclusões e observações finais.

\subsection{Cenário}

A abordagem empregada neste capítulo considera o seguinte cenário. Um veículo equipado com rastreador GPS parte de um local denominado origem e se move ao longo de um conjunto de vias em direção a outro local denominado destino, onde se encerra o deslocamento. As vias que compõem o caminho são representadas por polilinhas e as vias consecutivas de um caminho são conectadas, isto é, a interseção entre elas é apenas um dos seus extremos (ponto inicial ou ponto final). O critério adotado para a escolha do caminho pode ser o comprimento mínimo ou 
o tempo de viagem estimado com base nas velocidades médias que os veículos podem desenvolver em cada via do caminho.

Os dados de entrada, obtidos a partir dos dados oriundos dos receptores, são representados como uma tupla

$$
\mathcal{P}=<i, p, t, v, s>
$$

onde:

- $\quad i$ é a referência ao usuário (conforme políticas de privacidade);

- $p$ é a geometria referente ao local rastreado, representado no sistema de referência espacial WGS-84;

- $t$ é a referência temporal (timestamp com fuso horário) no momento do rastreamento do ponto;

- $\quad v$ é o valor da velocidade instantânea;

- $s$ indica o estado do ponto na trajetória: 0 indica o ponto inicial, 2 indica o ponto final e 1 nos demais casos. Se o veículo estiver desligado, nenhum dado é registrado, mesmo que esteja estacionado ao longo de uma das vias.

Um segmento de via corresponde a um elemento geométrico usado para representar um trecho da via entre dois cruzamentos consecutivos. Cada segmento de via é representado como uma tupla

$$
R=<w, l, n, o>
$$

onde:

- $\quad w$ é um identificador único do segmento da via;

- $\quad l$ é a geometria do segmento de via;

- $n$ é o nome da via;

- o é um indicador das direções permitidas de tráfego (mão única ou mão dupla).

O problema a ser solucionado consiste em, dado um conjunto de rotas rastreadas com GPS e a malha viária de uma localidade, calcular velocidade média, desvio-padrão e a quantidade de pontos usada para tais cálculos para cada segmento de via. Esses valores são então acrescentados à base de dados original referente à malha viária. 
O resultado esperado é um conjunto de tuplas

$$
S=<w, l, n, o, k, h, a, d, c>
$$

onde os quatro primeiros elementos se referem ao segmento de via $\mathcal{R}_{\mathrm{i}}=<w, l, n$, $o>$ correspondente, enquanto:

- $\quad k$ é o dia da semana (de '0’ para domingo até ‘6', sábado);

- $h$ é o intervalo de tempo (por exemplo, de '0' a '23' para intervalos de 1 hora

- hora do dia;

- $a$ é a velocidade média;

- $d$ é o desvio-padrão;

- $\quad c$ é o número de pontos utilizados no cálculo.

\subsection{Metodologia}

A Figura 15 ilustra o processo de cálculo de estatísticas das vias a partir dos conjuntos de dados descritos na seção 5.2. O objetivo da primeira fase é estabelecer a correta associação entre pontos GPS e as geometrias das vias (map matching). Essa fase é necessária devido a: (1) imprecisões nas geometrias das vias (ver seção 4.2) e a falta de informações sobre a largura das vias (ver seção 4.4); (2) imprecisões inerentes à aquisição de dados GPS. Combinadas, essas duas fontes de imprecisões implicam o posicionamento dos pontos fora das vias. Por outro lado, alguns desses pontos devem ser desconsiderados pois foram realmente obtidos fora das vias (por exemplo, em estacionamentos, condomínios ou vias não mapeadas). Esta fase inclui ainda a análise de direções para incrementar os resultados obtidos.

A segunda fase é classificação temporal dos pontos GPS. Os critérios de partição devem modelar as flutuações nos valores de velocidade para gerar estatísticas consistentes, baseadas em quantidades representativas de dados. Quanto maior for a amostra, mais representativos serão os resultados. O equilíbrio entre o número de intervalos de tempo e o tamanho das amostras é um fator relevante a ser discutido. 
A última etapa refere-se ao cálculo de estatísticas a partir das partições resultantes da fase anterior e ao armazenamento desses valores na base de dados original da malha viária.

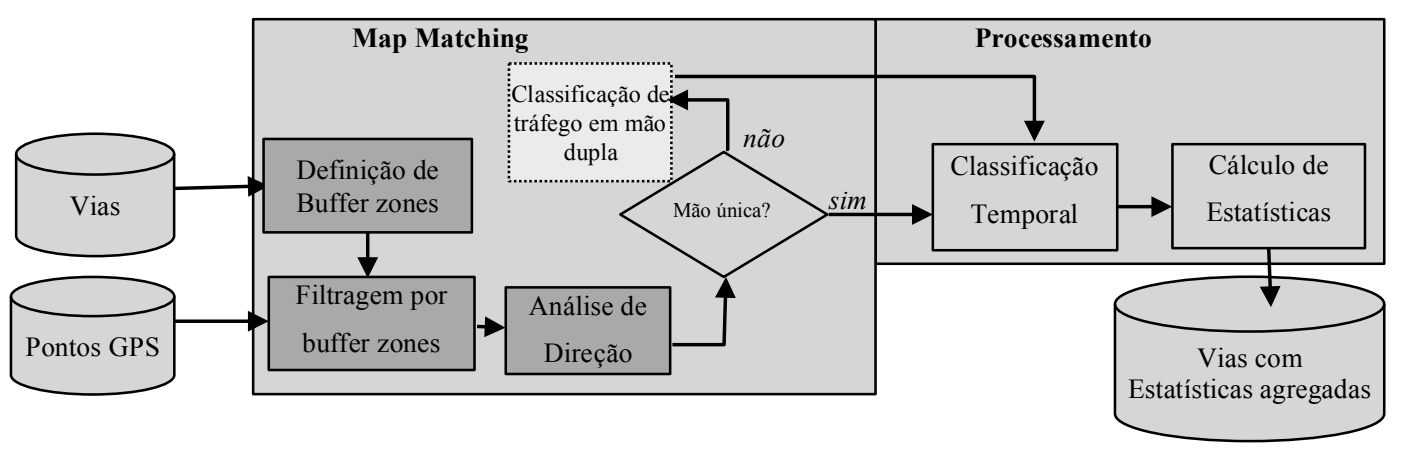

Figura 15 - Etapas de processamento propostas para agregar estatísticas de velocidade à malha viária.

\subsubsection{Map Matching}

Presume-se que, se os pontos são rastreados ao longo das trajetórias dos veículos, eles devem estar associados a algum segmento de via. Este problema é conhecido na literatura como map matching onde são propostos diversos algoritmos para estabelecer essa associação de forma acurada. Qualquer um desses algoritmos pode ser empregado nesta fase, assim como outros publicados posteriormente.

A metodologia de map matching empregada nesta fase foi dividida em duas fases: a primeira consiste na definição dos pontos contidos na vizinhança de cada uma das vias da malha viária, enquanto a segunda tem por objetivo analisar a direção do deslocamento dos veículos a cada ponto.

A motivação para propor a primeira fase é a identificação e posterior descarte de pontos rastreados fora das vias, devido à influência que podem causar nas estatísticas. Portanto, é necessário selecionar apenas os pontos que, supostamente, se movem ao longo das vias, descartando os demais. Considerando que há imprecisões nos valores de coordenadas obtidas com GPS e que as vias são representadas por polilinhas, na maioria das vezes sem largura diretamente atribuída, a solução adotada para filtrar os pontos mais prováveis de estarem associados a cada segmento de reta consiste na definição de zonas de vizinhança (buffer zones) $z_{i}$ em torno das vias. Desta maneira, são descartados pontos referentes a deslocamentos fora das vias e pontos de baixa precisão. 
O principal problema relacionado é a definição da largura das zonas de vizinhança: zonas estreitas significam o potencial descarte de pontos úteis para o cálculo das estatísticas; zonas largas significam a seleção de pontos fora dos limites da via, como veículos em vias próximas ou parados em acostamentos. A largura a ser adotada para as zonas deve ser compatível com a largura real da via, caso esse valor seja conhecido. Em virtude da indisponibilidade desse valor na base de dados empregada nos experimentos, foram analisados os resultados considerando zonas de 3,5 e 8 metros de largura.

O risco de erro é maior em regiões de interseção das zonas de vizinhança. Visando a minimizar tais incorreções nos casos de veículos que se deslocam no sentido oposto do tráfego, propõe-se analisar a direção do deslocamento.

As direções são calculadas como o azimute da linha definida por pares de pontos consecutivos $O_{i}=<\mathscr{P}_{i}, \mathscr{P}_{i+1}>$ pertencentes à mesma rota e ordenados pelos seus timestamps. O pareamento de pontos consecutivos permite indicar a direção de movimento de um determinado veículo, razão pela qual esses pontos serão doravante chamados pontos orientados, devido à orientação denotada pelo valor do azimute.

De acordo com o modelo apresentado na seção 5.2, cada segmento de via possui informação sobre a direção do trânsito: mão simples ou mão dupla. A análise de direção considera três casos:

a) Vias de mão única em uma tupla $\mathbb{R}$ : todos os veículos se movem na mesma direção da via, indicada por $A z_{R}$, e a distribuição desses valores coincide com as geometrias das vias;

b) Vias de mão dupla em uma tupla $\mathfrak{R}$ : os valores de direção observados são agrupados em torno de $A z_{R}$, o azimute da via, e $A z_{R} \pm 180^{\circ}$, a direção oposta.

c) Vias de mão dupla em duas tuplas $\mathbb{R}:$ os valores de direção são agrupados em torno do valor da direção da via $A z_{R}$. Porém, devido à proximidade entre as geometrias das vias, podem ser observados alguns valores próximos a $\mathrm{Az}_{\mathrm{R}} \pm 180^{\circ}$, provavelmente referentes à zona de vizinhança referente ao segmento de via da direção oposta.

O gráfico da figura 16a ilustra a distribuição de valores de azimute ao longo da Via Lungarno Gambacorti (ver mapa da figura 16a), localizada na 
cidade de Pisa, que é um exemplo de via que se enquadra no primeiro caso. A distribuição contínua de valores indica que todos os veículos seguem na mesma direção, mesmo em trechos curvilíneos.

O gráfico da figura $16 \mathrm{~b}$ ilustra a distribuição de valores de azimute ao longo da Via Fratelli Rosselli, de mão dupla, mas representada por uma única tupla de $R$ (ver mapa da figura 16b). É possível identificar dois grupos de valores próximos a $A z_{R}$ e a $A z_{R}+180^{\circ}$, devido ao tráfego nas duas direções. È possível também identificar a proporção de veículos que trafegam em cada direção. Ao computar estatísticas representativas para cada via, é necessário distinguir o fluxo em cada direção.
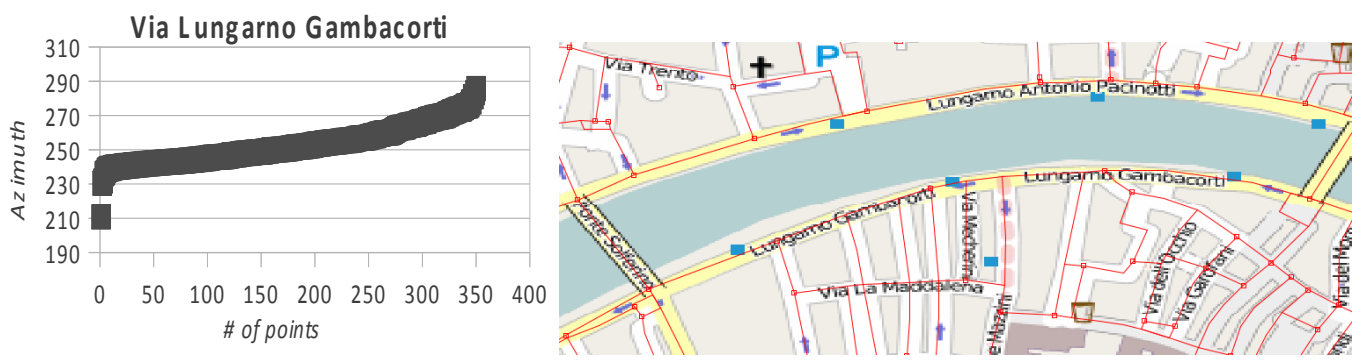

(a)
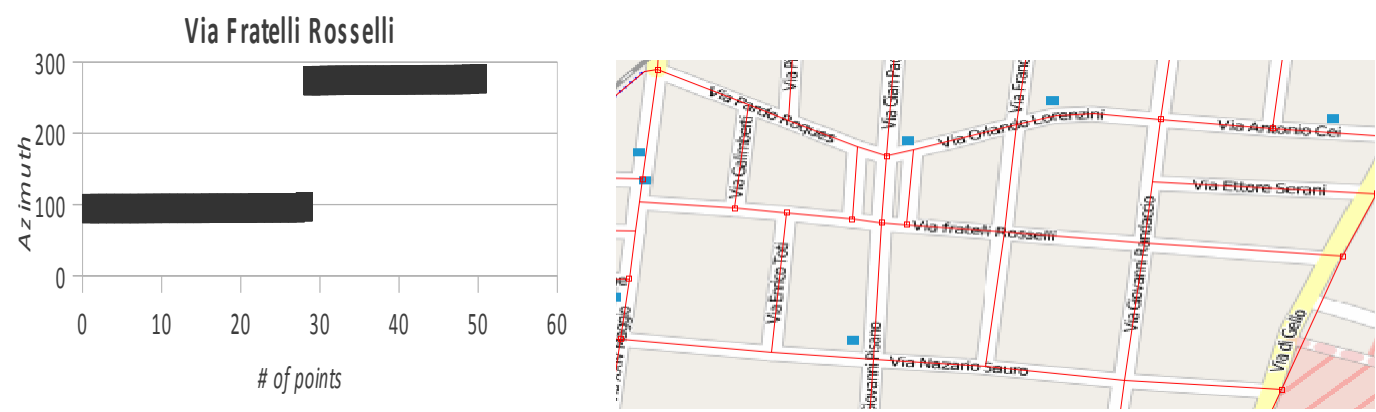

(b)
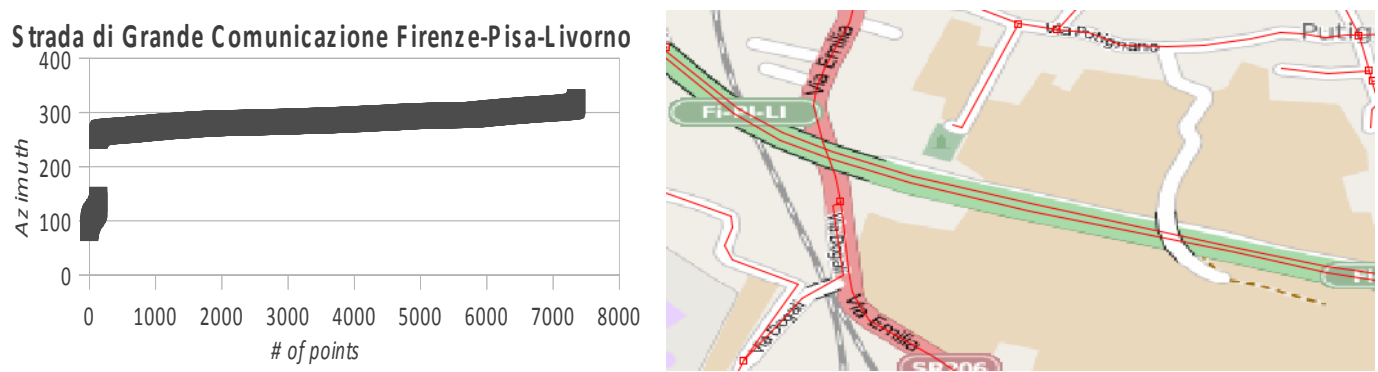

(c)

Figura 16 - Distribuição de valores de azimutes de pontos orientados. 
A Strada di Grande Comunicazione Firenze-Pisa-Livorno é um exemplo de via de mão dupla representadas por tuplas distintas, ou seja, cada direção é representada individualmente. As representações dessas vias, uma em cada direção, são geralmente próximas, o que leva ao risco de erros na associação entre via e ponto. A distribuição ilustrada na figura 16c se refere aos pontos supostamente rastreados ao longo da Strada. Podem ser identificados dois grupos apesar da premissa do fluxo em apenas uma direção: observa-se um pequeno conjunto de observações anormais (outliers) que, descartadas, permitem o cálculo de estatísticas mais representativas do real comportamento do tráfego na via.

Como as direções são supostamente opostas, o método propõe agrupar os pontos orientados de acordo com os valores de azimute: o primeiro grupo com valores próximos ao valor médio de azimute $(A)$, e o segundo grupo, contendo os outliers, em torno de A mais (ou menos) $180^{\circ}$, considerando a natureza cíclica dos valores de azimute por ser uma grandeza angular. No cálculo das estatísticas, são considerados apenas os valores no agrupamento próximo a $A$.

Entretanto, esta regra não se aplica às tuplas $\mathcal{R}$ referentes a vias de mão dupla (figura 16b) porque não se sabe a correta proporção entre os fluxos de veículos em cada direção. Uma solução seria o uso de algoritmos de clusterização para agrupar os valores de azimute em torno de 2 valores, o que permitiria distinguir os pontos que serão associados a cada via. Esta funcionalidade não foi implementada nos testes realizados.

Cabe relembrar que os pontos orientados $O_{i}$ são obtidos a partir de pontos consecutivos e que, ao arbitrar que cada par de pontos pertença à mesma zona de vizinhança $Z_{i}$, mais pontos orientados podem ser descartados, reduzindo a quantidade de pontos considerados nos cálculos das estatísticas. Se pontos consecutivos encontram-se em outras vias, o valor de azimute tende a ser diferente do azimute da via, o que afeta a análise de direções. Esta questão realça a necessidade de correto dimensionamento da taxa de rastreamento (um ponto a cada $n$ segundos ou a cada $s$ metros).

Outro aspecto a ser resolvido é a sobreposição de vizinhanças, quando um ponto está próximo a duas ou mais vias, podendo ser associado a qualquer uma delas. A Figura 5.3 ilustra um exemplo onde pontos GPS (na cor azul) estão contidos nas zonas de tonalidades mais densas (na cor verde), próximas às interseções das vias, representadas na cor vermelha. 


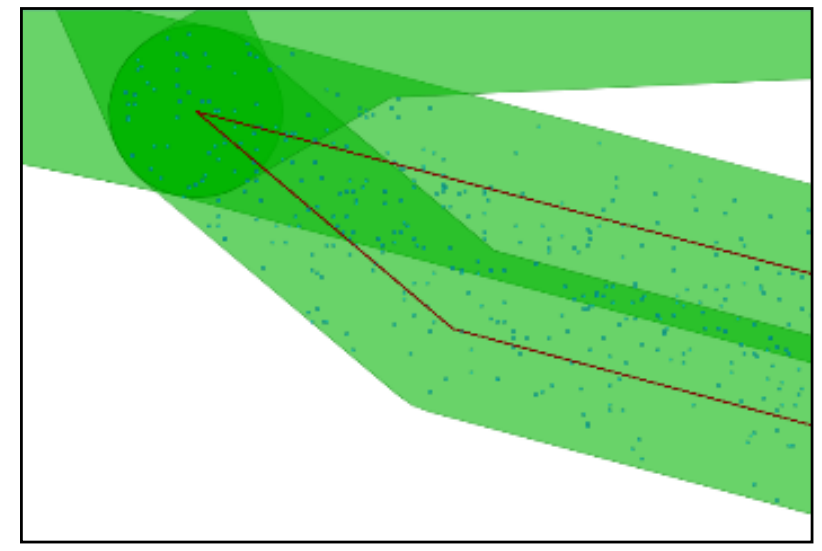

Figura 17 - Exemplos de pontos contidos em mais de uma zona de vizinhança.

Se $\mathscr{P}_{i+1}$ está localizado na região definida pela interseção das zonas $Z_{A} \mathrm{e}$ $Z_{B}$, ele pode ser associado aos respectivos trechos de via $\mathbb{R}_{A}$ e $\mathbb{R}_{B}$. Se $\mathscr{P}_{i}$ estiver associado à via $\mathbb{R}_{A}$, uma consulta simples irá descartar $O_{i}$, se $\mathscr{P}_{i+1}$ for associado à via $\mathbb{R}_{B}$. Para fins de análise de direção, esse descarte é desejável, razão pela qual, nos testes realizados, foram considerados os pontos orientados referentes aos pares de pontos consecutivos pertencentes à mesma vizinhança $Z_{i}$ mesmo que reduza a quantidade de pontos orientados empregados no cálculo das estatísticas das vias de mão dupla representados por uma única tupla $\mathbb{R}$.

\subsubsection{Classificação temporal}

Uma contribuição específica desta tese é o incremento da base de dados de segmentos de vias com informações dependentes do tempo. Isso significa que a velocidade media associada a cada segmento de via é calculada para diferentes intervalos de tempo, a fim de representar os diferentes estados do trânsito ao longo do tempo. Esta informação fornece importante subsídio ao planejamento de deslocamentos entre dois locais (origem e destino) considerando a dinâmica do tráfego ao longo do dia (e ao longo da semana). O principal parâmetro desta etapa é o tamanho do intervalo de tempo considerado na classificação: menores intervalos descrevem a dinâmica do tráfego de forma mais detalhada apesar da redução do tamanho de cada amostra; por outro lado, intervalos maiores empregarão maiores quantidades de pontos nos cálculos das estatísticas mas a dinâmica do trânsito está sujeita a maiores oscilações. 
No caso de análise macroscópica do tráfego, as variáveis introduzidas no capítulo 2 são normalmente representadas considerando intervalos de uma hora, razão pela qual este mesmo intervalo foi adotado nos experimentos descritos neste capítulo. Outro conceito introduzido no capítulo 2 que pode ser adotado neste contexto é adotar intervalos conforme a hierarquia de cada via, caso este dado esteja disponível.

\subsubsection{Cálculo das Estatísticas}

Nesta etapa, os pontos rastreados com GPS já associados às respectivas vias e divididos conforme os intervalos de tempo adotados (por exemplo, dias da semana e horas do dia). Para cada subconjunto são calculados a média e o desvio-padrão da velocidade, assim como a quantidade de pontos empregados no cálculo dessas estatísticas. A média indica o valor esperado para a tupla $\mathbb{R}$ no intervalo de tempo considerado; o desvio padrão indica o grau de dispersão dos valores em torno da média, servindo como indicador de anomalias no comportamento do tráfego; o número de pontos empregados nos cálculos indica a representatividade dos valores calculados ao mesmo tempo em que podem ser empregados para a definição de intervalos de confiança.

Por fim, os resultados são armazenados como novos atributos de $\mathbb{R}_{i}$ para compor as instâncias $S_{i, t}$, como especificado na seção 5.2.

\subsection{Experimentos}

\subsubsection{Aplicação com dados reais}

Os conjuntos de dados utilizados nos experimentos são: (1) pontos rastreados com receptores GPS instalados em 8575 veículos, na região de Pisa, Itália, entre os dias $1^{\circ}$ e 31 de maio de 2011; (2) vias da região analisada extraídas do repositório do Open Street Map.

O conjunto de dados referente aos pontos GPS contém 163.278.486 registros. Esse número é reduzido a 1.020.909 quando são excluídos os pontos 
fora da extensão espacial da base de dados referente às vias ${ }^{10}$. Após combinar pontos consecutivos, foram obtidos 783.622 pontos orientados. A rede viária possui 1.555 registros, dos quais 1.057 possuem nome (vias sem nome são ciclovias ou vias apenas para pedestres). Destas, 309 são vias de mão única. O mapa da Figura 18 ilustra a distribuição de pontos GPS ao longo das vias em uma região da cidade.

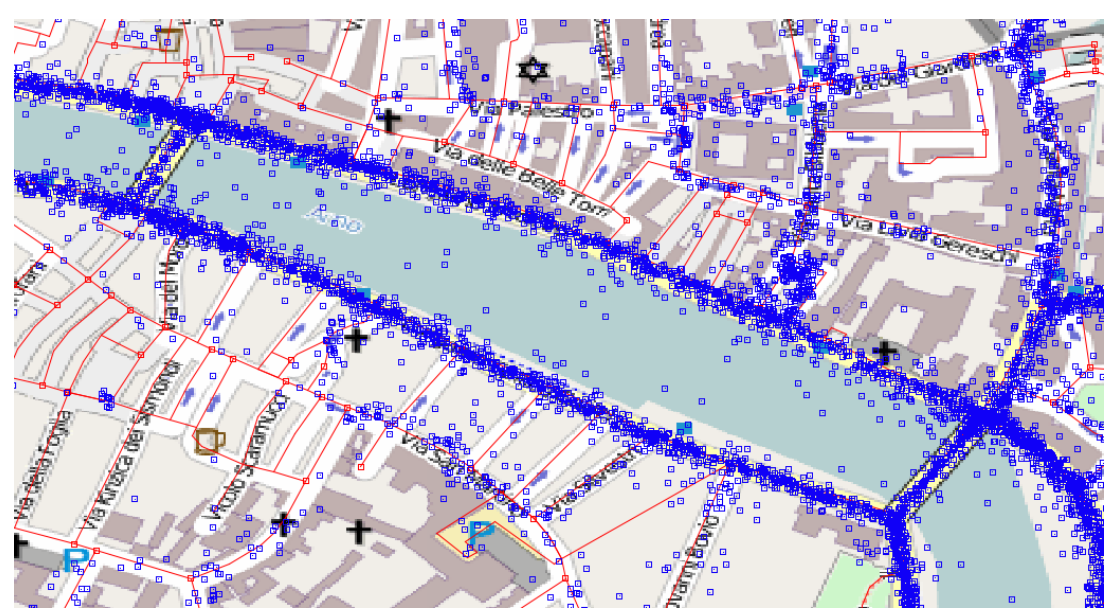

Figura 18- Exemplo da distribuição de pontos GPS ao longo das vias da cidade.

A Tabela 2 apresenta alguns resultados obtidos após a seleção dos pontos GPS com diferentes larguras de vizinhança. A primeira coluna contém os valores das larguras consideradas nos processamentos. A segunda coluna indica o número de pontos contidos nas respectivas vizinhanças, assim como a razão entre o valor indicado e a quantidade total de pontos disponíveis. De maneira análoga, a terceira coluna indica a quantidade de pontos orientados estão contidos nas respectivas vizinhanças e a razão entre esses valores e o total de pontos orientados formados a partir da base de dados original. Os valores da quarta coluna se referem às vias cujas estatísticas de velocidade foram calculadas em todo 0 processo, trazendo também a respectiva proporção em relação ao total de vias contidas na base de dados.

Como seria de se esperar, o número de pontos empregados nas estatísticas aumenta quando a largura das zonas de vizinhança aumenta. Porém esse crescimento não é uniforme, apresentando ganhos percentuais cada vez menores

\footnotetext{
${ }^{10}$ A extensão espacial é definida pelos valores máximo e mínimo tanto de latitude (extensão norte-sul) quanto de longitude (extensão leste-oeste) dentre os registros da base de dados referente às vias.
} 
conforme cresce a largura. Isso significa que os pontos estão mais concentrados nas primeiras vizinhanças e os ganhos obtidos aumentando a largura tendem a diminuir.

Tabela 2 - Dados sobre os resultados de processamento.

\begin{tabular}{|c|c|c|c|}
\hline $\begin{array}{c}\text { Largura } \\
(\mathbf{m})\end{array}$ & $\begin{array}{c}\text { Pontos GPS } \\
\mathbf{\%}\end{array}$ & $\begin{array}{c}\text { Pontos Orientados } \\
\mathbf{\%}\end{array}$ & $\begin{array}{c}\text { Vias com estatísticas } \\
\mathbf{\%}\end{array}$ \\
\hline 3 & 352.221 & 23.997 & 249 \\
& $34,5 \%$ & $3,06 \%$ & $23,6 \%$ \\
\hline 5 & 557.555 & 55.574 & 329 \\
& $54,6 \%$ & $7,09 \%$ & $31,1 \%$ \\
\hline 8 & 792.639 & 97.871 & 415 \\
& $77,6 \%$ & $12,5 \%$ & $39,3 \%$ \\
\hline
\end{tabular}

A Tabela 3 apresenta novos valores. A primeira e a segunda colunas correspondem, respectivamente, à primeira e à terceira coluna da Tabela 1. A terceira coluna apresenta a quantidade de vias de mão única que receberam estatísticas de velocidade: a propoção indicada é em relação ao número de vias de mão única existentes na rede viária. A quarta coluna apresenta o número de erros no processo de map matching (ou seja, dos pontos com direção oposta ao fluxo de veículos na via), assim como a proporção relativa ao número de pontos orientados. Os pontos que apresentaram tais erros não foram utilizados nos cálculos das estatísticas.

Tabela 3 - Dados adicionais sobre os resultados de processamento.

\begin{tabular}{|c|c|c|c|}
\hline $\begin{array}{c}\text { Largura } \\
(\mathbf{m})\end{array}$ & $\begin{array}{c}\text { Pontos Orientados } \\
\mathbf{\%}\end{array}$ & $\begin{array}{c}\text { Vias de mão única } \\
\mathbf{\%}\end{array}$ & $\begin{array}{c}\text { Erros de map matching } \\
\mathbf{\%}\end{array}$ \\
\hline 3 & 23.997 & 88 & 205 \\
& $3,06 \%$ & $28,5 \%$ & $0,85 \%$ \\
\hline 5 & 55.574 & 113 & 602 \\
& $7,09 \%$ & $36,6 \%$ & $1,08 \%$ \\
\hline 8 & 97.871 & 143 & 2263 \\
& $12,5 \%$ & $46,3 \%$ & $2,31 \%$ \\
\hline
\end{tabular}

$\mathrm{Na}$ etapa de classificação temporal, os dados remanescentes das etapas anteriores foram divididos em intervalos de uma hora, com base nos timestamps contidos nos registros. Para avaliar as variações ao longo da semana, os dados 
também foram classificados de acordo com os dias da semana, também extraído a partir dos timestamps.

Após a distribuição dos valores, é possível calcular as estatísticas de $\mathbb{R}_{i}$ para compor $S_{i, t}$. Contudo, é bom ressaltar que cada subconjunto de pontos pode conter valores anormais, ocasionados por influências externas. Algumas dessas observações podem ser pontuais e, dependendo do tamanho da amostra, também podem influenciar as estatísticas da via analisada.

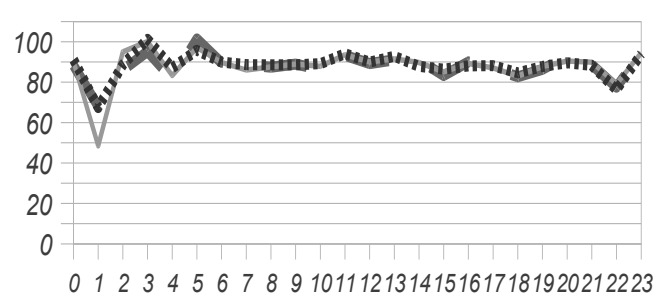

(a)

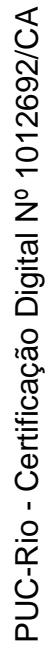

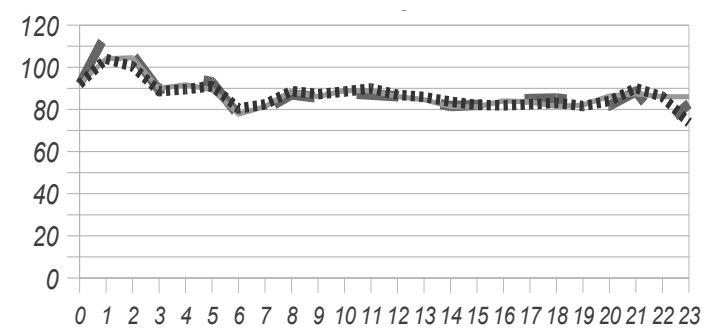

(b)

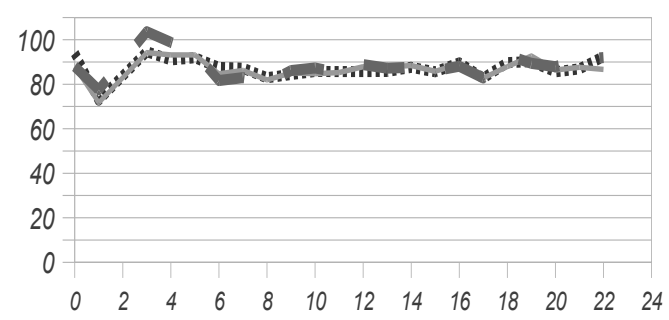

(d)

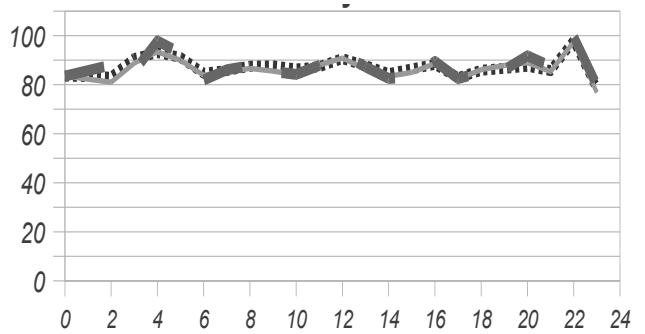

(f)

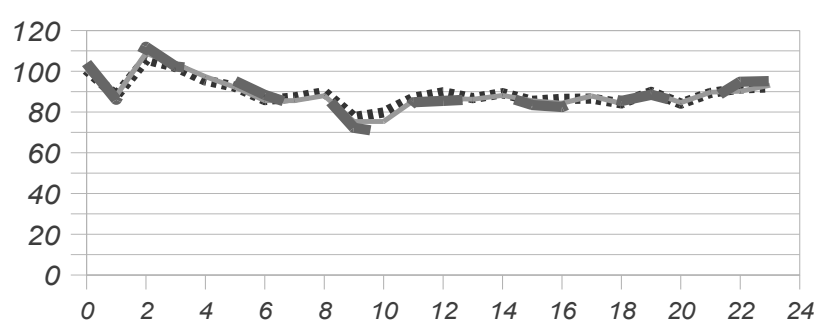

Legenda

(g)

Figura 19 - Exemplos de estatísticas de velocidade ao longo da semana. 
A Figura 19 apresenta os gráficos referentes à distribuição temporal das velocidades médias referentes a uma das vias da Strada di Grande Comunicazione Firenze-Pisa-Livorno comparando os resultados obtidos com diferentes larguras de vizinhança no domingo (a), na segunda-feira (b), na terça-feira (c), na quartafeira $(d)$, na quinta-feira (e), na sexta-feira $(f)$ e no sábado $(g)$. Em todos os gráficos, as abcissas representam as horas do dia e as ordenadas representam a velocidade média calculada $(\mathrm{em} \mathrm{km} / \mathrm{h})$. É possível identificar um comportamento anômalo na amostra de dados obtidos entre 5 h e $6 \mathrm{~h}$ de quinta-feira, provocado por um acidente ocorrido em uma das quatro quintas-feiras do período observado. Retirando os pontos obtidos no dia do acidente, a média das velocidades passa a ser $83.3 \mathrm{~km} / \mathrm{h}$, valor compatível com as velocidades observadas nos outros dias da semana no mesmo horário.

Para algumas vias, não houve pontos GPS rastreados ou todos foram descartados por não atenderem aos critérios espaciais e temporais estabelecidos ao longo deste capítulo. Consequentemente, não foram calculadas estatísticas para essas vias. Caso essas vias precisem ser empregadas em alguma rota, sugere-se adotar uma das estratégias a seguir para estimar a velocidade nessas vias: (1) atribuir a velocidade nominal, ou de projeto - não há tráfego suficiente para causar valores inferiores; (2) interpolar os valores a partir dos intervalos próximos - no caso de ausência pontual de valores entre os intervalos analisados; (3) atribuir zero ao valor da velocidade - o tempo de viagem é considerado alto demais devido à incerteza nos valores de velocidade.

\subsubsection{Estimação de tempo de viagem}

Um exemplo de aplicação dos valores calculados e acrescentados às vias é a estimação do tempo de viagem baseada nos valores médios de velocidade calculados previamente. Foram escolhidos para este exemplo, dois locais situados na área urbana de Pisa. Foram propostas três opções pelo serviço de roteamento do Google Maps, representadas pelos nomes das vias e seus respectivos comprimentos (Figura 20). Os tempos de viagem em cada uma das três rotas foram calculados pela soma dos tempos obtidos pela divisão do comprimento pela velocidade média da via. Os resultados obtidos para os roteamentos realizados entre $16 \mathrm{~h}$ e $17 \mathrm{~h}$ de uma quinta-feira estão apresentados na Tabela 4. 
Comparando as rotas $\# 1$ and $\# 2$, cabe ressaltar que o caminho mais curto não é o caminho mais rápido. Embora a rota \#3 seja a mais longa, a velocidade média de deslocamento é a maior, se comparada com as demais. Os resultados fornecidos pelo serviço do Google Maps indicam os mesmos fatos, apesar de indicarem menores valores de tempo de deslocamento.

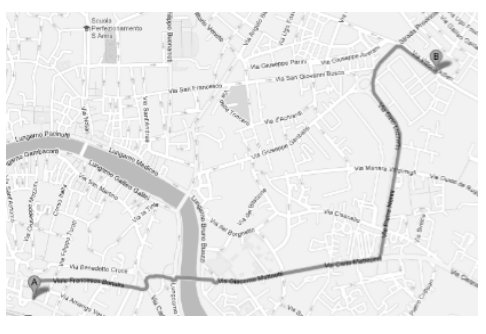

(a)

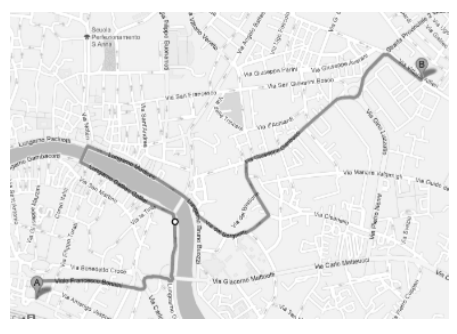

(b)

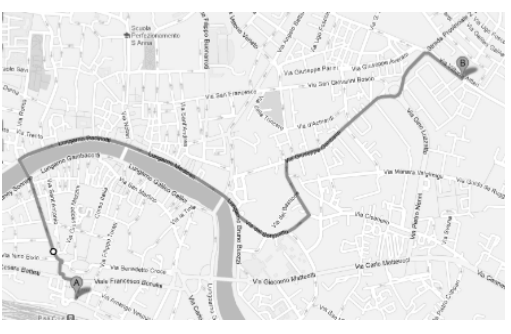

(c)

Figura 20 - Opções de rotas propostos pelo Google Maps.

Tabela 4 - Tempos de viagem estimados com base nos valores de velocidade média calculados previamente

\begin{tabular}{|r|r|c|c|c|r|}
\hline \multirow{2}{*}{ Rota } & \multirow{2}{*}{$\begin{array}{c}\text { Comprimento } \\
\text { (m) }\end{array}$} & $\begin{array}{c}\text { Buffer } \\
\mathbf{3 m}\end{array}$ & $\begin{array}{c}\text { Buffer } \\
\mathbf{5 m}\end{array}$ & $\begin{array}{c}\text { Buffer } \\
\mathbf{8 m}\end{array}$ & Google Maps \\
\hline 1 & 3402 & $13^{\prime} 48^{\prime \prime}$ & $13^{\prime} 5^{\prime \prime}$ & $13^{\prime} 48^{\prime}$ & 8 \\
\hline 2 & 3308 & $15^{\prime} 13^{\prime}$ & $14^{\prime} 32^{\prime}$ & $15^{\prime} 11^{\prime}$ & $11^{\prime}$ \\
\hline 3 & 4015 & $15^{\prime} 35^{\prime}$ & $14^{\prime} 44^{\prime}$ & $15^{\prime} 14^{\prime}$ & $11^{\prime}$ \\
\hline
\end{tabular}

\subsection{Trabalhos relacionados}

Algumas das aplicações que empregam dados rastreados com GPS são as frotas particulares (taxis, caminhões e ônibus, por exemplo). Masiero et al. (2011) apresenta uma metodologia baseada na regressão de valores de suporte (Support Vector Regression - SVR) para predizer o tempo de viagem de caminhões de entrega, com base em trajetórias rastreadas em ocasiões anteriores.

Sinn et al. (2012) descreve outra aplicação de predição de tempo de viagem a partir de dados obtidos com receptores GPS. Eles ainda apresentam um método para extrair automaticamente rotas de ônibus, paradas e horários. Em todos os casos, a análise considera trajetórias fixas (paradas e movimentos) e velocidades controladas. Outra metodologia de estimação do tempo de viagem foi 
proposta por Pang et al (2011) utilizando dados de GPS rastreados em ônibus. Contudo, foram empregados smartphones para reunir os dados para análise, o que torna questionável a validade dos dados para agregar uma malha viária.

O método proposto por Min and Wynter (2011) baseia-se em matrizes de correlação especial e as velocidades médias são obtidas a partir de dados históricos de algumas categorias de vias e fornece predições de velocidade e fluxo em intervalos que podem variar de 5 minutos até 1 hora.

A análise apresentada por Yuan et al. (2011) baseia-se em dados GPS referentes às trajetórias rastreadas durante três meses por 33.000 taxis em Beijing a fim de identificar anomalias no comportamento do tráfego. Embora as trajetórias dos taxis sejam supostamente mais flexíveis, elas são influenciadas pela existência de pontos de interesse públicos ou privados, como pontos turísticos, aeroportos, hotéis e centros de convenções.

Em contrapartida, em Biagioni et al. (2011), a inteligência dos motoristas de taxi para escolher rotas mais rápidas é modelada a partir das trajetórias que eles percorrem usualmente. Neste caso, em vez de empregar os valores de velocidade, são utilizadas as frequências com que eles passam pelas ruas da cidade. Assim, esse método classifica as ruas a partir das experiências e preferências dos motoristas.

A contribuição da metodologia proposta neste capítulo é a geração de estatísticas mais representativas para a malha viária de uma região a partir de trajetórias rastreadas com GPS sem o viés de grupos específicos de motoristas (taxistas, motoristas de ônibus ou caminhões, por exemplo) de ou tipos específicos de vias (como rodovias expressas). Além disso, a análise de direção permite incrementar a confiabilidade das estatísticas pela eliminação de valores de velocidade atribuídos incorretamente à via durante o processo de map matching.

\subsection{Conclusão}

Neste capítulo foi proposta uma metodologia para agregar a um conjunto de dados referente à malha viária de uma cidade estatísticas de velocidade calculadas a partir de trajetórias rastreadas, ao longo de um mês, com receptores GPS instalados em veículos. Os resultados obtidos descrevem o comportamento do tráfego ao longo dos dias da semana e das horas - embora a metodologia permita 
analisar diferentes intervalos de tempo. Com isso, é possível estimar tempos de viagem em rotas e basear os critérios de planejamento no tempo de viagem ao invés de escolher apenas a menor distância. É possível, também, identificar anomalias ocorridas no tráfego, pela comparação com a série histórica de valores de velocidade.

O método proposto é empregado em três fases: (1) map-matching, (2) classificação temporal dos pontos GPS e (3) cálculo das estatísticas e agregação dos valores calculados à malha viária original. Devido às imprecisões inerentes ao rastreamento com GPS e à existência de pontos rastreados afastados das vias, a análise ficou restrita aos pontos posicionados nas zonas de vizinhança em torno das vias, cujas dimensões devem ser compatíveis com os reais comprimentos das respectivas vias.

A contribuição da metodologia proposta neste capítulo é a geração de estatísticas mais representativas para a malha viária de uma região a partir de trajetórias rastreadas com GPS sem o viés de grupos específicos de motoristas ou tipos específicos de vias. Os valores obtidos permitem apoiar os planejamentos de deslocamentos baseados no tempo de viagem e detectar comportamentos anômalos no tráfego. Os dados considerados anormais, se forem caracterizados como eventuais, devem ser desconsiderados a fim de manter os valores das estatísticas representativos.

A análise combinada das Tabelas 5.1 e 5.2 mostram que o aumento da largura das zonas de vizinhança o aumento na quantidade de pontos implica em aumento na quantidade de pontos orientados, utilizados na análise de direção. Contudo, o ganho não é uniforme, mas decai ao mesmo tempo que permite a associação de pontos pertencentes a outras vias (outliers). A análise de direções, entretanto, permite identificar e eliminar as associações equivocadas. Mesmo com a possibilidade de erros, cresce o número de vias de mão única que recebem estatístiticas porque a maioria dos erros no processo de map matching ocorreram em um número reduzido de vias.

Deve-se enfatizar que muitos dos valores foram calculados sobre amostras com poucos pontos em cada intervalo de tempo. Os experimentos que adotaram vizinhanças de 3 metros de largura, $82 \%$ dos registros foram calculados com base em amostras com menos de 10 pontos. Com zonas de 5 e 7 metros de largura, essa proporção é de $79 \%$ e $76 \%$ respectivamente, o que não pode ser considerado um 
ganho expressivo, dado que aumenta o risco de ocorrência de outliers, como já foi abordado. Essa proporção pode aumentar de forma mais confiável se a taxa de aquisição de dados aumentar ou se forem considerados pontos rastreados por períodos maiores de tempo (não apenas um mês).

Em trabalhos futuros, sugere-se combinar a análise apresentada por Biagioni et al. (2011), baseada nas frequências, com a distribuição espaçotemporal dos pontos rastreados. Outra abordagem que pode ser empregada é o emprego do algoritmo apresentado por Lou et al (2009) para propor caminhos ao longo de trajetórias GPS com baixas taxas de registro.

Outra possibilidade de melhoria é classificação temporal adaptativa com o objetivo de detalhar melhor o comportamento do tráfego em vias com muitos pontos (intervalos de 15 minutos em vez de 1 hora) e agrupar intervalos de tempo contíguos no caso de amostras com poucos pontos (manhã - tarde - noite em vez de 1 hora). A falta de dados para essas vias significa que os usuários não costumam incluí-las nas suas viagens devido à baixa velocidade que é possível desenvolver ou à sua má conservação, por exemplo.

Outra aplicação possível é a combinação dos resultados obtidos por esta metodologia com valores obtidos com outras metodologias (como detectores de indução ou telefones celulares) visando a obter amostras maiores.

Por fim, os procedimentos empregados neste capítulo podem fornecer estatísticas de velocidades a pontos em locais estratégicos da malha viária, criando pontos de medição de velocidade (PMV) virtuais, complemetando a base de dados descrita na seção 3.2 . 


\section{Descrição do tráfego com base na velocidade}

Este capítulo apresenta uma abordagem para descrever estatisticamente o comportamento do tráfego. Conhecido o comportamento geral do tráfego observado em um ponto de monitoramento, é possível avaliar as possíveis variações decorrentes de ocorrências de trânsito pela comparação dos valores observados com os valores considerados normais.

A discussão neste capítulo baseia em experimentos que utilizam valores de velocidade medidos em vias públicas da Cidade do Rio de Janeiro, conforme antecipado nos Capítulos 3 e 4.

\subsection{Modelo de Dados Empregado nas Análises}

Face ao exposto nos Capítulos 3 e 4, foram empregados três conjuntos de dados na análise: malha viária da cidade do Rio de Janeiro, medições de velocidade e postagens do Twitter relacionadas ao tráfego na cidade. Cada um dos conjuntos de dados será descrito nas próximas seções.

\subsubsection{Malha viária da cidade do Rio de Janeiro}

Foi empregada a base de dados disponibilizada pelos serviços relacionados ao Google Maps para fins de roteamento e renderização de mapas de referência. A preferência pela escolha dessa base baseia-se na constante atualização dos dados cartográficos e na disponibilidade de uma API que permite customizar os parâmetros e interpretar os resultados de maneira inequívoca.

Dados da base da Prefeitura do Rio de Janeiro - Instituto Pereira Passos são usados para extrair dados complementares das vias, como a sua classificação hierárquica. Entretanto, em virtude da data de produção (2006), tal análise deve ser realizada com cautela. 


\subsubsection{Medições de velocidade}

Os valores de velocidade apresentados na página da empresa Maplink, conforme descritos na seção 3.2, estão organizados por vias, chamadas de corredores e classificadas conforme critérios da empresa. Para fins de orientação dos usuários, cada ponto de medição de velocidade (PMV) é indicado pelos cruzamentos com outras vias. A Figura 21 ilustra um exemplo referente à via expressa Linha Amarela, onde os PMV são indicados com as referências aos cruzamentos com a R. Edgard Werneck e com a Av. Geremário Dantas, entre outras.

Cada PMV é uma tupla

$$
\mathcal{P}=<o, c, r, g>
$$

onde (ver dicionário de dados no Anexo 1):

- $o$ é um número atribuído automaticamente aos pontos, em função da ordem em que foram extraídos da página da empresa e armazenados no banco de dados.

- $\quad c$ é o corredor analisado;

- $r$ é a referência ao corredor;

- $g$ é o ponto formado pelas coordenadas do ponto, extraídas da página.

A extração dos valores de velocidade foi programada para ser automática, a cada 20 minutos, sendo o programa reiniciado algumas vezes em horários diferentes, visando à maior distribuição das observações ao longo do tempo. Foram extraídos 6.142.589 valores de velocidade fornecidos pela empresa Maplink em sua página Web entre 12/06/2014 e 31/12/2014, referente a 602 pontos distribuídos nas vias de maior movimentação da cidade.

Cada registro é uma tupla

$$
v=<r, t, v, g>
$$

onde (ver dicionário de dados no Anexo 1):

- $r$ é a referência ao corredor;

- $t$ é a hora da observação;

- $v$ é o valor da velocidade observado em $t$;

- $g$ é o ponto formado pelas coordenadas do ponto, extraídas da página. 


\section{Veja as condições de trânsito ao vivo em Ln Amarela, trecho a trecho}

\section{Trânsito no sentido Vd de Manguinhos}

TRÂNSITO AGORA

O trecho tem no momento $0 \mathrm{~km}$ de filas e está levando $9 \mathrm{~min}$ para percorrer.

\section{SEM TRÂNSITO}

Esse trecho tem $11 \mathbf{k m}$ de extensão e leva 9min para percorrer.
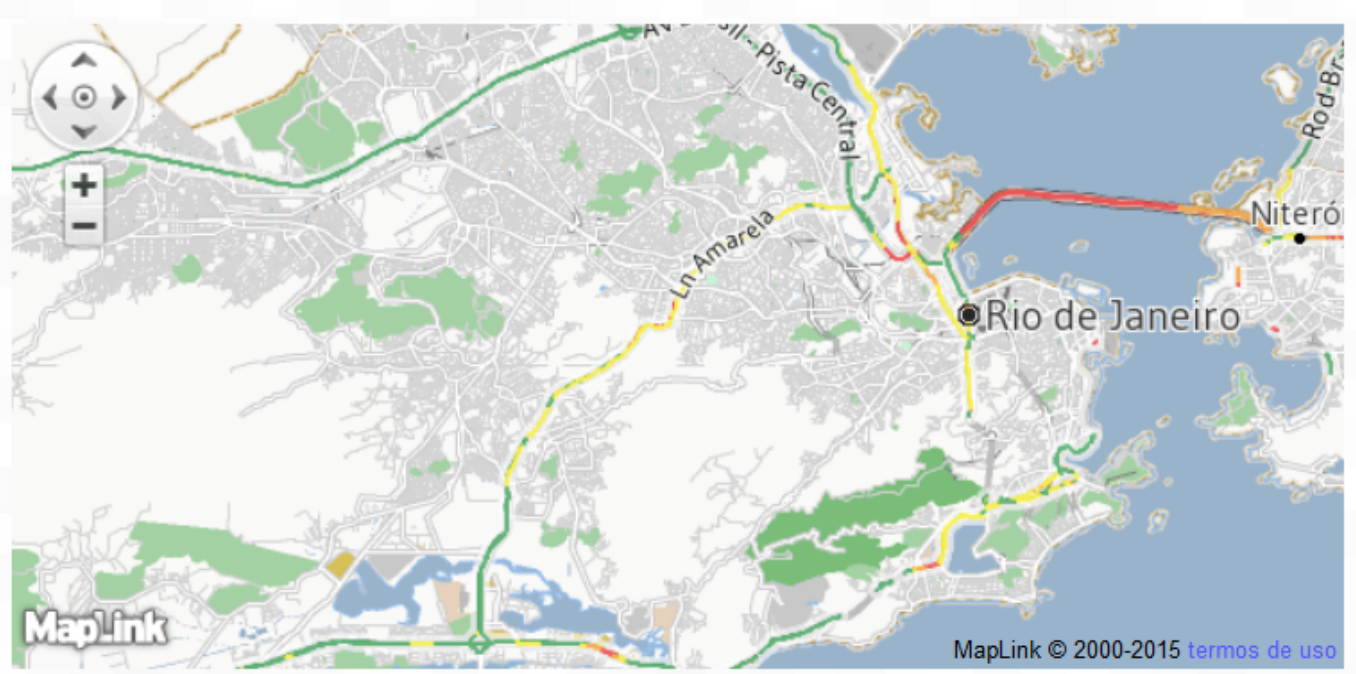

Trânsito livre no cruzamento da R Edgard Werneck

Trânsito livre no cruzamento da Av Geremário Dantas

Trânsito livre no cruzamento da Estr do Pau Ferro

Trânsito livre no cruzamento da R Agrolândia

Trânsito fluindo no cruzamento da R Borja Reis

Figura 21 - Extrato da página da empresa Maplink com informações sobre o tráfego no corredor Linha Amarela.

\subsection{Revisão conceitual}

Para realizar a análise exploratória dos valores coletados, é necessário abordar conceitos como a detecção de outliers, classificação por clusterização e métricas de similaridade entre conjuntos de dados, abordados detalhadamente nas próximas seções. 


\subsubsection{Detecção de outliers}

Os valores associados a variáveis aleatórias apresentam variações em torno de um valor mais provável, de acordo com a dispersão observada. Variações anormais (outliers) também podem ser observadas, devido tanto a erros de medição ou registro do valor quanto a condições incomuns ocorridas no contexto da medição. No caso de valores unidimensionais, a detecção de outliers pode ser baseada em indicadores estatísticos como a média ou a mediana associados ao desvio-padrão ou ao intervalo interquartílico (Braga, 2005), minimizando as ocorrências de valores menos prováveis.

Há divergências quanto ao emprego ou eliminação desses valores em análises estatísticas devido à anormalidade intrínseca das observações ao mesmo tempo em que pode indicar possibilidades críticas de ocorrência de um determinado fenômeno. Quando a quantidade de valores ditos anormais é relevante, a abordagem mais indicada pode ser um caso de clusterização, indicando diferentes tendências de comportamento possíveis.

Para os fins desta tese, os valores de outliers serão eliminados na análise global do comportamento do tráfego desde que não excedam $10 \%$ das amostras analisadas (Inicialmente, esse valor é arbitrário e pode variar de acordo com o tamanho da amostra). Entretanto, esses registros podem indicar a influência de algum acidente e podem ser aproveitados em outras análises. Caso esse limite seja excedido, os dados serão agrupados em duas classes, referentes ao tráfego normal e ao tráfego congestionado.

Para exemplificar os conceitos desta seção, serão empregados dois conjuntos de valores de velocidade medidos entre as $7 \mathrm{~h}$ e as $8 \mathrm{~h}$ : o primeiro contém valores registrados em um local às segundas-feiras, enquanto o segundo contém valores registrados no mesmo local às terças-feiras. A figura 22a ilustra a distribuição dos 84 valores da velocidade $(\mathrm{em} \mathrm{km} / \mathrm{h})$ versus horário do registro, todos obtidos às segundas-feiras. A figura $22 \mathrm{~b}$ ilustra a distribuição dos valores de velocidade obtidos às terças.

A distinção visual dos outliers é relativamente intuitiva, confirmando com os indicadores estatísticos apresentados. O histograma da figura 23a apresenta um valor destacado dos demais valores. $\mathrm{Na}$ figura $23 \mathrm{~b}$ não são observados tais 
valores. Empregando a regra dos intervalos interquartílicos ${ }^{11}$ aos valores observados às segundas-feiras, são considerados outliers os valores de velocidade acima de $79,5 \mathrm{~km} / \mathrm{h}$ e abaixo de $59,5 \mathrm{~km} / \mathrm{h}$. Outra possibilidade é o emprego dos intervalos de confiança para variáveis aleatórias de distribuição normal. Considerando o tamanho da amostra, os valores de média e desvio-padrão da amostra empregada, e o nível de significância de 99\%, são considerados anormais os valores acima de $71,4 \mathrm{~km} / \mathrm{h}$ e abaixo de $67,4 \mathrm{~km} / \mathrm{h}$.

O primeiro critério baseia-se nos valores do primeiro e do terceiro quartis das amostras avaliadas. Desta forma, os valores considerados anormais, não influenciam os valores dos limites estabelecidos. O segundo critério considera a distribuição normal dos valores da amostra, dependendo dos valores de média e desvio-padrão. Tais valores são calculados a partir de toda a amostra, sendo influenciados pelos valores considerados anormais. Por essa razão, Braga (2005) recomenda o emprego do primeiro critério, mesmo que a amplitude do intervalo seja normalmente maior.

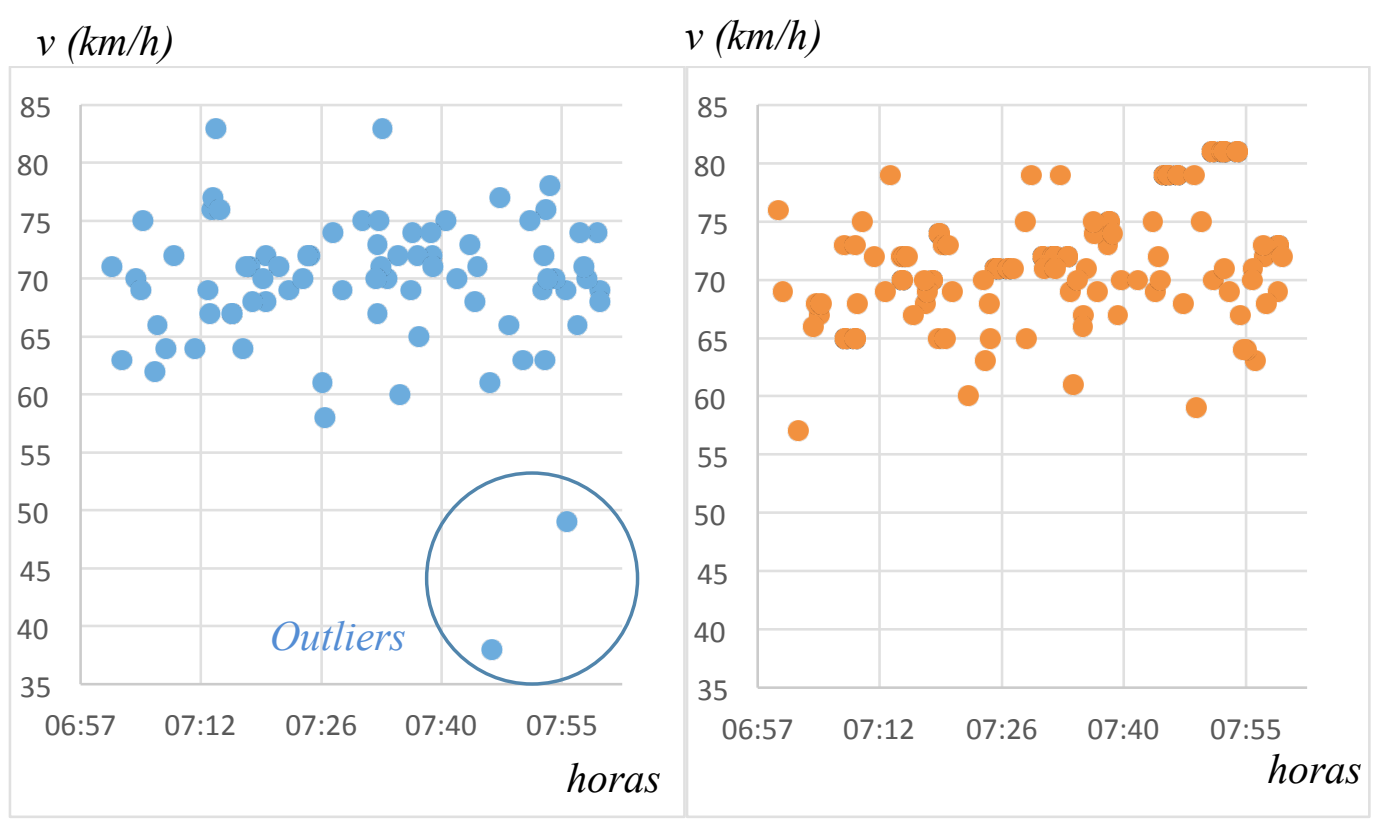

(a)

(b)

Figura 22 - Gráficos com valores de velocidade obtidos entre $7 \mathrm{~h}$ e $8 \mathrm{~h}$ de (a) segundasfeiras e (b) terças-feiras.

${ }^{11} \mathrm{O}$ intervalo interquartílico é definido pela diferença entre o primeiro e o terceiro quartis de uma amostra. São considerados como outliers os valores superiores à soma do terceiro quartil com 1,5 vezes o intervalo interquartílico, assim como os valores inferiores ao resto do primeiro quartil com 1,5 vezes o intervalo interquartílico. 


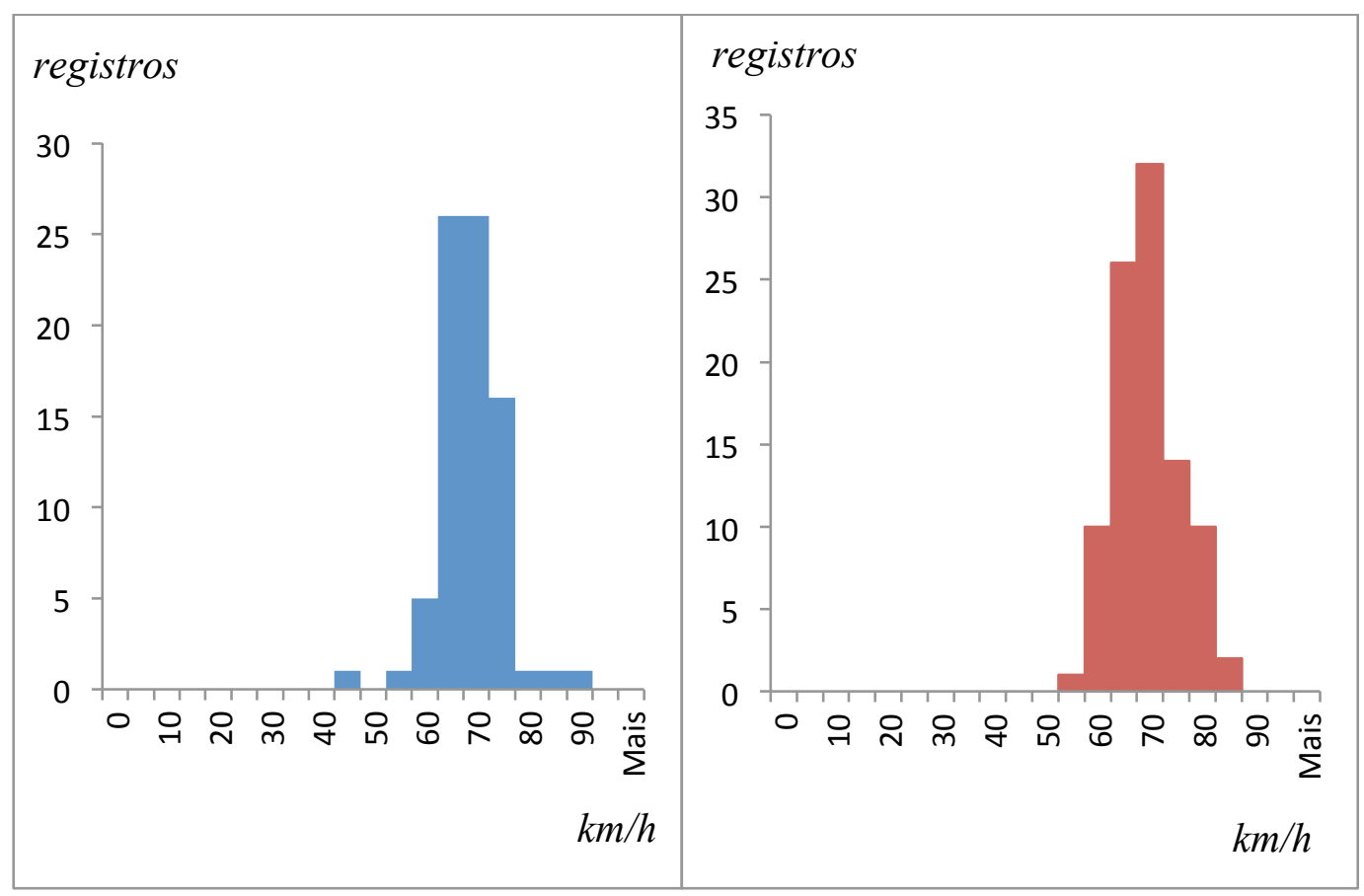

(a)

(b)

Figura 23 - Histogramas referentes aos valores de velocidade obtidos às (a) segundasfeiras e (b) terças-feiras.

\subsubsection{Detecção de agrupamentos de valores}

A detecção de valores anormais pode indicar uma ocorrência pontual de trânsito, razão pela qual esses valores serão avaliados individualmente, em conjunto com suas referências temporais. $O$ agrupamento desses valores pode indicar a persistência de um fator que alterou o tráfego por algum período, razão pela qual os grupamentos devem ser avaliados em conjunto com suas referências temporais.

Os algoritmos de clusterização tem por objetivo agrupar as amostras segundo uma métrica de similaridade, que é maximizada entre os elementos do cluster e é minimizada entre os conjuntos de cluster. Este conceito é aplicado na classificação de amostras de acordo com classes específicas, definidas por algum nível de similaridade, assim como se aplica à identificação de padrões em amostras multidimensionais.

A distância entre as classes pode ser medida pela menor distância observada entre elementos das classes (nearest neighbour ou single-linkage), pela maior distância (furthest neighbour ou complete-linkage), pela média das distâncias (group average ou average linkage) ou pela distância entre os respectivos centros de gravidade ou outros pontos representativos das classes (centroides). A 
especificação de uma distância mínima entre classes pode servir como critério para a criação de mais classes ou para a fusão de classes (método hierárquico).

Considerando como fixo o número de classes, os valores são particionados em função apenas da similaridade com os valores dos clusters existentes. O algoritmo k-means emprega este conceito de particionamento em função da distância ao centroide de cada cluster. O processo pode ser repetido, estabelecendo uma estrutura hierárquica de clusters ( $k$-means divisivo).

Para a finalidade desta tese, interessa avaliar a ocorrência de agrupamentos entre os valores de velocidade, indicando variações rotineiras de comportamento do trânsito, não perceptíveis pelos critérios de detecção de outliers. A primeira abordagem possível de ser empregada é a elaboração de um histograma baseado em intervalos de velocidade pré-definidos (por exemplo, $5 \mathrm{~km} / \mathrm{h}$ ). Intervalos sem (ou com poucos) valores observados são indícios de clusterização. Clusters com poucos valores observados são indícios de outliers. Portanto, estabelecer previamente tais parâmetros pode indicar valores residuais que podem facilitar a análise dos dados observados.

Por exemplo, analisando o histograma ilustrado na Figura 23, é possível identificar a descontinuidade nos intervalos de 45 e $55 \mathrm{~km} / \mathrm{h}$, assim como é possível identificar que esses clusters, possuem apenas um ponto, caracterizando outliers. Esses mesmos outliers foram identificados pelos critérios apresentados na seção 6.2.1 e, se tivessem sido eliminados antes da elaboração do histograma, haveria apenas um grupo de valores.

Observando o conjunto de dados de velocidade obtidos às segundas-feiras, porém no intervalo entre $10 \mathrm{~h}$ e $11 \mathrm{~h}$, é possível observar um grande número de outliers com baixa velocidade (Figura 24a). O método IIQ classifica como anormais as velocidades inferiores a $44,5 \mathrm{~km} / \mathrm{h}$ (12 valores) e superiores a 88 $\mathrm{km} / \mathrm{h}$. A análise do respectivo histograma (Figura 24b) indica a existência de dois grupamentos de valores, muito embora não haja descontinuidades nas faixas de valores. A aplicação do algoritmo $k$-means gerou dois conjuntos de valores: um com velocidades superiores (52 valores) e outro com valores inferiores (13 valores) a $47 \mathrm{~km} / \mathrm{h}$. Apenas um valor do grupamento inferior não foi considerado anormal pelo método dos intervalos interquartílicos. 


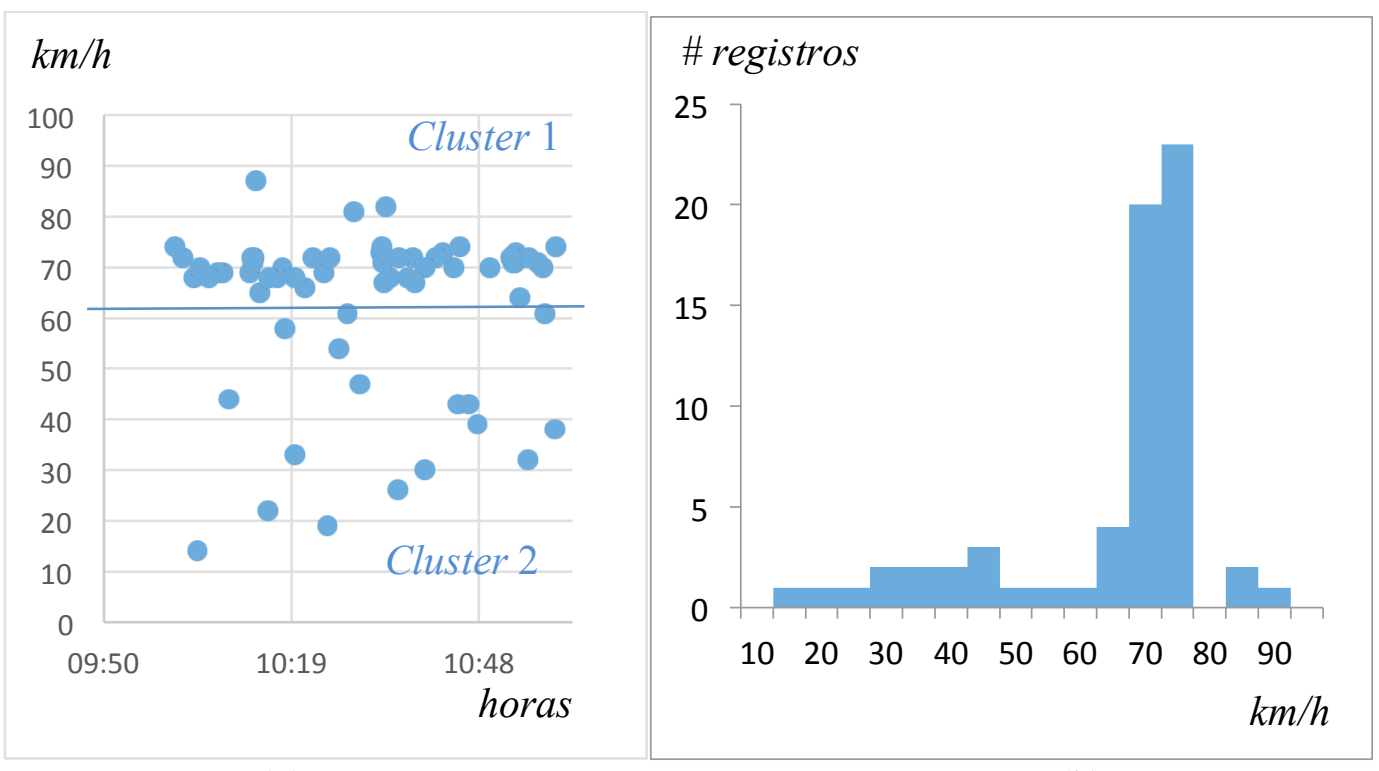

(a)

(b)

Figura 24 - Observações de velocidade às segundas feiras entre 10h e 11h: (a) distribuição dos valores e (b) Histograma com intervalos de $5 \mathrm{~km} / \mathrm{h}$.

O agrupamento identificado na região de altas velocidades consiste de 3 valores que podem ser desprezados se forem definidos tamanhos mínimos para os grupamentos, mesmo que não tenham sido eliminados pelo método IIQ.

\subsubsection{Métricas de similaridade entre distribuições de valores}

Ao observar os valores uma variável aleatória qualquer, pode-se calcular indicadores que descrevam tal amostra. Conceitos como média, mediana, moda, variância e desvio-padrão são amplamente empregados quando o objetivo é descrever a acurácia e a precisão das observações realizadas. $\mathrm{O}$ conceito de covariância quantifica o grau de associação entre duas variáveis aleatórias, enquanto o coeficiente de correlação quantifica a dependência linear entre tais variáveis (Hines et al, 2006). Em alguns casos, a associação linear pode ser observada após a transformação dos valores de uma das amostras (por exemplo, o logaritmo dos valores).

A identificação da relação entre os valores apresentados por duas variáveis aleatórias pode indicar a relação entre os fenômenos medidos. Os indicadores estatísticos já mencionados fornecem uma descrição geral da amostra, o que pode impedir comparações mais detalhadas e a observação de padrões ou tendências. 
Cha (2007) associa o conceito de similaridade ao de distância: quanto maior a distância entre dois objetos, maior a divergência, ou seja, menor a similaridade. Ele lista diversas métricas para similaridade e distância, classificando-as em famílias e indicando os óbices de implementação (como divisão por zero e logaritmo de zero). Outra métrica relacionada à medição de similaridade entre amostras é a distância de Levenshtein, dada pelo número mínimo de operações (inserções, deleções e substituições) necessárias para transformar uma string em outra.

Dentre as métricas de similaridade e as distâncias apresentadas por Cha (2007), observa-se que os valores das frequências relativas são analisados em pares dentro da ordem estabelecida dentro de cada amostra (primeiro com primeiro, segundo com segundo, e assim sucessivamente).

Observando as distribuições de velocidade usadas como exemplo, percebese que as amostras possuem tamanhos diferentes. As frequências absolutas ilustradas nos histogramas da Figura 23 não permitem comparação direta. São calculadas, então, as frequências relativas, dividindo as frequências observadas em cada intervalo pela quantidade de elementos existentes em toda a amostra. Sendo assim, os valores de distância e similaridade podem ser calculados independentemente do tamanho de cada amostra.

O valor da correlação de Pearson indica a alta dependência linear entre as duas amostras. Os coeficientes de similaridade dados pela função cosseno, pela fórmula de Jaccard e pela média harmônica são obtidos a partir do produto escalar dos vetores formados pelos valores das frequências relativas. O coeficiente de fidelidade é obtido pela soma das médias geométricas dos pares de valores comparados e está relacionado à distância de Bhattacharyya que, para dados normalmente distribuídos, fornece um limite superior para o erro de Bayes. A distância de Sørensen baseia-se na soma dos módulos das diferenças observadas entre os pares de valores comparados, muito semelhante à chamada distância de Manhattan.

Por exemplo, a Tabela 5 sintetiza os valores calculados com base nos conceitos apresentados nesta seção e nos conjuntos de valores representados pelos histogramas das figuras 23. Em todos os cálculos, não foram descartados os valores considerados anormais. Pode-se observar a relação entre os altos valores de similaridade e os baixos valores de distância. 
Como métrica de similaridade entre duas distribuições de frequências relativas $p_{1}$ e $p_{2}$, será adotada nesta tese a fórmula do cosseno (equação 6), baseada no produto interno das distribuições dividido pelo produto de suas normas. A razão dessa escolha é a simplicidade dos cálculos, sem a possibilidade de ocorrer divisões por zero, logaritmos de valores nulos, entre outras inconsistências computacionais.

$$
S=\frac{\left(p_{1} \cdot p_{2}\right)}{\left|p_{1}\right|\left|p_{2}\right|}
$$

Tabela 5 - Valores de similaridade e distância entre os valores de velocidade observados

$\begin{array}{ccc}\text { Fórmula } & \text { Similaridade } & \text { Distância } \\ \text { Pearson } & 0,961348 & \\ \text { Cosseno } & 0,972041 & \\ \text { Média Harmônica } & 0,9596702 & \\ \text { Jaccard } & 0,945230 & \\ \text { Fidelidade } & 0,972651 & \\ \text { Sørensen } & & 0,137002 \\ \text { Bhattacharyya } & & 0,02773 \\ \text { Euclidiana } & & 0,124705\end{array}$

\subsection{Metodologia para análise de amostras de velocidade}

As análises descritas nas seções anteriores serão aplicadas aos conjuntos de pontos de cada via, separadamente, conforme a seguinte sequência de operações:

1. Os valores de velocidade foram agrupados por dia da semana (de segunda a sexta) e hora (de 5 às 23 );

2. Em cada grupo foram excluídos possíveis outliers, empregando os limites computados com base nos primeiro e terceiro quartis da amostra;

3. Nos casos em que a proporção de observações anormais ultrapassou $10 \%$ das amostras observadas $^{12}$, a amostra foi clusterizada em dois grupos, sendo

\footnotetext{
${ }^{12} \mathrm{O}$ valor de $10 \%$ foi arbitrado.
} 
considerado nas análises somente o grupo com os maiores valores de velocidade;

4. Foram construídos histogramas com base nas amostras restantes, classificadas por dia da semana e hora do dia, em intervalos de $5 \mathrm{~km} / \mathrm{h}$;

5. Foram computadas as frequências relativas dos valores de velocidade a partir dos histogramas produzidos na operação 4 e dos tamanhos das amostras consideradas;

6. Foram calculadas as similaridades entre as distribuições de velocidades observadas em pontos consecutivos, nos mesmos dia e horário.

Os resultados obtidos após a realização dessas operações nas bases de dados empregadas estão descritos nas seções seguintes.

\subsubsection{Detecção de outliers}

Após analisar os valores abaixo dos quais as velocidades seriam consideradas anormais, os limites superior e inferior dos outliers, empregados no segundo passo, são mais distantes entre si nos horários considerados de pico, enquanto em horários de tráfego mais regular, os limites são mais próximos. Isso indica variação de velocidade, havendo dias com grande congestionamento e dias com fluxo livre. Valores negativos não implicam velocidades negativas, e sim uma consequência da grande dispersão de valores de velocidade presentes na amostra.

Como exemplo, considere dados referentes aos pontos de número 2354 e 2355, localizados na pista central da Avenida Brasil, sentido zona Oeste, no Bairro do Caju. Esses pontos estão distantes 585 metros entre si. O gráfico ilustrado na figura 25 mostra os valores de velocidade $(\mathrm{km} / \mathrm{h}) \mathrm{X}$ hora do dia. Os pontos registrados na mesma hora referem-se a diferentes dias da semana. Observa-se maior movimento na parte da manhã, reduzindo no meio do dia, aumentando na parte da tarde e tornando a reduzir até que se normalize após as $20 \mathrm{~h}$.

Ao considerarmos as amostras como uma série temporal, é possível analisar os dados em busca de padrões de tendência, variações cíclicas, sazonalidade, além de variações irregulares (Reis, 2014). É possível perceber, analisando o mesmo gráfico, o comportamento cíclico na distribuição de valores de velocidade, caracterizado pelo agrupamento de valores de velocidade em diferentes dias de 
semana, nos mesmos horários. Observa-se, no entanto, maior dispersão nos horários de pico. Nos PMV onde é observado esse comportamento cíclico, é possível enriquecer as estatísticas, classificando as observações apenas em função da hora do dia, eliminando a variável dia da semana.

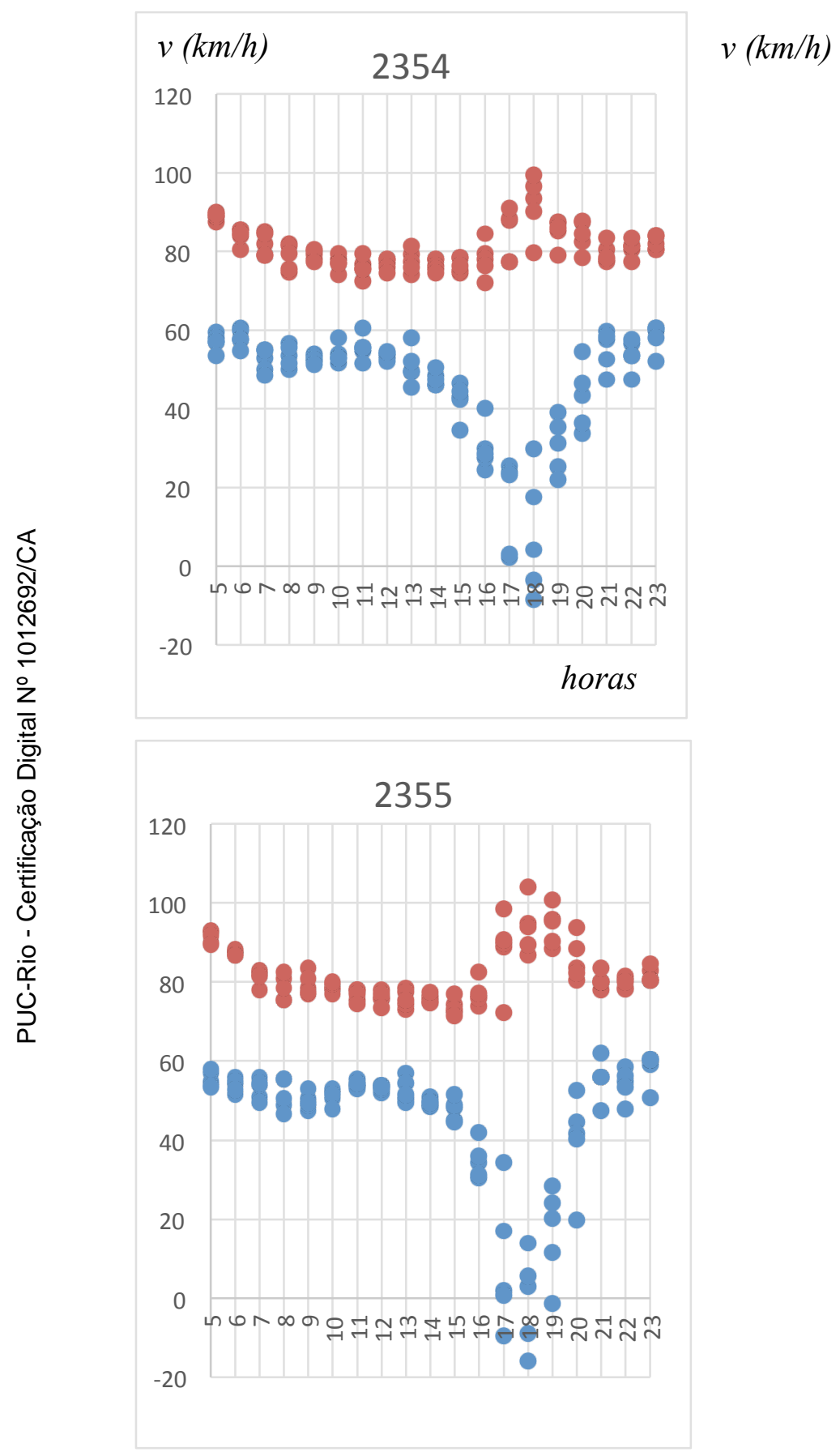

horas

Figura 25 - Limites superior e inferior de outliers observados nos pontos 2354 e 2355 em função da hora do dia, em diferentes dias da semana. 


\subsubsection{Detecção de agrupamentos de valores}

Foram submetidas ao processo de clusterização as amostras onde a quantidade de valores de velocidade considerados anormais excedeu $10 \%$ do total da amostra. O gráfico da Figura 26 indica que a ocorrência desses casos é maior entre $12 \mathrm{~h}$ e $16 \mathrm{~h}$, decrescendo nos horários considerados de pico. A explicação para esse fato é a maior variação de valores de velocidade nesses horários.

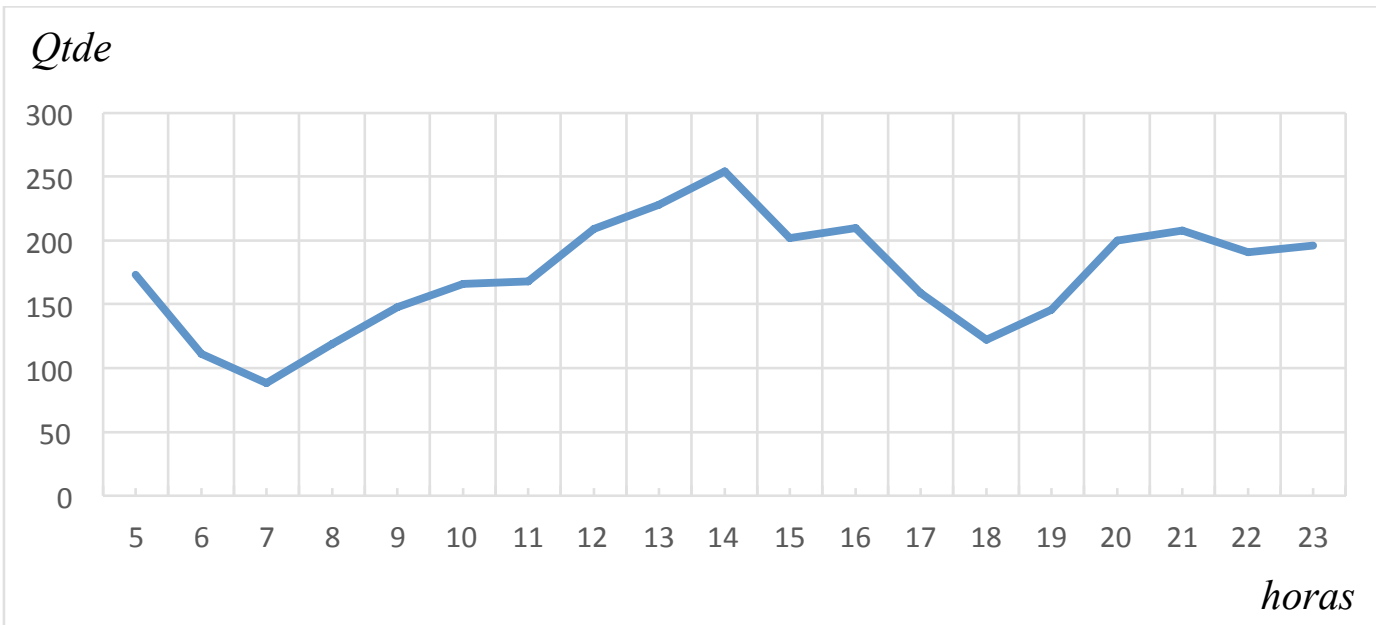

Figura 26 - Quantidade de agrupamentos detectados em função da hora do dia.

Do total de casos de formação de agrupamentos, $62 \%$ ocorreram nas vias expressas Avenida Brasil (pista central), Linha Amarela e Linha Vermelha, o que explica a ocorrência de um grupo com altos valores de velocidade se alternando com um grupo considerável de registros de baixos valores. Considerando o total de amostras registradas essas vias apresentam percentuais dentre os maiores (respectivamente, $0.10 \%, 0.14 \%$ e $0.34 \%$, sendo este último o maior percentual observado). Contudo, foram observados percentuais relativamente elevados (0.09\% dos registros) em outras vias como o Túnel André Rebouças (outra via expressa), Estrada do Galeão (via arterial secundária) e Autoestrada Lagoa-Barra (via coletora). Os demais valores apresentados foram inferiores a $0.05 \%$.

\subsubsection{Métricas de similaridade entre distribuições de valores}

Considerando que as condições do trânsito se propagam pela via ao longo do tempo, é esperado algum nível de correlação entre dois pontos monitorados consecutivos. A figura 27 ilustra os valores de similaridade observados entre os 
pontos 2354 e 2355. Para fins de realçar as diferenças encontradas, o eixo vertical apresenta apenas valores acima de 75\%. Observa-se que, após as 15h, a similaridade entre as distribuições diminui, chegando a cerca de $80 \%$ em alguns dias. Contudo, nos horários de fluxo normal, a similaridade ultrapassa 90\%. Em termos práticos, os valores maiores de similaridade revelam que ocorrem grandes variações na distribuição de velocidade.

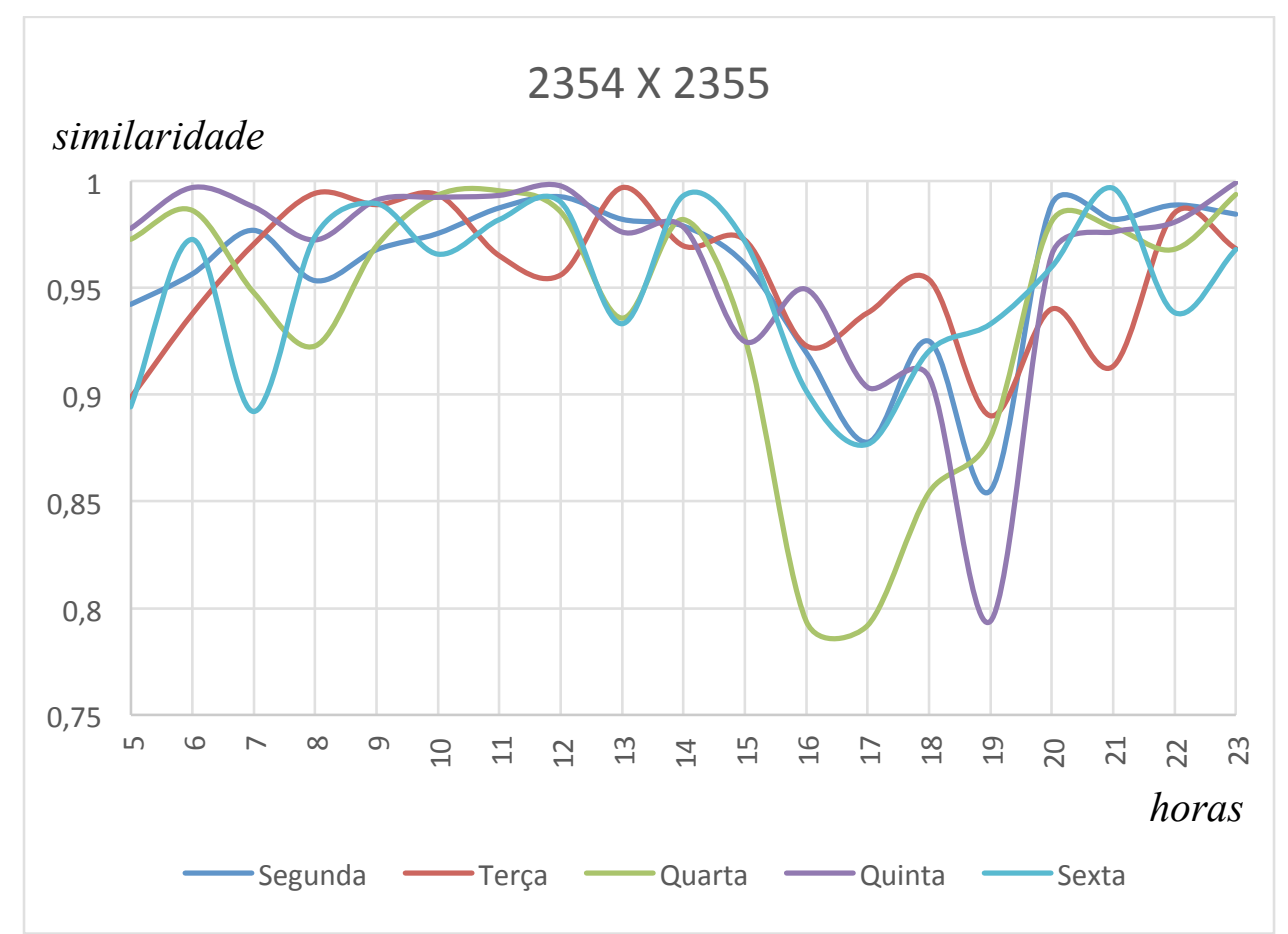

Figura 27 - Valores de similaridade entre as distribuições de velocidade, em função da hora do dia, nos pontos 2354 e 2355 .

Porém, outros pares de pontos, mesmo pertencendo à mesma via, podem apresentar pouca similaridade entre as distribuições de valores de velocidade em virtude da distância entre eles, da influência de entradas e saídas de veículos entre esses locais, entre outros fatores. Como exemplo, os valores de similaridade observados entre os pontos 2356 e 2357 são representados no gráfico da Figura 28. Ao longo dos 1100 metros existentes entre esses dois locais, existe uma entrada para veículos da pista lateral e sinalização alertando quanto à fiscalização eletrônica de velocidade (detalhe da Figura 29). 


\subsection{Conclusão}

Neste capítulo, foram analisados os dados de velocidade extraídos da página da empresa Maplink referentes à cidade do Rio de Janeiro, classificados de acordo com o dia da semana e com a hora do dia do registro. Dados similares estão disponíveis para outras cidades do país, o que permite a reprodução da metodologia proposta neste capítulo nessas cidades. Nas cidades onde não há disponibilidade desses dados, podem também ser empregadas estatísticas de velocidade obtidas com o emprego da metodologia proposta no Capítulo 5, considerando pontos ao longo da malha viária, ou por meio de contadores de loop (loop detectors), instalados ao longo da malha viária.

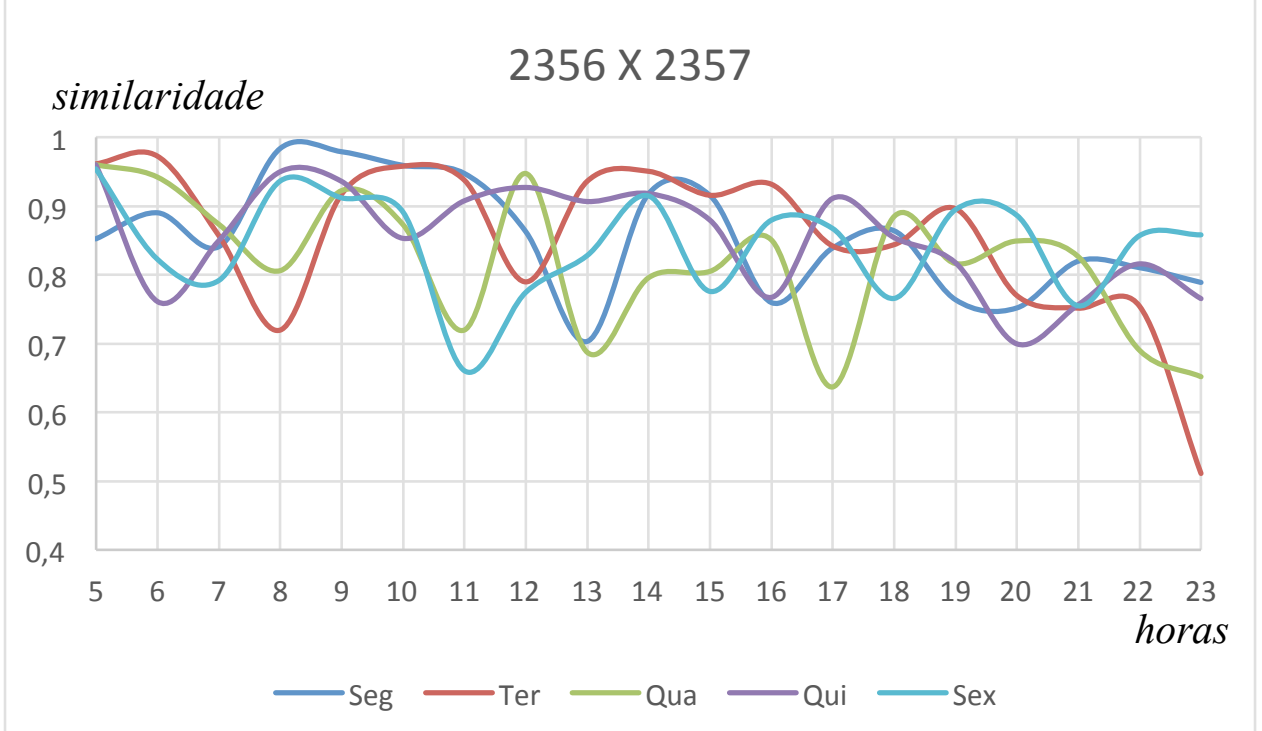

Figura 28 - Valores de similaridade entre as distribuições de velocidade, em função da hora do dia, nos pontos 2356 e 2357 


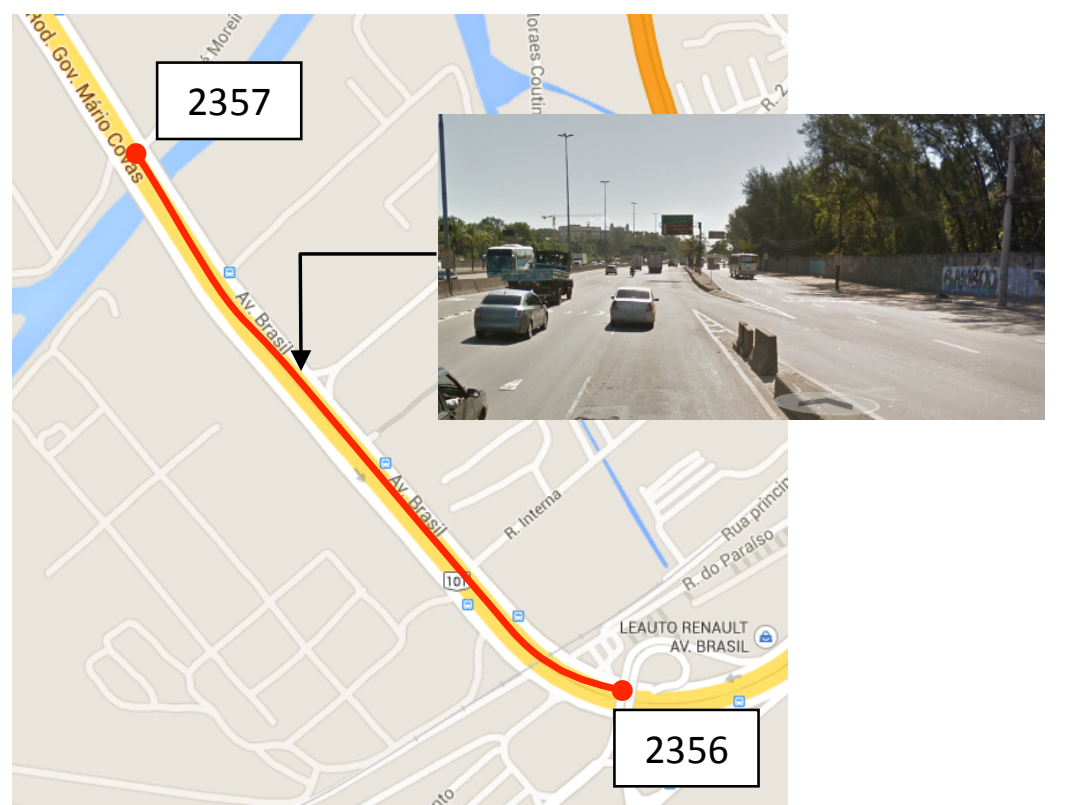

Figura 29 - Localização e posicionamento relativo entre os pontos 2356 e 2357.

O primeiro processo consiste na identificação dos valores considerados anormais, empregando o critério dos intervalos interquartílicos, e eliminação de tais valores. Em alguns dos casos, as observações anormais podem ser uma parcela representativa da amostra total, caracterizando a formação de agrupamentos isolados de valores de velocidade. Nos experimentos realizados foi empregado o grupamento com maior quantidade de observações.

O segundo processo consiste na classificação das amostras de velocidade referentes a cada PMV por dia da semana e por hora do dia. Analisando essas bases de dados, foi observado que:

- Em alguns PMV, a distribuição das velocidades nos dias úteis, ao longo do dia, é cíclica, o que permite desconsiderar a influência do dia da semana em tais pontos.

- ocorre grande variação de velocidade nos horários considerados de pico, refletindo nos limites dos quartis e, consequentemente, nos limites para classificação de outliers.

- Podem ser formados agrupamentos (clusters) entre os valores de velocidade, indicando dois estados distintos no fluxo: altas velocidades ou congestionamento, predominando o primeiro grupo. Tal comportamento foi observado predominantemente em PMV localizados em vias expressas. 
- a similaridade entre as distribuições de velocidade pode ser empregada na identificação de interferência no tráfego entre dois PMV. Altos valores de similaridade indicam alta correlação entre os perfis de velocidades comparados, enquanto baixos valores de similaridade indicam que a distribuição de valores de velocidade varia mais conforme se aproxima de zero. Tais variações são consequências da interferência do trânsito em virtude da entrada e saída de veículos de outras vias, sinais de trânsito, pedestres, entre outros fatores. 


\section{Avaliação das variações das velocidades após acidentes}

Já foi mencionado na seção 2.2 que congestionamentos são alterações no equilíbrio entre capacidade e fluxo de veículos. Também foi mencionado que os acidentes reduzem as capacidades do trânsito dado que faixas são interditadas e os motoristas precisam se adequar ao espaço disponível para trafegar. Foi visto no capítulo 6 que há horários em que o tráfego fluir sem resistência, em que a capacidade da via é superior ao fluxo de veículos que passa por ela. Nesses casos, a ocorrência de um acidente pode não alterar as velocidades, uma vez que os valores de fluxo e densidade se ajustam. Há, entretanto, horários em que o congestionamento se reflete na redução de velocidade, conforme foi abordado no Capítulo 6.

\subsection{Metodologia}

Este capítulo descreve como avaliar as variações de velocidade observadas nos PMV próximos a locais onde ocorreram acidentes de trânsito. A avaliação ocorre em três passos, detalhados nas próximas seções: (a) seleção dos dados, considerados os critérios de qualidade apresentados no capítulo 4; (b) ordenação dos pontos de monitoramento a serem avaliados; (c) avaliação dos valores de velocidade; e (d) identificação de propagação do congestionamento.

Novamente, a discussão neste capítulo baseia em experimentos que utilizam valores de velocidade medidos em vias públicas da Cidade do Rio de Janeiro.

\subsubsection{Seleção de Dados}

Além dos dados descritos na seção 6.1, foram empregados neste capítulo ocorrências selecionadas entre publicações no Twitter relacionadas às palavraschave acidente, colisão e enguiçado e localizadas na Cidade do Rio de Janeiro. Estas palavras-chaves são apresentadas por Redlich (2013) como parte de uma ontologia de fatos relacionados ao trânsito, que também inclui interdições (interdição e fechada), engarrafamentos (retenção, congestionamento e lentidão) e 
eventos climáticos (chuva, chuva forte, alagamento, bolsão d'água). O resultado da seleção dos tweets está detalhado no anexo 2.

$\mathrm{Na}$ seção 3.4, foi visto que a cada tweet estão associados diversos metadados. O processo de extração registrou apenas alguns deles, considerados úteis para esta aplicação. Assim, cada tweet é uma tupla

$$
\tau=<i, x, u, t, k, g>
$$

onde (ver dicionário de dados no Anexo 1):

- $i$ é identificador atribuído ao tweet.

- $x$ é o conteúdo da mensagem do tweet;

- $u$ é o nome do usuário que publicou o tweet;

- $t$ é o timestamp que contém data e hora da publicação;

- $k$ é a palavra-chave usada para extrair o tweet;

- $g$ é o ponto formado pelas coordenadas do ponto, extraídas da página.

Cada publicação selecionada possui uma área de abrangência espacial, ou seja, as vias existentes nas redondezas estão potencialmente sujeitas aos efeitos de redução de velocidade como consequência dessas ocorrências. Portanto, ao selecionar os pontos de medição de velocidade (PMV) posicionados próximos ao local associado a cada tweet, é selecionado também um conjunto de valores de velocidade, extraídos conforme explicado na seção 3.1 .2 e modelados na seção 6.1.2.

Afirmar que dois locais são próximos dependerá do conceito mais adequado de distância em relação à aplicação. A distância pode ser interpretada como o comprimento da linha geodésica ${ }^{13}$ que une dois pontos. Esta distância pode ser calculada pela extensão PostGIS do SGBD PostgreSQL, conforme as especificações de (OGC, 2010b). Contudo, a distância de Manhattan (ou do taxista) é dada pela soma dos comprimentos dos segmentos percorridos entre aqueles dois pontos. Essa distância pode ser obtida com soluções de roteamento, desde que a rede viária esteja configurada corretamente.

Nos testes realizados, foram selecionados inicialmente PMV distantes até dois quilômetros do local associado a cada tweet. Essa seleção é necessária devido à restrição de solicitações diárias realizadas pela API de roteamento do Google

\footnotetext{
${ }^{13}$ Menor curva que une dois pontos, medida sobre a superfície de referência.
} 
Maps. Com esta API, dados um ponto de origem (neste caso, um PMV) e um de destino (neste caso, o local indicado no tweet), pe possível extrair os pontos que definem a rota, instruções de deslocamento, comprimento de cada trecho e o comprimento total da mesma. Para o modelo de dados empregado nesta tese, cada rota é uma tupla

$$
R=<t, o, l>
$$

onde (ver dicionário de dados no Anexo 1):

- $\quad t$ é uma instância de $\mathcal{T}$ (seção 7.1);

- $\quad o$ é uma instância de $\mathcal{P}=<o, c, r, g>$;

- $l$ é o comprimento da rota fornecido pelo serviço do Google Maps.

São selecionados os pontos cujas respectivas rotas até o local do tweet não excedam três quilômetros. Tanto a distância geodésica quanto o comprimento máximo da rota foram arbitrados, levando em consideração a ordem de grandeza do comprimento das vias da cidade e as distâncias entre os pontos de medição de velocidade. Além desses fatores, a densidade de vias e a conformação topológica da malha viária são fatores que influenciarão essa escolha. O gráfico (b) não permite afirmar o horário em ocorreu o tweet, mas se for seguido o mesmo critério da análise do gráfico (a), a transição do quarto para o terceiro sextil se inicia por volta das 7:30h. Como se tratam de vias de hierarquias diferentes, permanece a questão quanto ao padrão de classificação do tráfego em função da distribuição das velocidades: o mesmo padrão se aplicaria a vias de hierarquias diferentes?

Após o filtro espacial, são selecionadas as amostras de velocidade registradas antes e depois do horário da publicação. Nos testes realizados, o intervalo de tempo considerou os registros realizados até duas horas antes e até duas horas depois. Cada amostra de velocidade é uma instância de $\mathcal{V}$ (seção 6.1.2), selecionada pelos critérios mencionados.

Como a extração ocorre a cada 20 minutos, cada amostra possui, normalmente, 12 valores de velocidade. São descartadas as amostras onde faltam valores. 


\subsubsection{Ordenação dos pontos}

O objetivo desta fase é ordenar os pontos quanto à distância ao local da publicação. Em muitos casos, a rota obtida para um PMV contém as rotas de outros PMV como uma única rota com vários pontos intermediários.

Outro fator a ser considerado é a existência de outras rotas que convergem no local do tweet mas chegam por direções diferentes. Os PMV devem ser agrupados de acordo com as rotas a fim de facilitar a análise da propagação dos efeitos.

\subsubsection{Avaliação dos valores de velocidade}

Mediante a ocorrência de um acidente em uma determinada via, são possíveis os seguintes cenários:

- O trânsito é normalmente congestionado, de modo que a redução de velocidade não é percebida;

- O trânsito reflete a redução de capacidade da via pela redução de velocidade;

- Havendo indícios de congestionamento, os motoristas optam por vias alternativas (Knoop, 2009), minimizando a influência do acidente principalmente em locais mais afastados.

Nota-se que as velocidades apresentam pequenas variações tanto antes quanto depois da ocorrência do fato.

Para detectar se o valor de velocidade observado é considerado normal, propõe-se empregar um indicador baseado na probabilidade de observar valores inferiores a ele, observados no mesmo dia da semana e no mesmo intervalo. Esse indicador, doravante chamado de frequências relativas cumulativas (FRC), é numericamente igual à soma das frequências relativas, calculadas na seção 6.3, nas faixas de velocidade inferiores. Com isso, baixos valores de velocidade poderão ser identificados como normais ao invés de ser classificado como reflexos do acidente.

Para exemplificar, considere os dados da Tabela 6, onde estão dispostas as distribuições relativas das velocidades do PMV \#1273 às quartas-feiras entre as 7h e as $10 \mathrm{~h}$. A primeira coluna indica a hora do dia, enquanto as demais colunas 
representam as frequências relativas dos valores contidos nas faixas de velocidade representadas $(\mathrm{em} \mathrm{km} / \mathrm{h})$.

Tabela 6 - Exemplo de frequências relativas das velocidades observadas em PMV

\begin{tabular}{|c|r|c|r|c|c|c|c|}
\hline Hora & $\mathbf{0 - 5}$ & $\mathbf{5 - 1 0}$ & $\mathbf{1 0 - 1 5}$ & $\mathbf{1 5}-\mathbf{2 0}$ & $\mathbf{2 0 - 2 5}$ & $\mathbf{2 5}-\mathbf{3 0}$ & $\mathbf{3 0 - 3 5}$ \\
\hline 7 & 0 & 0.013514 & 0.013514 & 0.054054 & 0.054054 & 0.067568 & 0.067568 \\
\hline 8 & 0 & 0.010753 & 0.053763 & 0.032258 & 0.086022 & 0.053763 & 0.043011 \\
\hline 9 & 0 & 0.013158 & 0 & 0.026316 & 0.065789 & 0.184211 & 0.065789 \\
\hline 10 & 0 & 0 & 0 & 0.015152 & 0.030303 & 0.060606 & 0.090909 \\
\hline
\end{tabular}

A célula realçada na tabela 6 indica que cerca de 5,4\% das velocidades observadas nesse PMV entre 7h e 7:59h apresentaram valores de velocidade entre 15 e $20 \mathrm{~km} / \mathrm{h}$. Se o valor de velocidade observado for de $17 \mathrm{~km} / \mathrm{h}$, o indicador proposto será composto pelas somas das frequências relativas referentes às faixas de velocidade inferiores e à faixa que contém o valor, neste exemplo, as de 0-5 $\mathrm{km} / \mathrm{h}$, de $5-10 \mathrm{~km} / \mathrm{h}$, a de $10-15 \mathrm{~km} / \mathrm{h}$ e a de $15-20 \mathrm{~km} / \mathrm{h}$. Ou seja, a chance de ocorrer velocidades menores ou iguais a $17 \mathrm{~km} / \mathrm{h}$ neste ponto e neste horário é de $(0+0.013514+0.013514+0.054054)$, ou seja, aproximadamente, de 13,5\%.

Outra forma de interpretar esse indicador é dividir o intervalo entre 0 e $1 \mathrm{em}$ quantis. Se, por exemplo, a soma de frequências relativas for igual a 0,25 o valor de velocidade considerado, dentre 100 valores de velocidade ordenados de forma crescente, ele ocuparia a $25^{\mathrm{a}}$ posição.

\subsubsection{Identificação de propagação do congestionamento}

Visando a incrementar a análise dos dados de velocidade, os tweets foram divididos de acordo com a hierarquia da via onde foi registrado. $\mathrm{O}$ valor da hierarquia da via foi obtido a partir da base de ruas obtida a partir do Geoportal da Prefeitura do Rio de Janeiro.

A análise da propagação remonta ao ordenamento dos pontos em grupos, de acordo com a interseção das rotas que levam ao local indicado pelo tweet. Emprega-se as FRC (seção 7.1.3) como parâmetro para avaliação das reduções e reunindo os valores observados nos PMV pertencentes a uma mesma rota. Então é composto o gráfico de propagação em que, no eixo horizontal estão representados os horários de observação e no eixo vertical estão indicados os PMV ordenados de baixo para cima, na ordem crescente do comprimento da rota que parte dele até o 
local do tweet. Os valores intermediários são interpolados e classificados conforme as faixas de valores de FRC predefinidas. Apesar de não haver padrão para classificar a gravidade do congestionamento com base na probabilidade, os intervalos empregados no gráfico dão a noção da redução real da velocidade.

A interpretação dos gráficos de propagação podem seguir duas vertentes: a análise horizontal considera a variação das FRC em um mesmo PMV ao longo do tempo, como indicado na Seção 7.3; a análise vertical considera a variação das FRC observadas ao longo de uma rota no horário indicado (de baixo para cima, à medida que se afasta do local indicado no tweet).

A transição de cores indica a mudança do quantil ${ }^{14}$ em que se encontra a velocidade observada. Se, por exemplo, com o passar do tempo (análise horizontal), ocorrer a transição da região que representa o terceiro sextil para aquela que representa o segundo sextil, presume-se que houve redução real de velocidade e, consequentemente, de capacidade da via. A transição da região referente ao segundo sextil para a região que representa o primeiro sextil destaca o agravamento das reduções. Se, ao longo da rota (análise vertical), ocorre a transição da região que representa o segundo sextil para aquela que representa o terceiro sextil, significa que os baixos valores de FRC ocorreram nos locais mais próximos ao local indicado no tweet mas não no PMV seguinte (dentro da mesma rota). O mesmo raciocínio se aplica às transições entre diferentes quantis, representados pelas outras cores.

\subsection{Experimentos Realizados}

Com base nos dados selecionados do Twitter, foi elaborado o gráfico da Figura 30, que ilustra a distribuição geográfica das ocorrências. Já o gráfico representado na Figura 31 apresenta a distribuição das ocorrências ao longo das horas do dia, discriminadas por palavra-chave. É possível destacar o grande número de ocorrências publicadas às $7 \mathrm{~h}$, às $19 \mathrm{~h}$ e às $20 \mathrm{~h}$ e o baixo número de registros publicados às $18 \mathrm{~h}$.

\footnotetext{
${ }^{14}$ Nos exemplos desta seção foi empregado o sextil, mas tanto a quantidade de classes como os seus limites podem ser customizados.
} 
O gráfico representado na Figura 32 soma as ocorrências, de modo que se observam dois períodos de redução mais acentuada, às $11 \mathrm{~h}$ e às $18 \mathrm{~h}$, assim como os picos observados às $7 \mathrm{~h}$, às $19 \mathrm{~h}$ e às $20 \mathrm{~h}$.

O gráfico ilustrado na Figura 33 ilustra a distribuição de valores de velocidade $(\mathrm{em} \mathrm{km} / \mathrm{h})$ em função do horário, referente a PMV descritos na legenda, vizinhos ao local indicado pelo tweet \#539728870866300929, e dispostos em ordem crescente do comprimento da respectiva rota. $\mathrm{O}$ eixo vertical está posicionado no horário de publicação do tweet, para fins de referência temporal.

Observa-se no mapa da Figura 34 que os PMV numerados entre 1309 e 1312 estão posicionados sobre a mesma via, unidos pela linha vermelha, enquanto os PMV \#1272 e \#1273 encontram-se em outra via, unidos pela linha de cor amarela. Após a interseção das linhas, ambas as rotas seguem o traçado da linha de cor vermelha. Voltando ao gráfico da Figura 33, é possível identificar a uniformidade dos valores observados nos conjuntos de pontos pertencentes à mesma rota. Ainda é possível observar que antes das $8 \mathrm{~h}$, os valores de velocidades das duas rotas são bem próximos. Depois, os valores do primeiro conjunto permanecem constantes, enquanto o segundo grupo apresenta reduções sucessivas durante cerca de uma hora e volta a subir. 


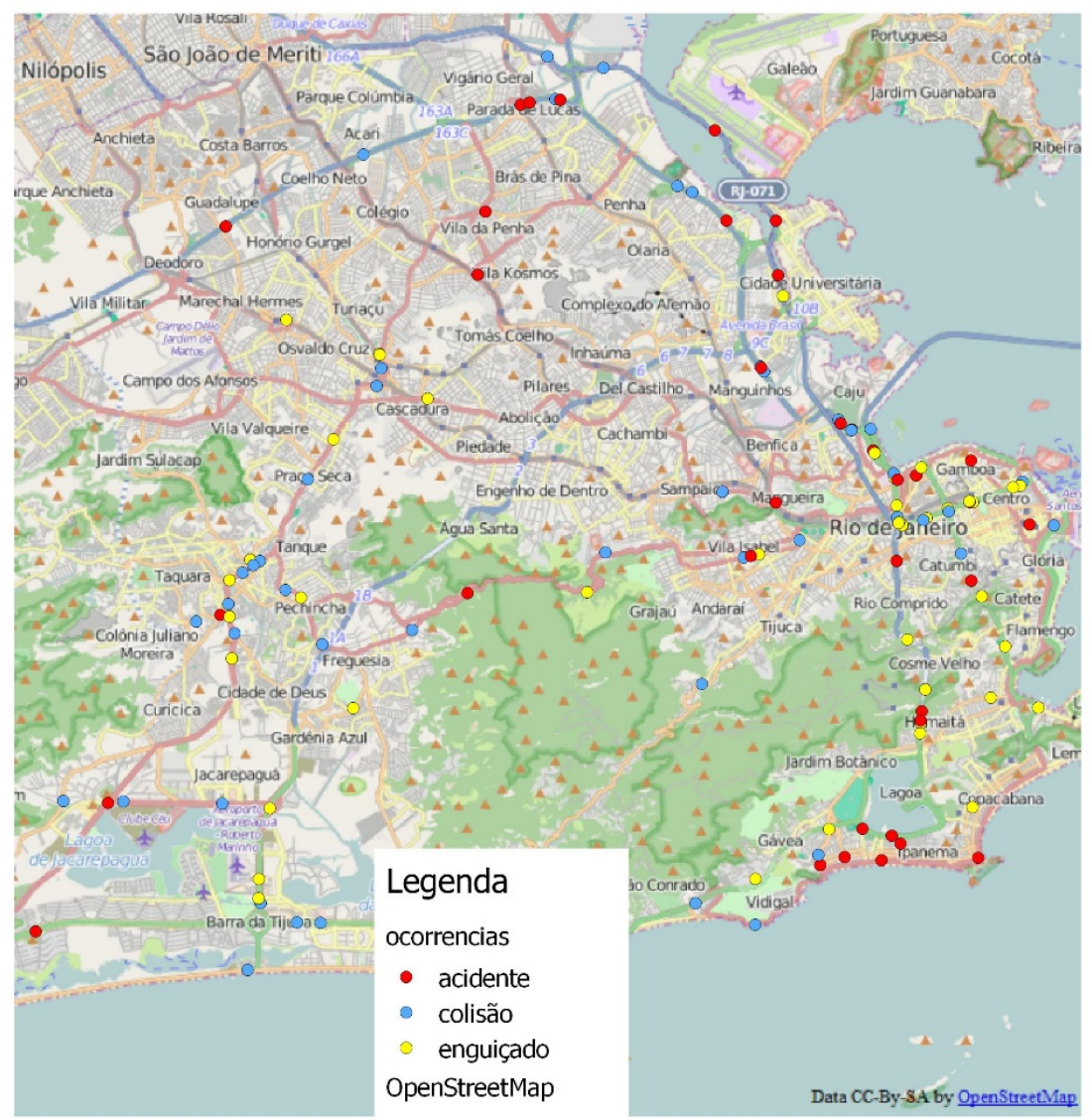

Figura 30 - Distribuição geográfica das ocorrências por palavra-chave (base cartográfica Open Street Maps).

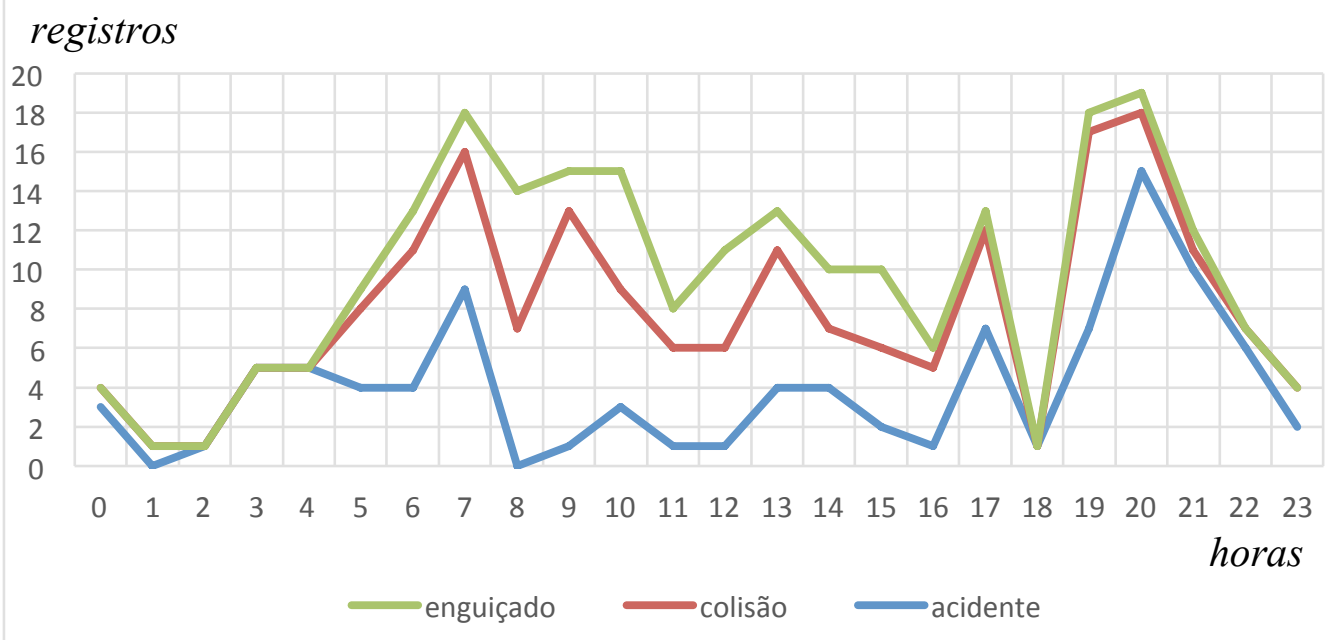

Figura 31 - Distribuição das ocorrências por palavra-chave e por hora do dia. 


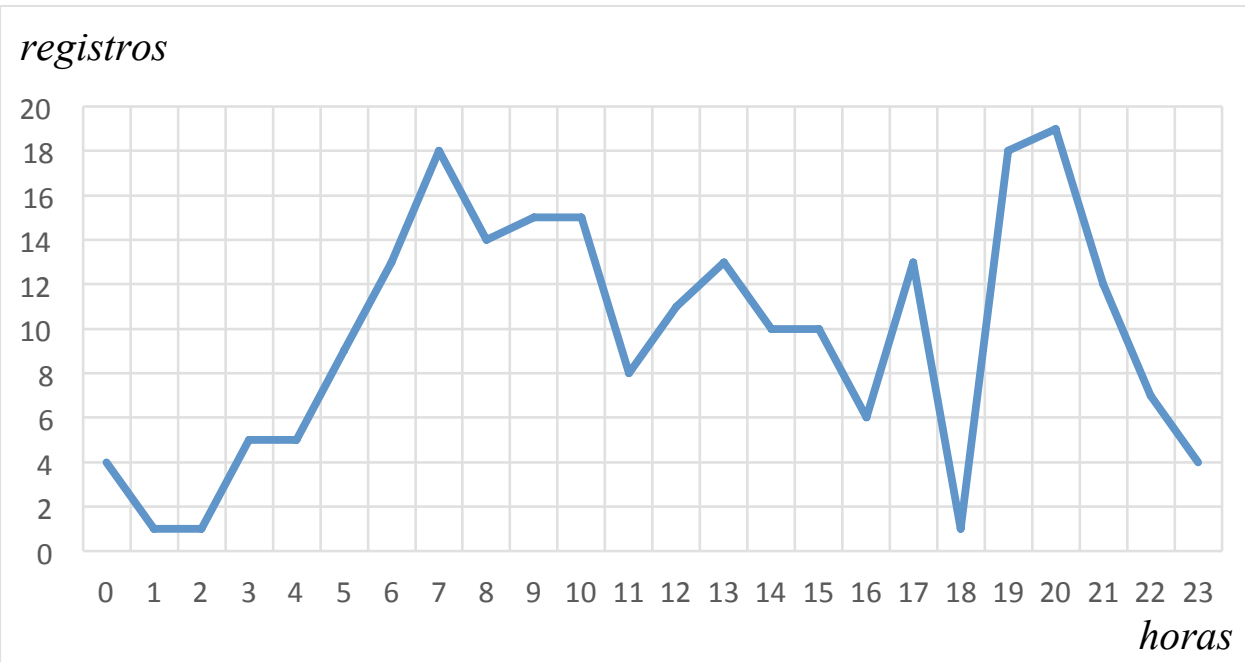

Figura 32 - Distribuição total das ocorrências por hora do dia.

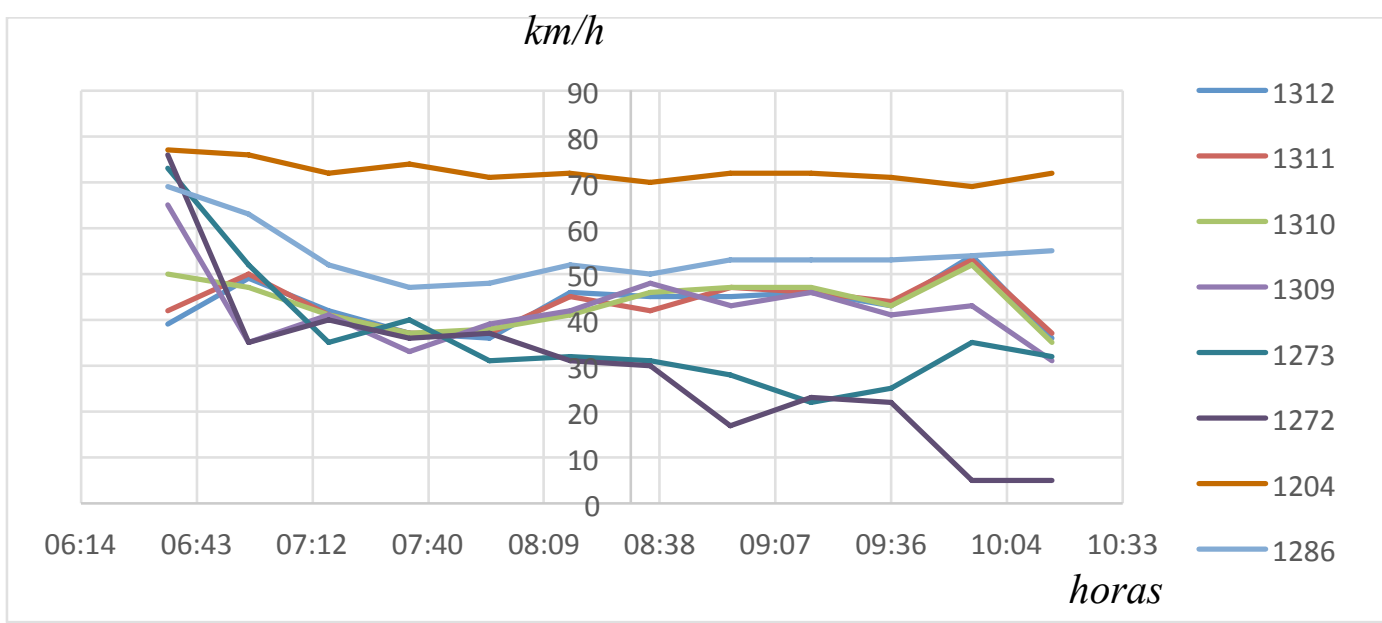

Figura 33 - Amostras de velocidade extraídas em locais vizinhos ao local de ocorrência do tweet \#539728870866300929.

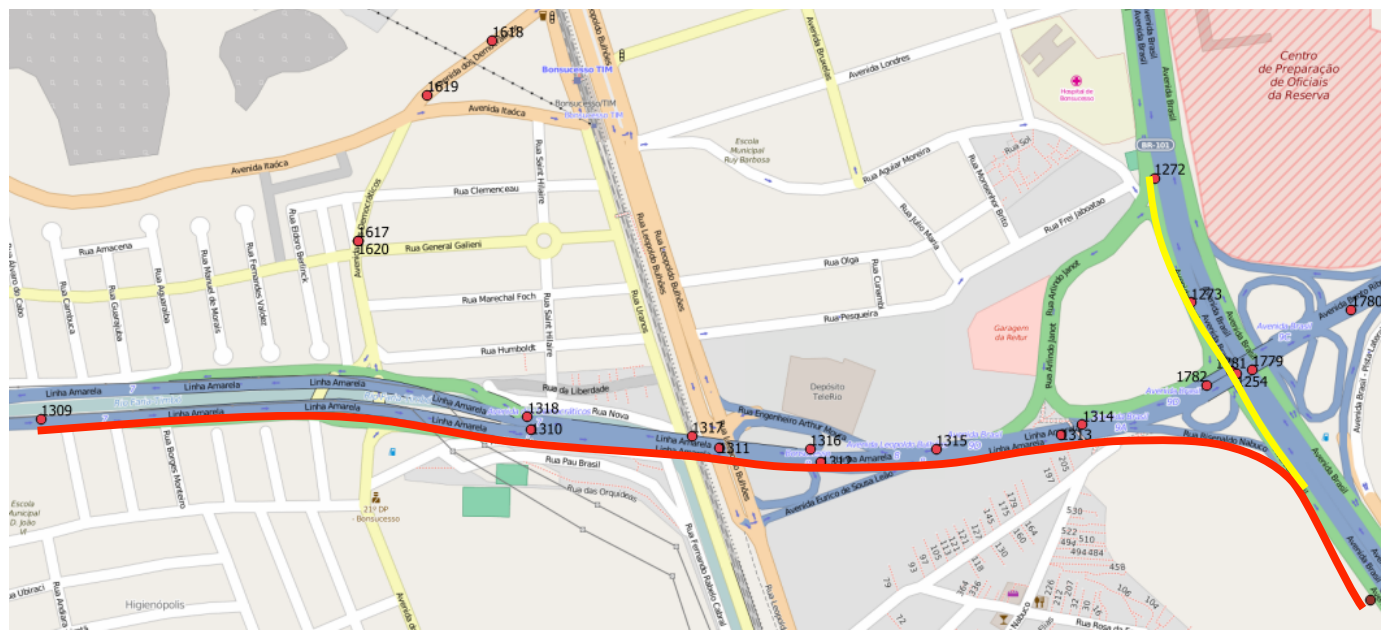

Figura 34 - Amostras de velocidade extraídas em locais vizinhos ao local de ocorrência do tweet \#539728870866300929. 
Observando novamente a Figura 33, é possível identificar duas outras linhas com valores de velocidade referentes aos PMV \#1204 e \#1286. Esses pontos atendem aos mesmos critérios estipulados para os demais pontos. Contudo, o comprimento da rota que parte desses pontos até o local indicado no tweet é de 2776m. Além disso, eles estão localizados no contrafluxo do local da ocorrência.

A Figura 35 apresenta os gráficos que representam a variação do indicador proposto (eixo vertical) ao longo do tempo (eixo horizontal) nos PMV (a)\#1272 e (b) \#1309. É possível identificar reduções bruscas nas probabilidades observadas no PMV \#1309, mesmo quando as velocidades observadas no gráfico da Figura 33 são crescentes. Isso significa que, mesmo que o valor absoluto da velocidade cresça, se o valor de FRC for baixo, esse valor é considerado baixo na comparação com os valores de velocidades observados naquele PMV no mesmo dia da semana e intervalo horário. A mesma dedução serve para interpretar um baixo valor absoluto de velocidade, comparando-o com outros valores obtidos nas mesmas condições: se o trânsito é sempre intenso e as velocidades são baixas, é possível observar altos valroes de FRC.

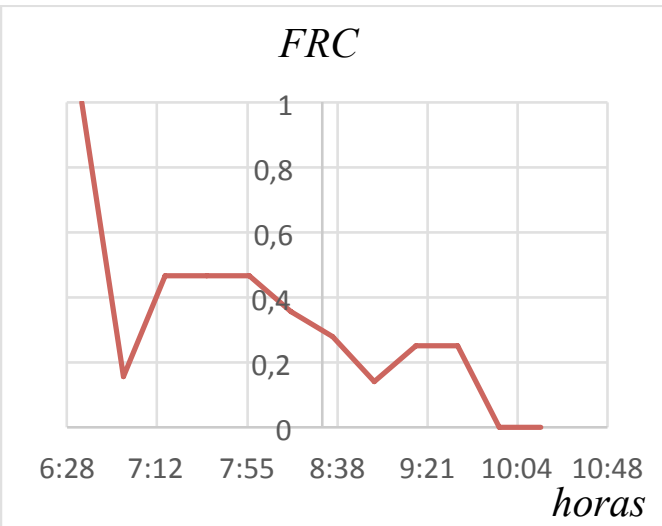

(a)

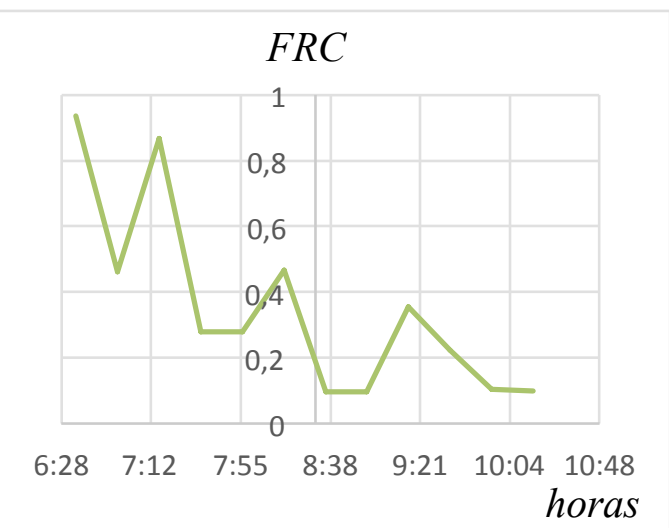

(b)

Figura 35 - Distribuições de probabilidades de velocidades nos PMV (a) \#1272 e (b) $\# 1309$.

O trecho a que se refere o gráfico da Figura 36a encontra-se em uma via arterial primária enquanto o gráfico da Figura 36b refere-se a um trecho localizado em uma via expressa. Observa-se que a região referente ao segundo sextil é maior na base do gráfico, indicando que as maiores reduções ocorrem no PMV mais próximo ao local indicado no tweet e que a redução demora a se propagar até o ponto mais afastado. 
Outra constatação que pode ser extraída da análise do gráfico é a propagação total do congestionamento antes do horário da postagem do tweet. De acordo com o gráfico (a), enquanto os valores referentes ao PMV \#1273 passam do quarto para o terceiro sextil por volta das 7:50h, a mesma transição referente ao PMV \#1272 ocorre por volta de 8:25h, enquanto a transição referente ao PMV \#1271 ocorre por volta de 8:25h. Enquanto isso, a publicação do tweet ocorreu às 8:32h. Como o intervalo entre as medições é de 20 minutos e não há padrão de associação do valor da distribuição com o estado do tráfego não é possível afirmar qual o horário em que ocorreu o acidente, mas é possível afirmar que as regiões vermelha e azul indicam as condições mais intensas de redução de velocidade.

O gráfico (b) não permite afirmar o horário em ocorreu o tweet, mas se for seguido o mesmo critério da análise do gráfico (a), a transição do quarto para o terceiro sextil se inicia por volta das 7:30h. Como se tratam de vias de hierarquias diferentes, permanece a questão quanto ao padrão de classificação do tráfego em função da distribuição das velocidades: o mesmo padrão se aplicaria a vias de hierarquias diferentes?

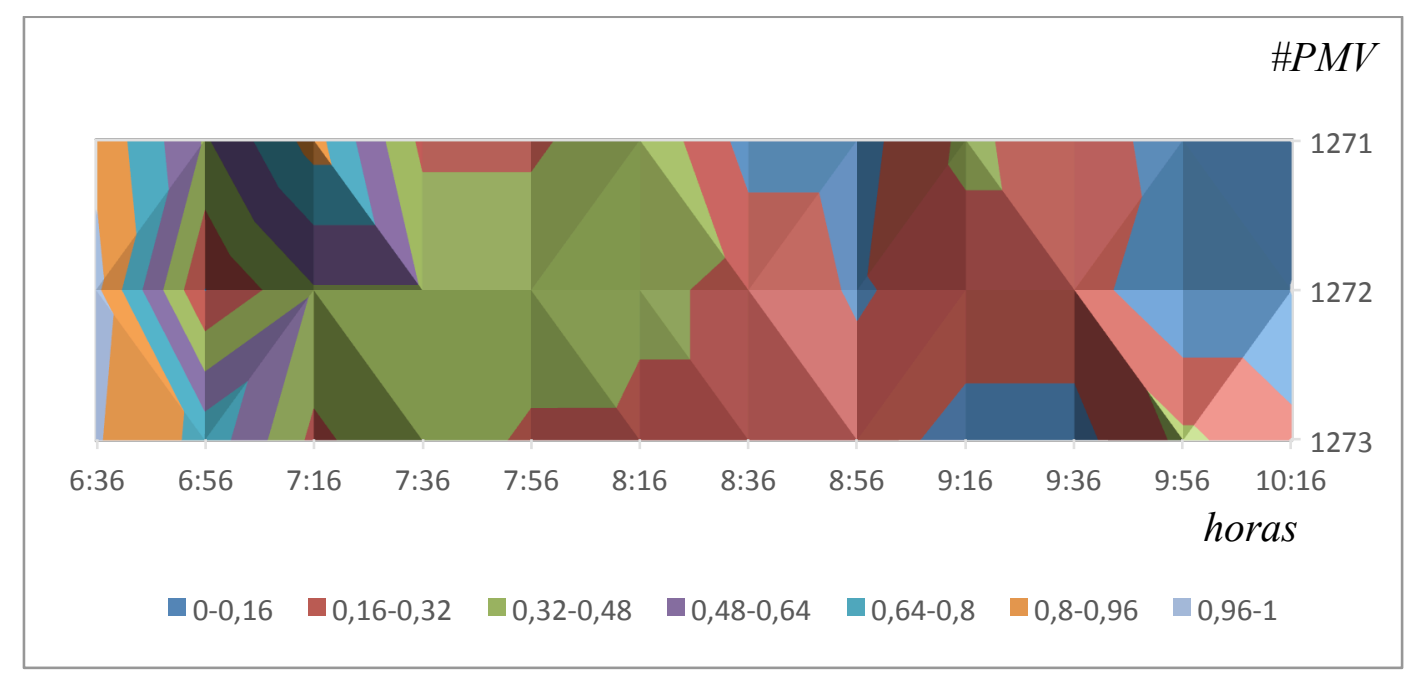

(a) 


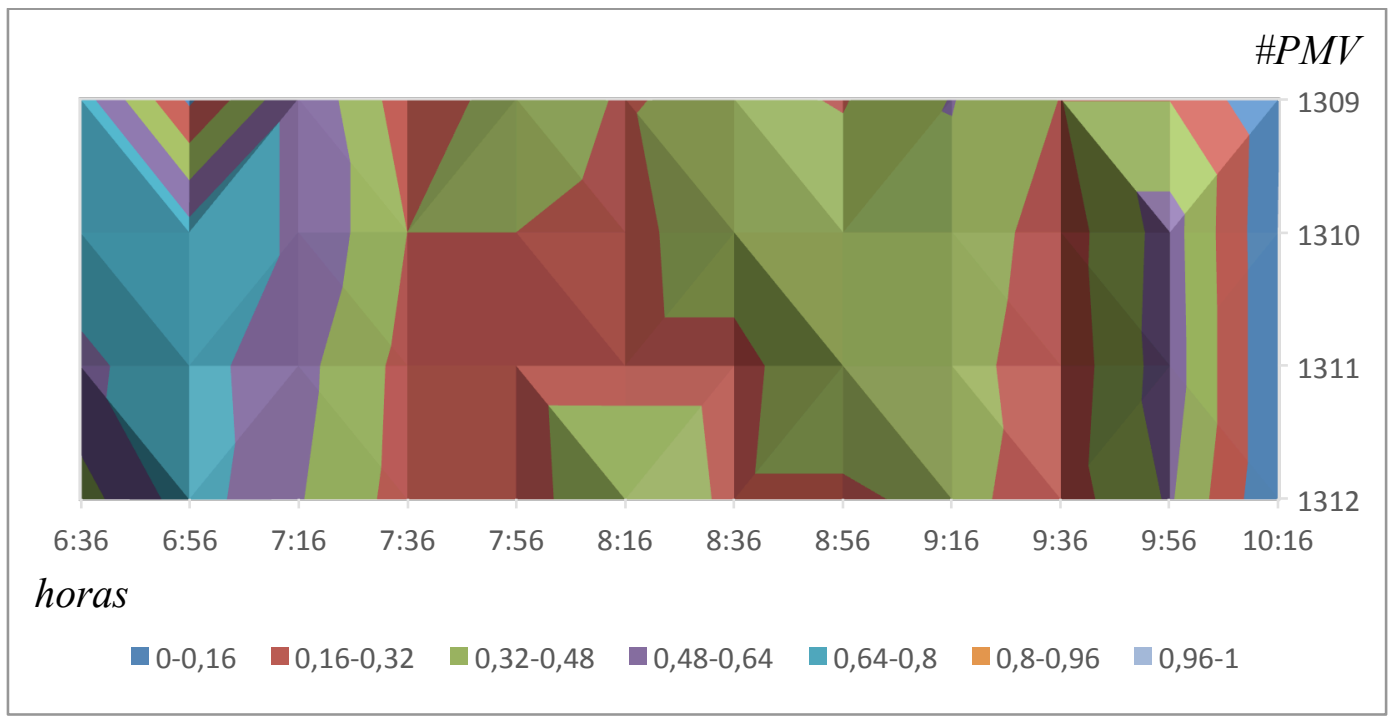

(b)

Figura 36 - Distribuições de probabilidades de velocidades nos trechos definidos pelos PMV (a) \#1273 - \#1272 - \#1271 e (b) \#1312 - \#1311 - \#1310 - \#1309.

Independente deste questionamento, é possível detectar a ocorrência dos congestionamentos e a propagação dos mesmos ao longo dos PMV disponíveis para análise.

Um exemplo obtido ao longo de uma via arterial secundária está representado no gráfico da Figura 37, referente ao tweet \#534379856176246784.

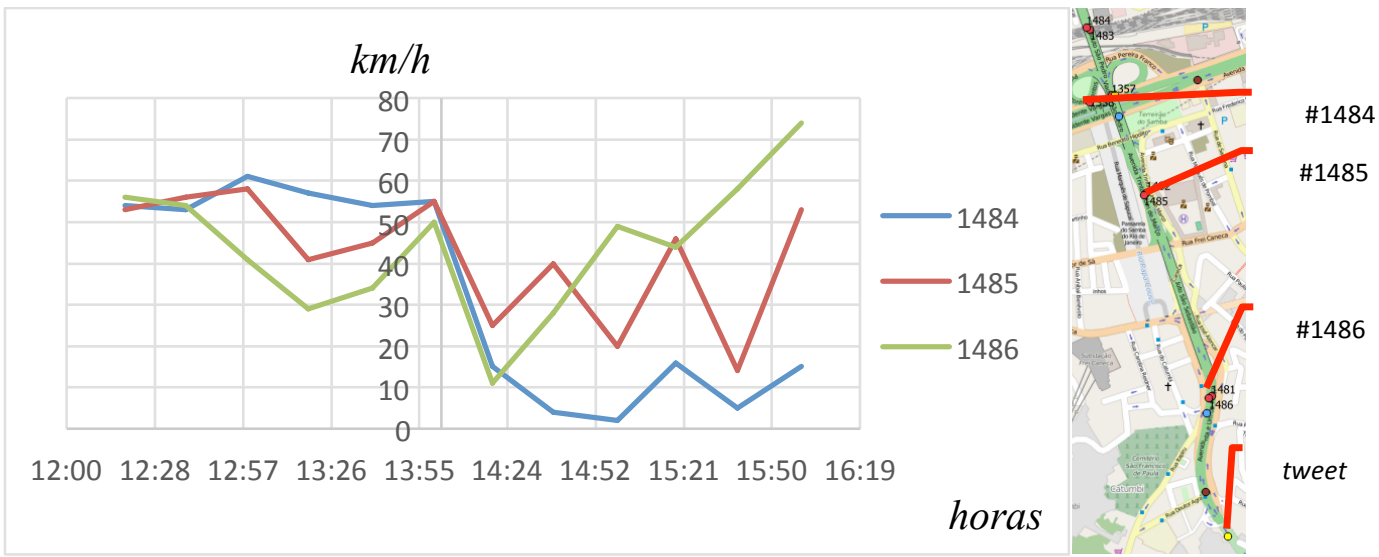

Figura 37 - Amostras de velocidade extraídas em locais vizinhos ao local de ocorrência do tweet \#534379856176246784.

É possível identificar a redução brusca da velocidade nos PMV próximos a partir do mesmo momento (o tempo de propagação foi menor que o intervalo entre as medições). O mapa no detalhe mostra que o PMV \#1486 é o mais próximo do local indicado no tweet e é o primeiro a retomar o valor normal da 
velocidade. Na sequência, os efeitos passam a ser percebidos nos PMV \#1485 e $\# 1484$.

A figura 38 ilustra a propagação do congestionamento com base na distribuição de velocidades dos PMV analisados. Nota-se a maior sensibilidade da via arterial secundária à redução de sua capacidade.

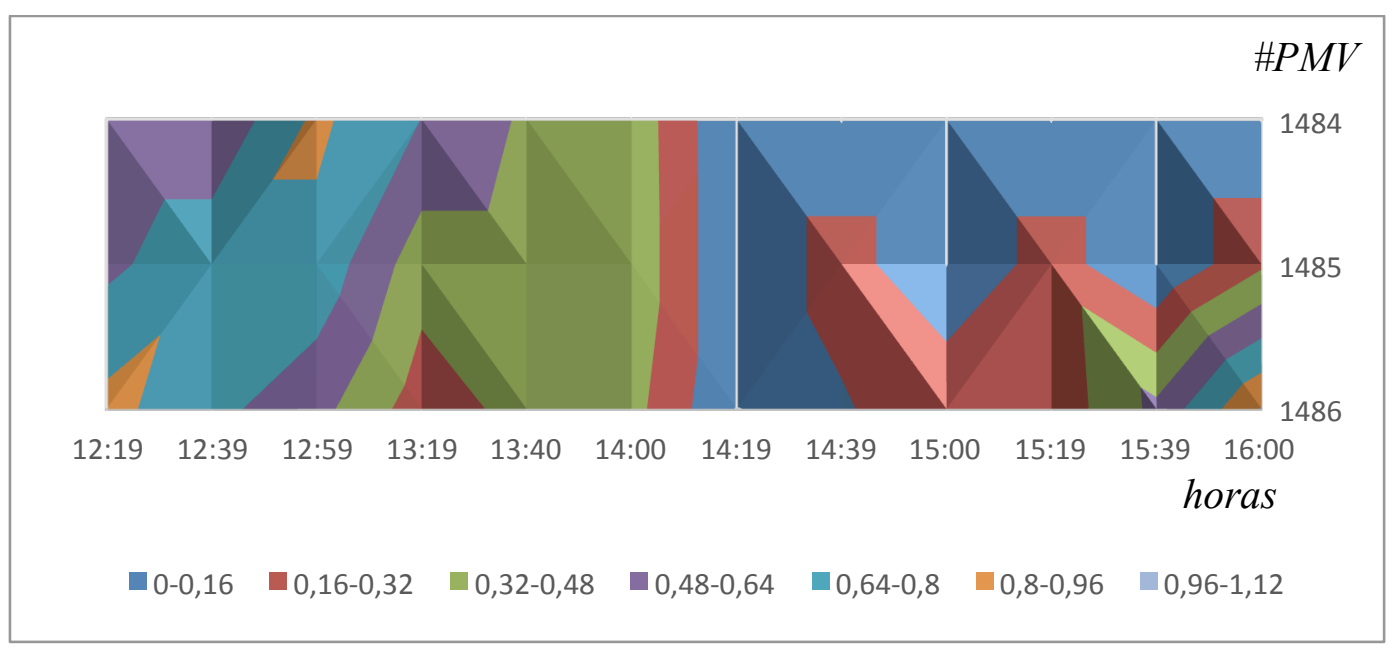

Figura 38 - Distribuições de probabilidades de velocidades nos trechos definidos pelos PMV \# 1486, \#1485 e \#1484.

\subsection{Conclusão}

Neste capítulo foi apresentada uma metodologia para diagnosticar as mudanças no tráfego causadas pela notificação de um acidente extraída de um tweet. Tais tweets devem ser avaliados quanto aos critérios descritos no Capítulo 4, visando a reduzir as incertezas temáticas, temporais e espaciais inerentes a mensagens textuais publicadas na Web. Além do Twitter, outras fontes de notícias sobre trânsito publicadas na Internet podem ser empregadas, desde que seja possível identificar o tipo da ocorrência (ver ontologia de fatos relacionados ao trânsito de Redlich, 2013), as coordenadas do local, data e hora (timestamp) da ocorrência. Caso as informações sobre trânsito não estejam estruturadas desta forma nas suas fontes, ainda é necessário extraí-las, mesmo que com algum grau de incerteza, empregando os métodos propostos por Albuquerque et al (2012a) e Albuquerque et al (2012b), por exemplo.

Outro conjunto de dados necessário à avaliação consiste nas estatísticas de velocidade medidas ao longo da malha viária. Nos experimentos apresentados 
neste capítulo, foram empregados os pontos de medição de velocidade (PMV) disponibilizados pela empresa Maplink, extraídos conforme explicado na seção 3.1.2 e modelados na seção 6.1.2. Como foi apresentado na Seção 6.4, esses PMV podem ser substituídos por pontos contidos na malha viária que possuam estatísticas de velocidades associadas ao ponto.

Além dos conjuntos de dados citados, é necessário dispor de uma solução de roteamento, o que implica a existência de uma malha viária atualizada tanto quanto à geometria quanto ao sentido do trânsito. Nos experimentos realizados, foi empregada a API do Google Maps (gratuita) para fornecer as rotas entre os PMV e os locais indicados nos tweets.

Como os dados e serviços mencionados estão livres na Web ou podem ser obtidos por meio de metodologias indicadas ao longo do texto, é possível reproduzir as análises indicadas neste capítulo em outras cidades.

O primeiro processo a ser executado consiste na seleção dos PMV vizinhos ao local indicado no tweet (distância a ser definida pelo usuário). A seleção é refinada pela identificação da rota que parte do local do PMV até o local do tweet, eliminando as rotas muito longas (limite a ser definido pelo usuário) devido às possíveis interferências externas no tráfego ao longo desse percurso.

O segundo passo consiste no ordenamento dos PMV ao longo das rotas obtidas, respeitando não apenas a distância entre o PMV e o local da ocorrência reportada pelo tweet mas também a conformação topológica da malha viária. Podem ser observadas várias rotas que convergem no local do tweet provenientes de direções diferentes. As rotas são agrupadas segundo essas direções e os PMV são, então, ordenados para analisar o tráfego em PMV consecutivos ao longo da malha viária.

O terceiro passo é a avaliação dos valores de velocidade. Foi proposto o conceito das frequências relativas cumulativas, FRC, que indica o quantil que contém o valor analisado dentre todos os valores de velocidade observados naquele PMV, dia da semana e hora. Com isso, é possível avaliar se variações de velocidade são normais para o horário ou se são um reflexo de algo incomum. $\mathrm{O}$ congestionamento é caracterizado quando a velocidade observada apresenta baixo valor de FRC (limite a ser definido pelo usuário).

O quarto passo é a identificação de propagação do congestionamento a partir da avaliação conjunta dos FRC observados em PMV ordenados nas rotas de 
que fazem parte. É possível identificar a propagação da redução a partir dos PMV mais próximos do local do tweet na direção dos PMV mais afastados, dentro da mesma rota. Analogamente, é possível observar a recuperação dos valores de FRC após o acidente primeiro nos PMV mais próximos. 


\section{Conclusões}

\subsection{Resumo}

O objetivo proposto na Seção 1.2 consistia em extrair conhecimento a partir da análise de valores de velocidade, utilizando como estudo de caso pontos distribuídos ao longo da Cidade do Rio de Janeiro e dados sobre acidentes ocorridos no período, extraídos de postagens no Twitter.

No Capítulo 2 a velocidade foi apresentada como uma variável macroscópica capaz de descrever o comportamento do tráfego e como um dos critérios de classificação hierárquica das vias urbanas.

No Capítulo 3, foram listadas fontes de dados disponíveis na Web relacionados às condições do tráfego, assim como serviços Web com funcionalidades úteis para as análises propostas nesta tese.

No Capítulo 4 foram introduzidos critérios de avaliação de qualidade para dados relacionados ao tráfego a partir das acurácias temática, temporal e espacial. Também foram introduzidos critérios de avaliação da confiabilidade, abrangendo a cobertura espacial, a completude dos dados, a proveniência e a vida útil dos dados. Também foi apresentada uma avaliação simplificada das fontes de dados apresentadas no Capítulo 3. Nos capítulos 4 e 7, foram apresentadas as precauções necessárias para utilizar o Twitter como fonte de dados de trânsito.

No Capítulo 5 foi proposta uma metodologia para calcular estatísticas de velocidade a partir de trajetórias rastreadas com receptores GPS instalados em veículos da cidade de Pisa. Após filtragem espacial e classificação temporal, foram calculados média e desvio-padrão de cada amostra, registrando a quantidade de pontos utilizada nos cálculos.

No capítulo 6, os valores de velocidade obtidos nos PMV distribuídos ao longo da cidade do Rio de Janeiro foram classificados por dia da semana e por hora do dia. Foi observado na maioria das vias observadas o comportamento cíclico na distribuição das velocidades nos dias úteis, ao longo do dia. Com isso, a classificação por dia da semana pode ser desconsiderada na análise, aumentando 
as amostras no cálculo de estatísticas de velocidade. Foi também observada grande variação de velocidade nos horários considerados de pico, refletindo nos limites dos quartis e, consequentemente, nos limites para classificação de outliers. Em PMV localizados em vias expressas, constatou-se a formação de clusters entre os valores de velocidade, indicando dois estados distintos no fluxo: altas velocidades ou congestionamento, predominando o primeiro grupo. Por fim, foi introduzida a similaridade entre as distribuições de velocidade como métrica relevante na identificação de interferências no tráfego entre dois PMV.

No capítulo 7, foi proposta uma metodologia para avaliar a influência de acidentes nos valores de velocidade ao longo da via em que houve o acidente e nas vias próximas. A metodologia consiste em quatro etapas: (1) a seleção dos PMV vizinhos; (2) o ordenamento dos PMV em rotas que convergem no local indicado no tweet; (3) a avaliação dos valores de velocidade; e (4) avaliação da propagação dos congestionamentos. Foi proposto o conceito das frequências relativas cumulativas, FRC, que permite avaliar se variações de velocidade são normais para o horário ou se são um reflexo de algo incomum. Esse conceito foi empregado tanto na terceira quanto na quarta etapa, permitindo visualizar a propagação da redução a partir dos PMV mais próximos do local do tweet na direção dos PMV mais afastados, dentro da mesma rota. Analogamente, é possível observar a recuperação dos valores de FRC após o acidente primeiro nos PMV mais próximos.

\subsection{Contribuições}

Para enfatizar as contribuições desta tese, é necessário rever as características dos trabalhos relacionados mencionados na seção 1.3.

A primeira contribuição a destacar é a avaliação das condições do tráfego a partir de valores de velocidade, de aquisição mais simples que os valores de fluxo e concentração. Enquanto os contadores de indução precisam ser fixados em locais estratégicos, pontos de medição de velocidade podem ser criados ao longo da malha viária empregando metodologias de cálculo de estatísticas de velocidade como a apresentada no capítulo 5 ou por Wang et al (2013). Este é, dentre os trabalhos relacionados, o único trabalho que emprega valores de velocidade ao invés do fluxo e da concentração de veículos. Contudo, a ênfase desse trabalho é a 
representação visual dos valores, sem analisar as causas das variações das velocidades observadas.

A segunda contribuição é a avaliação do tráfego em áreas urbanas, considerando os diferentes níveis hierárquicos das vias e as características decorrentes, como as interferências de tráfego inerentes às interseções, sinais de trânsito e fluxo de pedestres. As análises de Knoop (2009) e Chung e Recker (2012) compreendiam autoestradas, vias de alta velocidade e com baixa influência de tráfego chegando ou saindo das mesmas. Medeiros et al (2010) emprega dados de vias urbanas, porém são obtidos por observações de contadores de indução. Wang et al (2013) também analisa dados de vias urbanas.

A terceira contribuição é o emprego de publicações de eventos em redes sociais, permitindo rápido acesso à informação. As análises de Knoop (2009) e Chung e Recker (2012) empregaram relatórios oficiais das autoridades rodoviárias após a divulgação dos mesmos. Com o monitoramento das publicações, essas notificações podem ser disponibilizadas poucos minutos após a ocorrência de um acidente, o que pode agilizar a analisar as possíveis consequências no tráfego. Após a avaliação das acurácias temática, espacial e temporal, abordadas no capítulo 4, é possível avaliar a potencial redução dos valores de velocidade nas vias avaliadas e nas vias próximas.

A quarta contribuição diz respeito à extração de estatísticas de velocidade a partir de dados GPS, enfatizando as possíveis fontes de erro existentes nos processos de map matching e classificação temporal. As estatísticas calculadas tanto podem ser associadas a vias ou a pontos ao longo da malha viária, definindo pontos de medição de velocidade (PMV) virtuais, que podem adensar o conjunto de PMV a ser empregado nas metodologias descritas nos capítulos 6 e 7.

\subsection{Limitações}

Apesar dos resultados obtidos, há limitações na aplicação das metodologias apresentadas nesta tese.

A primeira está relacionada à extração dos valores de velocidade de apenas uma base de dados. Os PMV listados na seção 3.2 e no Anexo 3 foram distribuídos conforme os critérios da empresa Maplink, de modo que as avaliações propostas neste trabalho não cobrem toda a cidade uniformemente. Foram 
encontradas limitações na avaliação das velocidades em vias arteriais primárias e secundárias devido à distribuição de PMV que privilegia as vias expressas.

Outra limitação está relacionada com a seleção de tweets com conteúdo relevante e referência espacial consistente (existente e próxima ao local da ocorrência do fato relatado). Ainda sobre o Twitter, o limite de requisições restringe a aplicação da metodologia em toda a rede, uma vez que a extração foi configurada para selecionar tweets próximos aos PMV.

A terceira limitação identificada é a dependência dos serviços externos para geocodificação e roteamento. Erros ocorridos nessas operações indicam caminhos inexistentes e levam a análises equivocadas dos impactos no trânsito. Além disso, a restrição à quantidade de requisições (inclusive as automáticas) pode restringir as análises, dado que cada tweet pode ter vários PMV em sua vizinhança e, para cada par tweet-PMV é necessária uma requisição de roteamento.

Quanto à extração de velocidade, foram publicados algoritmos mais modernos para o processo de map matching, que podem substituir a metodologia proposta no capítulo 5. Contudo, com os valores já associados às vias, os demais processos podem ser realizados conforme especificado.

\subsection{Trabalhos Futuros}

De posse dos resultados obtidos e das limitações identificadas, percebe-se que os assuntos tratados não puderam ser esgotados, abrindo o caminho para a realização de trabalhos futuros, relacionados ao tema abordado nesta tese. Dentre essas possibilidades é possível citar:

- O adensamento do conjunto de PMV pela cidade a partir de rotas rastreadas por GPS instalados em ônibus, taxis e usuários voluntários de aplicativos que forneçam dados de velocidade, processadas conforme a metodologia proposta no capítulo 5 ou por Wang et al (2013). A partir desse conjunto, estender as avaliações de distribuição de velocidade e de propagação de congestionamento para vias de hierarquias inferiores.

- A avaliação do critério de seleção de tweets pela proximidade às vias, privilegiando as mensagens postadas por usuários que provavelmente estejam no trânsito em detrimento àquelas postadas em outros locais. 
- Avaliação da propagação de congestionamento com base em tweets selecionados com base em outras palavras-chave, conforme a relação proposta por Redlich (2013) onde, além das palavras utilizadas no capítulo 7 (acidente e enguiço), são indicadas interdições (interdição e fechada), engarrafamentos (retenção, congestionamento e lentidão) e eventos climáticos (chuva, chuva forte, alagamento, bolsão d'água).

- Identificação de padrões de reduções nas distribuições de velocidade apresentadas no capítulo 7 visando à predição de consgestionamentos em função dos diferentes tipos de ocorrência, dias da semana, horas e hierarquias das vias. 


\section{Referências Bibliográficas}

ASSOCIAÇÃO BRASILEIRA DE NORMAS TÉCNICAS. NBR 7032: Engenharia de Tráfego - Terminologia. Rio de Janeiro, 1983.

ALBUQUERQUE, F. C. et al. Extrator de fatos relacionados ao tráfego. In: Simpósio Brasileiro de Bancos de Dados - SBBD 2012, São Paulo. pp. 169-176. Disponível em: <http://www.lbd.dcc.ufmg.br/colecoes/sbbd/2012/0022.pdf>

. Georeferencing Facts in Road Networks. In: XIII Brazilian Symposium on GeoInformatics - GEOINFO 2012, Campos do Jordão. pp. 120127. ISSN 2179-4847.

- Pro-active monitoring of moving objects. In: 14th International Conference on Enterprise Information Systems - ICEIS 2012, Wroclaw.

ALBUQUERQUE, F. C. Environment changes detection: A proactive system to monitor moving objects. 2012. Dissertação de Mestrado, Departamento de Informática, PUC-Rio, Rio de Janeiro, 2012.

ALONSO, J. B. Mining Frequent Spatio-Temporal Patterns from Location Based Social Networks. Universitat Politècnica de Catalunya, 2014. Disponível em:

$<$ http://upcommons.upc.edu/eprints/bitstream/2117/24313/1/SpatioTemporal.pdf>

BARBOSA, I.; CASANOVA, M. A. Trust Indicator for Decisions Based on Geospatial Data. In: XII Brazilian Symposium on GeoInformatics - GEOINFO 2011, Campos do Jordão. pp. 49-60.

BIAGIONI, J. et al. EasyTracker: Automatic Transit Tracking , Mapping, and Arrival Time Prediction Using Smartphones. In: 9th ACM Conference on Embedded Networked Sensor Systems - ACM SenSys 2011, Seattle. Pages 6881. 
BRAGA, L. P. V., Introdução à Mineração de Dados - 2. Ed: Edição ampliada e revisada. Rio de Janeiro: Ed. E-papers, 2005.

BRASIL, Decreto $\mathrm{n}^{\circ}$ 6.666, de 27 de novembro de 2008: Institui, no âmbito do Poder Executivo federal, a Infra-Estrutura Nacional de Dados Espaciais - INDE, e dá outras providências. Diário Oficial da República Federativa do Brasil, Brasília, DF, 28 nov. 2008. Disponível em: < http://pesquisa.in.gov.br/imprensa/jsp/visualiza/index.jsp?jornal=1\&pagina $=57 \& d$ ata $=28 / 11 / 2008>$. Acesso em $21 \mathrm{dez} 2014$.

BRASIL, Lei $\mathrm{n}^{\mathrm{o}}$ 12.527, de 18 de novembro de 2011: Regula o acesso a informações previsto no inciso XXXIII do art. 5o, no inciso II do $\S 30$ do art. 37 e no $\S 20$ do art. 216 da Constituição Federal; altera a Lei no 8.112, de 11 de dezembro de 1990; revoga a Lei no 11.111, de 5 de maio de 2005, e dispositivos da Lei no 8.159, de 8 de janeiro de 1991; e dá outras providências. Diário Oficial da República Federativa do Brasil, Brasília, DF, 18 nov. 2008. Disponível em: $<$ http://pesquisa.in.gov.br/imprensa/jsp/visualiza/index.jsp?jornal=1000\&pagina= $1 \&$ data=18/11/2011>. Acesso em $21 \mathrm{dez} 2014$.

BRASIL, Lei ${ }^{\circ}$ 9.503, de 23 de setembro de 1997: Institui o Código de Trânsito Brasileiro. Diário Oficial da República Federativa do Brasil, Brasília, DF, 24 set. 1997. Disponível em: http://pesquisa.in.gov.br/imprensa/jsp/visualiza/index.jsp?jornal=1\&pagina=1\&da ta $=24 / 09 / 1997>$. Acesso em 21 dez 2014.

BRASIL. Departamento Nacional de Infraestrutura de Transportes. Diretoria Executiva. Instituto de Pesquisas Rodoviárias. Manual de projeto geométrico de travessias urbanas. Rio de Janeiro, 2009. Disponível em: $<$ http://www.sinaldetransito.com.br/normas/Manual_Projeto_Geometrico_DNIT.p $\mathrm{df}>$.

CHA, S. Comprehensive Survey on Distance/Similarity Measures between Probability Density Functions. International Journal of Mathematical Models and Methods in Applied Sciences. Issue 4, Volume 1, 2007. Disponível em: $<$ http://csis.pace.edu/ctappert/dps/d861-12/session4-p2.pdf $>$ 
CHUNG, Y.; RECKER, W. W. A methodological approach for estimating temporal and spatial extent of delays caused by freeway accidents. In: IEEE Transactions on Intelligent Transportation Systems. 2012. Volume 13, Issue 3. pp. $1454-1461$.

DA SILVA, P. C. M. Teoria do fluxo de tráfego, 3. Ed. Universidade de Brasília. Brasília, 2007.

DEMŠAR U.; ŠPATENKOVÁ O.; VIRRANTAUS K. Identifying Critical Locations in a Spatial Network with Graph Theory. Transactions in GIS, 2008, Volume 12 Issue 1. pp. 61-82.

DIAS, T. L.; CÂMARA, G.; DAVIS JR., C. A., Modelos espaço-temporais, In: Bancos de Dados Geográficos. Curitiba: Ed. Mundogeo, 2005. pp. 137167.

ESRI. ESRI Shapefile Technical Description. 1998. Disponível em: $<$ http://www.esri.com/library/whitepapers/pdfs/shapefile.pdf $>$

FURTADO, A. S.; FILETO, R.; RENSO, C. M-Attract: Assessing the Attractiveness of Places by using Moving Objects Trajectories Data. In: XIII Brazilian Symposium on GeoInformatics - GEOINFO 2012, Campos do Jordão. pp 84-95.

GOOGLE. API do Google Maps. 2013. <Disponível em: https://developers.google.com/maps/?hl=pt-br>

Google Maps and Waze, outsmarting traffic together. 2013. Disponível em: <http:/googleblog.blogspot.com.br/2013/06/google-maps-andwaze-outsmarting.html>

The bright side of sitting in traffic: Crowdsourcing road congestion data. 2009. Disponível em: <http://googleblog.blogspot.com.br/2009/08/brightside-of-sitting-in-traffic.html>

HINES, W. W. et al. Probabilidade e Estatística na Engenharia, 4. Ed., Rio de Janeiro: Livros Técnicos e Científicos, 2006. 
IBGE. Noções Básicas de Cartografia: elementos de representação. Rio de Janeiro, 2004. Disponível em: $<$ http://www.ibge.gov.br/home/geociencias/cartografia/manual_nocoes/elementos _representacao.html>

IETF. RFC 5870: 'geo' URI Scheme. 2010.

INTERNATIONAL ORGANIZATION FOR STANDARDIZATION. ISO 19157: Geographic information -- Data quality. 2013.

JOÃO, E. M. Causes and Consequences of Map Generalisation, Taylor \& Francis Ltd. Londres. 1998.

KNOOP V L. Road Incidents and Network Dynamics Effects on driving behaviour and traffic congestion. Delft, 2009. Doctoral Thesis - Transport Institute, Technische Universiteit Delft.

LOU, Y. et al. Map-matching for low-sampling-rate GPS trajectories. In: 17 th ACM International Conference on Advances in Geographic Information Systems - ACM SIGSPATIAL 2009. Seattle. pp. 352-361.

MACEACHREN, A.M., et al. Geo-Twitter Analytics: Applications in Crisis Management. In: 25th International Cartographic Conference - ICC 2011, Paris.

MAPLINK. De onde vem as informações de trânsito apresentadas no MapLink?. 2015. Disponível em: http://www.maplink.com.br/FAQ/transito . Termos de Uso do Maplink. 2010. Disponível em: $<$ http://www.maplink.com.br/TermosDeUso >

_ Web $\quad$ Services. 2015. Disponível em: http://dev.maplink.com.br/webservices/ MASIERO, L.; CASANOVA, M.A.; CARVALHO, M.T.M. 2011. Travel Time Prediction using Machine Learning. In: 4th ACM SIGSPATIAL International Workshop on Computational Transportation Science - IWCTS 2011, Chicago. pp. 34-38. 
MCGEE, J.; CAVERLEE, J.; CHENG, Z. A Geographic Study of Tie Strength in Social Media, In: 20th ACM international conference on Information and knowledge management - CIKM 2011, Glasgow. pp. 2333-2336.

MEDEIROS, C. B. et al. Managing sensor traffic data and forecasting unusual behaviour propagation. Geoinformatica, 2010, Volume 14 Issue 3. pp. 279-305.

MIN, W.; WYNTER, L. 2011. Real-time road traffic prediction with spatiotemporal correlations. In: Transportation Research Part C: Emerging Technologies. Volume 19 Issue 4. pp. 606-616.

OPEN GEOSPATIAL CONSORTIUM, OpenGIS® Implementation Standard for Geographic information - Simple feature access - Part 1: Common architecture. Versão 1.2.1. 2010.

OpenGIS® Implementation Standard for Geographic information Simple feature access - Part 2: SQL option. Version: 1.2.1. 2010.

OPEN KNOWLEDGE FOUNDATION. O que são Dados Abertos?. 2014. Disponível em: $\quad<$ http://opendatahandbook.org/pt_BR/what-is-opendata/index.html>

PANG, L. X. et al. On Mining Anomalous Patterns in Road Traffic Streams. In: Advanced Data Mining and Applications. Beijing: Springer-Verlag Berlin Heidelberg, 2011. pp. 237-251.

REDLICH. L. R., Modelagem de eventos de trânsito com base em clipping de grandes massas de dados da Web. Rio de Janeiro, 2013. 49 p. Dissertação de Mestrado - Departamento de Informática, PUC-Rio.

REIS, M. M., Análise de Séries Temporais, UFSC. 2014. Disponível em: $<$ http://www.inf.ufsc.br/ marcelo/Cap4.pdf $>$

RIO DE JANEIRO (Cidade). Dados Abertos. 2014. Disponível em: $<$ http://data.rio.rj.gov.br/about $>$. 
RIO DE JANEIRO (Estado). Secretaria de Estado de Transportes. Plano Diretor de Transporte Urbano da Região Metropolitana do Rio de Janeiro: Relatório 10 - Montagem da Rede e Diagnóstico Versão Final. Rio de Janeiro. 2005. Disponível em: <http://download.rj.gov.br/documentos/10112/1474054/DLFE59262.pdf/Relatorio10vfinalRelatorio6DiageMontagRede1.pdf $>$

SAKAKI, T.; OKAZAKI, M.; MATSUO, Y. Earthquake shakes Twitter users: real-time event detection by social sensors. In: 19th International Conference on World Wide Web - WWW 2010, Raleigh. pp. 851-860.

Salvatore R. et al. Discovering the Geographical Borders of Human Mobility, In: KI - Künstliche Intelligenz August 2012, Volume 26, Issue 3, pp 253-260.

SINN, M.; YOON J. W.; CALABRESE , F. Predicting arrival times of buses using real-time GPS measurements, In 15th IEEE Intelligent Transportation Systems Conference - ITSC 2012, Anchorage. pp. 1227 - 1232.

TRANSPORTATION RESEARCH BOARD, High Capacity Manual, 2000.

TWITTER. The Search API. 2014. Disponível em: $<$ https://dev.twitter.com/rest/public/search>

WANG, Z. et al. Visual Traffic Jam analysis based on trajectory data, In: IEEE Transactions on visualization and Computer Graphics, Volume 19 Issue 2, 2013. pp. $2159-2168$.

WU, J. J.; GAO, Z. Y.; SUN, H. J. Topological-based bottleneck analysis and improvement strategies for traffic networks. In: Sci China Ser E-Tech Sci, Volume 52 Issue 10, 2009. pp. 2814-2822.

YUAN, J. et al. T-Drive: Enhancing Driving Directions with Taxi Drivers' Intelligence, In: IEEE Transactions on Knowledge and Data Engineering Volume 25 Issue 1, 2011. pp. 220 - 232. 


\section{Apêndice 1: Dicionário de Dados}

\section{1 - Velocidade}

\subsubsection{Dicionário de Dados}

tempo (long integer): valor referente à época da leitura, em milissegundos, gerado diretamente pelo sistema. A conversão para época consiste na divisão desse valor por 1000 . geom (OGC point): campo que armazena a geometria do ponto que representa o local onde foi registrada a velocidade, conforme especificação do OpenGIS Consortium (OGC, 2010b). A geometria é construída a partir das coordenadas fornecidas na página da empresa Maplink, armazenadas no sistema de referência WGS84.

vel (double): valor da velocidade, em $\mathrm{km} / \mathrm{h}$, informado pela empresa Maplink.

\subsubsection{Processamentos adicionais}

Foi criado um índice espacial para otimizar as consultas referentes à geometria.

\subsubsection{Amostra}

\begin{tabular}{|c|c|r|}
\hline \multicolumn{1}{|c|}{ tempo } & \multicolumn{1}{|c|}{ geom } & vel \\
\hline 1420024815895 & $0101000020 E 61000006 B C 2 A C 06179845 C 037 E 38 F F D 87 E 736 C 0$ & 32 \\
\hline 1420024815895 & $0101000020 E 61000008 B 1 C 7 D 27 C 19645 C 0839 D 071 C A E E 636 C 0$ & 30 \\
\hline 1420024815879 & $0101000020 E 610000053094 F E 8 F 59945 C 0 C D 9 B 7928 C 0 E 836 C 0$ & 37 \\
\hline
\end{tabular}

\section{2 - PMV (Pontos de Medição de Velocidade)}

\subsubsection{Dicionário de Dados}

ordem (inteiro): identificador atribuído automaticamente ao ponto; corredor (texto): via sobre a qual foi medida a velocidade.

endereco (texto): referência sobre a localização do ponto ao longo da via.

geom (OGC point): campo que armazena a geometria do ponto que representa o local onde foi medida a velocidade. $\mathrm{O}$ valor deste campo é obtido a partir das coordenadas informadas na página da empresa Maplink. 


\subsubsection{Processamentos adicionais}

Foi criado um índice espacial para otimizar as consultas referentes à geometria.

\subsubsection{Amostra}

Ver anexo 3. O conteúdo do campo corredor foi adaptado para apresentar os nomes das vias sem codificações.

\section{3 - Twitter}

\subsubsection{Dicionário de Dados}

id (long integer): identificador atribuído ao tweet;

texto (texto): conteúdo da mensagem do tweet.

usuario (texto): nome do usuário que publicou o tweet.

tempo (timestamp): data e hora da publicação.

keyword (texto): Palavra-chave usada para extrair o tweet ou a indicação de que o tweet foi publicado com geolocalização;

\subsubsection{Processamentos adicionais}

Em virtude das repetições dos valores, as consultas SQL são otimizadas com o emprego da cláusula DISTINCT.

\subsubsection{Amostra}

\begin{tabular}{|c|c|c|c|c|}
\hline id & texto & usuario & tempo & keyword \\
\hline 550072541122166785 & $\begin{array}{l}\text { Minha amg sofreu um acidente } \\
\text { terrível, mas está td bem c ela } \\
\text { \#askmahomieq bom, diz p ela q a } \\
\text { gente quer ela bem logo" }\end{array}$ & auslexota & $\begin{array}{c}30 / 12 / 2014 \\
21: 34\end{array}$ & GeoLocation \\
\hline 550069564802093057 & $\begin{array}{l}\text { Retirados os } 3 \text { carros envolvidos em } \\
\text { acidente na Linha Vermelha, sentido } \\
\text { centro, altura da Maré. Lentidão no } \\
\text { local. \#viasexpressas }\end{array}$ & OperacoesRio & $\begin{array}{c}30 / 12 / 2014 \\
21: 22\end{array}$ & acidente \\
\hline 550059284701405184 & $\begin{array}{c}\text { Retirado ônibus enguiçado na } \\
\text { Avenida Ministro Edgard Romero, } \\
\text { altura da Rua Vaz Lobo, sentido } \\
\text { Campinho. Trânsito lento. }\end{array}$ & OperacoesRio & $\begin{array}{c}30 / 12 / 2014 \\
20: 42\end{array}$ & enguiçado \\
\hline
\end{tabular}




\section{4 - Tweetgeo}

\subsubsection{Dicionário de Dados}

id (long integer): identificador atribuído ao tweet;

geom (OGC point): campo que armazena a geometria do ponto que representa o local onde foi publicada a mensagem. O valor deste campo é extraído do campo Geolocation

\subsubsection{Processamentos adicionais}

Esta tabela armazena apenas a geometria e o identificador do tweet. A recuperação dos demais valores referentes ao tweet é obtida pela junção com a tabela Twitter, empregado como chave primária o campo $i d$. Foi criado um índice espacial para otimizar as consultas referentes à geometria.

\subsubsection{Amostra}

\begin{tabular}{|l|l|}
\hline \multicolumn{1}{|c|}{ id } & \multicolumn{1}{c|}{ geom } \\
\hline 550221749095514112 & $0101000020 E 61000009 A D 76 C 40 D F B 145 C 07 C 74345882 F 236 C 0$ \\
\hline 550072541122166785 & $0101000020 E 6100000 E F 3 B 86 C 77 E 9845 C 07 D 00 F 7 E 1 C 5 F 736 C 0$ \\
\hline 550065167216558081 & $0101000020 E 6100000 F 369 F C 5 F 819 F 45 C 002 E 9 C D 6 E 4 E D 536 C 0$ \\
\hline 550057088139800577 & $0101000020 E 6100000632 B 053027 A 245 C 0 B F 5 B 28 B 239 D 536 C 0$ \\
\hline 550055347361026048 & $0101000020 E 61000007 C 2 B 1213 D 49 E 45 C 09087 B E B B 95 D 936 C 0$ \\
\hline 550044106718990336 & $0101000020 E 6100000 A 15089 C A 8 A A 645 C 06 D E 82463 C E E 336 C 0$ \\
\hline 549996366089707520 & $0101000020 E 610000092 B 64 C E 11 C A F 45 C 09 E 00 D 41 E 40 F 936 C 0$ \\
\hline 549954625353560064 & $0101000020 E 6100000842 E E 1 D 05 B A 245 C 07 B 8269 B D 84 D 736 C 0$ \\
\hline 549941117937258496 & $0101000020 E 6100000 E A D 9626 D 42 B 045 C 06503441 C 46 E C 36 C 0$ \\
\hline
\end{tabular}

\section{5 - Geotweet}

\subsubsection{Dicionário de Dados}

id (long integer): identificador atribuído ao tweet;

geom (OGC point): campo que armazena a geometria do ponto que representa o local de onde foi publicada a mensagem. $O$ valor deste campo foi obtido pela interpretação do texto e atribuição manual das coordenadas em tweets sem geolocalização. 


\subsubsection{Processamentos adicionais}

Esta tabela armazena apenas a geometria e o identificador do tweet. A recuperação dos demais valores referentes ao tweet é obtida pela junção com a tabela Twitter, empregado como chave primária o campo id.

\subsubsection{Amostra}

\begin{tabular}{|c|c|}
\hline id & \multicolumn{1}{|c|}{ geom } \\
\hline 533170908014579712 & $0101000020 E 61000001 C 2 F A D C 5 D 1 A 545 C 0 A F D A 6 B 4636 E C 36 C 0$ \\
\hline 533130565877510144 & $0101000020 E 6100000 B C 2 A A 837 E 8 A F 45 C 011446 E 34 E 3 D 736 C 0$ \\
\hline 533074792963133441 & $0101000020 E 6100000 F 75283 D A C 4 A 745 C 0 B F E A E 3 C A 09 D 736 C 0$ \\
\hline 533035449217220609 & $0101000020 E 610000013 C 3 B 9 C 9749 F 45 C 0389283 F 6 E 7 E A 36 C 0$ \\
\hline 533032324456517632 & $0101000020 E 6100000 B 81 C 6 F 711 E 9 A 45 C 08 B 8 C 2445 C B E 536 C 0$ \\
\hline 533006414860804096 & $0101000020 E 6100000 C 9 C B 568 D A B 9 E 45 C 073 A E C 63 E 8 E D 736 C 0$ \\
\hline 533002203938971648 & $0101000020 E 6100000 B 89765 C F 6 D A 545 C 08907 E 4 A F 95 D 036 C 0$ \\
\hline 532978735059062784 & $0101000020 E 6100000084350 E A D B 9 A 45 C 01 B 72 B 0 F 981 E 636 C 0$ \\
\hline 532975913903067136 & $0101000020 E 61000007 D C D 8 A 4 E 5 C 9 B 45 C 0421 C 4 F 1 E 71 F C 36 C 0$ \\
\hline 532970662387011585 & $0101000020 E 6100000 E C 3 F 247 E 3 E 9745 C 0 A 8 A B 58 A F F 1 E 636 C 0$ \\
\hline
\end{tabular}

\section{6 - Ocorrencias}

\subsubsection{Dicionário de Dados}

id (long integer): identificador atribuído ao tweet;

texto (texto): conteúdo da mensagem do tweet.

usuario (texto): nome do usuário que publicou o tweet.

tempo (timestamp): data e hora da publicação.

geom (OGC point): campo que armazena a geometria do ponto que representa o local de onde foi publicada a mensagem.

\subsubsection{Processamentos adicionais}

Esta tabela é construída a partir da união das tabelas obtidas pela junção das tabelas geotweet e tweetgeo com a tabela twitter. Foram selecionadas as mensagens publicadas pelos usuários @OperacoesRio e @odia24horas. Foi criado um índice espacial para otimizar as consultas referentes à geometria. 


\subsubsection{Amostra}

\begin{tabular}{|c|c|c|c|c|}
\hline id & texto & tempo & usuario & geom \\
\hline 550065167216558081 & $\begin{array}{l}\text { Acidente ocupa uma faixa da } \\
\text { Linha Vermelha, sentido } \\
\text { Baixada, altura da Infraero. } \\
\text { Trânsito normal. } \\
\text { http://t.co/QZnnUX92r1 }\end{array}$ & $\begin{array}{r}30 / 12 / 2014 \\
21: 05\end{array}$ & OperacoesRio & $\begin{array}{r}0101000020 \mathrm{E} 6100000 \\
\text { F369FC5F819F45C002 } \\
\text { E9CD6E4ED536C0 }\end{array}$ \\
\hline 550057088139800577 & $\begin{array}{l}\text { Acidente com carro ocupa } \\
\text { uma faixa da Linha Vermelha, } \\
\text { sentido Baixada, na altura da } \\
\text { Maré. Trânsito normal. } \\
\text { http://t.co/k1CQEFSw6O }\end{array}$ & $\begin{array}{r}30 / 12 / 2014 \\
20: 33\end{array}$ & OperacoesRio & $\begin{array}{r}0101000020 \mathrm{E} 6100000 \\
632 \mathrm{~B} 053027 \mathrm{~A} 245 \mathrm{C} 0 \mathrm{~B} \\
\text { F5B28B239D536C0 }\end{array}$ \\
\hline
\end{tabular}




\section{Apêndice 2: Tweets Analisados}

\section{1 - Lista Geral de Tweets selecionados}

Os tweets listados em seguida foram selecionados pelos critérios estabelecidos no Capítulo 7. Estão listados cronologicamente em ordem decrescente.

\begin{tabular}{|c|c|c|}
\hline id & tempo & texto \\
\hline 550065167216558081 & $\begin{array}{r}30 / 12 / 2014 \\
21: 05\end{array}$ & $\begin{array}{l}\text { Acidente ocupa uma faixa da Linha Vermelha, sentido Baixada, } \\
\text { altura da Infraero. Trânsito normal. http://t.co/QZnnUX92r1 }\end{array}$ \\
\hline 550057088139800577 & $\begin{array}{r}30 / 12 / 2014 \\
20: 33\end{array}$ & $\begin{array}{l}\text { Acidente com carro ocupa uma faixa da Linha Vermelha, sentido } \\
\text { Baixada, na altura da Maré. Trânsito normal. } \\
\text { http://t.co/k1CQEFSw6O }\end{array}$ \\
\hline 550055347361026048 & $\begin{array}{r}30 / 12 / 2014 \\
20: 26\end{array}$ & $\begin{array}{l}\text { Acidente com } 3 \text { carros ocupa uma faixa da Linha Vermelha, } \\
\text { sentido centro, altura da Maré. Lentidão no local. } \\
\text { http://t.co/YXLGTPV3Vx }\end{array}$ \\
\hline 549876812424024066 & $\begin{array}{r}30 / 12 / 2014 \\
08: 37\end{array}$ & $\begin{array}{l}\text { Colisão entre carro e ônibus na Rua Padre Manso, altura da Rua } \\
\text { Quaxima, sentido Marechal Hermes. Uma faixa ocupada. } \\
\text { http://t.co/FviyAWT2Uz }\end{array}$ \\
\hline 549874418684399616 & $\begin{array}{r}30 / 12 / 2014 \\
08: 27\end{array}$ & $\begin{array}{l}\text { Colisão entre moto e táxi no sentido Vaz Lobo. Uma faixa } \\
\text { ocupada. Retenções. http://t.co/zUJjE54n96 }\end{array}$ \\
\hline 549828524312645632 & $\begin{array}{r}30 / 12 / 2014 \\
05: 25\end{array}$ & $\begin{array}{l}\text { Acidente ocupa faixa da Estrada Mal. Miguel Salazar Mendes de } \\
\text { Moraes, altura da Av. Cidade de Deus, sentido Taquara. } \\
\text { http://t.co/FMlhjrPo99 }\end{array}$ \\
\hline 549685330710761474 & $\begin{array}{r}29 / 12 / 2014 \\
19: 56\end{array}$ & $\begin{array}{l}\text { Acidente com } 4 \text { carros e um ônibus ocupa uma faixa e provoca } \\
\text { lentidão na Av. Ayrton Senna, sentido Linha Amarela, altura da } \\
\text { Vila do Pan }\end{array}$ \\
\hline 549684704031408128 & $\begin{array}{r}29 / 12 / 2014 \\
19: 53\end{array}$ & $\begin{array}{l}\text { Acidente com três carros ocupa uma faixa do Túnel do Joá, } \\
\text { sentido Barra. Retenção no local. http://t.co/LntsD6V93X }\end{array}$ \\
\hline 549595773004832768 & $\begin{array}{r}29 / 12 / 2014 \\
14: 00\end{array}$ & $\begin{array}{l}\text { Acidente entre dois ônibus na Av. Ayrton Senna, altura do Casa } \\
\text { Shopping, sentido orla. Retenções. http://t.co/Pq1zvohPjK }\end{array}$ \\
\hline 549593281919598592 & $\begin{array}{r}29 / 12 / 2014 \\
13: 50\end{array}$ & $\begin{array}{l}\text { Acidente entre ônibus e utilitário na pista lateral da Av. Brasil, } \\
\text { altura de Bonsucesso, sentido Centro. Retenções. }\end{array}$ \\
\hline 549123774285504513 & $28 / 12 / 2014$ & $\begin{array}{l}\text { Colisão entre carro e moto ocupa uma faixa da Linha Amarela, na } \\
\text { chegada à Av Ayrton Senna. Equipes atuam no local. }\end{array}$ \\
\hline
\end{tabular}




\begin{tabular}{|c|c|c|}
\hline id & tempo & texto \\
\hline & $06: 44$ & http://t.co/QNnDi2QVbE \\
\hline 548975111408078848 & $\begin{array}{r}27 / 12 / 2014 \\
20: 54\end{array}$ & $\begin{array}{l}\text { Acidente com } 3 \text { carros ocupa uma faixa da Av Ayrton Senna, } \\
\text { sentido Linha Amarela, altura da Vivo. CET-Rio no local } \\
\text { http://t.co/giKdSoyhUM }\end{array}$ \\
\hline 548974168998281216 & $\begin{array}{r}27 / 12 / 2014 \\
20: 50\end{array}$ & 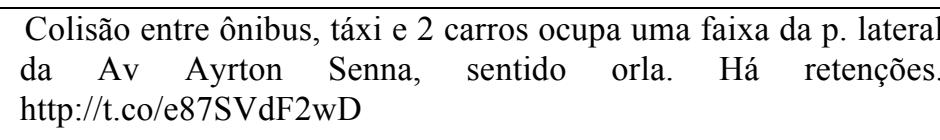 \\
\hline 548740704067809280 & $\begin{array}{r}27 / 12 / 2014 \\
05: 22\end{array}$ & $\begin{array}{l}\text { Acidente com um carro ocupa uma faixa da Estrada do } \\
\text { Mendanha, altura do n } 3885 \text {, no sentido Barra. Equipes no local } \\
\text { http://t.co/D0YAhqUWlz }\end{array}$ \\
\hline 548608001284665344 & $\begin{array}{r}26 / 12 / 2014 \\
20: 35\end{array}$ & $\begin{array}{l}\text { Colisão entre dois carros ocupa uma faixa da pista central da Av } \\
\text { Brasil, em Irajá, sentido ZOeste. Equipes no local. } \\
\text { http://t.co/3WhBpwW4GE }\end{array}$ \\
\hline 548299974618804224 & $\begin{array}{r}26 / 12 / 2014 \\
00: 11\end{array}$ & $\begin{array}{l}\text { Acidente com } 3 \text { carros ocupa } 1 \text { faixa da Est das Capoeiras, sent } \\
\text { Av Cesário de Melo, próx Carrefour. CET-Rio no local. } \\
\text { http://t.co/VE8I2EohVK }\end{array}$ \\
\hline 548017431365439488 & $\begin{array}{r}25 / 12 / 2014 \\
05: 28\end{array}$ & $\begin{array}{l}\text { Colisão entre carro e táxi interdita } \mathrm{p} \text { central da Av Armando } \\
\text { Lombardi, sent Recreio, alt Av Fernando Mattos. Desvio: pista } \\
\text { lateral. }\end{array}$ \\
\hline 547935491878686720 & $\begin{array}{r}25 / 12 / 2014 \\
00: 02\end{array}$ & $\begin{array}{l}\text { Acidente com um carro ocupa uma faixa na subida da } \\
\text { Autoestrada Grajaú-Jpa, sentido Jacarepaguá. CET-Rio no local } \\
\text { http://t.co/nix3PHY1VP }\end{array}$ \\
\hline 547678780307677184 & $\begin{array}{r}24 / 12 / 2014 \\
07: 02\end{array}$ & $\begin{array}{l}\text { Segue parcialmente interditada a Av. Armando Lombardi, sentido } \\
\text { Recreio, devido a um acidente com onnibus, alt IBMEC } \\
\text { http://t.co/TvGNV781HP }\end{array}$ \\
\hline 547316100526915584 & $\begin{array}{r}23 / 12 / 2014 \\
07: 01\end{array}$ & $\begin{array}{l}\text { Colisão entre dois carros ocupa uma faixa da AV Niemeyer, após } \\
\text { o Vips, no sentido São Conrado. Sem retenções. } \\
\text { http://t.co/liL2piBevK }\end{array}$ \\
\hline 547205221525372928 & $\begin{array}{r}22 / 12 / 2014 \\
23: 41\end{array}$ & $\begin{array}{l}\text { Colisão com carreta, utilitário e } 2 \text { carros ocupa } 1 \text { faixa da } p \\
\text { central da Av Brasil, sentido Zona } \\
\text { http://t.co/mb6vhsVXml }\end{array}$ \\
\hline 547188895876517888 & $\begin{array}{r}22 / 12 / 2014 \\
22: 36\end{array}$ & $\begin{array}{l}\text { Colisão entre ônibus e carro interdita pista lateral da Av } \\
\text { Maracanã, sentido São Cristóvão. Desvio: pista central. } \\
\text { http://t.co/6SHDzPWfLG }\end{array}$ \\
\hline 546594647833726976 & $\begin{array}{r}21 / 12 / 2014 \\
07: 14\end{array}$ & \begin{tabular}{l}
\multicolumn{5}{l}{ Colisão entre moto e ônibus ocupa faixa da R. Cândido Benício, } \\
altura da R. Ana Teles, sentido Praça Seca \\
http://t.co/TAIe57MFV8
\end{tabular} \\
\hline 546511816365326336 & $\begin{array}{r}21 / 12 / 2014 \\
01: 45\end{array}$ & $\begin{array}{l}\text { Colisão entre táxi e carro ocupa uma faixa da Av Maracanã } \\
\text { sentido Radial Oeste, altura do Belini. Equipes no local } \\
\text { http://t.co/wBsy2ZaoGC }\end{array}$ \\
\hline
\end{tabular}




\begin{tabular}{|c|c|c|}
\hline id & tempo & texto \\
\hline 546421039240990720 & $\begin{array}{r}20 / 12 / 2014 \\
19: 45\end{array}$ & $\begin{array}{l}\text { Colisão entre carreta, utilitário e } 2 \text { carros causa retenções na p. } \\
\text { central da Av Brasil, sentido } \text { Centro, em Lucas. } \\
\text { http://t.co/3BAtnR18e8 }\end{array}$ \\
\hline 546347049277333504 & $\begin{array}{r}20 / 12 / 2014 \\
14: 51\end{array}$ & $\begin{array}{l}\text { Colisão entre utilitário e táxi ocupa duas faixas do Alto da Boa } \\
\text { Vista, altura da R. São Miguel, sentido Tijuca } \\
\text { http://t.co/t4syfOXpE7 }\end{array}$ \\
\hline 546087139197214720 & $\begin{array}{r}19 / 12 / 2014 \\
21: 38\end{array}$ & $\begin{array}{l}\text { Acidente com } 3 \text { carros ocupa uma faixa e provoca lentidão na Av. } \\
\text { Ayrton Senna, sentido L.Amarela, alt. do Barra Music. } \\
\text { http://t.co/zt2j3BhZi7 }\end{array}$ \\
\hline 546076973848477696 & $\begin{array}{r}19 / 12 / 2014 \\
20: 57\end{array}$ & $\begin{array}{l}\text { Acidente com carro ocupa faixa da Estrada do Pau Ferro, sent. } \\
\text { Pechincha, alt. da R.Claudino de Oliveira. Retenções. } \\
\text { http://t.co/3pqjtmJ5mW }\end{array}$ \\
\hline 545378020475691008 & $\begin{array}{r}17 / 12 / 2014 \\
22: 40\end{array}$ & $\begin{array}{l}\text { Acidente com carreta ocupa uma faixa da Estrada das Capoeiras, } \\
\text { altura da Estrada Rio São Paulo. Retenções no local. } \\
\text { http://t.co/cFvDcBKJe7 }\end{array}$ \\
\hline 545198911976005632 & $\begin{array}{r}17 / 12 / 2014 \\
10: 48\end{array}$ & $\begin{array}{l}\text { Colisão de } 2 \text { carros, ônibus e caminhão causa lentidão na Est. dos } \\
\text { Bandeirantes, alt. BRT Curicica, sent Taquara. } \\
\text { http://t.co/H16BZ7c9VS }\end{array}$ \\
\hline 545151094691618817 & $\begin{array}{r}17 / 12 / 2014 \\
07: 38\end{array}$ & $\begin{array}{l}\text { Av Pastor Martin Luther King Jr tem faixa ocupada na altura do } \\
\text { metrô de Vicente de Carvalho, por acidente com moto. } \\
\text { http://t.co/VbgrGb0TXQ }\end{array}$ \\
\hline 545146708590473216 & $\begin{array}{r}17 / 12 / 2014 \\
07: 21\end{array}$ & $\begin{array}{l}\text { Colisão de caminhão e ônibus ocupa faixa da Rua Gilberto } \\
\text { Cardoso, altura do Flamengo. Sem retenção. CET-Rio na via. } \\
\text { http://t.co/U1GcngqQAy }\end{array}$ \\
\hline 545111876506779648 & $\begin{array}{r}17 / 12 / 2014 \\
05: 02\end{array}$ & $\begin{array}{l}\text { Colisão entre moto e ônibus ocupa } 1 \text { faixa da } \mathrm{p} \text {. central da } \mathrm{Av} \\
\text { Brasil, sentido Centro, no Caju. Retenções até Benfica. } \\
\text { http://t.co/823XzdpsWg }\end{array}$ \\
\hline 544739222410649600 & $\begin{array}{r}16 / 12 / 2014 \\
04: 22\end{array}$ & $\begin{array}{l}\text { Acidente com carro ocupa faixa na p.central da Av. Brasil, sent. } \\
\text { centro, alt. de Irajá. Bombeiros e CET-Rio no local. } \\
\text { http://t.co/20TT4SVdlC }\end{array}$ \\
\hline 544418494981230592 & $\begin{array}{r}15 / 12 / 2014 \\
07: 07\end{array}$ & $\begin{array}{l}\text { Av Salvador de Sá, alt Rua Heitor Carrilho, tem faixa ocupada } \\
\text { por colisão de dois carros. CET-Rio na via. Retenção. } \\
\text { http://t.co/wzNRn2lgLT }\end{array}$ \\
\hline 544407368914595840 & $\begin{array}{r}15 / 12 / 2014 \\
06: 23\end{array}$ & $\begin{array}{l}\text { Colisão de carro e moto ocupa faixa da Linha Vermelha, altura de } \\
\text { Caxias, sentido Centro. Retenções. CET-Rio na via. } \\
\text { http://t.co/aVBCOtqNpN }\end{array}$ \\
\hline 544245514259021824 & $\begin{array}{r}14 / 12 / 2014 \\
19: 40\end{array}$ & $\begin{array}{l}\text { Colisão entre } 2 \text { ônibus e utilitário ocupa } 1 \text { faixa da pista lateral da } \\
\text { Av Brasil, sentido ZOeste, em Benfica. http://t.co/Bi9mpaCrK1 }\end{array}$ \\
\hline 544083467525312512 & $\begin{array}{r}14 / 12 / 2014 \\
08: 56\end{array}$ & $\begin{array}{l}\text { Colisão entre carro e táxi na Avenida Osvaldo Aranha, altura do } \\
\text { metrô de São Cristovão, sentido Méier. } 1 \text { fx.ocupada. } \\
\text { http://t.co/7iqxBfnUsX }\end{array}$ \\
\hline
\end{tabular}




\begin{tabular}{|c|c|c|}
\hline id & tempo & texto \\
\hline 543554850105991168 & $\begin{array}{r}12 / 12 / 2014 \\
21: 55\end{array}$ & $\begin{array}{l}\text { Acidente com moto ocupa uma faixa do Elevado Paulo de } \\
\text { Frontin, próximo à estrada do Túnel Rebouças. Há retenções. } \\
\text { http://t.co/LqcFnqizoj }\end{array}$ \\
\hline 543369259259146241 & $\begin{array}{r}12 / 12 / 2014 \\
09: 38\end{array}$ & $\begin{array}{l}\text { Colisão entre moto, carro e caminhão ocupa } 1 \text { faixa da Lagoa- } \\
\text { Barra, sent Barra, altura acesso p/ Túnel do S. Conrado } \\
\text { http://t.co/xBgLReDATq }\end{array}$ \\
\hline 543364451366236161 & $\begin{array}{r}12 / 12 / 2014 \\
09: 19\end{array}$ & $\begin{array}{l}\text { Colisão entre utilitário e carro ocupa } 1 \text { faixa do Túnel Santa } \\
\text { Bárbara, sentido Catumbi. Há retenções: http://t.co/L8r19iQPnW }\end{array}$ \\
\hline 543185649956696064 & $\begin{array}{r}11 / 12 / 2014 \\
21: 28\end{array}$ & $\begin{array}{l}\text { Acidente com moto e carro ocupa uma faixa e provoca retenção } \\
\text { na Rua das Laranjeiras, sentido Cosme Velo } \\
\text { http://t.co/BPNGYxlul0 }\end{array}$ \\
\hline 543170206948802560 & $\begin{array}{r}11 / 12 / 2014 \\
20: 27\end{array}$ & $\begin{array}{l}\text { Acidente com três carros ocupa uma faixa e provoca lentidão no } \\
\text { Elevado Paulo de Frontin, sentido Lagoa. } \\
\text { http://t.co/o7G07XuvZC }\end{array}$ \\
\hline 543164309597999104 & $\begin{array}{r}11 / 12 / 2014 \\
20: 03\end{array}$ & $\begin{array}{l}\text { Acidente com táxi e carro ocupa uma faixa e provoca retenção na } \\
\text { Av.Ayrton Senna, altura da Vila do Pan, sentido orla. } \\
\text { http://t.co/nOVR8gHy2K }\end{array}$ \\
\hline 542996881836490752 & $\begin{array}{r}11 / 12 / 2014 \\
08: 58\end{array}$ & $\begin{array}{l}\text { Colisão de } 2 \text { carros ocupa } 2 \text { faixas da Av. Brasil, pista central, na } \\
\text { Penha, sentido Centro. Lentidão. CET-Rio na via. } \\
\text { http://t.co/qnhImaeBHX }\end{array}$ \\
\hline 542452529460572161 & $\begin{array}{r}09 / 12 / 2014 \\
20: 55\end{array}$ & $\begin{array}{l}\text { Acidente com carro ocupa uma faixa e provoca retenção na } \\
\text { Av.Salvador Allende, sent. Linha Amarela, alt. do Condomínio } \\
\text { Barra Sunday }\end{array}$ \\
\hline 542427532952215552 & $\begin{array}{r}09 / 12 / 2014 \\
19: 16\end{array}$ & $\begin{array}{l}\text { Acidente com carro e moto ocupa faixa e provoca retenção na } \\
\text { Av. Alfredo Balthazar da Silveira, altura do Barra World. } \\
\text { http://t.co/AbL4dcRHBF }\end{array}$ \\
\hline 542335222650392576 & $\begin{array}{r}09 / 12 / 2014 \\
13: 09\end{array}$ & $\begin{array}{l}\text { Acidente com ônibus ocupa } 1 \text { faixa da R. Barata Ribeiro, altura } \\
\text { da R. Hilário de Gouveia. Há retenções. http://t.co/RxhZLPalf8 }\end{array}$ \\
\hline 542020567541374977 & $\begin{array}{r}08 / 12 / 2014 \\
16: 19\end{array}$ & $\begin{array}{l}\text { Colisão entre carro e utilitário na R. Mário Ribeiro, próx. da Av. } \\
\text { Bartolomeu Mitre, sentido PUC. Uma fx. ocupada. } \\
\text { http://t.co/mWu15EFqks }\end{array}$ \\
\hline 541924357807677440 & $\begin{array}{r}08 / 12 / 2014 \\
09: 56\end{array}$ & $\begin{array}{l}\text { Colisão de carro e moto ocupa faixa da Radial oeste, sentido } \\
\text { Centro, altura do Maracanã. Bombeiros na via. } \\
\text { http://t.co/WHHrLexU7v }\end{array}$ \\
\hline 541914680856301569 & $\begin{array}{r}08 / 12 / 2014 \\
09: 18\end{array}$ & $\begin{array}{l}\text { Colisão de carro e utilitário na Av. Brasil, sentido Centro, pista } \\
\text { central, na Penha. PM e CET-Rio na via. Lentidão. } \\
\text { http://t.co/R80W4cccXk }\end{array}$ \\
\hline 541912806908387328 & $\begin{array}{r}08 / 12 / 2014 \\
09: 10\end{array}$ & $\begin{array}{l}\text { Colisão de } 2 \text { carros ocupa faixa da Av das Américas, alt. do } \\
\text { Santander, sentido São Conrado. Lentidão. CET-Rio na via. } \\
\text { http://t.co/9Ryzv2KCjc }\end{array}$ \\
\hline
\end{tabular}




\begin{tabular}{|c|c|c|}
\hline id & tempo & texto \\
\hline 541726066113396736 & $\begin{array}{r}07 / 12 / 2014 \\
20: 48\end{array}$ & $\begin{array}{l}\text { Acidente envolvendo moto ocupa uma faixa e provoca lentidão } \\
\text { na primeira galeria do Túnel Rebouças, sentido Centro. } \\
\text { http://t.co/YAMj6OvSCI }\end{array}$ \\
\hline 541457126208458752 & $\begin{array}{r}07 / 12 / 2014 \\
03: 00\end{array}$ & $\begin{array}{l}\text { Acidente com utilitário na Estrada do Catonho, próx Estrada do } \\
\text { Cafundá. A via } \begin{array}{c}\text { opera em } \\
\text { http://t.co/Ct07kxsc76 }\end{array}\end{array}$ \\
\hline 541337826080464896 & $\begin{array}{r}06 / 12 / 2014 \\
19: 06\end{array}$ & $\begin{array}{l}\text { Colisão entre } 2 \text { carros e ônibus ocupa faixa da Est. dos } \\
\text { Bandeirantes, altura da R. Otacílio Novais, sentido Barra } \\
\text { http://t.co/ivTrQhkNro }\end{array}$ \\
\hline 541299974101684225 & $\begin{array}{r}06 / 12 / 2014 \\
16: 35\end{array}$ & $\begin{array}{l}\text { Acidente entre moto e carro na Ponte da Joatinga, sentido Barra. } \\
\text { Há reflexos na Autoestrada Lagoa-Barra: } \\
\text { http://t.co/mMgaUD3OAC }\end{array}$ \\
\hline 541155215336960000 & $\begin{array}{r}06 / 12 / 2014 \\
07: 00\end{array}$ & $\begin{array}{l}\text { Acidente com carro e moto ocupa uma faixa da L.Vermelha, alt } \\
\text { de Cordovil, sent. Centro. Retenção no local. } \\
\text { http://t.co/uAO9gJ6iCB }\end{array}$ \\
\hline 541146263312273408 & $\begin{array}{r}06 / 12 / 2014 \\
06: 24\end{array}$ & $\begin{array}{l}\text { Colisão entre dois carros ocupa faixa da Estrada Rio do A, altura } \\
\text { da Estrada Rio-São Paulo. Retenção no local } \\
\text { http://t.co/v3tMtbTGoA }\end{array}$ \\
\hline 541137970187624448 & $\begin{array}{r}06 / 12 / 2014 \\
05: 52\end{array}$ & $\begin{array}{l}\text { Colisão entre } 2 \text { carros ocupa faixa da pista central da Av. Brasil, } \\
\text { sent. Zona Oeste, alt. de Deodoro. Sem retenção } \\
\text { http://t.co/SwxWMQjD5W }\end{array}$ \\
\hline 541011529202532352 & $\begin{array}{r}05 / 12 / 2014 \\
21: 29\end{array}$ & $\begin{array}{l}\text { Acidente com dois carros ocupa uma faixa da Av. Salvador } \\
\text { Allende, sentido Recreio, altura do } 31^{\circ} \text { Batalhão. \#zonaoeste } \\
\text { http://t.co/s3jSt8ReLK }\end{array}$ \\
\hline 540988818828976129 & $\begin{array}{r}05 / 12 / 2014 \\
19: 59\end{array}$ & $\begin{array}{l}\text { Colisão entre dois carros ocupa uma faixa da Rua Barata Ribeiro, } \\
\text { altura da Rua Miguel Lemos. \#zonasul http://t.co/3Gb7WHOzkC }\end{array}$ \\
\hline 540584898776420352 & $\begin{array}{r}04 / 12 / 2014 \\
17: 14\end{array}$ & $\begin{array}{l}\text { Acidente com moto ocupa duas faixas da Av. Brasil, pista central, } \\
\text { em Benfica, sentido Zona Oeste. Retenções. } \\
\text { http://t.co/rnhJ4papA6 }\end{array}$ \\
\hline 540261672338718720 & $\begin{array}{r}03 / 12 / 2014 \\
19: 49\end{array}$ & $\begin{array}{l}\text { Colisão entre } 2 \text { motos ocupa } 1 \text { faixa do Gasômetro, sentido } \\
\text { Centro, altura da descida p/ Av Franc Bicalho. Há retenção } \\
\text { http://t.co/YaMeaBKWVE }\end{array}$ \\
\hline 540249165305888770 & $\begin{array}{r}03 / 12 / 2014 \\
19: 00\end{array}$ & $\begin{array}{l}\text { Colisão entre ônibus e carro ocupa } 1 \text { faixa da Av. Ayrton Senna, } \\
\text { sentido Linha Amarela, altura do giro do Cebolão: } \\
\text { http://t.co/0hpxQdnbbJ }\end{array}$ \\
\hline 540173389420175360 & $\begin{array}{r}03 / 12 / 2014 \\
13: 59\end{array}$ & $\begin{array}{l}\text { Interditada pista lateral da Av. Pres Vargas, sentido Candelária, } \\
\text { alt da Cedae, por acidente. Desvio na R Carmo Neto. } \\
\text { http://t.co/uPXVn2O1nt }\end{array}$ \\
\hline 540137486320545792 & $\begin{array}{r}03 / 12 / 2014 \\
11: 36\end{array}$ & $\begin{array}{l}\text { Colisão de carro e moto ocupa faixa da Linha Vermelha, sentido } \\
\text { Baixada, alt. Cidade Universitária. Bombeiros na via. } \\
\text { http://t.co/LHNL7RBc6T }\end{array}$ \\
\hline
\end{tabular}




\begin{tabular}{|c|c|c|}
\hline id & tempo & texto \\
\hline 540115398922756099 & $\begin{array}{r}03 / 12 / 2014 \\
10: 08\end{array}$ & $\begin{array}{l}\text { Colisão de ônibus e carro ocupa faixa da Av. } 31 \\
\text { sentido Ce Março, } \\
\text { http://t.co/46FRAQk89p }\end{array}$ \\
\hline 540069278100094977 & $\begin{array}{r}03 / 12 / 2014 \\
07: 05\end{array}$ & $\begin{array}{l}\text { Colisão de carro e moto ocupa faixa da Autoestrada Lagoa-Barra } \\
\text { e causa retenção sentido Lagoa. CET-Rio no local. } \\
\text { http://t.co/gTmydvAtPn }\end{array}$ \\
\hline 540064012692504576 & $\begin{array}{r}03 / 12 / 2014 \\
06: 44\end{array}$ & $\begin{array}{l}\text { Colisão de } 2 \text { carros e ônibus ocupa faixa da av. Nelson Cardoso, } \\
\text { sent. Taquara. Retenção. CET-Rio na via. http://t.co/N8Vv5hrr26 }\end{array}$ \\
\hline 540061141997596672 & $\begin{array}{r}03 / 12 / 2014 \\
06: 33\end{array}$ & $\begin{array}{l}\text { Colisão entre carro e ônibus ocupa faixa da Av. Marechal } \\
\text { Floriano, altura da R. Uruguaiana: http://t.co/EP91ZgfPiM }\end{array}$ \\
\hline 540011248209764352 & $\begin{array}{r}03 / 12 / 2014 \\
03: 14\end{array}$ & $\begin{array}{l}\text { Acidente com carreta interdita a pista central da Av Brasil, sent } \\
\text { Centro, próx ao Into. Desvio pela pista lateral. } \\
\text { http://t.co/Udi9joACQE }\end{array}$ \\
\hline 539752820920950784 & $\begin{array}{r}02 / 12 / 2014 \\
10: 07\end{array}$ & $\begin{array}{l}\text { Colisão de dois carros ocupa faixa da segunda galeria do Túnel } \\
\text { Rebouças, sentido Lagoa. Há lentidão. CET-Rio na via. } \\
\text { http://t.co/w2levv9OT6 }\end{array}$ \\
\hline 539728870866300929 & $\begin{array}{r}02 / 12 / 2014 \\
08: 32\end{array}$ & $\begin{array}{l}\text { Colisão entre carro e moto na p. lateral da Av. Brasil, sentido } \\
\text { Centro, altura da Fiocruz. Uma fx. ocupada. } \\
\text { http://t.co/LfC3w9GhJ9 }\end{array}$ \\
\hline 539699374687674368 & $\begin{array}{r}02 / 12 / 2014 \\
06: 35\end{array}$ & $\begin{array}{l}\text { Acidente entre ônibus e carro ocupa uma faixa e provoca retenção } \\
\text { na Rua Cândido Benício, altura da Leroy Merlin. } \\
\text { http://t.co/epAjFDCPc6 }\end{array}$ \\
\hline 539693247270883328 & $\begin{array}{r}02 / 12 / 2014 \\
06: 11\end{array}$ & $\begin{array}{l}\text { Acidente entre carro e moto ocupa uma faixa da Av. Ayrton } \\
\text { Senna, altura do Barra Music, sentido Linha Amarela. } \\
\text { http://t.co/HXld6DK9jf }\end{array}$ \\
\hline 539636130686062592 & $\begin{array}{r}02 / 12 / 2014 \\
02: 24\end{array}$ & $\begin{array}{l}\text { Acidente com moto ocupa uma faixa, mas não provoca retenção, } \\
\text { na Ponte da Joatinga, sentido Barra. http://t.co/niL6Zcjmla }\end{array}$ \\
\hline 539577202350628865 & $\begin{array}{r}01 / 12 / 2014 \\
22: 30\end{array}$ & $\begin{array}{l}\text { Acidente entre dois carros ocupa uma faixa e provoca retenção na } \\
\text { Av. das Américas, na altura do Freeway, sent. Barra } \\
\text { http://t.co/l1CyDgLXmW }\end{array}$ \\
\hline 539539836458135552 & $\begin{array}{r}01 / 12 / 2014 \\
20: 01\end{array}$ & $\begin{array}{l}\text { Acidente ocupa uma faixa e provoca retenção na Estrada do } \\
\text { Catonho, sentido Taquara, na altura da Est. do Cafundá. } \\
\text { http://t.co/HeKCInC2Wd }\end{array}$ \\
\hline 539534462615187457 & $\begin{array}{r}01 / 12 / 2014 \\
19: 40\end{array}$ & $\begin{array}{l}\text { Acidente envolvendo três carros ocupa uma faixa e provoca } \\
\text { retenção no Túnel Rebouças, sentido Praça da Bandeira. } \\
\text { http://t.co/m9H7k3oJ6R }\end{array}$ \\
\hline 539130867411476480 & $\begin{array}{r}30 / 11 / 2014 \\
16: 56\end{array}$ & $\begin{array}{l}\text { Colisão entre carro e moto no Túnel Acústico, sentido Lagoa. } \\
\text { Uma faixa ocupada. Retenção a partir da Rocinha. } \\
\text { http://t.co/iZJ6J8m1x3 }\end{array}$ \\
\hline
\end{tabular}




\begin{tabular}{|c|c|c|}
\hline id & tempo & texto \\
\hline 539079113386909696 & $\begin{array}{r}30 / 11 / 2014 \\
13: 30\end{array}$ & $\begin{array}{l}\text { Colisão entre } 2 \text { carros na Av. P.Guilherme Decaminada, altura da } \\
\begin{array}{llllll}\text { Estr. do Cortume, sentido Av. Brasil. } 1 & \text { fx } \\
\text { ocupada:http://t.co/GeNyiI5JIX } & & & & \end{array}\end{array}$ \\
\hline 538981669001129986 & $\begin{array}{r}30 / 11 / 2014 \\
07: 03\end{array}$ & $\begin{array}{l}\text { Acidente com carro ocupa faixa da Av.Padre Guilherme } \\
\text { Decaminada, alt R. Cap.Lopes Dorneles, sent.Barra. Sem } \\
\text { retenção. http://t.co/IhUrjtsYgJ }\end{array}$ \\
\hline 538977279821357057 & $\begin{array}{r}30 / 11 / 2014 \\
06: 46\end{array}$ & $\begin{array}{l}\text { Acidente com carro ocupa faixa do Túnel Rebouças, sentido } \\
\text { Praça da Bandeira. Trânsito sem retenção. CET-Rio no local } \\
\text { http://t.co/Jrxgf31BGd }\end{array}$ \\
\hline 538955246060306432 & $\begin{array}{r}30 / 11 / 2014 \\
05: 18\end{array}$ & $\begin{array}{l}\text { Acidente com moto ocupa faixa na Estrada dos Bandeirantes, } \\
\text { sentido Taquara, altura da Praça do Bandolim. Sem retenção } \\
\text { http://t.co/igt1VSsFGB }\end{array}$ \\
\hline 538854477185294336 & $\begin{array}{r}29 / 11 / 2014 \\
22: 38\end{array}$ & $\begin{array}{l}\text { Acidente com ônibus e carro ocupa faixa e provoca retenção na } \\
\text { R.Felipe Cardoso, 521, altura da Av.Isabel, sent.Barra; } \\
\text { http://t.co/kkp1S7f8Ts }\end{array}$ \\
\hline 538838930255118336 & $\begin{array}{r}29 / 11 / 2014 \\
21: 36\end{array}$ & $\begin{array}{l}\text { Acidente com carro ocupa uma faixa e provoca retenção na Av } \\
\text { Borges de Medeiros, na altura do Jockey. http://t.co/BTlc0hs3Pk }\end{array}$ \\
\hline 538453903667253248 & $\begin{array}{r}28 / 11 / 2014 \\
20: 06\end{array}$ & $\begin{array}{l}\text { Acidente com carro interdita trecho da Rua Cupertino Durão, } \\
\text { Leblon, alt do Kumon. Desvio pela Av Ataulfo de Paiva. } \\
\text { http://t.co/5yF6cR5iWq }\end{array}$ \\
\hline 538017268169314305 & $\begin{array}{r}27 / 11 / 2014 \\
15: 11\end{array}$ & $\begin{array}{l}\text { Acidente com ônibus interdita parcialmente a pista central da Av } \\
\text { Brasil, sentido ZO, altura da Penha. Há retenções } \\
\text { http://t.co/Dw5L2V1Ii6 }\end{array}$ \\
\hline 537924766275878913 & $\begin{array}{r}27 / 11 / 2014 \\
09: 03\end{array}$ & $\begin{array}{l}\text { Na Barra, acidente com carro ocupa } 1 \text { faixa do Mergulhão Billy } \\
\text { Blanco, sentido } \\
\text { http://t.co/8zRW1f8WD8 }\end{array}$ \\
\hline 537535253535924224 & $\begin{array}{r}26 / 11 / 2014 \\
07: 16\end{array}$ & $\begin{array}{l}\text { Colisão entre } 3 \text { carros na Ponte, sentido Niterói, causa retenções } \\
\text { na Av. Brasil e na Linha Vermelha, sentido Centro } \\
\text { http://t.co/opzNgCIXoA }\end{array}$ \\
\hline 536942253814460416 & $\begin{array}{r}24 / 11 / 2014 \\
15: 59\end{array}$ & $\begin{array}{l}\text { Interditada Est. Rio-SP, nos } 2 \text { sentidos, devido à colisão entre } 2 \\
\text { caminhões e } 3 \text { carros, altura da } \\
\text { http.//t.co/wexjaM5h1O }\end{array}$ \\
\hline 536941143108227072 & $\begin{array}{r}24 / 11 / 2014 \\
15: 55\end{array}$ & $\begin{array}{l}\text { Colisão entre } 2 \text { caminhões, } 1 \text { carreta e } 1 \text { utilitário ocupa } 1 \text { faixa } \\
\text { da p central da Brasil, sent Centro, alt Manguinhos } \\
\text { http://t.co/lvoM1on9mo }\end{array}$ \\
\hline 536840726319878144 & $\begin{array}{r}24 / 11 / 2014 \\
09: 16\end{array}$ & $\begin{array}{l}\text { Colisão entre } 2 \text { ônibus e moto interdita sentido Gávea da R, } \\
\text { Jardim Botânico, altura do Jockey. Via em "pare e siga" } \\
\text { http://t.co/duj8Q5GaES }\end{array}$ \\
\hline 535305461596049409 & $\begin{array}{r}20 / 11 / 2014 \\
03: 35\end{array}$ & $\begin{array}{l}\text { Acidente entre ônibus e táxi ocupa uma faixa da Av. Presidente } \\
\text { Vargas, sentido Praça da } \\
\text { http://t.co/EfyxJOnP7S }\end{array}$ \\
\hline
\end{tabular}




\begin{tabular}{|c|c|c|}
\hline id & tempo & texto \\
\hline 534696018319667200 & $\begin{array}{r}18 / 11 / 2014 \\
11: 13\end{array}$ & $\begin{array}{l}\text { Atualização: colisão entre moto e caminhão ocupa } 2 \text { faixas da } \\
\text { pista central da Av Brasil, sent Centro, alt Manguinhos: } \\
\text { http://t.co/yvdqttSESm }\end{array}$ \\
\hline 534379856176246784 & $\begin{array}{r}17 / 11 / 2014 \\
14: 17\end{array}$ & $\begin{array}{l}\text { Colisão entre caminhão e } 4 \text { carros interdita o Túnel Sta Bárbara, } \\
\text { sentido Laranjeiras. Opção p/ Zona Sul é o Rebouças } \\
\text { http://t.co/cyrfrz901W }\end{array}$ \\
\hline 534376048972931074 & $\begin{array}{r}17 / 11 / 2014 \\
14: 02\end{array}$ & $\begin{array}{l}\text { Colisão entre caminhão e } 4 \text { carros ocupa } 1 \text { faixa do Túnel Santa } \\
\text { Bárbara, sentido } \\
\text { http://t.co/MxMJhUjOGB }\end{array}$ \\
\hline 534272954075340800 & $\begin{array}{r}17 / 11 / 2014 \\
07: 12\end{array}$ & $\begin{array}{l}\text { Interditada a p. central da Av Ayrton Senna, sentido LAmarela, } \\
\text { devido a acidente com carro. Desvio pela p. lateral. } \\
\text { http://t.co/wGee1Jc1co }\end{array}$ \\
\hline 533170908014579712 & $\begin{array}{r}14 / 11 / 2014 \\
06: 13\end{array}$ & $\begin{array}{l}\text { @ LeiSecaRJ 06:12 acidente agora na Grajau sentido centro carro } \\
\text { capotou vai ficar ruim }\end{array}$ \\
\hline 533130565877510144 & $\begin{array}{r}14 / 11 / 2014 \\
03: 33\end{array}$ & $\begin{array}{l}\text { Acidente envolvendo dois carros ocupa uma faixa na pista central } \\
\text { da Av. Brasil, sentido Centro, na altura de Guadalupe. Não há } \\
\text { retenções. }\end{array}$ \\
\hline 533074792963133441 & $\begin{array}{r}13 / 11 / 2014 \\
23: 51\end{array}$ & $\begin{array}{l}\text { Acidente ocupa uma faixa da Av. Brás de Pina, na altura da Praça } \\
\text { Rubey Wanderley, sentido Penha. Trânsito sem retença. } \\
\text { \#zonanorte }\end{array}$ \\
\hline 533035449217220609 & $\begin{array}{r}13 / 11 / 2014 \\
21: 15\end{array}$ & $\begin{array}{l}\text { Acidente deixa um ferido e complica o trânsito em Vila Isabel. } \\
\text { Saiba: http://t.co/OxJ8Sa6JPB. }\end{array}$ \\
\hline 533032324456517632 & $\begin{array}{r}13 / 11 / 2014 \\
21: 03\end{array}$ & $\begin{array}{l}\text { Ônibus enguiçado provoca retenções na Via Binário, na altura da } \\
\text { Rua Equador, em Santo Cristo. \#centro }\end{array}$ \\
\hline 533006414860804096 & $\begin{array}{r}13 / 11 / 2014 \\
19: 20\end{array}$ & $\begin{array}{l}\text { Acidente entre um carro e duas motos provoca retenções na Linha } \\
\text { Vermelha, sentido Centro, na altura da Cidade Universitária } \\
\text { \#viasexpressas }\end{array}$ \\
\hline 533002203938971648 & $\begin{array}{r}13 / 11 / 2014 \\
19: 03\end{array}$ & $\begin{array}{l}\text { \#AvBrasil Acidente com van ocupa três faixas da pista central, } \\
\text { altura de Cordovil, sentido \#ZonaOeste. \#LinhaVermelha é a } \\
\text { melhor opção. }\end{array}$ \\
\hline 532978735059062784 & $\begin{array}{r}13 / 11 / 2014 \\
17: 30\end{array}$ & $\begin{array}{l}\text { \#Centrorj Acidente com moto ocupa uma faixa da Avenida } \\
\text { Francisco Bicalho, altura da Rodoviária, sentido Avenida } \\
\text { Rodrigues Alves. }\end{array}$ \\
\hline 532975913903067136 & $\begin{array}{r}13 / 11 / 2014 \\
17: 18\end{array}$ & $\begin{array}{l}\text { Acidente envolvendo ônibus ocupa faixa da Av. Vieira Souto, no } \\
\text { acesso para a Av. Henrique Dumont. \#zonasul }\end{array}$ \\
\hline 532970662387011585 & $\begin{array}{r}13 / 11 / 2014 \\
16: 58\end{array}$ & $\begin{array}{l}\text { Ônibus enguiçado ocupa faixa da pista central da Av. Pres. } \\
\text { Vargas, altura da Uruguaiana, sentido Z. Norte. \#centro }\end{array}$ \\
\hline 532964072732753920 & $\begin{array}{r}13 / 11 / 2014 \\
16: 31\end{array}$ & $\begin{array}{l}\text { \#ZonaOeste Colisão entre caminhão e carro ocupa faixa da Av. } \\
\text { Embaixador Abelardo Bueno, sentido Recreio, altura da Av. }\end{array}$ \\
\hline
\end{tabular}




\begin{tabular}{|c|c|c|}
\hline id & tempo & texto \\
\hline & & Salvador Allende. \\
\hline 532939021241307136 & $\begin{array}{r}13 / 11 / 2014 \\
14: 52\end{array}$ & $\begin{array}{l}\text { Ônibus enguiçado ocupa } 1 \text { faixa da Est. Grajaú-Jpa, sentido } \\
\text { Grajaú, altura do } \mathrm{km} 4 \text {. Trânsito intenso. \#viasexpressas }\end{array}$ \\
\hline 532935421366648832 & $\begin{array}{r}13 / 11 / 2014 \\
14: 38\end{array}$ & $\begin{array}{l}\text { Ônibus enguiçado ocupa } 1 \text { faixa da R. Cândido Benício, sentido } \\
\text { Tanque, altura da R. Capitão Menezes. \#zonaoeste }\end{array}$ \\
\hline 532923518439403520 & $\begin{array}{r}13 / 11 / 2014 \\
13: 50\end{array}$ & $\begin{array}{l}\text { Colisão entre caminhão e carro ocupa faixa da Estrada dos } \\
\text { Bandeirantes, altura da R. André Rocha, sentido Av. Nelson } \\
\text { Cardoso. \#zonaoeste }\end{array}$ \\
\hline 532915743835582464 & $\begin{array}{r}13 / 11 / 2014 \\
13: 19\end{array}$ & $\begin{array}{l}\text { Colisão entre } 2 \text { motos e carro ocupa } 1 \text { faixa da Est. Lagoa-Barra, } \\
\text { sentido Lagoa, altura do Fashion Mall. Há retenções. } \\
\text { \#viasexpressas }\end{array}$ \\
\hline 532915541116452864 & $\begin{array}{r}13 / 11 / 2014 \\
13: 19\end{array}$ & $\begin{array}{l}\text { Ônibus enguiçado ocupa } 1 \text { faixa da R. Carolina Machado, sentido } \\
\text { Cascadura, altura da R. José de Queiroz. \#zonanorte }\end{array}$ \\
\hline 532906241417547776 & $\begin{array}{r}13 / 11 / 2014 \\
12: 42\end{array}$ & $\begin{array}{l}\text { Colisão entre moto e carro interdita uma faixa da Est. dos } \\
\text { Bandeirantes, sentido Barra, altura da Est. Mal. Miguel Salazar } \\
\text { Mendes de Moraes. }\end{array}$ \\
\hline 532905878731886592 & $\begin{array}{r}13 / 11 / 2014 \\
12: 40\end{array}$ & $\begin{array}{l}\text { Ônibus enguiçado ocupa } 1 \text { faixa da Av. Geremário Dantas, altura } \\
\text { da R. Cel. Francisco Lobo. Há retenção. }\end{array}$ \\
\hline 532897459664846848 & $\begin{array}{r}13 / 11 / 2014 \\
12: 07\end{array}$ & $\begin{array}{l}\text { Carro enguiçado ocupa } 1 \text { faixa da Av. Francisco Bicalho, sentido } \\
\text { Centro, altura do prédio do IML. Retenção no local. \#centro }\end{array}$ \\
\hline 532896481381208064 & $\begin{array}{r}13 / 11 / 2014 \\
12: 03\end{array}$ & $\begin{array}{l}\text { Colisão entre moto e carro interdita uma faixa do Elevado } 31 \text { de } \\
\text { Março, sentido Laranjeiras, altura do Catumbi. Há retenções. }\end{array}$ \\
\hline 532854320862343168 & $\begin{array}{r}13 / 11 / 2014 \\
09: 15\end{array}$ & $\begin{array}{l}\text { Ônibus enguiçado ocupa faixa da R. Barata Ribeiro, altura da R. } \\
\text { Barão de Ipanema. \#zonasul }\end{array}$ \\
\hline 532845074376564737 & $\begin{array}{r}13 / 11 / 2014 \\
08: 39\end{array}$ & $\begin{array}{l}\text { Carro enguiçado ocupa } 1 \text { faixa do Gasômetro, sentido Centro, } \\
\text { altura do INTO. Há retenções. \#viasexpressas }\end{array}$ \\
\hline 532837109712060416 & $\begin{array}{r}13 / 11 / 2014 \\
08: 07\end{array}$ & $\begin{array}{l}\text { Caminhão enguiçado ocupa faixa da Av. Visconde de } \\
\text { Albuquerque, altura da R. Mário Ribeiro, sentido Av. Niemeyer. } \\
\text { \#zonasul }\end{array}$ \\
\hline 532830357826322433 & $\begin{array}{r}13 / 11 / 2014 \\
07: 40\end{array}$ & $\begin{array}{l}\text { Colisão entre carro e ônibus causa retenção na Est. dos } \\
\text { Bandeirantes, altura da GSK, sentido Taquara. Foto: @ cratiu } \\
\text { http://t.co/VVeQUadNvI }\end{array}$ \\
\hline 532812988466888704 & $\begin{array}{r}13 / 11 / 2014 \\
06: 31\end{array}$ & $\begin{array}{l}\text { Colisão entre ônibus e taxi ocupa uma faixa da Rua Teodoro da } \\
\text { Silva, próx Rua Silva Pinto, em Vila Isabel. Há retenções. } \\
\text { \#zonanorte }\end{array}$ \\
\hline 532804819531354112 & $\begin{array}{r}13 / 11 / 2014 \\
05: 59\end{array}$ & $\begin{array}{l}\text { Carro enguiçado causa retenções na } 1^{\mathrm{a}} \text { galeria do Túnel } \\
\text { Rebouças, sentido Rio Comprido. Há retenções. CET-Rio no } \\
\text { local. \#viasexpressas }\end{array}$ \\
\hline
\end{tabular}




\begin{tabular}{|c|c|c|}
\hline id & tempo & texto \\
\hline 532783900503072768 & $\begin{array}{r}13 / 11 / 2014 \\
04: 35\end{array}$ & $\begin{array}{l}\text { Acidente com um carro ocupa uma faixa da Linha Vermelha, } \\
\text { sentido \#centro, altura da Maré. CET-Rio no local. \#viasexpressas }\end{array}$ \\
\hline 532701087799992320 & $\begin{array}{r}12 / 11 / 2014 \\
23: 06\end{array}$ & $\begin{array}{l}\text { @LeiSecaRJ Acidente na saída da segunda galeria do tunel } \\
\text { Rebouças, sentido Centro. }\end{array}$ \\
\hline 532684448601346048 & $\begin{array}{r}12 / 11 / 2014 \\
22: 00\end{array}$ & $\begin{array}{l}\text { Acidente com caminhão ocupa } 3 \text { faixas da Av Brasil, sentido } \\
\text { Centro, altura de Parada de Lucas. CET-Rio no local. } \\
\text { http://t.co/N25GOzPZfz }\end{array}$ \\
\hline 532684040735043584 & $\begin{array}{r}12 / 11 / 2014 \\
21: 59\end{array}$ & $\begin{array}{l}\text { Acidente com caminhão ocupa } 3 \text { faixas da Av Brasil, sentido } \\
\text { Centro, altura de Parada de Lucas. CET-Rio no local. } \\
\text { \#viasexpressas }\end{array}$ \\
\hline 532622096346931200 & $\begin{array}{r}12 / 11 / 2014 \\
17: 52\end{array}$ & $\begin{array}{l}\text { \#AvBrasil Acidente entre quatro carros ocupa uma faixa e deixa } \\
\text { retenção na pista central, altura de Manguinhos, sentido } \\
\text { \#ZonaOeste. }\end{array}$ \\
\hline 532619963308462080 & $\begin{array}{r}12 / 11 / 2014 \\
17: 44\end{array}$ & $\begin{array}{l}\text { Acidente com moto na } 2^{\mathrm{a}} \text { galeria do Túnel Rebouças, sentido } \\
\text { Lagoa. Trânsito lento. \#viasexpressas }\end{array}$ \\
\hline 532618859388633088 & $\begin{array}{r}12 / 11 / 2014 \\
17: 40\end{array}$ & $\begin{array}{l}\text { \#ZonaOeste Colisão entre dois carros ocupa uma faixa na Estrada } \\
\text { dos Três Rios, altura da Estrada do Guanumbi. Trânsito lento. }\end{array}$ \\
\hline 532589283757268992 & $\begin{array}{r}12 / 11 / 2014 \\
15: 42\end{array}$ & $\begin{array}{l}\text { Ônibus enguiçado ocupa } 1 \text { faixa da Av. Ten. Cel. Muniz de } \\
\text { Aragão, sentido Freguesia, altura da R. Mal. Terra Ururahy. } \\
\text { Trânsito intenso. }\end{array}$ \\
\hline 532581248359600129 & $\begin{array}{r}12 / 11 / 2014 \\
15: 10\end{array}$ & $\begin{array}{l}\text { Colisão entre ônibus e } 4 \text { carros ocupa } 2 \text { faixas da pista central da } \\
\text { Av. Brasil, sent Centro, altura Ramos. Retenções } \\
\text { http://t.co/6xBZSKKpnN }\end{array}$ \\
\hline 532574057917853696 & $\begin{array}{r}12 / 11 / 2014 \\
14: 42\end{array}$ & $\begin{array}{l}\text { \#ZonaOeste Acidente com caminhão ocupa uma faixa da Estrada } \\
\text { dos Bandeirantes, altura da Rua Benvindo de Novaes, sentido } \\
\text { Taquara. }\end{array}$ \\
\hline 532568738441478144 & $\begin{array}{r}12 / 11 / 2014 \\
14: 20\end{array}$ & $\begin{array}{l}\text { Túnel Zuzu Angel, sentido Barra, tem uma faixa interditada } \\
\text { devido a um caminhão enguiçado. Há retenção. \#viasexpressas }\end{array}$ \\
\hline 532533649343004673 & $\begin{array}{r}12 / 11 / 2014 \\
12: 01\end{array}$ & $\begin{array}{l}\text { Colisão entre moto e carro ocupa } 1 \text { faixa da Av. Visconde de } \\
\text { Albuquerque, sentido Praça Sibélius, altura da R. Prof. Azevedo } \\
\text { Marques. }\end{array}$ \\
\hline 532532324421087232 & $\begin{array}{r}12 / 11 / 2014 \\
11: 56\end{array}$ & $\begin{array}{l}\text { Colisão entre ônibus e táxi ocupa } 1 \text { faixa da Av. Nelson Cardoso, } \\
\text { sentido Taquara, altura da R. Farmacêutico Silva Araújo. Há } \\
\text { retenção. }\end{array}$ \\
\hline 532523687770357760 & $\begin{array}{r}12 / 11 / 2014 \\
11: 21\end{array}$ & $\begin{array}{l}\text { Colisão entre dois carros interdita faixa da \#LinhaVermelha, } \\
\text { sentido \#Centrorj, altura de Cordovil. Há retenções. }\end{array}$ \\
\hline 532520954166272000 & $\begin{array}{r}12 / 11 / 2014 \\
11: 11\end{array}$ & $\begin{array}{l}\text { Caminhão enguiçado ocupa } 1 \text { faixa do Viaduto dos Pracinhas, } \\
\text { sentido Av. Pres. Vargas, logo após a saída da Av. Francisco } \\
\text { Bicalho. Há lentidão }\end{array}$ \\
\hline
\end{tabular}




\begin{tabular}{|c|c|c|}
\hline id & tempo & texto \\
\hline 532518375529144322 & $\begin{array}{r}12 / 11 / 2014 \\
11: 00\end{array}$ & $\begin{array}{l}\text { Caminhão enguiçado ocupa } 1 \text { faixa da Av. Venceslau Brás, altura } \\
\text { da UFRJ. Há retenções. \#zonasul }\end{array}$ \\
\hline 532513089460379648 & $\begin{array}{r}12 / 11 / 2014 \\
10: 39\end{array}$ & $\begin{array}{l}\text { Ônibus enguiçado ocupa } 1 \text { faixa da R. São Clemente, altura do }{ }^{\circ} \\
\text { 144, em Botafogo. Há retenção no local. \#zonasul }\end{array}$ \\
\hline 532508833512685568 & $\begin{array}{r}12 / 11 / 2014 \\
10: 22\end{array}$ & $\begin{array}{l}\text { Ônibus enguiçado ocupa } 1 \text { faixa da pista lateral da Av. Pres. } \\
\text { Vargas, sentido Candelária, altura da Central. Há retenção. } \\
\text { \#centro }\end{array}$ \\
\hline 532504292243288064 & $\begin{array}{r}12 / 11 / 2014 \\
10: 04\end{array}$ & $\begin{array}{l}\text { Caminhão enguiçado ocupa } 1 \text { faixa da Est. dos Bandeirantes, } \\
\text { altura da Est. do Guerenguê, sentido Barra. Trânsito intenso. } \\
\text { \#zonaoeste }\end{array}$ \\
\hline 532504046809403392 & $\begin{array}{r}12 / 11 / 2014 \\
10: 03\end{array}$ & $\begin{array}{l}\text { \#ZonaOeste Colisão entre ônibus e carro interdita uma faixa da } \\
\text { Est. do Guerenguê, sentido Taquara, altura da R. Cônego Felipe. } \\
\text { Há retenção. }\end{array}$ \\
\hline 532499923191988224 & $\begin{array}{r}12 / 11 / 2014 \\
09: 47\end{array}$ & $\begin{array}{l}\text { Colisão entre } 2 \text { carros ocupa } 1 \text { faixa da Av. das Américas, sentido } \\
\text { São Conrado, altura do shopping Village Mall. Há retenções. } \\
\text { \#zonaoeste }\end{array}$ \\
\hline 532488480665128960 & $\begin{array}{r}12 / 11 / 2014 \\
09: 02\end{array}$ & $\begin{array}{l}\text { Colisão entre moto e carro ocupa } 1 \text { faixa da pista central da Av. } \\
\text { Brasil, sentido Centro, altura de Manguinhos. Há retenção. } \\
\text { \#viasexpressas }\end{array}$ \\
\hline 532475088688648192 & $\begin{array}{r}12 / 11 / 2014 \\
08: 08\end{array}$ & $\begin{array}{l}\text { \#ZonaNorte Colisão entre carro e moto na Avenida Marechal } \\
\text { Rondon, na altura da Rua Frei Pinto. Uma faixa interditada. } \\
\text { Retenção no local. }\end{array}$ \\
\hline 532451618005217281 & $\begin{array}{r}12 / 11 / 2014 \\
06: 35\end{array}$ & $\begin{array}{l}\text { Caminhão enguiçado ocupa uma faixa e provoca retenções na } \\
\text { Rua Pinheiro Machado, na altura do Palácio Guanabara, sentido } \\
\text { Botafogo \#zonasul }\end{array}$ \\
\hline 532335548510113792 & $\begin{array}{r}11 / 11 / 2014 \\
22: 54\end{array}$ & $\begin{array}{l}\text { Acidente envolvendo uma moto e um carro ocupa uma faixa e } \\
\text { provoca retenções na Ponte Joatinga, sentido Recreio. } \\
\text { http://t.co/iEOx3OyJB0 }\end{array}$ \\
\hline 532300754783318016 & $\begin{array}{r}11 / 11 / 2014 \\
20: 36\end{array}$ & $\begin{array}{l}\text { Acidente envolvendo um ônibus e um carro provoca retenções na } \\
\text { Av.Pastor Martin Luther King,altura da Av. Meriti, sentido } \\
\text { Vicente de Carvalho }\end{array}$ \\
\hline 532299608509415425 & $\begin{array}{r}11 / 11 / 2014 \\
20: 31\end{array}$ & $\begin{array}{l}\text { Acidente com carro no sentido Centro da Linha Vermelha, altura } \\
\text { do Galeão, ocupa uma faixa. Trânsito intenso. \#viasexpressas }\end{array}$ \\
\hline 532290350770307072 & $\begin{array}{r}11 / 11 / 2014 \\
19: 54\end{array}$ & $\begin{array}{l}\text { Acidente com moto e táxi ocupa } 2 \text { faixas da pista lateral e } \\
\text { provoca retenções na Av.das Américas, alt Salvador Allende } \\
\text { http://t.co/UM2Ny461jo }\end{array}$ \\
\hline 532285755792838657 & $\begin{array}{r}11 / 11 / 2014 \\
19: 36\end{array}$ & $\begin{array}{l}\text { Veículo enguiçado ocupa uma faixa e provoca retenções na } \\
\text { Av.Ayrton Senna, na altura da ponte estaiada, sentido Linha } \\
\text { Amarela. \#zonaoeste }\end{array}$ \\
\hline
\end{tabular}




\begin{tabular}{|c|c|c|}
\hline id & tempo & texto \\
\hline 532246929829535744 & $\begin{array}{r}11 / 11 / 2014 \\
17: 02\end{array}$ & $\begin{array}{l}\text { Colisão entre carro e moto ocupa faixa da Av. Emb. Abelardo } \\
\text { Bueno, sentido Linha Amarela, altura do Shopping Metropolitano. } \\
\text { \#zonaoeste }\end{array}$ \\
\hline 532244679686123520 & $\begin{array}{r}11 / 11 / 2014 \\
16: 53\end{array}$ & $\begin{array}{l}\text { \#ZonaOeste Colisão entre ônibus e carro ocupa uma faixa da } \\
\text { Avenida Nelson Cardoso, altura da Rua Marechal Beviláqua, } \\
\text { sentido Praça Seca. }\end{array}$ \\
\hline 532228843919376384 & $\begin{array}{r}11 / 11 / 2014 \\
15: 50\end{array}$ & $\begin{array}{l}\text { Táxi enguiçado causa retenção no Viaduto dos Marinheiros, no } \\
\text { sentido Radial Oeste. Uma faixa está ocupada. \#centro }\end{array}$ \\
\hline 532227122891591680 & $\begin{array}{r}11 / 11 / 2014 \\
15: 43\end{array}$ & $\begin{array}{l}\text { Acidente com carro na pista central da Av. Presidente Vargas, } \\
\text { sentido Praça da Bandeira, próximo à Central do Brasil. \#centro }\end{array}$ \\
\hline 532226159606775808 & $\begin{array}{r}11 / 11 / 2014 \\
15: 39\end{array}$ & $\begin{array}{l}\text { Utilitário enguiçado ocupa } 1 \text { faixa da } 1^{\text {a }} \text { galeria do Rebouças, } \\
\text { sentido Praça da Bandeira. Há retenção. \#viasexpressas }\end{array}$ \\
\hline 532198729395470336 & $\begin{array}{r}11 / 11 / 2014 \\
13: 50\end{array}$ & $\begin{array}{l}\text { Colisão entre } 4 \text { carros ocupa faixa da pista central da Av. das } \\
\text { Américas, altura do Barra Shopping, sentido São Conrado. } \\
\text { \#zonaoeste }\end{array}$ \\
\hline 532176760524529664 & $\begin{array}{r}11 / 11 / 2014 \\
12: 23\end{array}$ & $\begin{array}{l}\text { Est dos Bandeirantes, na Taquara, com } 1 \text { faixa ocupada por causa } \\
\text { de caminhão enguiçado, sentido Barra, altura da empresa Roche. } \\
\text { \#zonaoeste }\end{array}$ \\
\hline 532155694645272576 & $\begin{array}{r}11 / 11 / 2014 \\
10: 59\end{array}$ & $\begin{array}{l}\text { Carro enguiçado no Túnel Santa Bárbara, sentido Laranjeiras, } \\
\text { causa retenção. \#viasexpressas }\end{array}$ \\
\hline 532150368227311616 & $\begin{array}{r}11 / 11 / 2014 \\
10: 38\end{array}$ & $\begin{array}{l}\text { Colisão entre } 2 \text { carros ocupa } 1 \text { faixa da pista central da Av. } \\
\text { Brasil, sentido Centro, altura de Cordovil. Há retenções. } \\
\text { \#viasexpressas }\end{array}$ \\
\hline 532141044767653888 & $\begin{array}{r}11 / 11 / 2014 \\
10: 01\end{array}$ & $\begin{array}{l}\text { Acidente com ônibus interdita R. Sacadura Cabral entre R. Pedro } \\
\text { Ernesto e R. do Livramento. Desvio do tráfego de veículos é feito } \\
\text { p/ R. (+) }\end{array}$ \\
\hline 532134021011357696 & $\begin{array}{r}11 / 11 / 2014 \\
09: 33\end{array}$ & $\begin{array}{l}\text { Colisão entre } 3 \text { carros ocupa } 1 \text { faixa da Av. Lúcio Costa, altura do } \\
\text { Barril } 8000 \text {, sentido São Conrado. Há retenções. }\end{array}$ \\
\hline 532129262938357761 & $\begin{array}{r}11 / 11 / 2014 \\
09: 14\end{array}$ & $\begin{array}{l}\text { Colisão entre caminhão e carro ocupa faixa da pista lateral da Av. } \\
\text { Brasil, sentido Centro, altura de Benfica. \#viasexpressas }\end{array}$ \\
\hline 532124485408002048 & $\begin{array}{r}11 / 11 / 2014 \\
08: 55\end{array}$ & $\begin{array}{l}\text { Táxi enguiçado ocupa uma faixa da Linha Vermelha, altura da } \\
\text { Maré, sentido Centro. Trânsito intenso. \#viasexpressas }\end{array}$ \\
\hline 532121093595987968 & $\begin{array}{r}11 / 11 / 2014 \\
08: 42\end{array}$ & $\begin{array}{l}\text { Colisão entre carro e moto na Av. Presidente Antônio Carlos, } \\
\text { altura da Av. Beira Mar, sentido Candelária. Retenções no local. } \\
\text { \#centro }\end{array}$ \\
\hline 532114242414313473 & $\begin{array}{r}11 / 11 / 2014 \\
08: 14\end{array}$ & $\begin{array}{l}\text { \#ZonaNorte: ônibus enguiçado ocupa } 1 \text { faixa da Av. Dom Hélder } \\
\text { Câmara, sentido Centro, altura da R. da Pedreira. Há retenções. }\end{array}$ \\
\hline 532108504933597184 & $11 / 11 / 2014$ & $\begin{array}{l}\text { Carro enguiçado ocupa } 1 \text { faixa da pista lateral da Av. Ayrton } \\
\text { Senna, sentido orla, altura do supermercado Makro. Trânsito }\end{array}$ \\
\hline
\end{tabular}




\begin{tabular}{|c|c|c|}
\hline id & tempo & texto \\
\hline & $07: 52$ & lento. \#zonaoeste \\
\hline 532107094686986244 & $\begin{array}{r}11 / 11 / 2014 \\
07: 46\end{array}$ & $\begin{array}{l}\text { Carro enguiçado ocupa faixa da Av. Ayrton Senna, altura do } \\
\text { Hospital Lourenço Jorge, sentido praia. \#zonaoeste }\end{array}$ \\
\hline 532050273595056128 & $\begin{array}{r}11 / 11 / 2014 \\
04: 00\end{array}$ & $\begin{array}{l}\text { Poste é destruído em acidente entre caminhão e carro na Taquara. } \\
\text { Saiba: http://t.co/0FrsF2od0e. }\end{array}$ \\
\hline 531925319432019968 & $\begin{array}{r}10 / 11 / 2014 \\
19: 44\end{array}$ & $\begin{array}{l}\text { Colisão entre carro e moto ocupa uma faixa da Av } 31 \text { de Março, } \\
\text { sentido Santo Cristo, altura da Av Pres Vargas. Reflexos no Santa } \\
\text { Bárbara. }\end{array}$ \\
\hline 531889385768484864 & $\begin{array}{r}10 / 11 / 2014 \\
17: 21\end{array}$ & $\begin{array}{l}\text { Acidente com carro ocupa uma faixa da Av. Nossa Senhora de } \\
\text { Copacabana, altura da Rua Joaquim Nabuco. Bombeiros no local. } \\
\text { \#zonasul }\end{array}$ \\
\hline 531838401159647233 & $\begin{array}{r}10 / 11 / 2014 \\
13: 58\end{array}$ & $\begin{array}{l}\text { Colisão entre utilitário e } 2 \text { carros ocupa } 1 \text { faixa da pista lateral da } \\
\text { Av. Brasil, sentido Zona Oeste, altura da Penha. Há retenções. }\end{array}$ \\
\hline 531830661167185920 & $\begin{array}{r}10 / 11 / 2014 \\
13: 28\end{array}$ & $\begin{array}{l}\text { Acidente ente táxi e moto na Rua Evaristo da Veiga, no \#centro, } \\
\text { altura da Rua Senador Dantas. Trânsito lento. }\end{array}$ \\
\hline 531822064513331200 & $\begin{array}{r}10 / 11 / 2014 \\
12: 53\end{array}$ & $\begin{array}{l}\text { Acidente com três carros causa retenção na segunda galeria do } \\
\text { Túnel Rebouças, no sentido Lagoa. }\end{array}$ \\
\hline 531817336266035200 & $\begin{array}{r}10 / 11 / 2014 \\
12: 35\end{array}$ & $\begin{array}{l}\text { Carro enguiçado na } 1^{\mathrm{a}} \text { galeria do Túnel Rebouças, sentido Lagoa. } \\
\text { O trânsito é lento e uma faixa está ocupada. \#viasexpressas }\end{array}$ \\
\hline 531793970670891008 & $\begin{array}{r}10 / 11 / 2014 \\
11: 02\end{array}$ & $\begin{array}{l}\text { Colisão entre moto e caminhão ocupa } 1 \text { faixa da pista central da } \\
\text { Av. Brasil, sentido Centro, altura da Penha. Há retenção. }\end{array}$ \\
\hline 531793391072575488 & $\begin{array}{r}10 / 11 / 2014 \\
10: 59\end{array}$ & $\begin{array}{l}\text { Caminhão enguiçado ocupa } 1 \text { faixa da R. Conselheiro Galvão, } \\
\text { sentido Campinho, altura do Mercadão de Madureira. Há } \\
\text { retenções. \#zonanorte }\end{array}$ \\
\hline 531791537869697024 & $\begin{array}{r}10 / 11 / 2014 \\
10: 52\end{array}$ & $\begin{array}{l}\text { Ônibus enguiçado ocupa } 1 \text { faixa da pista lateral da Av. Pres. } \\
\text { Vargas, sentido Candelária, altura da Av. Rio Branco. Há } \\
\text { retenções. \#centro }\end{array}$ \\
\hline 531784739913756672 & $\begin{array}{r}10 / 11 / 2014 \\
10: 25\end{array}$ & $\begin{array}{l}\text { Colisão entre } 2 \text { carros ocupa } 1 \text { faixa da Av. Nelson Cardos, altura } \\
\text { da R. Imbuí, sentido Taquara. Trânsito intenso. \#zonaoeste }\end{array}$ \\
\hline 531767748305903616 & $\begin{array}{r}10 / 11 / 2014 \\
09: 18\end{array}$ & $\begin{array}{l}\text { Colisão entre } 2 \text { motos ocupa } 1 \text { faixa da pista central da Av. Pres. } \\
\text { Vargas, sentido Candelária, altura dos Correios. Há retenções. } \\
\text { \#centro }\end{array}$ \\
\hline 531763569151737856 & $\begin{array}{r}10 / 11 / 2014 \\
09: 01\end{array}$ & $\begin{array}{l}\text { Caminhão enguiçado ocupa } 1 \text { faixa do Viaduto dos Pracinhas, } \\
\text { sentido Av. Pres. Vargas. Há retenções. \#centro }\end{array}$ \\
\hline 531759354023002112 & $\begin{array}{r}10 / 11 / 2014 \\
08: 44\end{array}$ & $\begin{array}{l}\text { Ônibus enguiçado na pista central da Av. Presidente Vargas, } \\
\text { altura dos Correios, sentido Candelária. Trânsito lento. \#centro }\end{array}$ \\
\hline 531746668371529728 & $10 / 11 / 2014$ & $\begin{array}{l}\text { \#AvBrasil Acidente com dois carros e um utilitário causa } \\
\text { retenção na pista central, no Caju, sentido \#Centrorj. Uma faixa }\end{array}$ \\
\hline
\end{tabular}




\begin{tabular}{|c|c|c|}
\hline id & tempo & texto \\
\hline & $07: 54$ & interditada. \\
\hline 531740913836371968 & $\begin{array}{r}10 / 11 / 2014 \\
07: 31\end{array}$ & $\begin{array}{l}\text { Acidente com dois ônibus interdita duas faixas da R. Cordeiro da } \\
\text { Graça, altura da Av. Cidade de Lima, no Santo Cristo. Retenção } \\
\text { no local. }\end{array}$ \\
\hline 531729700415340544 & $\begin{array}{r}10 / 11 / 2014 \\
06: 46\end{array}$ & $\begin{array}{l}\text { Ônibus enguiçado provoca retenção na R.Conselheiro Galvão,em } \\
\text { Madureira, altura da Av.Edgar Romero até a R.Domingos } \\
\text { Fernandes, sent. Campinho }\end{array}$ \\
\hline 531591375960408064 & $\begin{array}{r}09 / 11 / 2014 \\
21: 37\end{array}$ & $\begin{array}{l}\text { Acidente provoca retenção na } \text { Estrada Grajaú-Jacarepaguá, } \\
\text { sentido Grajaú, na altura do Hospital Cardoso Fontes } \\
\text { \#viasexpressas }\end{array}$ \\
\hline 531587339404206080 & $\begin{array}{r}09 / 11 / 2014 \\
21: 21\end{array}$ & $\begin{array}{l}\text { Acidente provoca retenção na Av. Brasil, sentido Centro, na } \\
\text { altura do INTO. \#viasexpressas }\end{array}$ \\
\hline 531573409327874048 & $\begin{array}{r}09 / 11 / 2014 \\
20: 25\end{array}$ & $\begin{array}{l}\text { Acidente ocupa uma faixa e provoca retenção na Av.Paulo de } \\
\text { Frontin, na altura da Rua Barão de Itapagipe, sentido \#centro. } \\
\text { Equipes no local. }\end{array}$ \\
\hline 531527365797892098 & $\begin{array}{r}09 / 11 / 2014 \\
17: 22\end{array}$ & $\begin{array}{l}\text { Colisão envolvendo } 1 \text { carro ocupa faixa do Viaduto do } \\
\text { Gasômetro, sentido Centro, altura do acesso para a Via Binário } \\
\text { \#centro }\end{array}$ \\
\hline 531457100736917504 & $\begin{array}{r}09 / 11 / 2014 \\
12: 43\end{array}$ & $\begin{array}{l}\text { Colisão entre carro e van ocupa faixa da Est. Grajaú-Jacarepaguá, } \\
\text { altura do Lins, sentido Grajaú. \#viasexpressas }\end{array}$ \\
\hline 531426156986503168 & $\begin{array}{r}09 / 11 / 2014 \\
10: 40\end{array}$ & $\begin{array}{l}\text { Acidente envolvendo carro ocupa faixa da Av. Epitácio Pessoa, } \\
\text { sentido Corte, altura da R. Aníbal de Mendonça. \#zonasul }\end{array}$ \\
\hline 531379097621262336 & $\begin{array}{r}09 / 11 / 2014 \\
07: 33\end{array}$ & $\begin{array}{l}\text { Acidente envolvendo um carro ocupa faixa da pista lateral da Av. } \\
\text { das Américas, altura da R. Luis Aranha, sentido Barra. \#zonaoeste }\end{array}$ \\
\hline 531365900994101248 & $\begin{array}{r}09 / 11 / 2014 \\
06: 41\end{array}$ & $\begin{array}{l}\text { Acidente com moto ocupa uma faixa da pista central da Av } \\
\text { Brasil, em Parada de Lucas, sentido \#zonaoeste. CET-Rio no } \\
\text { local. \#viasexpressas }\end{array}$ \\
\hline 531364343238369280 & $\begin{array}{r}09 / 11 / 2014 \\
06: 35\end{array}$ & $\begin{array}{l}\text { Colisão entre dois carros ocupa uma faixa da Av das Américas, } \\
\text { sentido Santa Cruz, próximo Mundial. CET-Rio no local. } \\
\text { \#zonaoeste }\end{array}$ \\
\hline 531341839149039616 & $\begin{array}{r}09 / 11 / 2014 \\
05: 05\end{array}$ & $\begin{array}{l}\text { Colisão entre carro e taxi ocupa uma faixa da Rua Lopo Saraiva, } \\
\text { altura do } \mathrm{n}^{\circ} 33 \text {, sentido Taquara. CET-Rio no local. \#zonaoeste }\end{array}$ \\
\hline 531341602363813890 & $\begin{array}{r}09 / 11 / 2014 \\
05: 04\end{array}$ & $\begin{array}{l}\text { Acidente com carro ocupa } 2 \text { faixas da Av Salvador Allende, } \\
\text { altura da Av Emb Abelardo Bueno, sentido Est Bandeirantes } \\
\text { http://t.co/CeJwFlUiNh }\end{array}$ \\
\hline 531274506338590720 & $\begin{array}{r}09 / 11 / 2014 \\
00: 38\end{array}$ & $\begin{array}{l}\text { Colisão entre carro e taxi ocupa uma faixa da pista central da Av } \\
\text { Brasil, sentido Centro, em Manguinhos. Equipes no local. } \\
\text { \#viasexpressas }\end{array}$ \\
\hline
\end{tabular}




\begin{tabular}{|c|c|c|}
\hline id & tempo & texto \\
\hline 531257024940875776 & $\begin{array}{r}08 / 11 / 2014 \\
23: 28\end{array}$ & $\begin{array}{l}\text { Acidente com um carro ocupa } 2 \text { faixas da pista central da Av } \\
\text { Brasil, sentido Centro, no Caju. Há retenções. CET-Rio no local. } \\
\text { \#viasexpressas }\end{array}$ \\
\hline 531254872902205440 & $\begin{array}{r}08 / 11 / 2014 \\
23: 20\end{array}$ & $\begin{array}{l}\text { Colisão entre dois carros ocupa uma faixa da Av Francisco } \\
\text { Bicalho, sentido Cidade Nova, altura da Leopoldina. Equipes no } \\
\text { local. \#centro }\end{array}$ \\
\hline 531217029928615936 & $\begin{array}{r}08 / 11 / 2014 \\
20: 49\end{array}$ & $\begin{array}{l}\text { Acidente com moto ocupa uma faixa do Túnel Santa Bárbara, } \\
\text { sentido Catumbi. Há retenções. CET-Rio no local. \#viasexpressas }\end{array}$ \\
\hline 531163456469467136 & $\begin{array}{r}08 / 11 / 2014 \\
17: 16\end{array}$ & $\begin{array}{l}\text { Ônibus enguiçado ocupa faixa da R. Teodoro da Silva, altura da } \\
\text { R. Visconde de Abaeté. Retenção. \#zonanorte }\end{array}$ \\
\hline 531094885802450944 & $\begin{array}{r}08 / 11 / 2014 \\
12: 44\end{array}$ & $\begin{array}{l}\text { Carro enguiçado ocupa faixa da } 2 \text { a galeria do Rebouças, sentido } \\
\text { Lagoa. \#viasexpressas }\end{array}$ \\
\hline 531048452365766656 & $\begin{array}{r}08 / 11 / 2014 \\
09: 39\end{array}$ & $\begin{array}{l}\text { Colisão entre moto e carro causa retenção na Av. Geremário } \\
\text { Dantas, sentido Freguesia, altura da Linha Amarela. \#zonaoeste }\end{array}$ \\
\hline 531027896371253249 & $\begin{array}{r}08 / 11 / 2014 \\
08: 18\end{array}$ & $\begin{array}{l}\text { Ônibus enguiçado ocupa faixa da pista lateral da Av. Pres. } \\
\text { Vargas, sentido Pça da Bandeira, altura do } 31 \text { de Março. \#centro }\end{array}$ \\
\hline 531027388172632065 & $\begin{array}{r}08 / 11 / 2014 \\
08: 16\end{array}$ & $\begin{array}{l}\text { Caminhão enguiçado ocupa faixa da Av. Francisco Bicalho, } \\
\text { sentido \#Centro, altura da Rodoviária. }\end{array}$ \\
\hline 531008871129948160 & $\begin{array}{r}08 / 11 / 2014 \\
07: 02\end{array}$ & $\begin{array}{l}\text { Acidente com moto ocupa duas faixas da R. VIsconde de Niterói, } \\
\text { altura da Mangueira, sentido Benfica. \#zonanorte }\end{array}$ \\
\hline 530903056444321792 & $\begin{array}{r}08 / 11 / 2014 \\
00: 02\end{array}$ & $\begin{array}{l}\text { Acidente envolvendo } 2 \text { ônibus e um carro ocupa uma faixa e } \\
\text { provoca retenções na Av. General San Martin, altura da } \\
\text { Bartolomeu Mitre. \#zonasul }\end{array}$ \\
\hline 530849402437779456 & $\begin{array}{r}07 / 11 / 2014 \\
20: 28\end{array}$ & $\begin{array}{l}\text { Caminhão enguiçado provoca retenções na Av.Nelson Cardoso, } \\
\text { na Taquara, sentido Madureira, na altura da Est. do Tindiba. } \\
\text { \#zonaoeste }\end{array}$ \\
\hline 530845078680797184 & $\begin{array}{r}07 / 11 / 2014 \\
20: 11\end{array}$ & $\begin{array}{l}\text { Colisão entre caminhão e carro ocupa uma faixa da Avenida } \\
\text { Ayrton Senna, sentido Linha Amarela, na altura Av. Luis Carlos } \\
\text { Prestes. Retenção. }\end{array}$ \\
\hline 530843694887632896 & $\begin{array}{r}07 / 11 / 2014 \\
20: 06\end{array}$ & $\begin{array}{l}\text { Acidente entre caminhão e carro ocupa uma faixa da pista central } \\
\text { da Avenida Brasil, em Ramos. Retenção no sentido Zona Oeste. } \\
\text { \#viasexpressas }\end{array}$ \\
\hline 530831433947172864 & $\begin{array}{r}07 / 11 / 2014 \\
19: 17\end{array}$ & $\begin{array}{l}\text { Colisão entre dois ônibus ocupa uma faixa da Av. Rio de Janeiro, } \\
\text { sentido Av. Brasil, altura do Caju. Retenção. }\end{array}$ \\
\hline 530822721094287361 & $\begin{array}{r}07 / 11 / 2014 \\
18: 42\end{array}$ & $\begin{array}{l}\text { \#ZonaSul Acidente entre carro e moto complica trânsito em } \\
\text { Ipanema. Confira: http://t.co/RgJYjBGkAV }\end{array}$ \\
\hline 530801264318496768 & $\begin{array}{r}07 / 11 / 2014 \\
17: 17\end{array}$ & $\begin{array}{l}\text { \#AvBrasil Colisão envolvendo dois caminhões e um carro } \\
\text { interdita uma faixa da pista central, altura de Irajá, sentido }\end{array}$ \\
\hline
\end{tabular}




\begin{tabular}{|c|c|c|}
\hline id & tempo & texto \\
\hline & & \#ZonaOeste. Retenção. \\
\hline 530801162308816896 & $\begin{array}{r}07 / 11 / 2014 \\
17: 17\end{array}$ & $\begin{array}{l}\text { Colisão envolvendo dois caminhões e carro na pista central da } \\
\text { Av. Brasil, no Caju, sentido \#ZonaOeste. Uma faixa ocupada. } \\
\text { Retenção. }\end{array}$ \\
\hline 530776929105088512 & $\begin{array}{r}07 / 11 / 2014 \\
15: 40\end{array}$ & $\begin{array}{l}\text { Caminhão enguiçado ocupa uma faixa da Estrada do Cafundá, } \\
\text { altura da R. Godofredo Viana, sentido Estr. do Catonho. } \\
\text { Retenção. }\end{array}$ \\
\hline 530760595818037250 & $\begin{array}{r}07 / 11 / 2014 \\
14: 36\end{array}$ & $\begin{array}{l}\text { Acidente com caminhão ocupa } 1 \text { faixa da Av. Visconde de } \\
\text { Albuquerque, sentido Gávea, altura da Av. Gal. San Martin: } \\
\text { http://t.co/125fQuUiF7 }\end{array}$ \\
\hline 530753018749530112 & $\begin{array}{r}07 / 11 / 2014 \\
14: 05\end{array}$ & $\begin{array}{l}\text { Acidente envolvendo um carro ocupa } 1 \text { faixa da Av. Afrânio de } \\
\text { Melo Franco, altura da R. Gilberto Cardoso, no Leblon. Trânsito } \\
\text { intenso. }\end{array}$ \\
\hline 530747386369703936 & $\begin{array}{r}07 / 11 / 2014 \\
13: 43\end{array}$ & $\begin{array}{l}\text { Colisão entre } 3 \text { carros ocupa } 1 \text { faixa da Linha Vermelha, sentido } \\
\text { Centro, altura do Parque das Missões. Há retenções. } \\
\text { \#ViasExpressas }\end{array}$ \\
\hline 530740288034471937 & $\begin{array}{r}07 / 11 / 2014 \\
13: 15\end{array}$ & $\begin{array}{l}\text { Ônibus enguiçado na pista lateral da Av. Presidente Vargas, } \\
\text { altura da Central do Brasil, sentido Candelária. Retenções. } \\
\text { \#centro }\end{array}$ \\
\hline 530736567691010049 & $\begin{array}{r}07 / 11 / 2014 \\
13: 00\end{array}$ & $\begin{array}{l}\text { Colisão entre carro e ônibus na Av. Rio Branco, sentido Praça } \\
\text { Mauá, altura da Av. Pres. Vargas. Uma faixa ocupada. Sem } \\
\text { retenção. \#centro }\end{array}$ \\
\hline 530726712863367168 & $\begin{array}{r}07 / 11 / 2014 \\
12: 21\end{array}$ & $\begin{array}{l}\text { Colisão entre dois carros na Rua São Francisco Xavier, altura da } \\
\text { Rua Conselheiro Olegário. Retenções. \#zonanorte }\end{array}$ \\
\hline 530719907219271680 & $\begin{array}{r}07 / 11 / 2014 \\
11: 54\end{array}$ & $\begin{array}{l}\text { Acidente com moto ocupa } 1 \text { faixa do Gasômetro, sentido Centro, } \\
\text { altura do INTO. Há retenção. \#viasexpressas }\end{array}$ \\
\hline 529392478739120128 & $\begin{array}{r}03 / 11 / 2014 \\
19: 59\end{array}$ & $\begin{array}{l}\text { Colisão entre dois carros causa retenção na Av. Ayrton Senna, } \\
\text { altura do Aeroporto de Jacarepaguá, sentido L.Amarela. } \\
\text { http://t.co/47lfrgKV3j }\end{array}$ \\
\hline 528073404583120896 & $\begin{array}{r}31 / 10 / 2014 \\
04: 38\end{array}$ & $\begin{array}{l}\text { Acidente com carreta ocupa uma faixa da Av Ayrton Senna, } \\
\text { sentido orla, altura do Lourenço Jorge. CET-Rio no local. } \\
\text { http://t.co/Ix9krPoUlg }\end{array}$ \\
\hline 527702688775933952 & $\begin{array}{r}30 / 10 / 2014 \\
04: 04\end{array}$ & $\begin{array}{l}\text { Lentidão sentido Centro na Av. Brasil por acidente com } \\
\text { caminhão, na Penha. Bombeiros na via. http://t.co/9Bbd } 4 \mathrm{ZmZDz}\end{array}$ \\
\hline 527233944421285888 & $\begin{array}{r}28 / 10 / 2014 \\
21: 02\end{array}$ & $\begin{array}{l}\text { Colisão entre carro e moto ocupa } 2 \text { faixas da LVermelha, na } \\
\text { Maré, sentido Baixada. CET-Rio, PM e Bombeiros no local. } \\
\text { http://t.co/EgQ4PDVV8a }\end{array}$ \\
\hline 527209851185672192 & $\begin{array}{r}28 / 10 / 2014 \\
19: 26\end{array}$ & $\begin{array}{l}\text { Colisão entre moto e ônibus interdita o acesso da Av Rio Branco } \\
\text { através do Aterro. Desvio pela Rua do Passeio. }\end{array}$ \\
\hline
\end{tabular}




\begin{tabular}{|c|c|c|}
\hline id & tempo & texto \\
\hline & & http://t.co/bMky5CNBxF \\
\hline 526704974336495616 & $\begin{array}{r}27 / 10 / 2014 \\
10: 00\end{array}$ & $\begin{array}{l}\text { Acidente com caminhão ocupa duas faixas da pista central da Av. } \\
\text { Brasil, em Ramos, sentido Zona Oeste. Retenção } \\
\text { http://t.co/VTLsDnT8EP }\end{array}$ \\
\hline 525734642490429441 & $\begin{array}{r}24 / 10 / 2014 \\
17: 44\end{array}$ & $\begin{array}{l}\text { Acidente c carro, na Av S Cruz, sent Bangu, perto da R Francisco } \\
\text { Real (Realengo). Interdição parcial. G. Municipal no local. } \\
\text { Queda de poste }\end{array}$ \\
\hline 525162339314565120 & $\begin{array}{r}23 / 10 / 2014 \\
03: 50\end{array}$ & $\begin{array}{l}\text { Acidente com carreta ocupa } 2 \text { faixas da Av Brasil, sent Centro, alt } \\
\text { da Linha Vermelha. Carga na via. Equipes no local. } \\
\text { http://t.co/DPzdMmoDA0 }\end{array}$ \\
\hline 524496120748048384 & $\begin{array}{r}21 / 10 / 2014 \\
07: 43\end{array}$ & $\begin{array}{l}\text { Acidente entre } 2 \text { motos ocupa uma faixa do Túnel Sta Bárbara, } \\
\text { sentido Laranjeiras. Retenção até o Vd } 31 \text { de Março. } \\
\text { http://t.co/MZkz0ly0Dr }\end{array}$ \\
\hline
\end{tabular}

\section{2 - Resultados de processamento de tweets localizados em vias expressas}

Segue uma amostra dos resultados obtidos pelos processamentos especificados no Capítulo 7 considerando tweets posicionados em vias expressas. A classificação hierárquica foi obtida a partir da base de dados da Prefeitura da Cidade do Rio de Janeiro.

\section{Tweets onde a posição não coincide com local indicado no texto.}

Id: 550055347361026048 (2014-12-30 20:26:29.0)

Texto: Acidente com 3 carros ocupa uma faixa da Linha Vermelha, sentido centro, altura da Maré. Lentidão no local. http://t.co/YXLGTPV3Vx

PMV: 13351653

Id: 541299974101684225 (2014-12-06 16:35:45.0)

Texto: Acidente entre moto e carro na Ponte da Joatinga, sentido Barra. Há reflexos na Autoestrada Lagoa-Barra: http://t.co/mMgaUD3OAC

PMV: 176217611512170415111703

\section{Tweet que apresentou erro no roteamento}


Id: 539752820920950784 (2014-12-02 10:07:55.0)

Texto: Colisão de dois carros ocupa faixa da segunda galeria do Túnel Rebouças, sentido Lagoa. Há lentidão. CET-Rio na via. http://t.co/w2levv9OT6

PMV: 164016591658156213821657138116391561156313861383

Tweets em que não houve PMV com rotas com extensão menor que $3 \mathrm{~km}$.

Id: 547205221525372928 (2014-12-22 23:41:06.0)

Texto: Colisão com carreta, utilitário e 2 carros ocupa 1 faixa da p. central da Av Brasil, sentido Zona Oeste, na Penha. http://t.co/mb6vhsVXml

Id: 538017268169314305 (2014-11-27 15:11:27.0)

Texto: Acidente com ônibus interdita parcialmente a pista central da Av. Brasil, sentido ZO, altura da Penha. Há retenções: http://t.co/Dw5L2V1Ii6

Id: $532523687770357760(2014-11-12$ 11:21:55.0)

Texto: Colisão entre dois carros interdita faixa da \#LinhaVermelha, sentido \#Centrorj, altura de Cordovil. Há retenções.

Id: 532299608509415425 (2014-11-11 20:31:30.0)

Texto: Acidente com carro no sentido Centro da Linha Vermelha, altura do Galeão, ocupa uma faixa. Trânsito intenso. \#viasexpressas

Tweets em que não houve amostras de velocidade suficientes para a avaliação.

Id: $549685330710761474(2014-12-29$ 19:56:10.0)

Texto: Acidente com 4 carros e um ônibus ocupa uma faixa e provoca lentidão na Av. Ayrton Senna, sentido Linha Amarela, altura da Vila do Pan

PMV: 14791513

Id: $549684704031408128(2014-12-29$ 19:53:40.0) 
Texto: Acidente com três carros ocupa uma faixa do Túnel do Joá, sentido Barra. Retenção no local. http://t.co/LntsD6V93X

PMV: 17641763176217611512170415111703

Id: 549123774285504513 (2014-12-28 06:44:44.0)

Texto: Colisão entre carro e moto ocupa uma faixa da Linha Amarela, na chegada à Av Ayrton Senna. Equipes atuam no local. http://t.co/QNnDi2QVbE

PMV: 129713301474132912981622

Id: $548975111408078848(2014-12-27$ 20:54:00.0)

Texto: Acidente com 3 carros ocupa uma faixa da Av Ayrton Senna, sentido Linha Amarela, altura da Vivo. CET-Rio no local. http://t.co/giKdSoyhUM

PMV: 1407147114721478

Id: $548974168998281216(2014-12-27$ 20:50:15.0)

Texto: Colisão entre ônibus, táxi e 2 carros ocupa uma faixa da p. lateral da Av Ayrton Senna, sentido orla. Há retenções. http://t.co/e87SVdF2wD

PMV: 147714801479

Id: $547678780307677184(2014-12-24$ 07:02:51.0)

Texto: Segue parcialmente interditada a Av. Armando Lombardi, sentido Recreio, devido a um acidente com ônibus, alt IBMEC http://t.co/TvGNV781HP

PMV: 151217041508170017681761176717661764176515111703

Id: $546421039240990720(2014-12-20$ 19:45:02.0)

Texto: Colisão entre carreta, utilitário e 2 carros causa retenções na p. central da Av Brasil, sentido Centro, em Lucas. http://t.co/3BAtnR18e8

PMV: 12621251

Id: 543369259259146241(2014-12-12 09:38:21.0) 
Texto: Colisão entre moto, carro e caminhão ocupa 1 faixa da Lagoa-Barra, sent Barra, altura acesso p/ Túnel do S. Conrado http://t.co/xBgLReDATq

PMV: 17051713178417121706164317891707

Id: 541726066113396736 (2014-12-07 20:48:53.0)

Texto: Acidente envolvendo moto ocupa uma faixa e provoca lentidão na primeira galeria do Túnel Rebouças, sentido Centro. http://t.co/YAMj6OvSCI

PMV: 1388

Id: 540069278100094977 (2014-12-03 07:05:24.0)

Texto: Colisão de carro e moto ocupa faixa da Autoestrada Lagoa-Barra e causa retenção sentido Lagoa. CET-Rio no local. http://t.co/gTmydvAtPn

PMV: 1706164217881711170517131712

Id: $539693247270883328(2014-12-02$ 06:11:11.0)

Texto: Acidente entre carro e moto ocupa uma faixa da Av. Ayrton Senna, altura do Barra Music, sentido Linha Amarela. http://t.co/HXld6DK9jf

PMV: 1297133013291298

Id: 539577202350628865 (2014-12-01 22:30:04.0)

Texto: Acidente entre dois carros ocupa uma faixa e provoca retenção na Av. das Américas, na altura do Freeway, sent. Barra http://t.co/11CyDgLXmW

PMV: 14711472

Id: $539534462615187457(2014-12-01$ 19:40:14.0)

Texto: Acidente envolvendo três carros ocupa uma faixa e provoca retenção no Túnel Rebouças, sentido Praça da Bandeira. http://t.co/m9H7k3oJ6R

PMV: 1388138913941405139313921638164113911390140416971399

Id: $539130867411476480(2014-11-30$ 16:56:30.0) 
Texto: Colisão entre carro e moto no Túnel Acústico, sentido Lagoa. Uma faixa ocupada. Retenção a partir da Rocinha. http://t.co/iZJ6J8m1x3

PMV: 1709

Id: 538977279821357057 (2014-11-30 06:46:11.0)

Texto: Acidente com carro ocupa faixa do Túnel Rebouças, sentido Praça da Bandeira. Trânsito sem retenção. CET-Rio no local. http://t.co/Jrxgf3lBGd

PMV: 1388

Id: $532581248359600129(2014-11-12$ 15:10:39.0)

Texto: Colisão entre ônibus e 4 carros ocupa 2 faixas da pista central da Av. Brasil, sent Centro, altura Ramos. Retenções http://t.co/6xBZSKKpnN

PMV: 1335

Id: $532581248359600129(2014-11-12$ 15:10:39.0)

Texto: Colisão entre ônibus e 4 carros ocupa 2 faixas da pista central da Av. Brasil, sent Centro, altura Ramos. Retenções http://t.co/6xBZSKKpnN

PMV: 1270126913351271

\section{Tweets em que não foram detectadas rotas para a avaliação da expansão}

Id: $549595773004832768(2014-12-29$ 14:00:17.0)

Texto: Acidente entre dois ônibus na Av. Ayrton Senna, altura do Casa Shopping, sentido orla. Retenções. http://t.co/Pq1zvohPjK

PMV: 14791513 


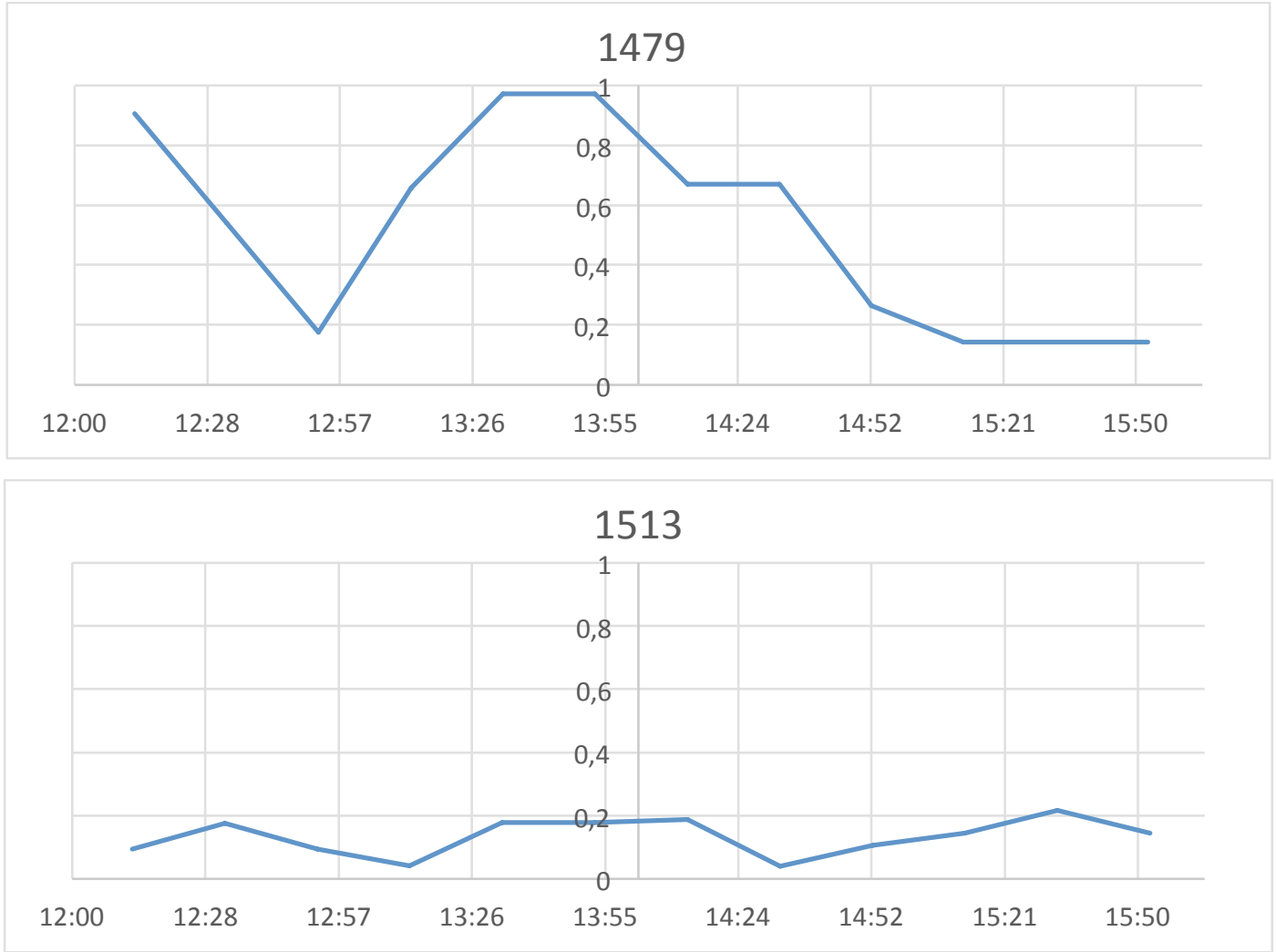

Id: 548608001284665344 (2014-12-26 20:35:14.0)

Texto: Colisão entre dois carros ocupa uma faixa da pista central da Av Brasil, em Irajá, sentido ZOeste. Equipes no local. http://t.co/3WhBpvW4GE

PMV: 1250126012591295

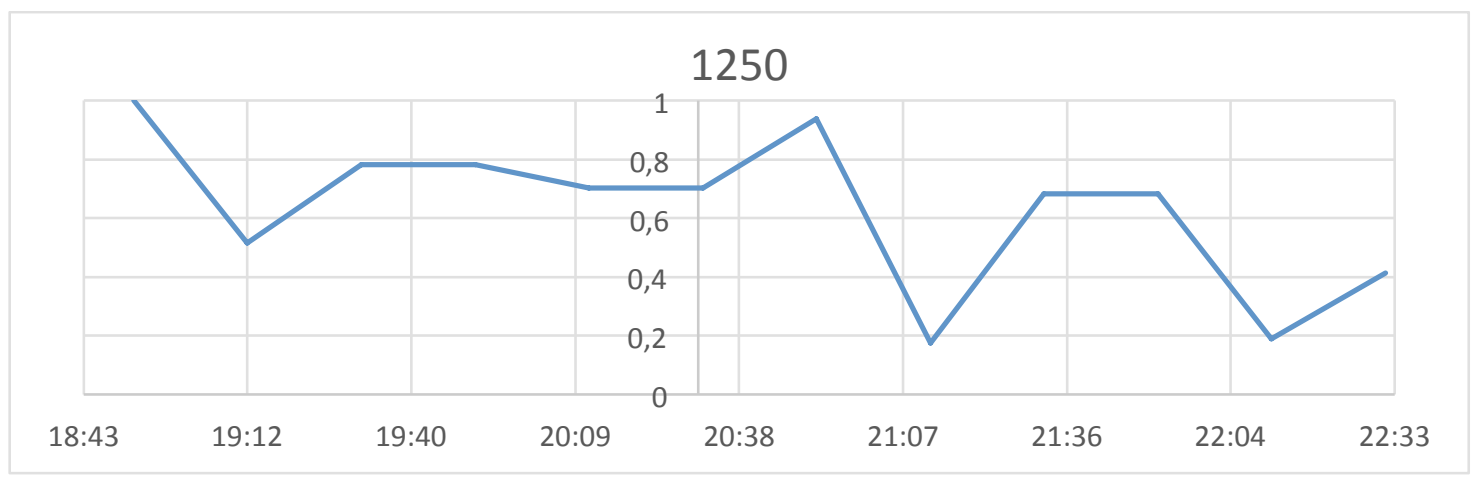

Id: 545111876506779648 (2014-12-17 05:02:53.0)

Texto: Colisão entre moto e ônibus ocupa 1 faixa da p. central da Av Brasil, sentido Centro, no Caju. Retenções até Benfica. http://t.co/823XzdpsWg

PMV: 12011730173117291728172717831258127912781277 

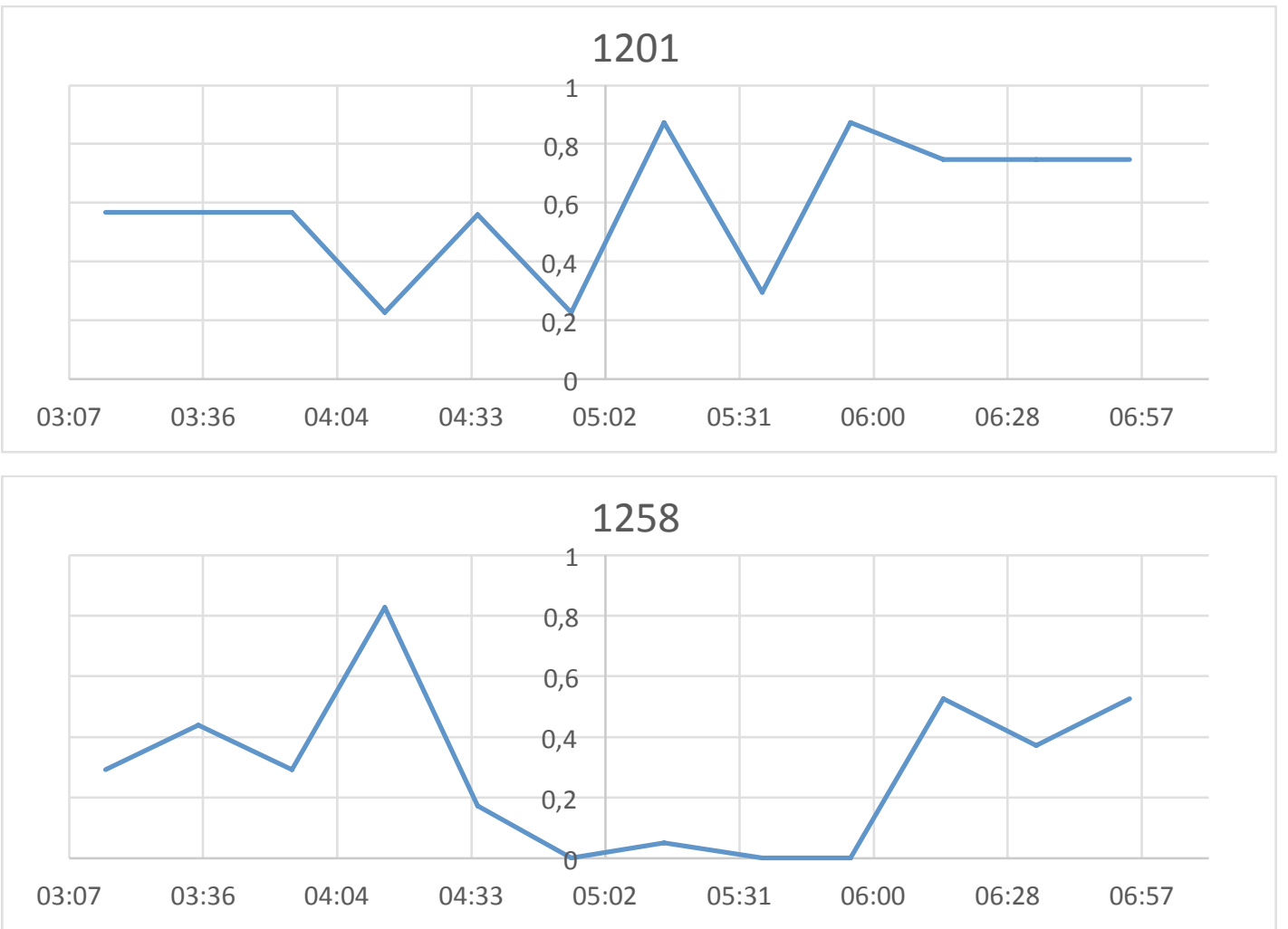

Id: 544407368914595840 (2014-12-15 06:23:26.0)

Texto: Colisão de carro e moto ocupa faixa da Linha Vermelha, altura de Caxias, sentido Centro. Retenções. CET-Rio na via. http://t.co/aVBCOtqNpN

PMV: 1337

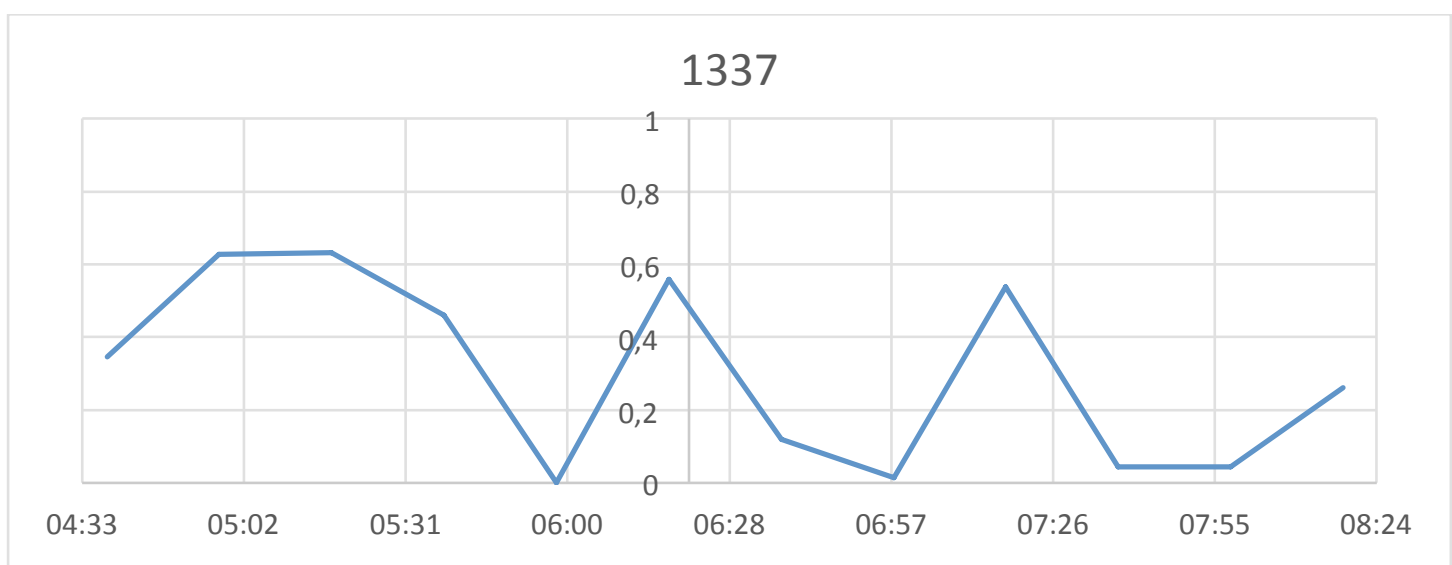


Id: $544245514259021824(2014-12-14$ 19:40:16.0)

Texto: Colisão entre 2 ônibus e utilitário ocupa 1 faixa da pista lateral da Av Brasil, sentido ZOeste, em Benfica. http://t.co/Bi9mpaCrK1

PMV: 12551274 (na mesma pista da ocorrência)
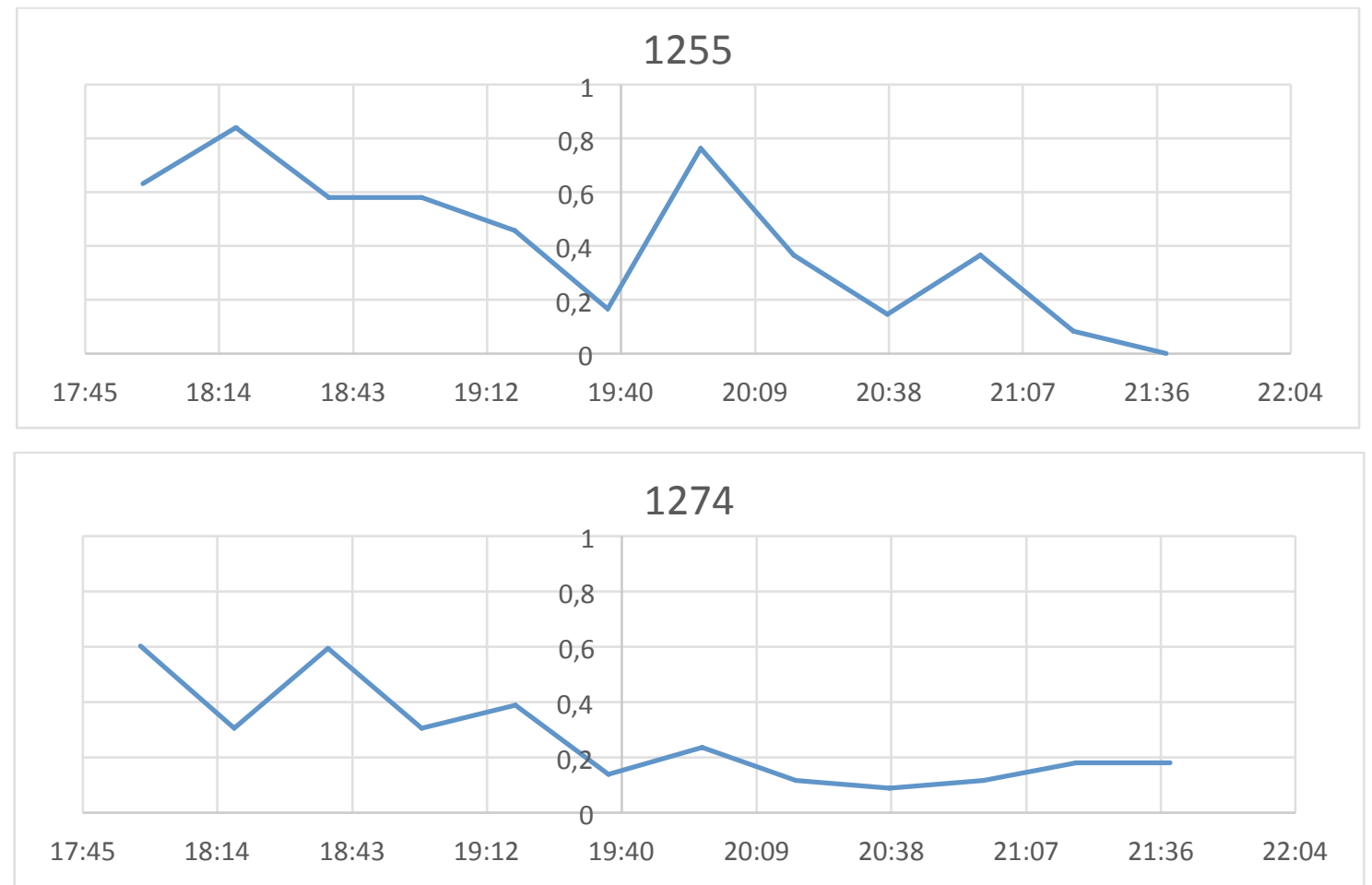

Id: $542996881836490752(2014-12-1108: 58: 39.0)$

Texto: Colisão de 2 carros ocupa 2 faixas da Av. Brasil, pista central, na Penha, sentido Centro. Lentidão. CET-Rio na via. http://t.co/qnhImaeBHX

PMV: 12671266126812531290

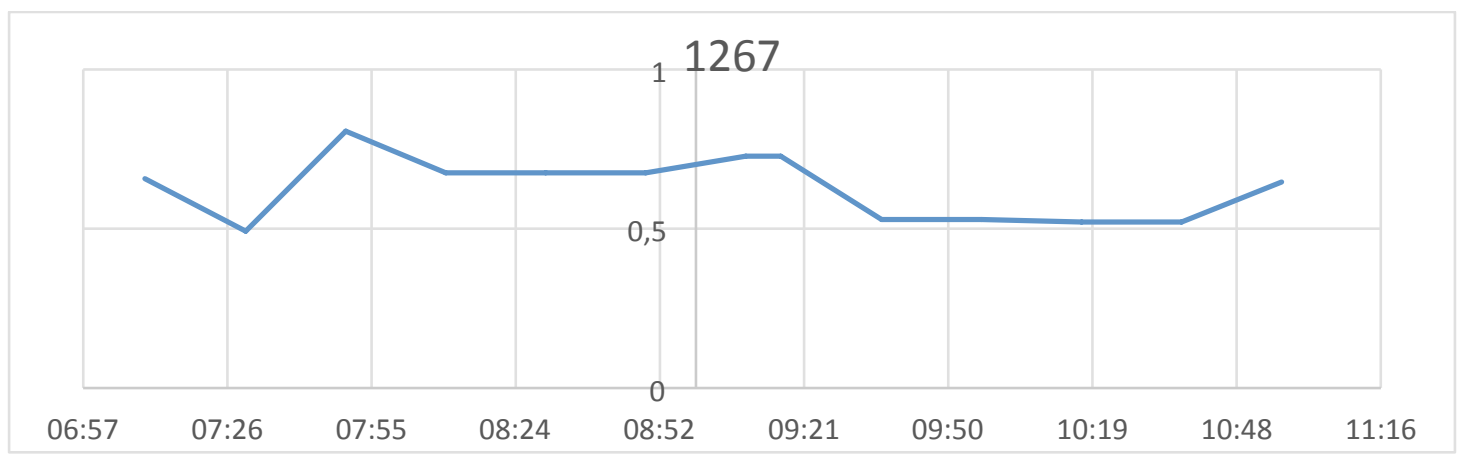




\section{Tweets com rotas identificadas}

Id: $544083467525312512(2014-12-14$ 08:56:21.0)

Texto: Colisão entre carro e táxi na Avenida Osvaldo Aranha, altura do metrô de São Cristovão, sentido Méier. 1 fx.ocupada. http://t.co/7iqxBfnUsX

PMV: 172113641370136614451444169513621443135913461373144214411347 13501694137213611282

Status: Rota $1(1445,1444,1442,1442)$

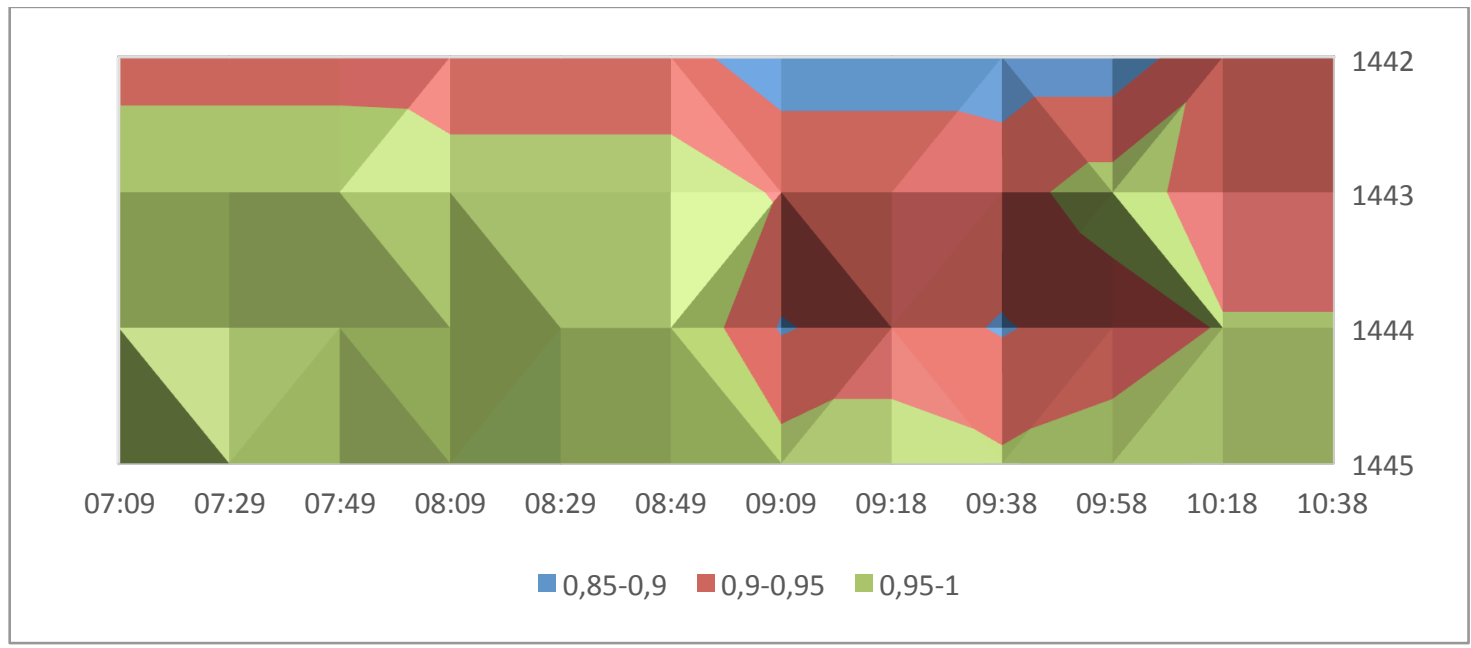

Id: 543554850105991168 (2014-12-12 21:55:49.0)

Texto: Acidente com moto ocupa uma faixa do Elevado Paulo de Frontin, próximo à estrada do Túnel Rebouças. Há retenções. http://t.co/LqcFnqizoj

PMV: 139914031696140013671404169714451392144413911362172114431359 13901346137313681485138913661580134713581350

Status: Rota $1(1696,1445,1444,1443)$ 


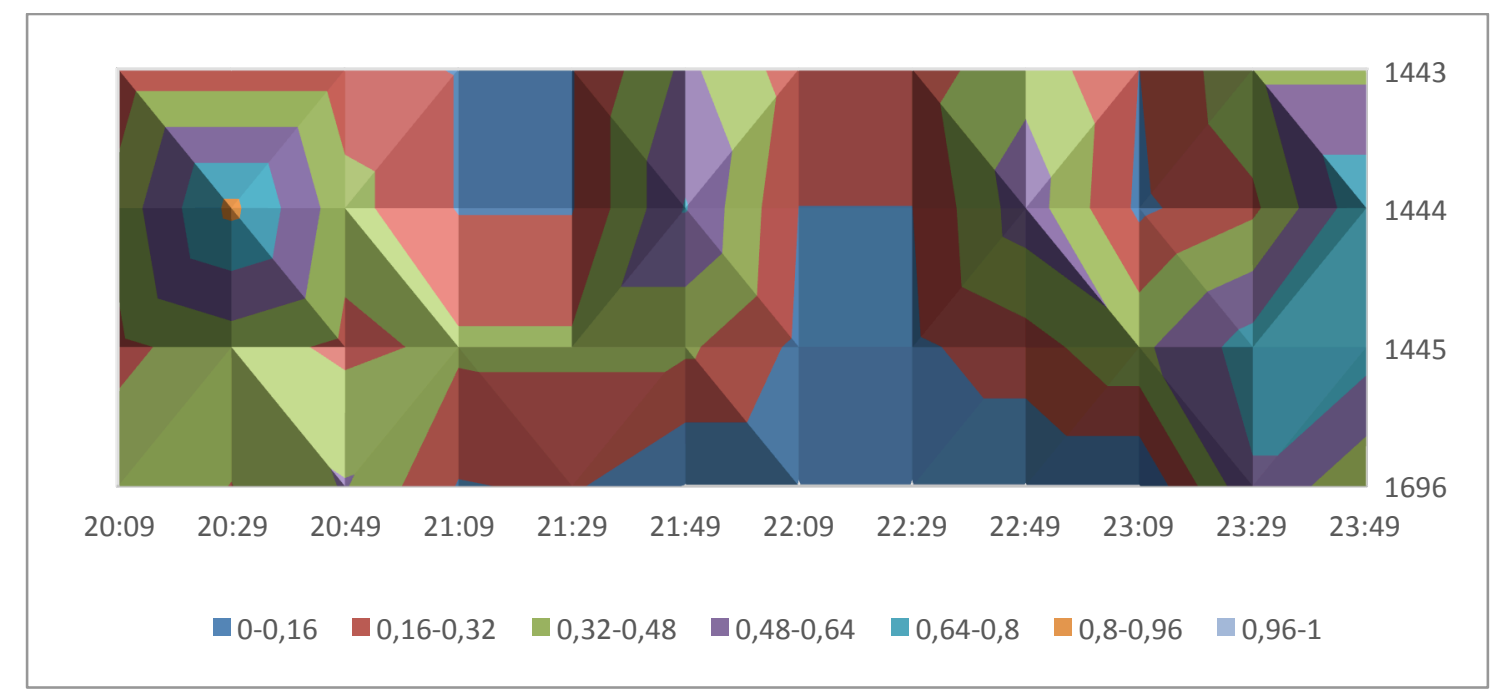

Id: 542020567541374977 (2014-12-08 16:19:08.0)

Texto: Colisão entre carro e utilitário na R. Mário Ribeiro, próx. da Av. Bartolomeu Mitre, sentido PUC. Uma fx. ocupada. http://t.co/mWu15EFqks

PMV: 171617691715172017721771171413841385172515551557171917731718 1554163617241717159816371723155915581770170915651383159913861556 1560

Status: Rota $1(1769,1384,1383)$

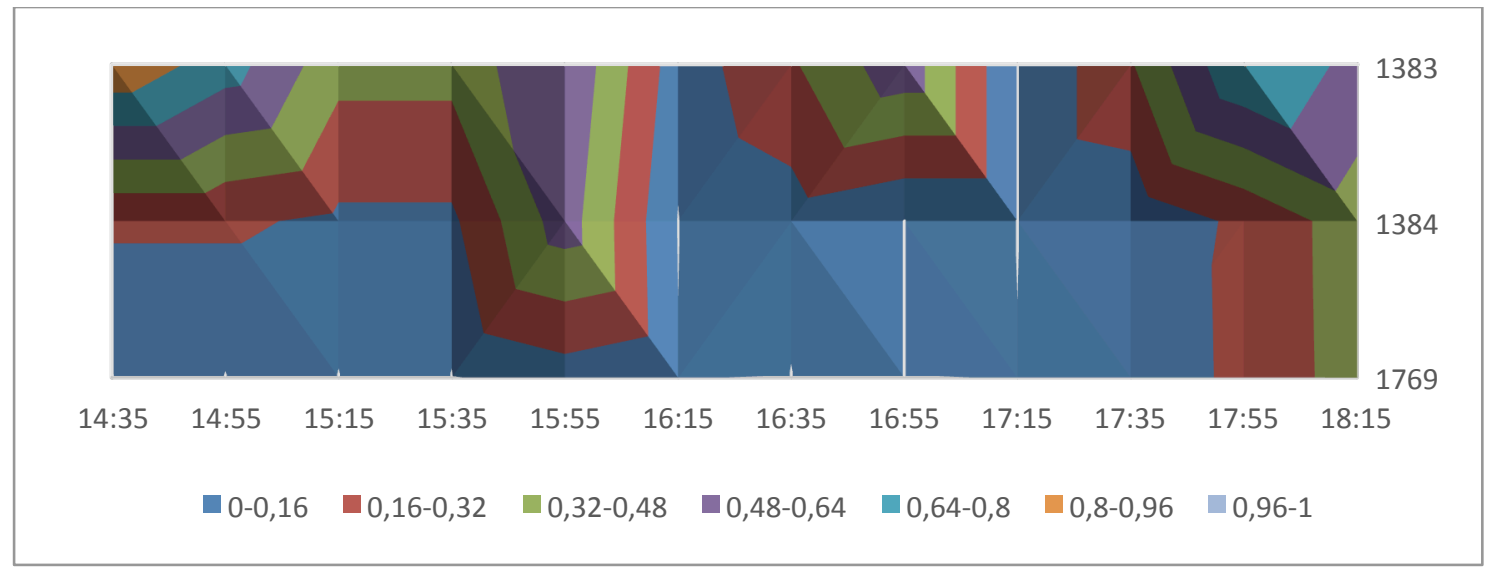

Id: $540261672338718720(2014-12-03$ 19:49:54.0)

Texto: Colisão entre 2 motos ocupa 1 faixa do Gasômetro, sentido Centro, altura da descida p/ Av Franc Bicalho. Há retenção http://t.co/YaMeaBKWVE

PMV: 12581279127812771256 
Status: Rota $1(1258,1279,1277)$

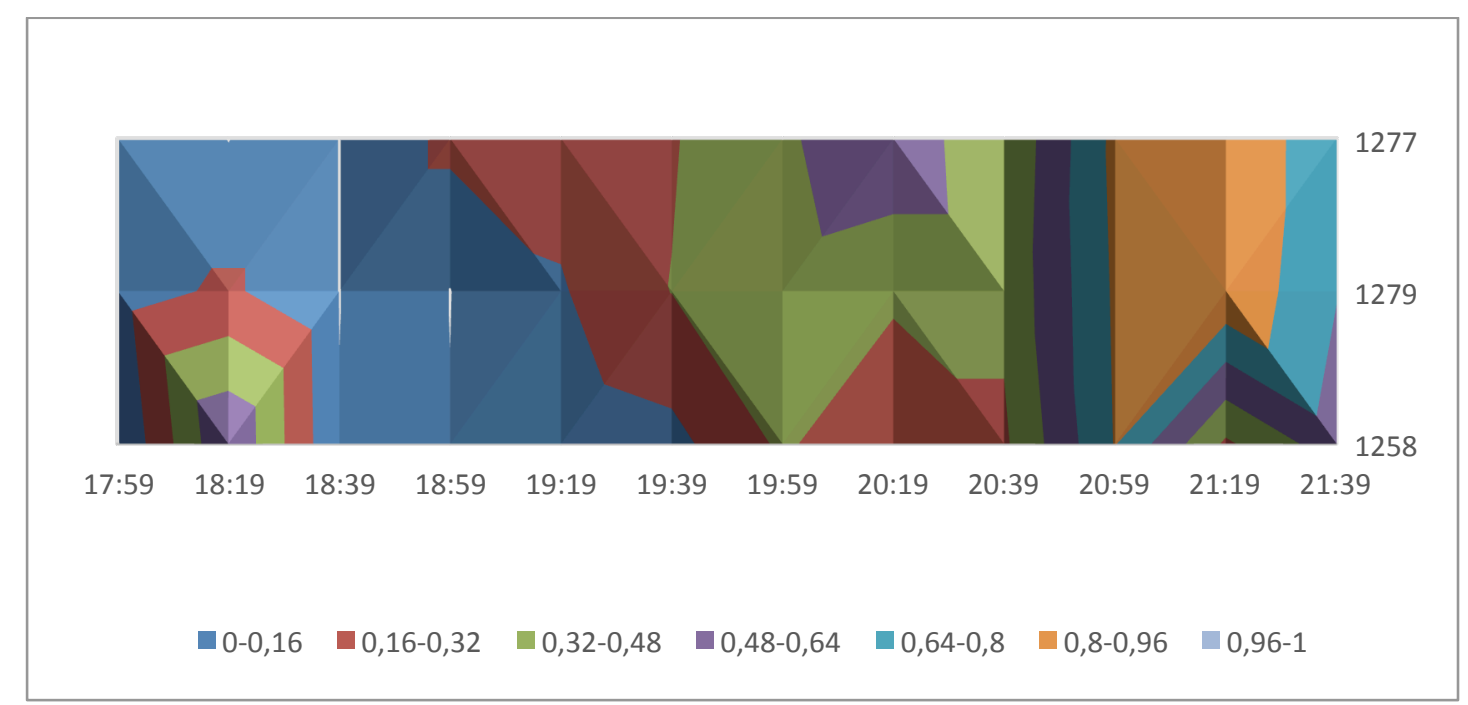

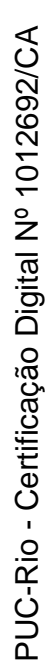

Id: 532897459664846848(2014-11-13 12:07:09.0)

Texto: Carro enguiçado ocupa 1 faixa da Av. Francisco Bicalho, sentido Centro, altura do prédio do IML. Retenção no local. \#centro

PMV: 144314321442144113611373128213721728125813601362178313401439 14381364137014401435143717291445172213391374

Status: Rota 1 (1443, 1442, 1441, 1282)

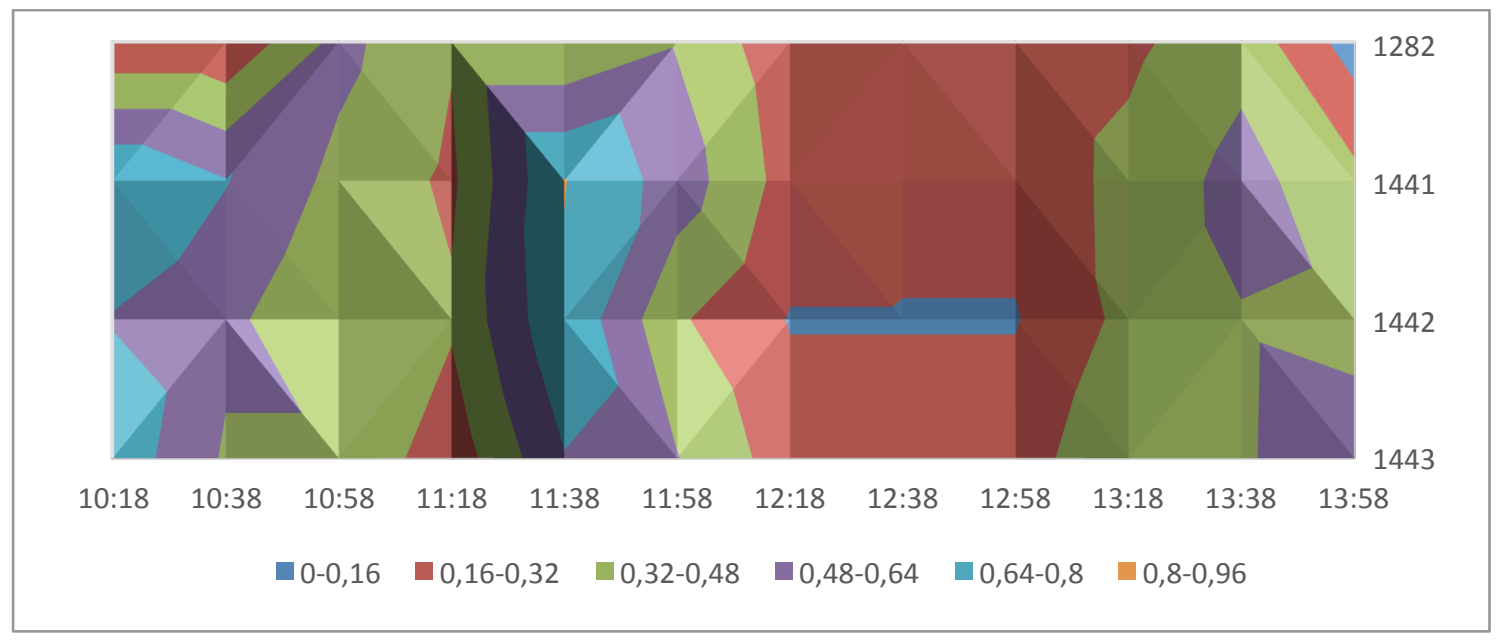




\section{Apêndice 3: Descrição dos Pontos de Medição de Velocidade}

\begin{tabular}{|c|c|c|c|}
\hline ordem & corredor & endereco & coordenadas \\
\hline 1201 & Avenida Brasil - pista central & Vevd Prf. Rufino de Almeida Pizarro & $\begin{array}{r}22^{\circ} 53^{\prime} 16.463 \mathrm{~S} \\
43^{\circ} 13^{\prime} 24.070^{\prime \prime} \mathrm{W}^{\prime \prime}\end{array}$ \\
\hline 1202 & Avenida Brasil - pista central & Av Pres. João Goulart & $\begin{array}{r}22^{\circ} 53^{\prime} 5.582 \mathrm{~S} \\
43^{\circ} 13^{\prime} 39.526^{\prime \prime} \mathrm{W}^{\prime \prime}\end{array}$ \\
\hline 1203 & Avenida Brasil - pista central & Vd Ataulfo Alves & $\begin{array}{r}22^{\circ} 53^{\prime} 13.449 \mathrm{~S} \\
43^{\circ} 13^{\prime} 56.912^{\prime \prime} \mathrm{W}^{\prime \prime}\end{array}$ \\
\hline 1204 & Avenida Brasil - pista central & Vd de Manguinhos & $\begin{array}{r}22^{\circ} 52^{\prime} 46.354 \mathrm{~S} \\
43^{\circ} 14^{\prime} 23.450^{\prime \prime} \mathrm{W}^{\prime \prime}\end{array}$ \\
\hline 1205 & Avenida Brasil - pista central & Vd Eng. Edno Machado & $\begin{array}{r}22^{\circ} 51^{\prime} 39.553 \mathrm{~S} \\
43^{\circ} 14^{\prime} 51.988^{\prime \prime} \mathrm{W}^{\prime \prime}\end{array}$ \\
\hline 1206 & Avenida Brasil - pista central & Trevos das Missões & $\begin{array}{r}22^{\circ} 48^{\prime} 57.183 \mathrm{~S} \\
43^{\circ} 17^{\prime} 19.655^{\prime \prime} \mathrm{W}^{\prime \prime}\end{array}$ \\
\hline 1207 & Avenida Brasil - pista central & R Bulhões Marcial & $\begin{array}{r}22^{\circ} 48^{\prime} 55.777 \mathrm{~S} \\
43^{\circ} 18^{\prime} 3.694^{\prime \prime} \mathrm{W}^{\prime \prime}\end{array}$ \\
\hline 1208 & Avenida Brasil - pista central & Trevo das Margaridas & $\begin{array}{r}22^{\circ} 49^{\prime} 12.940 \mathrm{~S} \\
43^{\circ} 19^{\prime} 12.636^{\prime \prime} \mathrm{W}^{\prime \prime}\end{array}$ \\
\hline 1209 & Avenida Brasil - pista central & Av Pst. Martin Luther King Júnior & $\begin{array}{r}22^{\circ} 49^{\prime} 27.998 \mathrm{~S} \\
43^{\circ} 19^{\prime} 58.816^{\prime \prime} \mathrm{W}^{\prime \prime}\end{array}$ \\
\hline 1210 & Avenida Brasil - pista central & R Pedro Jório & $\begin{array}{r}22^{\circ} 49^{\prime} 49.885 \mathrm{~S} \\
43^{\circ} 20^{\prime} 59.115^{\prime \prime} \mathrm{W}^{\prime \prime}\end{array}$ \\
\hline 1211 & Avenida Brasil - pista central & Av Pref. Sá Lessa & $\begin{array}{r}22^{\circ} 49^{\prime} 57.060 \mathrm{~S} \\
43^{\circ} 21^{\prime} 18.501^{\prime \prime} \mathrm{W}^{\prime \prime}\end{array}$ \\
\hline 1212 & Avenida Brasil - pista central & Estr Rio D Ouro & $\begin{array}{r}22^{\circ} 50 ' 2.459 \mathrm{~S} \\
43^{\circ} 21^{\prime} 32.486^{\prime \prime} \mathrm{W}^{\prime \prime}\end{array}$ \\
\hline 1213 & Avenida Brasil - pista central & Estr João Paulo & $\begin{array}{r}22^{\circ} 50^{\prime} 8.686 \mathrm{~S} \\
43^{\circ} 21^{\prime} 43.989^{\prime \prime} \mathrm{W}^{\prime \prime}\end{array}$ \\
\hline 1214 & Avenida Brasil - pista central & Estr Camboatá & $\begin{array}{r}22^{\circ} 50^{\prime} 14.853 \mathrm{~S} \\
43^{\circ} 21^{\prime} 54.073 " 3^{\prime \prime}\end{array}$ \\
\hline 1215 & Avenida Brasil - pista central & Estr Mal. Alencastro & $\begin{array}{r}22^{\circ} 51^{\prime} 6.963 \mathrm{~S} \\
43^{\circ} 23^{\prime} 17.742^{\prime \prime} \mathrm{W}^{\prime \prime}\end{array}$ \\
\hline 1216 & Avenida Brasil - pista central & Estr da Equitação & $\begin{array}{r}22^{\circ} 51^{\prime} 25.812 \mathrm{~S} \\
43^{\circ} 24^{\prime} 6.727^{\prime \prime} \mathrm{W}^{\prime \prime}\end{array}$ \\
\hline 1217 & Avenida Brasil - pista central & R Hélio do Amaral & $\begin{array}{r}22^{\circ} 51^{\prime} 55.781 \mathrm{~S} \\
43^{\circ} 25^{\prime} 33.643^{\prime \prime} \mathrm{W}^{\prime \prime}\end{array}$ \\
\hline 1218 & Avenida Brasil - pista central & Estr da Cancela Preta & $\begin{array}{r}22^{\circ} 51^{\prime} 40.741 \mathrm{~S} \\
43^{\circ} 26^{\prime} 57.042^{\prime \prime} \mathrm{W}^{\prime \prime}\end{array}$ \\
\hline 1219 & Avenida Brasil - pista central & R Dra. Maria Estrela & $22^{\circ} 51^{\prime} 34.453 \mathrm{~S}$ \\
\hline
\end{tabular}




\begin{tabular}{|c|c|c|c|}
\hline ordem & corredor & endereco & coordenadas \\
\hline & & & $43^{\circ} 27^{\prime} 31.673^{\prime \prime} \mathrm{W}^{\prime \prime}$ \\
\hline 1220 & Avenida Brasil - pista central & Av Guianas & $\begin{array}{r}22^{\circ} 51 ' 21.398 \mathrm{~S} \\
43^{\circ} 28^{\prime} 43.715^{\prime \prime} \mathrm{W}^{\prime \prime}\end{array}$ \\
\hline 1221 & Avenida Brasil - pista central & Cam Rodrigues & $\begin{array}{r}22^{\circ} 51^{\prime} 25.122 \mathrm{~S} \\
43^{\circ} 29^{\prime} 49.553^{\prime \prime W}\end{array}$ \\
\hline 1222 & Avenida Brasil - pista central & Estr Sete Riachos & $\begin{array}{r}22^{\circ} 51 ' 37.617 \mathrm{~S} \\
43^{\circ} 30^{\prime} 53.244^{\prime \prime} \mathrm{W}^{\prime \prime}\end{array}$ \\
\hline 1223 & Avenida Brasil - pista central & Estr do Mendanha & $\begin{array}{r}22^{\circ} 51^{\prime} 39.442 \mathrm{~S} \\
43^{\circ} 32^{\prime} 6.306^{\prime \prime} \mathrm{W}^{\prime \prime}\end{array}$ \\
\hline 1224 & Avenida Brasil - pista central & Estr do Pedregoso & $\begin{array}{r}22^{\circ} 51^{\prime} 42.397 \mathrm{~S} \\
43^{\circ} 33^{\prime} 2.709^{\prime \prime} \mathrm{W}^{\prime \prime}\end{array}$ \\
\hline 1225 & Avenida Brasil - pista central & Estr Rio - São Paulo & $\begin{array}{r}22^{\circ} 52^{\prime} 0.694 \mathrm{~S} \\
43^{\circ} 35^{\prime} 30.066^{\prime \prime} \mathrm{W}^{\prime \prime}\end{array}$ \\
\hline 1226 & Avenida Brasil - pista central & Av dos Palmares & $\begin{array}{r}22^{\circ} 52^{\prime} 34.448 \mathrm{~S} \\
43^{\circ} 36^{\prime} 50.319^{\prime \prime} \mathrm{W}^{\prime}\end{array}$ \\
\hline 1227 & Avenida Brasil - pista central & R Agaí & $\begin{array}{r}22^{\circ} 52^{\prime} 56.404 \mathrm{~S} \\
43^{\circ} 38^{\prime} 19.640^{\prime \prime} \mathrm{W}^{\prime \prime}\end{array}$ \\
\hline 1228 & Avenida Brasil - pista central & Rod BR-101 & $\begin{array}{r}22^{\circ} 53 ' 21.006 \mathrm{~S} \\
43^{\circ} 39^{\prime} 42.446^{\prime \prime} \mathrm{W}^{\prime \prime}\end{array}$ \\
\hline 1229 & Avenida Brasil - pista central & Estr Pe. Guilherme Decaminada & $\begin{array}{r}22^{\circ} 53^{\prime} 38.436 \mathrm{~S} \\
43^{\circ} 40^{\prime} 35.450^{\prime \prime} \mathrm{W}^{\prime \prime}\end{array}$ \\
\hline 1230 & Avenida Brasil - pista central & Estr Aterrado do Leme & $\begin{array}{r}22^{\circ} 53^{\prime} 26.325 \mathrm{~S} \\
43^{\circ} 39^{\prime} 55.615^{\prime \prime} \mathrm{W}^{\prime \prime}\end{array}$ \\
\hline 1231 & Avenida Brasil - pista central & R Agaí & $\begin{array}{r}22^{\circ} 53^{\prime} 8.920 \mathrm{~S} \\
43^{\circ} 38^{\prime} 59.239^{\prime \prime} \mathrm{W}^{\prime \prime}\end{array}$ \\
\hline 1232 & Avenida Brasil - pista central & Estr do Campinho & $\begin{array}{r}22^{\circ} 52^{\prime} 57.692 \mathrm{~S} \\
43^{\circ} 38^{\prime} 19.040^{\prime \prime} \mathrm{W}^{\prime \prime}\end{array}$ \\
\hline 1233 & Avenida Brasil - pista central & Estr do Tingui & $\begin{array}{r}22^{\circ} 52^{\prime} 42.109 \mathrm{~S} \\
43^{\circ} 37^{\prime} 5.510^{\prime \prime} \mathrm{W}^{\prime \prime}\end{array}$ \\
\hline 1234 & Avenida Brasil - pista central & Estr Rio - São Paulo & $\begin{array}{r}22^{\circ} 52^{\prime} 13.565 \mathrm{~S} \\
43^{\circ} 36^{\prime} 3.968^{\prime \prime} \mathrm{W}^{\prime \prime}\end{array}$ \\
\hline 1235 & Avenida Brasil - pista central & Cam Da. Júlia & $\begin{array}{r}22^{\circ} 51^{\prime} 59.993 \mathrm{~S} \\
43^{\circ} 35^{\prime} 24.771^{\prime \prime} \mathrm{W}\end{array}$ \\
\hline 1236 & Avenida Brasil - pista central & Estr do Pedregoso & $\begin{array}{r}22^{\circ} 51^{\prime} 55.216 \mathrm{~S} \\
43^{\circ} 34^{\prime} 23.389^{\prime \prime} \mathrm{W}\end{array}$ \\
\hline 1237 & Avenida Brasil - pista central & Estr do Mendanha & $\begin{array}{r}22^{\circ} 51^{\prime} 43.565 \mathrm{~S} \\
43^{\circ} 33^{\prime} 10.172^{\prime \prime} \mathrm{W}^{\prime \prime}\end{array}$ \\
\hline 1238 & Avenida Brasil - pista central & Estr Sete Riachos & $\begin{array}{r}22^{\circ} 51^{\prime} 40.102 \mathrm{~S} \\
43^{\circ} 32^{\prime} 6.027^{\prime \prime} \mathrm{W}^{\prime \prime}\end{array}$ \\
\hline 1239 & Avenida Brasil - pista central & Av Guianas & $\begin{array}{r}22^{\circ} 51^{\prime} 25.547 \mathrm{~S} \\
43^{\circ} 29^{\prime} 48.738^{\prime \prime W "}\end{array}$ \\
\hline 1240 & Avenida Brasil - pista central & Av Marrocos & $\begin{array}{r}22^{\circ} 51^{\prime} 20.813 \mathrm{~S} \\
43^{\circ} 29^{\prime} 33.666^{\prime \prime} \mathrm{W}^{\prime \prime}\end{array}$ \\
\hline
\end{tabular}




\begin{tabular}{|c|c|c|c|}
\hline ordem & corredor & endereco & coordenadas \\
\hline 1241 & Avenida Brasil - pista central & R Dra. Maria Estrela & $\begin{array}{r}22^{\circ} 51^{\prime} 22.035 \mathrm{~S} \\
43^{\circ} 28^{\prime} 43.679^{\prime \prime} \mathrm{W}\end{array}$ \\
\hline 1242 & Avenida Brasil - pista central & Estr da Cancela Preta & $\begin{array}{r}22^{\circ} 51 ' 34.959 \mathrm{~S} \\
43^{\circ} 27^{\prime} 31.567^{\prime \prime} "\end{array}$ \\
\hline 1243 & Avenida Brasil - pista central & R Pacaembu & $\begin{array}{r}22^{\circ} 51^{\prime} 42.767 \mathrm{~S} \\
43^{\circ} 26^{\prime} 48.572^{\prime \prime} \mathrm{W}^{\prime \prime}\end{array}$ \\
\hline 1244 & Avenida Brasil - pista central & Estr da Equitação & $\begin{array}{r}22^{\circ} 51^{\prime} 56.240 \mathrm{~S} \\
43^{\circ} 25^{\prime} 33.770^{\prime \prime} \mathrm{W}^{\prime \prime}\end{array}$ \\
\hline 1245 & Avenida Brasil - pista central & Estr Mal. Alencastro & $\begin{array}{r}22^{\circ} 51^{\prime} 26.207 \mathrm{~S} \\
43^{\circ} 24^{\prime} 6.379^{\prime \prime} \mathrm{W}^{\prime \prime}\end{array}$ \\
\hline 1246 & Avenida Brasil - pista central & Estr Camboatá & $\begin{array}{r}22^{\circ} 51^{\prime} 0.917 \mathrm{~S} \\
43^{\circ} 23^{\prime} 4.783^{\prime \prime} \mathrm{W}^{\prime}\end{array}$ \\
\hline 1247 & Avenida Brasil - pista central & R Waldemar Coelho dos Santos & $\begin{array}{r}22^{\circ} 50^{\prime} 39.521 \mathrm{~S} \\
43^{\circ} 22^{\prime} 33.180^{\prime \prime} \mathrm{W}^{\prime \prime}\end{array}$ \\
\hline 1248 & Avenida Brasil - pista central & Estr João Paulo & $\begin{array}{r}22^{\circ} 50^{\prime} 15.568 \mathrm{~S} \\
43^{\circ} 21^{\prime} 54.197^{\prime \prime} \mathrm{W}^{\prime \prime}\end{array}$ \\
\hline 1249 & Avenida Brasil - pista central & Av Pst. Martin Luther King Júnior & $\begin{array}{r}22^{\circ} 50^{\prime} 1.502 \mathrm{~S} \\
43^{\circ} 21^{\prime} 28.278^{\prime \prime} \mathrm{W}^{\prime \prime}\end{array}$ \\
\hline 1250 & Avenida Brasil - pista central & Trevo das Margaridas & $\begin{array}{r}22^{\circ} 49^{\prime} 28.424 \mathrm{~S} \\
43^{\circ} 19^{\prime} 58.533^{\prime \prime} "\end{array}$ \\
\hline 1251 & Avenida Brasil - pista central & R Bulhões Marcial & $\begin{array}{r}22^{\circ} 49^{\prime} 9.878 \mathrm{~S} \\
43^{\circ} 18^{\prime} 36.764^{\prime \prime} \mathrm{W}^{\prime \prime}\end{array}$ \\
\hline 1252 & Avenida Brasil - pista central & Trevos das Missões & $\begin{array}{r}22^{\circ} 48^{\prime} 52.021 \mathrm{~S} \\
43^{\circ} 17^{\prime} 41.634^{\prime \prime} \mathrm{W}^{\prime \prime}\end{array}$ \\
\hline 1253 & Avenida Brasil - pista central & Vd Eng. Edno Machado & $\begin{array}{r}22^{\circ} 49^{\prime} 57.243 \mathrm{~S} \\
43^{\circ} 15^{\prime} 58.879^{\prime \prime} \mathrm{W}^{\prime \prime}\end{array}$ \\
\hline 1254 & Avenida Brasil - pista central & Vd de Manguinhos & $\begin{array}{r}22^{\circ} 52^{\prime} 15.805 \mathrm{~S} \\
43^{\circ} 14^{\prime} 46.901 " \mathrm{~W}\end{array}$ \\
\hline 1255 & Avenida Brasil - pista central & Vd Ataulfo Alves & $\begin{array}{r}22^{\circ} 52^{\prime} 46.842 \mathrm{~S} \\
43^{\circ} 14^{\prime} 23.798^{\prime \prime} \mathrm{W}^{\prime \prime}\end{array}$ \\
\hline 1256 & Avenida Brasil - pista central & Av Pres. João Goulart & $\begin{array}{r}22^{\circ} 53^{\prime} 11.616 \mathrm{~S} \\
43^{\circ} 13^{\prime} 47.421^{\prime \prime} \mathrm{W}^{\prime \prime}\end{array}$ \\
\hline 1257 & Avenida Brasil - pista central & Vevd Prf. Rufino de Almeida Pizarro & $\begin{array}{r}22^{\circ} 53^{\prime} 6.014 \mathrm{~S} \\
43^{\circ} 13^{\prime} 39.182^{\prime \prime} \mathrm{W}\end{array}$ \\
\hline 1258 & Avenida Brasil - pista central & Av Francisco Bicalho & $\begin{array}{r}22^{\circ} 53^{\prime} 32.230 \mathrm{~S} \\
43^{\circ} 12^{\prime} 58.545^{\prime \prime} \mathrm{W}^{\prime \prime}\end{array}$ \\
\hline 1259 & Avenida Brasil - pista lateral & R André Fill & $\begin{array}{r}22^{\circ} 49^{\prime} 32.829 \mathrm{~S} \\
43^{\circ} 20^{\prime} 9.947^{\prime \prime} \mathrm{W}^{\prime \prime}\end{array}$ \\
\hline 1260 & Avenida Brasil - pista lateral & Trevo das Margaridas & $\begin{array}{r}22^{\circ} 49^{\prime} 17.808 \mathrm{~S} \\
43^{\circ} 19^{\prime} 24.403^{\prime \prime W "}\end{array}$ \\
\hline 1261 & Avenida Brasil - pista lateral & R Martinica & $\begin{array}{r}22^{\circ} 49^{\prime} 12.130 \mathrm{~S} \\
43^{\circ} 19^{\prime} 0.175^{\prime \prime} \mathrm{W}^{\prime \prime}\end{array}$ \\
\hline 1262 & Avenida Brasil - pista lateral & R Mundaú & $\begin{array}{r}22^{\circ} 49^{\prime} 8.622 \mathrm{~S} \\
43^{\circ} 18^{\prime} 33.237^{\prime \prime} \mathrm{W}^{\prime \prime}\end{array}$ \\
\hline
\end{tabular}




\begin{tabular}{|c|c|c|c|}
\hline ordem & corredor & endereco & coordenadas \\
\hline 1263 & Avenida Brasil - pista lateral & R Bulhões Marcial & $\begin{array}{r}22^{\circ} 48^{\prime} 58.766 \mathrm{~S} \\
43^{\circ} 18^{\prime} 11.864^{\prime \prime} \mathrm{W}^{\prime \prime}\end{array}$ \\
\hline 1264 & Avenida Brasil - pista lateral & Trevos das Missões & $\begin{array}{r}22^{\circ} 48^{\prime} 58.126 \mathrm{~S} \\
43^{\circ} 17^{\prime} 20.189^{\prime \prime} \mathrm{W}^{\prime \prime}\end{array}$ \\
\hline 1265 & Avenida Brasil - pista lateral & Av Shultz Wenk & $\begin{array}{r}22^{\circ} 49^{\prime} 3.209 \mathrm{~S} \\
43^{\circ} 17^{\prime} 12.988^{\prime \prime} \mathrm{W}^{\prime \prime}\end{array}$ \\
\hline 1266 & Avenida Brasil - pista lateral & Av Lobo Júnior & $\begin{array}{r}22^{\circ} 49^{\prime} 20.415 \mathrm{~S} \\
43^{\circ} 16^{\prime} 50.734^{\prime \prime} \mathrm{W}^{\prime \prime}\end{array}$ \\
\hline 1267 & Avenida Brasil - pista lateral & R Cd. de Agrolongo & $\begin{array}{r}22^{\circ} 49^{\prime} 39.157 \mathrm{~S} \\
43^{\circ} 16^{\prime} 26.646^{\prime \prime} \mathrm{W}^{\prime \prime}\end{array}$ \\
\hline 1268 & Avenida Brasil - pista lateral & Av Teixeira de Castro & $\begin{array}{r}22^{\circ} 50^{\prime} 12.117 \mathrm{~S} \\
43^{\circ} 15^{\prime} 32.332^{\prime \prime} \mathrm{W}^{\prime \prime}\end{array}$ \\
\hline 1269 & Avenida Brasil - pista lateral & Vd Eng. Edno Machado & $\begin{array}{r}22^{\circ} 51 ' 3.781 \mathrm{~S} \\
43^{\circ} 14^{\prime} 51.940^{\prime \prime} \mathrm{W}^{\prime \prime}\end{array}$ \\
\hline 1270 & Avenida Brasil - pista lateral & R Srg. Silva Nunes & $\begin{array}{r}22^{\circ} 51^{\prime} 11.187 \mathrm{~S} \\
43^{\circ} 14^{\prime} 52.281^{\prime \prime} "\end{array}$ \\
\hline 1271 & Avenida Brasil - pista lateral & R Aguiar Moreira & $\begin{array}{r}22^{\circ} 51^{\prime} 41.460 \mathrm{~S} \\
43^{\circ} 14^{\prime} 53.117^{\prime \prime} \mathrm{W}^{\prime \prime}\end{array}$ \\
\hline 1272 & Avenida Brasil - pista lateral & R Arlindo Janot & $\begin{array}{r}22^{\circ} 52^{\prime} 6.816 \mathrm{~S} \\
43^{\circ} 14^{\prime} 51.013^{\prime \prime} \mathrm{W}^{\prime \prime}\end{array}$ \\
\hline 1273 & Avenida Brasil - pista lateral & Vd de Manguinhos & $\begin{array}{r}22^{\circ} 52^{\prime} 12.556 \mathrm{~S} \\
43^{\circ} 14^{\prime} 49.179^{\prime \prime} \mathrm{W}^{\prime \prime}\end{array}$ \\
\hline 1274 & Avenida Brasil - pista lateral & R Célio Nascimento & $\begin{array}{r}22^{\circ} 52^{\prime} 45.575 \mathrm{~S} \\
43^{\circ} 14^{\prime} 25.324^{\prime \prime} \mathrm{W}^{\prime \prime}\end{array}$ \\
\hline 1275 & Avenida Brasil - pista lateral & Vd Ataulfo Alves & $\begin{array}{r}22^{\circ} 53^{\prime} 14.490 \mathrm{~S} \\
43^{\circ} 13^{\prime} 57.067^{\prime \prime} \mathrm{W}^{\prime \prime}\end{array}$ \\
\hline 1276 & Avenida Brasil - pista lateral & R Pref. Olympio de Melo & $\begin{array}{r}22^{\circ} 53^{\prime} 14.324 \mathrm{~S} \\
43^{\circ} 13^{\prime} 51.995^{\prime \prime} \mathrm{W}^{\prime \prime}\end{array}$ \\
\hline 1277 & Avenida Brasil - pista lateral & Av Pres. João Goulart & $\begin{array}{r}22^{\circ} 53^{\prime} 9.079 \mathrm{~S} \\
43^{\circ} 13^{\prime} 43.469^{\prime \prime} \mathrm{W}^{\prime \prime}\end{array}$ \\
\hline 1278 & Avenida Brasil - pista lateral & Vevd Prf. Rufino de Almeida Pizarro & $\begin{array}{r}22^{\circ} 53^{\prime} 6.472 \mathrm{~S} \\
43^{\circ} 13^{\prime} 38.812^{\prime \prime} \mathrm{W}^{\prime \prime}\end{array}$ \\
\hline 1279 & Avenida Brasil - pista lateral & R Bela & $\begin{array}{r}22^{\circ} 53^{\prime} 6.458 \mathrm{~S} \\
43^{\circ} 13^{\prime} 38.521^{\prime \prime} \mathrm{W}^{\prime \prime}\end{array}$ \\
\hline 1280 & Avenida Brasil - pista lateral & R José Clemente & $\begin{array}{r}22^{\circ} 53^{\prime} 11.748 \mathrm{~S} \\
43^{\circ} 13^{\prime} 30.332^{\prime \prime} \mathrm{W}^{\prime \prime}\end{array}$ \\
\hline 1281 & Avenida Brasil - pista lateral & R Alm. Mariath & $\begin{array}{r}22^{\circ} 53^{\prime} 21.876 \mathrm{~S} \\
43^{\circ} 13^{\prime} 8.280^{\prime \prime} \mathrm{W}^{\prime \prime}\end{array}$ \\
\hline 1282 & Avenida Brasil - pista lateral & Av Francisco Bicalho & $\begin{array}{r}22^{\circ} 53^{\prime} 46.173 \mathrm{~S} \\
43^{\circ} 12^{\prime} 51.988^{\prime \prime} \mathrm{W}^{\prime \prime}\end{array}$ \\
\hline 1283 & Avenida Brasil - pista lateral & Vevd Prf. Rufino de Almeida Pizarro & $\begin{array}{r}22^{\circ} 53^{\prime} 14.239 \mathrm{~S} \\
43^{\circ} 13^{\prime} 25.579^{\prime \prime} \mathrm{W}^{\prime \prime}\end{array}$ \\
\hline 1284 & Avenida Brasil - pista lateral & Av Pres. João Goulart & $\begin{array}{r}22^{\circ} 53^{\prime} 5.257 \mathrm{~S} \\
43^{\circ} 13^{\prime} 39.794^{\prime \prime} \mathrm{W}^{\prime \prime}\end{array}$ \\
\hline
\end{tabular}




\begin{tabular}{|c|c|c|c|}
\hline ordem & corredor & endereco & coordenadas \\
\hline 1285 & Avenida Brasil - pista lateral & Vd Ataulfo Alves & $\begin{array}{r}22^{\circ} 53^{\prime} 8.073 \mathrm{~S} \\
43^{\circ} 13^{\prime} 44.712^{\prime \prime} \mathrm{W}^{\prime \prime}\end{array}$ \\
\hline 1286 & Avenida Brasil - pista lateral & Vd de Manguinhos & $\begin{array}{r}22^{\circ} 52^{\prime} 45.940 \mathrm{~S} \\
43^{\circ} 14^{\prime} 23.130^{\prime \prime} \mathrm{W}^{\prime \prime}\end{array}$ \\
\hline 1287 & Avenida Brasil - pista lateral & R Ary Leão & $\begin{array}{r}22^{\circ} 51^{\prime} 40.238 \mathrm{~S} \\
43^{\circ} 14^{\prime} 51.483^{\prime \prime} "\end{array}$ \\
\hline 1288 & Avenida Brasil - pista lateral & Vd Eng. Edno Machado & $\begin{array}{r}22^{\circ} 51^{\prime} 3.435 \mathrm{~S} \\
43^{\circ} 14^{\prime} 49.889^{\prime \prime} \mathrm{W}\end{array}$ \\
\hline 1289 & Avenida Brasil - pista lateral & Av Brg. Trompowski & $\begin{array}{r}22^{\circ} 50^{\prime} 57.552 \mathrm{~S} \\
43^{\circ} 14^{\prime} 48.929^{\prime \prime} \mathrm{W}^{\prime \prime}\end{array}$ \\
\hline 1290 & Avenida Brasil - pista lateral & Rod BR-040 & $\begin{array}{r}22^{\circ} 49^{\prime} 56.828 \mathrm{~S} \\
43^{\circ} 15^{\prime} 57.505^{\prime \prime} \mathrm{W}^{\prime \prime}\end{array}$ \\
\hline 1291 & Avenida Brasil - pista lateral & Trevos das Missões & $\begin{array}{r}22^{\circ} 48^{\prime} 56.871 \mathrm{~S} \\
43^{\circ} 17^{\prime} 19.482^{\prime \prime} \mathrm{W}^{\prime \prime}\end{array}$ \\
\hline 1292 & Avenida Brasil - pista lateral & Rod BR-040 & $\begin{array}{r}22^{\circ} 48^{\prime} 55.483 \mathrm{~S} \\
43^{\circ} 17^{\prime} 22.591^{\prime \prime} \mathrm{W}^{\prime \prime}\end{array}$ \\
\hline 1293 & Avenida Brasil - pista lateral & R Bulhões Marcial & $\begin{array}{r}22^{\circ} 48^{\prime} 51.114 \mathrm{~S} \\
43^{\circ} 17^{\prime} 44.632^{\prime \prime} \mathrm{W}^{\prime \prime}\end{array}$ \\
\hline 1294 & Avenida Brasil - pista lateral & Rod Pres. Dutra & $\begin{array}{r}22^{\circ} 49^{\prime} 6.079 \mathrm{~S} \\
43^{\circ} 18^{\prime} 31.929^{\prime \prime} \mathrm{W}^{\prime \prime}\end{array}$ \\
\hline 1295 & Avenida Brasil - pista lateral & Trevo das Margaridas & $\begin{array}{r}22^{\circ} 49^{\prime} 11.088 \mathrm{~S} \\
43^{\circ} 19^{\prime} 7.595^{\prime \prime} \mathrm{W}^{\prime \prime}\end{array}$ \\
\hline 1296 & Avenida Brasil - pista lateral & Av Pst. Martin Luther King Júnior & $\begin{array}{r}22^{\circ} 49^{\prime} 27.711 \mathrm{~S} \\
43^{\circ} 19^{\prime} 59.322^{\prime \prime}{ }^{\prime \prime}\end{array}$ \\
\hline 1297 & Linha Amarela & R Edgard Werneck & $\begin{array}{r}22^{\circ} 57^{\prime} 14.411 \mathrm{~S} \\
43^{\circ} 21^{\prime} 26.486^{\prime \prime} \mathrm{W}^{\prime \prime}\end{array}$ \\
\hline 1298 & Linha Amarela & Av Geremário Dantas & $\begin{array}{r}22^{\circ} 56^{\prime} 43.363 \mathrm{~S} \\
43^{\circ} 21^{\prime} 14.980^{\prime \prime} \mathrm{W}^{\prime \prime}\end{array}$ \\
\hline 1299 & Linha Amarela & Estr do Pau Ferro & $\begin{array}{r}22^{\circ} 55^{\prime} 59.150 \mathrm{~S} \\
43^{\circ} 20^{\prime} 42.843^{\prime \prime} \mathrm{W}^{\prime \prime}\end{array}$ \\
\hline 1300 & Linha Amarela & R Agrolândia & $\begin{array}{r}22^{\circ} 55^{\prime} 34.034 \mathrm{~S} \\
43^{\circ} 20^{\prime} 25.448^{\prime \prime} \mathrm{W}^{\prime \prime}\end{array}$ \\
\hline 1301 & Linha Amarela & R Borja Reis & $\begin{array}{r}22^{\circ} 55^{\prime} 29.182 \mathrm{~S} \\
43^{\circ} 20^{\prime} 16.559^{\prime \prime} \mathrm{W}^{\prime \prime}\end{array}$ \\
\hline 1302 & Linha Amarela & R Dois de Fevereiro & $\begin{array}{r}22^{\circ} 54^{\prime} 0.470 \mathrm{~S} \\
43^{\circ} 18^{\prime} 11.387^{\prime \prime} \mathrm{W}^{\prime \prime}\end{array}$ \\
\hline 1303 & Linha Amarela & Av Amaro Cavalcânti & $\begin{array}{r}22^{\circ} 53^{\prime} 45.626 \mathrm{~S} \\
43^{\circ} 18^{\prime} 2.917^{\prime \prime} \mathrm{W}^{\prime \prime}\end{array}$ \\
\hline 1304 & Linha Amarela & R Goiás & $\begin{array}{r}22^{\circ} 53^{\prime} 43.890 \mathrm{~S} \\
43^{\circ} 18^{\prime} 2.140^{\prime \prime} \mathrm{W}^{\prime \prime}\end{array}$ \\
\hline 1305 & Linha Amarela & Av Carlos Lacerda & $\begin{array}{r}22^{\circ} 53 ' 27.593 \mathrm{~S} \\
43^{\circ} 17^{\prime} 51.544^{\prime \prime} \mathrm{W}^{\prime \prime}\end{array}$ \\
\hline 1306 & Linha Amarela & Av D. Hélder Câmara & $\begin{array}{r}22^{\circ} 53^{\prime} 7.737 \mathrm{~S} \\
43^{\circ} 17^{\prime} 29.975^{\prime \prime} \mathrm{W}^{\prime \prime}\end{array}$ \\
\hline
\end{tabular}




\begin{tabular}{|c|c|c|c|}
\hline ordem & corredor & endereco & coordenadas \\
\hline 1307 & Linha Amarela & Av Pst. Martin Luther King Júnior & $\begin{array}{r}22^{\circ} 52^{\prime} 53.587 \mathrm{~S} \\
43^{\circ} 16^{\prime} 57.980^{\prime \prime} \mathrm{W}^{\prime \prime}\end{array}$ \\
\hline 1308 & Linha Amarela & Estr Velha da Pavuna & $\begin{array}{r}22^{\circ} 52^{\prime} 30.635 \mathrm{~S} \\
43^{\circ} 16^{\prime} 17.635^{\prime \prime} \mathrm{W}^{\prime \prime}\end{array}$ \\
\hline 1309 & Linha Amarela & Av dos Democráticos & $\begin{array}{r}22^{\circ} 52^{\prime} 17.906 \mathrm{~S} \\
43^{\circ} 15^{\prime} 46.651^{\prime \prime} \mathrm{W}^{\prime \prime}\end{array}$ \\
\hline 1310 & Linha Amarela & R Uranos & $\begin{array}{r}22^{\circ} 52^{\prime} 18.370 \mathrm{~S} \\
43^{\circ} 15^{\prime} 22.156^{\prime \prime} \mathrm{W}^{\prime \prime}\end{array}$ \\
\hline 1311 & Linha Amarela & R Leopoldo Bulhões & $\begin{array}{r}22^{\circ} 52^{\prime} 19.251 \mathrm{~S} \\
43^{\circ} 15^{\prime} 12.770^{\prime \prime} \mathrm{W}^{\prime \prime}\end{array}$ \\
\hline 1312 & Linha Amarela & R Erico de Souza Leão & $\begin{array}{r}22^{\circ} 52^{\prime} 19.875 \mathrm{~S} \\
43^{\circ} 15^{\prime} 7.654^{\prime \prime} \mathrm{W}^{\prime \prime}\end{array}$ \\
\hline 1313 & Linha Amarela & Vd de Manguinhos & $\begin{array}{r}22^{\circ} 52^{\prime} 18.635 \mathrm{~S} \\
43^{\circ} 14^{\prime} 55.680^{\prime \prime} \mathrm{W}^{\prime \prime}\end{array}$ \\
\hline 1314 & Linha Amarela & R Arlindo Janot & $\begin{array}{r}22^{\circ} 52^{\prime} 18.184 \mathrm{~S} \\
43^{\circ} 14^{\prime} 54.592^{\prime \prime} \mathrm{W}^{\prime \prime}\end{array}$ \\
\hline 1315 & Linha Amarela & R Eng. Artur Moura & $\begin{array}{r}22^{\circ} 52^{\prime} 19.295 \mathrm{~S} \\
43^{\circ} 15^{\prime} 1.914^{\prime \prime} \mathrm{W}^{\prime \prime}\end{array}$ \\
\hline 1316 & Linha Amarela & R Leopoldo Bulhões & $\begin{array}{r}22^{\circ} 52^{\prime} 19.288 \mathrm{~S} \\
43^{\circ} 15^{\prime} 8.214^{\prime \prime} \mathrm{W}^{\prime \prime}\end{array}$ \\
\hline 1317 & Linha Amarela & R Uranos & $\begin{array}{r}22^{\circ} 52^{\prime} 18.698 \mathrm{~S} \\
43^{\circ} 15^{\prime} 14.108^{\prime \prime} \mathrm{W}^{\prime \prime}\end{array}$ \\
\hline 1318 & Linha Amarela & Av dos Democráticos & $\begin{array}{r}22^{\circ} 52^{\prime} 17.805 \mathrm{~S} \\
43^{\circ} 15^{\prime} 22.326^{\prime \prime} \mathrm{W}^{\prime \prime}\end{array}$ \\
\hline 1319 & Linha Amarela & Estr Velha da Pavuna & $\begin{array}{r}22^{\circ} 52^{\prime} 22.461 \mathrm{~S} \\
43^{\circ} 16^{\prime} 3.567^{\prime \prime} \mathrm{W}^{\prime \prime}\end{array}$ \\
\hline 1320 & Linha Amarela & Av Pst. Martin Luther King Júnior & $\begin{array}{r}22^{\circ} 52^{\prime} 34.935 \mathrm{~S} \\
43^{\circ} 16^{\prime} 34.100^{\prime \prime} \mathrm{W}^{\prime \prime}\end{array}$ \\
\hline 1321 & Linha Amarela & Av D. Hélder Câmara & $\begin{array}{r}22^{\circ} 52^{\prime} 52.889 \mathrm{~S} \\
43^{\circ} 16^{\prime} 58.606^{\prime \prime} \mathrm{W}^{\prime \prime}\end{array}$ \\
\hline 1322 & Linha Amarela & R Goiás & $\begin{array}{r}22^{\circ} 53 ' 22.667 \mathrm{~S} \\
43^{\circ} 17^{\prime} 46.525^{\prime \prime} \mathrm{W}^{\prime \prime}\end{array}$ \\
\hline 1323 & Linha Amarela & Av Amaro Cavalcânti & $\begin{array}{r}22^{\circ} 53^{\prime} 43.887 \mathrm{~S} \\
43^{\circ} 18^{\prime} 2.785^{\prime \prime} \mathrm{W}^{\prime \prime}\end{array}$ \\
\hline 1324 & Linha Amarela & R Dois de Fevereiro & $\begin{array}{r}22^{\circ} 53^{\prime} 45.125 \mathrm{~S} \\
43^{\circ} 18^{\prime} 3.277^{\prime \prime} \mathrm{W}^{\prime \prime}\end{array}$ \\
\hline 1325 & Linha Amarela & R Borja Reis & $\begin{array}{r}22^{\circ} 53^{\prime} 59.848 \mathrm{~S} \\
43^{\circ} 18^{\prime} 11.768^{\prime \prime} \mathrm{W}^{\prime \prime}\end{array}$ \\
\hline 1326 & Linha Amarela & Tun da Suiça Carioca & $\begin{array}{r}22^{\circ} 54^{\prime} 53.605 \mathrm{~S} \\
43^{\circ} 19^{\prime} 11.801^{\prime \prime} \mathrm{W}^{\prime \prime}\end{array}$ \\
\hline 1327 & Linha Amarela & Estr do Pau Ferro & $\begin{array}{r}22^{\circ} 55^{\prime} 30.561 \mathrm{~S} \\
43^{\circ} 20^{\prime} 20.427^{\prime \prime} \mathrm{W}^{\prime \prime}\end{array}$ \\
\hline 1328 & Linha Amarela & Av Geremário Dantas & $\begin{array}{r}22^{\circ} 55^{\prime} 59.078 \mathrm{~S} \\
43^{\circ} 20^{\prime} 43.612^{\prime \prime} \mathrm{W}^{\prime \prime}\end{array}$ \\
\hline
\end{tabular}




\begin{tabular}{|c|c|c|c|}
\hline ordem & corredor & endereco & coordenadas \\
\hline 1329 & Linha Amarela & R Edgard Werneck & $\begin{array}{r}22^{\circ} 56^{\prime} 43.158 \mathrm{~S} \\
43^{\circ} 21^{\prime} 15.652^{\prime \prime} \mathrm{W}^{\prime \prime}\end{array}$ \\
\hline 1330 & Linha Amarela & Av Ayrton Senna & $\begin{array}{r}22^{\circ} 57^{\prime} 14.161 \mathrm{~S} \\
43^{\circ} 21^{\prime} 26.940^{\prime \prime} \mathrm{W}^{\prime \prime}\end{array}$ \\
\hline 1331 & Avenida Bento Ribeiro Dantas & Vd de Manguinhos & $\begin{array}{r}22^{\circ} 51^{\prime} 56.811 \mathrm{~S} \\
43^{\circ} 14^{\prime} 23.706^{\prime \prime} \mathrm{W}^{\prime \prime}\end{array}$ \\
\hline 1332 & Avenida Bento Ribeiro Dantas & Av Pres. João Goulart & $\begin{array}{r}22^{\circ} 51 ' 57.102 \mathrm{~S} \\
43^{\circ} 14^{\prime} 23.485^{\prime \prime} \mathrm{W}^{\prime \prime}\end{array}$ \\
\hline 1333 & $\begin{array}{l}\text { Linha Vermelha - Av. Pres. João } \\
\text { Goulart }\end{array}$ & Rod BR-116 & $\begin{array}{r}22^{\circ} 48^{\prime} 9.307 \mathrm{~S} \\
43^{\circ} 20^{\prime} 22.768^{\prime \prime} \mathrm{W}^{\prime \prime}\end{array}$ \\
\hline 1334 & $\begin{array}{l}\text { Linha Vermelha - Av. Pres. João } \\
\text { Goulart }\end{array}$ & Duque de Caxias & $\begin{array}{r}22^{\circ} 48^{\prime} 9.404 \mathrm{~S} \\
43^{\circ} 20^{\prime} 16.566^{\prime \prime} \mathrm{W}^{\prime \prime}\end{array}$ \\
\hline 1335 & $\begin{array}{l}\text { Linha Vermelha - Av. Pres. João } \\
\text { Goulart }\end{array}$ & Av Brg. Trompowski & $\begin{array}{r}22^{\circ} 50^{\prime} 23.784 \mathrm{~S} \\
43^{\circ} 14^{\prime} 29.052^{\prime \prime} \mathrm{W}^{\prime \prime}\end{array}$ \\
\hline 1336 & $\begin{array}{l}\text { Linha Vermelha - Av. Pres. João } \\
\text { Goulart }\end{array}$ & Av Bento Ribeiro Dantas & $\begin{array}{r}22^{\circ} 51^{\prime} 14.720 \mathrm{~S} \\
43^{\circ} 14^{\prime} 21.297^{\prime \prime} \mathrm{W}^{\prime \prime}\end{array}$ \\
\hline 1337 & $\begin{array}{l}\text { Linha Vermelha - Av. Pres. João } \\
\text { Goulart }\end{array}$ & Av Brasil & $\begin{array}{r}22^{\circ} 52^{\prime} 23.700 \mathrm{~S} \\
43^{\circ} 13^{\prime} 56.490^{\prime \prime} \mathrm{W}^{\prime \prime}\end{array}$ \\
\hline 1338 & $\begin{array}{l}\text { Linha Vermelha - Av. Pres. João } \\
\text { Goulart }\end{array}$ & Vd Prf. Mário Henrique Simonsen & $\begin{array}{r}22^{\circ} 53^{\prime} 15.617 \mathrm{~S} \\
43^{\circ} 13^{\prime} 31.655^{\prime \prime} \mathrm{W}^{\prime \prime}\end{array}$ \\
\hline 1339 & $\begin{array}{l}\text { Linha Vermelha - Av. Pres. João } \\
\text { Goulart }\end{array}$ & R Campo de São Cristóvão & $\begin{array}{r}22^{\circ} 53^{\prime} 47.340 \mathrm{~S} \\
43^{\circ} 13^{\prime} 8.572^{\prime \prime} \mathrm{W}^{\prime \prime}\end{array}$ \\
\hline 1340 & $\begin{array}{l}\text { Linha Vermelha - Av. Pres. João } \\
\text { Goulart }\end{array}$ & Vevd Prf. Rufino de Almeida Pizarro & $\begin{array}{r}22^{\circ} 53^{\prime} 54.615 \mathrm{~S} \\
43^{\circ} 13^{\prime} 7.198^{\prime \prime} \mathrm{W}^{\prime \prime}\end{array}$ \\
\hline 1341 & $\begin{array}{l}\text { Linha Vermelha - Av. Pres. João } \\
\text { Goulart }\end{array}$ & Av Bento Ribeiro Dantas & $\begin{array}{r}22^{\circ} 52^{\prime} 19.440 \mathrm{~S} \\
43^{\circ} 13^{\prime} 56.084^{\prime \prime} \mathrm{W}^{\prime \prime}\end{array}$ \\
\hline 1342 & $\begin{array}{l}\text { Linha Vermelha - Av. Pres. João } \\
\text { Goulart }\end{array}$ & Av Brg. Trompowski & $\begin{array}{r}22^{\circ} 51^{\prime} 14.541 \mathrm{~S} \\
43^{\circ} 14^{\prime} 20.813^{\prime \prime} \mathrm{W}^{\prime \prime}\end{array}$ \\
\hline 1343 & $\begin{array}{l}\text { Linha Vermelha - Av. Pres. João } \\
\text { Goulart }\end{array}$ & Rod BR-040 & $\begin{array}{r}22^{\circ} 49^{\prime} 13.180 \mathrm{~S} \\
43^{\circ} 15^{\prime} 23.648^{\prime \prime} \mathrm{W}^{\prime \prime}\end{array}$ \\
\hline 1344 & $\begin{array}{l}\text { Avenida Presidente Vargas - } \\
\text { Pista Central }\end{array}$ & Av Rio Branco & $\begin{array}{r}22^{\circ} 54^{\prime} 3.844 \mathrm{~S} \\
43^{\circ} 10^{\prime} 44.510^{\prime \prime} \mathrm{W}^{\prime \prime}\end{array}$ \\
\hline 1345 & $\begin{array}{l}\text { Avenida Presidente Vargas - } \\
\text { Pista Central }\end{array}$ & Av Trinta e Um de Março & $\begin{array}{r}22^{\circ} 54^{\prime} 14.866 \mathrm{~S} \\
43^{\circ} 11^{\prime} 17.957^{\prime \prime} \mathrm{W}^{\prime \prime}\end{array}$ \\
\hline 1346 & $\begin{array}{l}\text { Avenida Presidente Vargas - } \\
\text { Pista Central }\end{array}$ & Vd dos Marinheiros & $\begin{array}{r}22^{\circ} 54^{\prime} 30.923 \mathrm{~S} \\
43^{\circ} 12^{\prime} 9.181^{\prime \prime} \mathrm{W}^{\prime \prime}\end{array}$ \\
\hline 1347 & $\begin{array}{l}\text { Avenida Presidente Vargas - } \\
\text { Pista Central }\end{array}$ & Av Trinta e Um de Março & $\begin{array}{r}22^{\circ} 54^{\prime} 31.638 \mathrm{~S} \\
43^{\circ} 12^{\prime} 7.457^{\prime \prime} \mathrm{W}^{\prime \prime}\end{array}$ \\
\hline 1348 & $\begin{array}{l}\text { Avenida Presidente Vargas - } \\
\text { Pista Central }\end{array}$ & Av Rio Branco & $\begin{array}{r}22^{\circ} 54^{\prime} 15.363 \mathrm{~S} \\
43^{\circ} 11^{\prime} 17.768^{\prime \prime} \mathrm{W}^{\prime \prime}\end{array}$ \\
\hline 1349 & $\begin{array}{l}\text { Avenida Presidente Vargas - } \\
\text { Pista Central }\end{array}$ & R da Quitanda & $\begin{array}{r}22^{\circ} 54^{\prime} 4.732 \mathrm{~S} \\
43^{\circ} 10^{\prime} 44.289^{\prime \prime} \mathrm{W}^{\prime \prime}\end{array}$ \\
\hline 1350 & $\begin{array}{l}\text { Avenida Presidente Vargas - } \\
\text { Pista Lateral }\end{array}$ & Av Trinta e Um de Março & $\begin{array}{r}22^{\circ} 54^{\prime} 33.056 \mathrm{~S} \\
43^{\circ} 12^{\prime} 10.141^{\prime \prime} \mathrm{W}^{\prime \prime}\end{array}$ \\
\hline
\end{tabular}




\begin{tabular}{|c|c|c|c|}
\hline ordem & corredor & endereco & coordenadas \\
\hline 1351 & $\begin{array}{l}\text { Avenida Presidente Vargas - } \\
\text { Pista Lateral }\end{array}$ & Av Rio Branco & $\begin{array}{r}22^{\circ} 54^{\prime} 15.908 \mathrm{~S} \\
43^{\circ} 11^{\prime} 17.530^{\prime \prime} \mathrm{W}^{\prime \prime}\end{array}$ \\
\hline 1352 & $\begin{array}{l}\text { Avenida Presidente Vargas - } \\
\text { Pista Lateral }\end{array}$ & R da Quitanda & $\begin{array}{r}22^{\circ} 54^{\prime} 4.920 \mathrm{~S} \\
43^{\circ} 10^{\prime} 44.180^{\prime \prime} \mathrm{W}^{\prime \prime}\end{array}$ \\
\hline 1353 & $\begin{array}{l}\text { Avenida Presidente Vargas - } \\
\text { Pista Lateral }\end{array}$ & R Primeiro de Março & $\begin{array}{r}22^{\circ} 54^{\prime} 3.939 \mathrm{~S} \\
43^{\circ} 10^{\prime} 39.971 " \mathrm{~W}^{\prime \prime}\end{array}$ \\
\hline 1354 & $\begin{array}{l}\text { Avenida Presidente Vargas - } \\
\text { Pista Lateral }\end{array}$ & Av Rio Branco & $\begin{array}{r}22^{\circ} 54^{\prime} 1.978 \mathrm{~S} \\
43^{\circ} 10^{\prime} 40.572^{\prime \prime} \mathrm{W}^{\prime \prime}\end{array}$ \\
\hline 1355 & $\begin{array}{l}\text { Avenida Presidente Vargas - } \\
\text { Pista Lateral }\end{array}$ & Av Passos & $\begin{array}{r}22^{\circ} 54^{\prime} 6.465 \mathrm{~S} \\
43^{\circ} 10^{\prime} 53.945^{\prime \prime} \mathrm{W}^{\prime \prime}\end{array}$ \\
\hline 1356 & $\begin{array}{l}\text { Avenida Presidente Vargas - } \\
\text { Pista Lateral }\end{array}$ & R Pereira Franco & $\begin{array}{r}22^{\circ} 54^{\prime} 16.131 \mathrm{~S} \\
43^{\circ} 11^{\prime} 23.624^{\prime \prime} \mathrm{W}^{\prime \prime}\end{array}$ \\
\hline 1357 & $\begin{array}{l}\text { Avenida Presidente Vargas - } \\
\text { Pista Lateral }\end{array}$ & Av Trinta e Um de Março & $\begin{array}{r}22^{\circ} 54^{\prime} 24.815 \mathrm{~S} \\
43^{\circ} 11^{\prime} 51.372^{\prime \prime} \mathrm{W}^{\prime \prime}\end{array}$ \\
\hline 1358 & $\begin{array}{l}\text { Avenida Presidente Vargas - } \\
\text { Pista Lateral }\end{array}$ & R Cmte. Mauriti & $\begin{array}{r}22^{\circ} 54^{\prime} 25.614 \mathrm{~S} \\
43^{\circ} 11^{\prime} 54.067^{\prime \prime} \mathrm{W}^{\prime \prime}\end{array}$ \\
\hline 1359 & $\begin{array}{l}\text { Avenida Presidente Vargas - } \\
\text { Pista Lateral }\end{array}$ & R Francisco Bicalho & $\begin{array}{r}22^{\circ} 54^{\prime} 31.063 \mathrm{~S} \\
43^{\circ} 12^{\prime} 10.950^{\prime \prime} \mathrm{W}^{\prime \prime}\end{array}$ \\
\hline 1360 & $\begin{array}{l}\text { Linha Vermelha - Vevd Prf } \\
\text { Rufino de Almeida Pizarro }\end{array}$ & Av Pedro II & $\begin{array}{r}22^{\circ} 54^{\prime} 4.258 \mathrm{~S} \\
43^{\circ} 13^{\prime} 1.065^{\prime \prime} \mathrm{W}^{\prime \prime}\end{array}$ \\
\hline 1361 & $\begin{array}{l}\text { Linha Vermelha - Vevd Prf } \\
\text { Rufino de Almeida Pizarro }\end{array}$ & Vd Eng. Paulo de Sousa Reis & $\begin{array}{r}22^{\circ} 54^{\prime} 18.722 \mathrm{~S} \\
43^{\circ} 12^{\prime} 51.454^{\prime \prime} \mathrm{W}^{\prime \prime}\end{array}$ \\
\hline 1362 & $\begin{array}{l}\text { Linha Vermelha - Vevd Prf } \\
\text { Rufino de Almeida Pizarro }\end{array}$ & R Francisco Eugênio & $\begin{array}{r}22^{\circ} 54^{\prime} 25.587 \mathrm{~S} \\
43^{\circ} 12^{\prime} 46.743^{\prime \prime} \mathrm{W}^{\prime \prime}\end{array}$ \\
\hline 1363 & $\begin{array}{l}\text { Linha Vermelha - Vevd Prf } \\
\text { Rufino de Almeida Pizarro }\end{array}$ & R Elpídio Boamorte & $\begin{array}{r}22^{\circ} 54^{\prime} 30.975 \mathrm{~S} \\
43^{\circ} 12^{\prime} 43.172^{\prime \prime} \mathrm{W}^{\prime \prime}\end{array}$ \\
\hline 1364 & $\begin{array}{l}\text { Linha Vermelha - Vevd Prf } \\
\text { Rufino de Almeida Pizarro }\end{array}$ & Vd dos Marinheiros & $\begin{array}{r}22^{\circ} 54^{\prime} 35.661 \mathrm{~S} \\
43^{\circ} 12^{\prime} 38.326^{\prime \prime} \mathrm{W}^{\prime \prime}\end{array}$ \\
\hline 1365 & $\begin{array}{l}\text { Linha Vermelha - Vevd Prf } \\
\text { Rufino de Almeida Pizarro }\end{array}$ & Vd dos Aviadores & $\begin{array}{r}22^{\circ} 54^{\prime} 37.485 \mathrm{~S} \\
43^{\circ} 12^{\prime} 35.950^{\prime \prime} \mathrm{W}^{\prime \prime}\end{array}$ \\
\hline 1366 & $\begin{array}{l}\text { Linha Vermelha - Vevd Prf } \\
\text { Rufino de Almeida Pizarro }\end{array}$ & Vd dos Fuzileiros & $\begin{array}{r}22^{\circ} 54 ' 39.985 \mathrm{~S} \\
43^{\circ} 12^{\prime} 34.862^{\prime \prime} \mathrm{W}^{\prime \prime}\end{array}$ \\
\hline 1367 & $\begin{array}{l}\text { Linha Vermelha - Vevd Prf } \\
\text { Rufino de Almeida Pizarro }\end{array}$ & Vevd Eng. Freyssinet & $\begin{array}{r}22^{\circ} 54^{\prime} 43.263 \mathrm{~S} \\
43^{\circ} 12^{\prime} 34.949^{\prime \prime} \mathrm{W}^{\prime \prime}\end{array}$ \\
\hline 1368 & $\begin{array}{l}\text { Linha Vermelha - Vevd Prf } \\
\text { Rufino de Almeida Pizarro }\end{array}$ & Vd dos Aviadores & $\begin{array}{r}22^{\circ} 54^{\prime} 43.330 \mathrm{~S} \\
43^{\circ} 12^{\prime} 34.642^{\prime \prime} \mathrm{W}^{\prime \prime}\end{array}$ \\
\hline 1369 & $\begin{array}{l}\text { Linha Vermelha - Vevd Prf } \\
\text { Rufino de Almeida Pizarro }\end{array}$ & Vd dos Marinheiros & $\begin{array}{r}22^{\circ} 54^{\prime} 37.711 \mathrm{~S} \\
43^{\circ} 12^{\prime} 35.397^{\prime \prime} \mathrm{W}^{\prime \prime}\end{array}$ \\
\hline 1370 & $\begin{array}{l}\text { Linha Vermelha - Vevd Prf } \\
\text { Rufino de Almeida Pizarro }\end{array}$ & R Elpídio Boamorte & $\begin{array}{r}22^{\circ} 54^{\prime} 35.568 \mathrm{~S} \\
43^{\circ} 12^{\prime} 37.946^{\prime \prime} \mathrm{W}^{\prime \prime}\end{array}$ \\
\hline 1371 & $\begin{array}{l}\text { Linha Vermelha - Vevd Prf } \\
\text { Rufino de Almeida Pizarro }\end{array}$ & R Francisco Eugênio & $\begin{array}{r}22^{\circ} 54^{\prime} 24.658 \mathrm{~S} \\
43^{\circ} 12^{\prime} 45.663^{\prime \prime} \mathrm{W}^{\prime \prime}\end{array}$ \\
\hline 1372 & $\begin{array}{l}\text { Linha Vermelha - Vevd Prf } \\
\text { Rufino de Almeida Pizarro }\end{array}$ & Vd Eng. Paulo de Sousa Reis & $\begin{array}{r}22^{\circ} 54^{\prime} 24.198 \mathrm{~S} \\
43^{\circ} 12^{\prime} 46.008^{\prime \prime} \mathrm{W}^{\prime \prime}\end{array}$ \\
\hline
\end{tabular}




\begin{tabular}{|c|c|c|c|}
\hline ordem & corredor & endereco & coordenadas \\
\hline 1373 & $\begin{array}{l}\text { Linha Vermelha - Vevd Prf } \\
\text { Rufino de Almeida Pizarro }\end{array}$ & Av Pedro Ii & $\begin{array}{r}22^{\circ} 54^{\prime} 19.007 \mathrm{~S} \\
43^{\circ} 12^{\prime} 51.074^{\prime \prime} \mathrm{W}^{\prime \prime}\end{array}$ \\
\hline 1374 & $\begin{array}{l}\text { Linha Vermelha - Vevd Prf } \\
\text { Rufino de Almeida Pizarro }\end{array}$ & R Campo de São Cristóvão & $\begin{array}{r}22^{\circ} 53^{\prime} 47.301 \mathrm{~S} \\
43^{\circ} 13^{\prime} 8.352^{\prime \prime} \mathrm{W}^{\prime \prime}\end{array}$ \\
\hline 1375 & $\begin{array}{l}\text { Linha Vermelha - Vevd Prf } \\
\text { Rufino de Almeida Pizarro }\end{array}$ & R Alm. Mariath & $\begin{array}{r}22^{\circ} 53^{\prime} 41.596 \mathrm{~S} \\
43^{\circ} 13^{\prime} 10.889^{\prime \prime} \mathrm{W}^{\prime \prime}\end{array}$ \\
\hline 1376 & $\begin{array}{l}\text { Linha Vermelha - Vevd Prf } \\
\text { Rufino de Almeida Pizarro }\end{array}$ & Vd Prf. Mário Henrique Simonsen & $\begin{array}{r}22^{\circ} 53 ' 32.865 \mathrm{~S} \\
43^{\circ} 13^{\prime} 17.569^{\prime \prime} \mathrm{W}^{\prime \prime}\end{array}$ \\
\hline 1377 & $\begin{array}{l}\text { Linha Vermelha - Vevd Prf } \\
\text { Rufino de Almeida Pizarro }\end{array}$ & Av Brasil & $\begin{array}{r}22^{\circ} 53^{\prime} 15.777 \mathrm{~S} \\
43^{\circ} 13^{\prime} 31.349^{\prime \prime} \mathrm{W}^{\prime \prime}\end{array}$ \\
\hline 1378 & $\begin{array}{l}\text { Linha Vermelha - Vevd Prf } \\
\text { Rufino de Almeida Pizarro }\end{array}$ & Av Pres João Goulart & $\begin{array}{r}22^{\circ} 53^{\prime} 2.131 \mathrm{~S} \\
43^{\circ} 13^{\prime} 42.203^{\prime \prime} \mathrm{W}^{\prime \prime}\end{array}$ \\
\hline 1379 & Ponte Rio-Niterói & Av Gov. Roberto Silveira & $\begin{array}{r}22^{\circ} 52^{\prime} 21.687 \mathrm{~S} \\
43^{\circ} 12^{\prime} 19.203^{\prime \prime} \mathrm{W}^{\prime \prime}\end{array}$ \\
\hline 1380 & Ponte Rio-Niterói & Av Rio de Janeiro & $\begin{array}{r}22^{\circ} 52^{\prime} 21.869 \mathrm{~S} \\
43^{\circ} 12^{\prime} 20.151^{\prime \prime} "\end{array}$ \\
\hline 1381 & Avenida Borges de Medeiros & R Prf. Abelardo Lobo & $\begin{array}{r}22^{\circ} 57^{\prime} 45.435 \mathrm{~S} \\
43^{\circ} 12^{\prime} 20.897^{\prime \prime} \mathrm{W}^{\prime \prime}\end{array}$ \\
\hline 1382 & Avenida Borges de Medeiros & R Carlos Esmeraldino & $\begin{array}{r}22^{\circ} 57^{\prime} 46.604 \mathrm{~S} \\
43^{\circ} 12^{\prime} 30.534^{\prime \prime} \mathrm{W}^{\prime \prime}\end{array}$ \\
\hline 1383 & Avenida Borges de Medeiros & R Gen. Garzon & $\begin{array}{r}22^{\circ} 57^{\prime} 51.130 \mathrm{~S} \\
43^{\circ} 12^{\prime} 52.849^{\prime \prime} \mathrm{W}^{\prime \prime}\end{array}$ \\
\hline 1384 & Avenida Borges de Medeiros & R Mário Ribeiro & $\begin{array}{r}22^{\circ} 58^{\prime} 19.453 \mathrm{~S} \\
43^{\circ} 13^{\prime} 3.657^{\prime \prime} \mathrm{W}^{\prime \prime}\end{array}$ \\
\hline 1385 & Avenida Borges de Medeiros & Av Epitácio Pessoa & $\begin{array}{r}22^{\circ} 58^{\prime} 44.839 \mathrm{~S} \\
43^{\circ} 13^{\prime} 3.329^{\prime \prime} \mathrm{W}^{\prime \prime}\end{array}$ \\
\hline 1386 & Avenida Borges de Medeiros & Av Epitácio Pessoa & $\begin{array}{r}22^{\circ} 58^{\prime} 4.596 \mathrm{~S} \\
43^{\circ} 13^{\prime} 2.622^{\prime \prime} \mathrm{W}^{\prime \prime}\end{array}$ \\
\hline 1387 & Túnel André Reboucas & R Cosme Velho & $\begin{array}{r}22^{\circ} 566^{\prime} 53.565 \mathrm{~S} \\
43^{\circ} 12^{\prime} 11.487^{\prime \prime} \mathrm{W}^{\prime \prime}\end{array}$ \\
\hline 1388 & Túnel André Reboucas & Vd José de Alencar & $\begin{array}{r}22^{\circ} 56^{\prime} 20.814 \mathrm{~S} \\
43^{\circ} 12^{\prime} 9.373^{\prime \prime} \mathrm{W}^{\prime \prime}\end{array}$ \\
\hline 1389 & Túnel André Reboucas & R Alm. Alexandrino & $\begin{array}{r}22^{\circ} 56^{\prime} 17.004 \mathrm{~S} \\
43^{\circ} 12^{\prime} 13.686^{\prime \prime} \mathrm{W}^{\prime \prime}\end{array}$ \\
\hline 1390 & Túnel André Reboucas & R Sta. Alexandrina & $\begin{array}{r}22^{\circ} 56^{\prime} 11.149 \mathrm{~S} \\
43^{\circ} 12^{\prime} 24.769^{\prime \prime} \mathrm{W}^{\prime \prime}\end{array}$ \\
\hline 1391 & Túnel André Reboucas & Av Paulo de Frontin & $\begin{array}{r}22^{\circ} 56^{\prime} 4.908 \mathrm{~S} \\
43^{\circ} 12^{\prime} 34.567^{\prime \prime} \mathrm{W}^{\prime \prime}\end{array}$ \\
\hline 1392 & Túnel André Reboucas & R Paula Ramos & $\begin{array}{r}22^{\circ} 56^{\prime} 1.149 \mathrm{~S} \\
43^{\circ} 12^{\prime} 35.335^{\prime \prime} \mathrm{W}^{\prime \prime}\end{array}$ \\
\hline 1393 & Túnel Antônio Reboucas & R Sta. Alexandrina & $\begin{array}{r}22^{\circ} 56^{\prime} 1.838 \mathrm{~S} \\
43^{\circ} 12^{\prime} 35.819^{\prime \prime} \mathrm{W}^{\prime \prime}\end{array}$ \\
\hline 1394 & Túnel Antônio Reboucas & R Alm. Alexandrino & $\begin{array}{r}22^{\circ} 56^{\prime} 11.613 \mathrm{~S} \\
43^{\circ} 12^{\prime} 25.712^{\prime \prime} \mathrm{W}^{\prime \prime}\end{array}$ \\
\hline
\end{tabular}




\begin{tabular}{|c|c|c|c|}
\hline ordem & corredor & endereco & coordenadas \\
\hline 1395 & Túnel Antônio Reboucas & Vd José de Alencar & $\begin{array}{r}22^{\circ} 56^{\prime} 20.584 \mathrm{~S} \\
43^{\circ} 12^{\prime} 10.175^{\prime \prime} \mathrm{W}^{\prime \prime}\end{array}$ \\
\hline 1396 & Túnel Antônio Reboucas & R Cosme Velho & $\begin{array}{r}22^{\circ} 56^{\prime} 23.188 \mathrm{~S} \\
43^{\circ} 12^{\prime} 9.060^{\prime \prime} \mathrm{W}^{\prime \prime}\end{array}$ \\
\hline 1397 & Túnel Antônio Reboucas & R Maria Eugênia & $\begin{array}{r}22^{\circ} 56^{\prime} 53.786 \mathrm{~S} \\
43^{\circ} 12^{\prime} 12.016^{\prime \prime} \mathrm{W}^{\prime \prime}\end{array}$ \\
\hline 1398 & Avenida Paulo de Frontin & Pça Sta. Alexandrina & $\begin{array}{r}22^{\circ} 55^{\prime} 59.349 \mathrm{~S} \\
43^{\circ} 12^{\prime} 34.667^{\prime \prime} \mathrm{W}^{\prime \prime}\end{array}$ \\
\hline 1399 & Avenida Paulo de Frontin & R Haddock Lobo & $\begin{array}{r}22^{\circ} 55^{\prime} 27.098 \mathrm{~S} \\
43^{\circ} 12^{\prime} 34.440^{\prime \prime} \mathrm{W}^{\prime \prime}\end{array}$ \\
\hline 1400 & Avenida Paulo de Frontin & Vd dos Fuzileiros & $\begin{array}{r}22^{\circ} 54^{\prime} 49.936 \mathrm{~S} \\
43^{\circ} 12^{\prime} 35.550^{\prime \prime} \mathrm{W}^{\prime \prime}\end{array}$ \\
\hline 1401 & Avenida Paulo de Frontin & Vd dos Pracinhas & $\begin{array}{r}22^{\circ} 54^{\prime} 39.176 \mathrm{~S} \\
43^{\circ} 12^{\prime} 31.642^{\prime \prime} \mathrm{W}^{\prime \prime}\end{array}$ \\
\hline 1402 & Avenida Paulo de Frontin & Av Francisco Bicalho & $\begin{array}{r}22^{\circ} 54^{\prime} 36.919 \mathrm{~S} \\
43^{\circ} 12^{\prime} 30.415^{\prime \prime} \mathrm{W}^{\prime \prime}\end{array}$ \\
\hline 1403 & Avenida Paulo de Frontin & R Haddock Lobo & $\begin{array}{r}22^{\circ} 54^{\prime} 54.529 \mathrm{~S} \\
43^{\circ} 12^{\prime} 37.068^{\prime \prime} \mathrm{W}^{\prime \prime}\end{array}$ \\
\hline 1404 & Avenida Paulo de Frontin & R Sta. Alexandrina & $\begin{array}{r}22^{\circ} 55^{\prime} 32.004 \mathrm{~S} \\
43^{\circ} 12^{\prime} 34.994^{\prime \prime} \mathrm{W}^{\prime \prime}\end{array}$ \\
\hline 1405 & Avenida Paulo de Frontin & Tun Antônio Rebouças & $\begin{array}{r}22^{\circ} 566^{\prime} 2.993 \mathrm{~S} \\
43^{\circ} 12^{\prime} 36.086^{\prime \prime} \mathrm{W}^{\prime \prime}\end{array}$ \\
\hline 1406 & Avenida das Américas & Av Juan Manoel Fangio & $\begin{array}{r}23^{\circ} 0^{\prime} 0.725 \mathrm{~S} \\
43^{\circ} 20^{\prime} 5.411^{\prime \prime} \mathrm{W}^{\prime \prime}\end{array}$ \\
\hline 1407 & Avenida das Américas & Av Ayrton Senna & $\begin{array}{r}22^{\circ} 59^{\prime} 58.068 \mathrm{~S} \\
43^{\circ} 21^{\prime} 30.470^{\prime \prime} \mathrm{W}^{\prime \prime}\end{array}$ \\
\hline 1408 & Avenida das Américas & Av Salvador Allende & $\begin{array}{r}22^{\circ} 59^{\prime} 59.252 \mathrm{~S} \\
43^{\circ} 24^{\prime} 4.003^{\prime \prime} \mathrm{W}^{\prime \prime}\end{array}$ \\
\hline 1409 & Avenida das Américas & Estr Benvindo de Novais & $\begin{array}{r}23^{\circ} 0^{\prime} 36.197 \mathrm{~S} \\
43^{\circ} 27^{\prime} 1.773^{\prime \prime W " W "}\end{array}$ \\
\hline 1410 & Avenida das Américas & Estr Ver. Alceu de Carvalho & $\begin{array}{r}23^{\circ} 1^{\prime} 0.623 \mathrm{~S} \\
43^{\circ} 28^{\prime} 37.398^{\prime \prime} \mathrm{W}^{\prime \prime}\end{array}$ \\
\hline 1411 & Avenida das Américas & Estr do Pontal & $\begin{array}{r}23^{\circ} 11^{\prime} 8.031 \mathrm{~S} \\
43^{\circ} 30^{\prime} 24.614^{\prime \prime} \mathrm{W}^{\prime \prime}\end{array}$ \\
\hline 1412 & Avenida das Américas & Estr Roberto Burle Marx & $\begin{array}{r}23^{\circ} 0^{\prime} 44.202 \mathrm{~S} \\
43^{\circ} 32^{\prime} 23.579^{\prime \prime} \mathrm{W}^{\prime \prime}\end{array}$ \\
\hline 1413 & Avenida das Américas & Cam Abreu & $\begin{array}{r}23^{\circ} 0{ }^{\prime} 37.594 \mathrm{~S} \\
43^{\circ} 32^{\prime} 31.095^{\prime \prime} \mathrm{W}^{\prime \prime}\end{array}$ \\
\hline 1414 & Avenida das Américas & Estr da Matriz & $\begin{array}{r}23^{\circ} 0^{\prime} 11.068 \mathrm{~S} \\
43^{\circ} 34^{\prime} 6.504^{\prime \prime} \mathrm{W}^{\prime \prime}\end{array}$ \\
\hline 1415 & Avenida das Américas & Estr do Magarça & $\begin{array}{r}22^{\circ} 58^{\prime} 42.932 \mathrm{~S} \\
43^{\circ} 36^{\prime} 40.172^{\prime \prime} \mathrm{W}^{\prime \prime}\end{array}$ \\
\hline 1416 & Avenida das Américas & Estr da Pedra & $\begin{array}{r}22^{\circ} 58^{\prime} 7.676 \mathrm{~S} \\
43^{\circ} 38^{\prime} 9.283^{\prime \prime} \mathrm{W}^{\prime \prime}\end{array}$ \\
\hline
\end{tabular}




\begin{tabular}{|c|c|c|c|}
\hline ordem & corredor & endereco & coordenadas \\
\hline 1417 & Avenida das Américas & Estr da Matriz & $\begin{array}{r}22^{\circ} 58^{\prime} 42.932 \mathrm{~S} \\
43^{\circ} 36^{\prime} 40.172^{\prime \prime} \mathrm{W}^{\prime \prime}\end{array}$ \\
\hline 1418 & Avenida das Américas & Estr Roberto Burle Marx & $\begin{array}{r}23^{\circ} 0^{\prime} 38.920 \mathrm{~S} \\
43^{\circ} 32^{\prime} 31.545^{\prime \prime} \mathrm{W}^{\prime \prime}\end{array}$ \\
\hline 1419 & Avenida das Américas & Estr do Pontal & $\begin{array}{r}23^{\circ} 0^{\prime} 46.597 \mathrm{~S} \\
43^{\circ} 32^{\prime} 24.569^{\prime \prime} \mathrm{W}^{\prime \prime}\end{array}$ \\
\hline 1420 & Avenida das Américas & Estr Ver. Alceu de Carvalho & $\begin{array}{r}23^{\circ} 11^{\prime} 8.031 \mathrm{~S} \\
43^{\circ} 30^{\prime} 24.614^{\prime \prime} \mathrm{W}^{\prime \prime}\end{array}$ \\
\hline 1421 & Avenida das Américas & Estr Benvindo de Novais & $\begin{array}{r}23^{\circ} 1^{\prime} 1.789 \mathrm{~S} \\
43^{\circ} 28^{\prime} 38.180^{\prime \prime} \mathrm{W}^{\prime \prime}\end{array}$ \\
\hline 1422 & Avenida das Américas & Av Glaucio Gil & $\begin{array}{r}23^{\circ} 0^{\prime} 47.286 \mathrm{~S} \\
43^{\circ} 27^{\prime} 41.323^{\prime \prime} \mathrm{W}^{\prime \prime}\end{array}$ \\
\hline 1423 & Avenida das Américas & Av Alfredo Baltazar da Silveira & $\begin{array}{r}23^{\circ} 0^{\prime} 36.199 \mathrm{~S} \\
43^{\circ} 26^{\prime} 57.747^{\prime \prime} \mathrm{W}^{\prime \prime}\end{array}$ \\
\hline 1424 & Avenida das Américas & Av Ayrton Senna & $\begin{array}{r}23^{\circ} 0^{\prime} 1.455 \mathrm{~S} \\
43^{\circ} 24^{\prime} 5.540^{\prime \prime} \mathrm{W}^{\prime \prime}\end{array}$ \\
\hline 1425 & Avenida das Américas & Av Armando Lombardi & $\begin{array}{r}23^{\circ} 0^{\prime} 2.140 \mathrm{~S} \\
43^{\circ} 20^{\prime} 20.263^{\prime \prime} \mathrm{W}^{\prime \prime}\end{array}$ \\
\hline 1426 & $\begin{array}{l}\text { Avenida das Américas - Pista } \\
\text { Central }\end{array}$ & Cebolão Aba Um & $\begin{array}{r}23^{\circ} 0^{\prime} 0.694 \mathrm{~S} \\
43^{\circ} 24^{\prime} 5.836^{\prime \prime} \mathrm{W}^{\prime \prime}\end{array}$ \\
\hline 1427 & $\begin{array}{l}\text { Avenida das Américas - Pista } \\
\text { Central }\end{array}$ & Cebolão Aba Dois & $\begin{array}{r}23^{\circ} 0^{\prime} 0.508 \mathrm{~S} \\
43^{\circ} 21^{\prime} 57.760^{\prime \prime} \mathrm{W}^{\prime \prime}\end{array}$ \\
\hline 1428 & $\begin{array}{l}\text { Avenida das Américas - Pista } \\
\text { Central }\end{array}$ & Av Armando Lombardi & $\begin{array}{r}23^{\circ} 0^{\prime} 1.307 \mathrm{~S} \\
43^{\circ} 20^{\prime} 23.353^{\prime \prime} \mathrm{W}^{\prime \prime}\end{array}$ \\
\hline 1429 & $\begin{array}{l}\text { Avenida das Américas - Pista } \\
\text { Central }\end{array}$ & Cebolão Aba Dois & $\begin{array}{r}23^{\circ} 0^{\prime} 0.520 \mathrm{~S} \\
43^{\circ} 20^{\prime} 24.928^{\prime \prime} \mathrm{W}^{\prime \prime}\end{array}$ \\
\hline 1430 & $\begin{array}{l}\text { Avenida das Américas - Pista } \\
\text { Central }\end{array}$ & Cebolão Aba Um & $\begin{array}{r}22^{\circ} 59^{\prime} 59.889 \mathrm{~S} \\
43^{\circ} 21^{\prime} 57.725^{\prime \prime} \mathrm{W}^{\prime \prime}\end{array}$ \\
\hline 1431 & $\begin{array}{l}\text { Avenida das Américas - Pista } \\
\text { Central }\end{array}$ & Av Salvador Allende & $\begin{array}{r}23^{\circ} 0^{\prime} 0.050 \mathrm{~S} \\
43^{\circ} 24^{\prime} 4.856^{\prime \prime} \mathrm{W}^{\prime \prime}\end{array}$ \\
\hline 1432 & Avenida Francisco Bicalho & Vd Eng. Paulo de Sousa Reis & $\begin{array}{r}22^{\circ} 54^{\prime} 11.939 \mathrm{~S} \\
43^{\circ} 12^{\prime} 36.651^{\prime \prime} \mathrm{W}^{\prime \prime}\end{array}$ \\
\hline 1433 & Avenida Francisco Bicalho & R Francisco Eugênio & $\begin{array}{r}22^{\circ} 54^{\prime} 24.465 \mathrm{~S} \\
43^{\circ} 12^{\prime} 35.859^{\prime \prime} \mathrm{W}^{\prime \prime}\end{array}$ \\
\hline 1434 & Avenida Francisco Bicalho & Vd dos Pracinhas & $\begin{array}{r}22^{\circ} 54^{\prime} 30.094 \mathrm{~S} \\
43^{\circ} 12^{\prime} 35.532^{\prime \prime} \mathrm{W}^{\prime \prime}\end{array}$ \\
\hline 1435 & Avenida Francisco Bicalho & Vd dos Marinheiros & $\begin{array}{r}22^{\circ} 54^{\prime} 35.767 \mathrm{~S} \\
43^{\circ} 12^{\prime} 32.151^{\prime \prime} \mathrm{W}^{\prime \prime}\end{array}$ \\
\hline 1436 & Avenida Francisco Bicalho & Vd Eng. Paulo de Sousa Reis & $\begin{array}{r}22^{\circ} 54^{\prime} 29.393 \mathrm{~S} \\
43^{\circ} 12^{\prime} 34.082^{\prime \prime} \mathrm{W}^{\prime \prime}\end{array}$ \\
\hline 1437 & Avenida Francisco Bicalho & Vd do Gasômetro & $\begin{array}{r}22^{\circ} 54^{\prime} 10.527 \mathrm{~S} \\
43^{\circ} 12^{\prime} 35.161^{\prime \prime} \mathrm{W}^{\prime \prime}\end{array}$ \\
\hline 1438 & $\begin{array}{l}\text { Avenida Francisco Bicalho - } \\
\text { Pista Lateral }\end{array}$ & R Pedro Alves & $\begin{array}{r}22^{\circ} 54^{\prime} 30.674 \mathrm{~S} \\
43^{\circ} 12^{\prime} 33.428^{\prime \prime} \mathrm{W}^{\prime \prime}\end{array}$ \\
\hline
\end{tabular}




\begin{tabular}{|c|c|c|c|}
\hline ordem & corredor & endereco & coordenadas \\
\hline 1439 & $\begin{array}{l}\text { Avenida Francisco Bicalho - } \\
\text { Pista Lateral }\end{array}$ & R Gen. Luiz Mendes de Morais & $\begin{array}{r}22^{\circ} 544^{\prime} 25.649 \mathrm{~S} \\
43^{\circ} 12^{\prime} 33.687^{\prime \prime} \mathrm{W}^{\prime \prime}\end{array}$ \\
\hline 1440 & $\begin{array}{l}\text { Avenida Francisco Bicalho - } \\
\text { Pista Lateral }\end{array}$ & Av Rodrigues Alves & $\begin{array}{r}22^{\circ} 54^{\prime} 8.140 \mathrm{~S} \\
43^{\circ} 12^{\prime} 34.831^{\prime \prime} \mathrm{W}^{\prime \prime}\end{array}$ \\
\hline 1441 & $\begin{array}{l}\text { Avenida Francisco Bicalho - } \\
\text { Pista Lateral }\end{array}$ & R Cmte. Garcia Pires & $\begin{array}{r}22^{\circ} 53^{\prime} 57.633 \mathrm{~S} \\
43^{\circ} 12^{\prime} 38.249^{\prime \prime} \mathrm{W}^{\prime \prime}\end{array}$ \\
\hline 1442 & $\begin{array}{l}\text { Avenida Francisco Bicalho - } \\
\text { Pista Lateral }\end{array}$ & Av Pedro Ii & $\begin{array}{r}22^{\circ} 54{ }^{\prime} 5.671 \mathrm{~S} \\
43^{\circ} 12^{\prime} 37.661 " 1^{\prime \prime}\end{array}$ \\
\hline 1443 & $\begin{array}{l}\text { Avenida Francisco Bicalho - } \\
\text { Pista Lateral }\end{array}$ & Vd Eng. Paulo de Sousa Reis & $\begin{array}{r}22^{\circ} 54^{\prime} 14.619 \mathrm{~S} \\
43^{\circ} 12^{\prime} 37.095^{\prime \prime} \mathrm{W}^{\prime \prime}\end{array}$ \\
\hline 1444 & $\begin{array}{l}\text { Avenida Francisco Bicalho - } \\
\text { Pista Lateral }\end{array}$ & R Francisco Eugênio & $\begin{array}{r}22^{\circ} 544^{\prime} 23.779 \mathrm{~S} \\
43^{\circ} 12^{\prime} 36.507^{\prime \prime} \mathrm{W}^{\prime \prime}\end{array}$ \\
\hline 1445 & $\begin{array}{l}\text { Avenida Francisco Bicalho - } \\
\text { Pista Lateral }\end{array}$ & R Elpídio Boamorte & $\begin{array}{r}22^{\circ} 54^{\prime} 29.472 \mathrm{~S} \\
43^{\circ} 12^{\prime} 36.142^{\prime \prime} \mathrm{W}^{\prime \prime}\end{array}$ \\
\hline 1446 & Avenida Rodrigues Alves & Av Br. de Tefé & $\begin{array}{r}22^{\circ} 53^{\prime} 42.456 \mathrm{~S} \\
43^{\circ} 11^{\prime} 1.419^{\prime \prime} \mathrm{W}^{\prime \prime}\end{array}$ \\
\hline 1447 & Avenida Rodrigues Alves & Av Rio de Janeiro & $\begin{array}{r}22^{\circ} 53^{\prime} 38.407 \mathrm{~S} \\
43^{\circ} 11^{\prime} 57.141^{\prime \prime} \mathrm{W}^{\prime \prime}\end{array}$ \\
\hline 1448 & Avenida Rodrigues Alves & R Sto. Cristo & $\begin{array}{r}22^{\circ} 53^{\prime} 48.576 \mathrm{~S} \\
43^{\circ} 12^{\prime} 19.682^{\prime \prime} \mathrm{W}^{\prime \prime}\end{array}$ \\
\hline 1449 & Avenida Rodrigues Alves & Av Br. de Tefé & $\begin{array}{r}22^{\circ} 53 ' 34.142 \mathrm{~S} \\
43^{\circ} 11^{\prime} 38.486^{\prime \prime} \mathrm{W}^{\prime \prime}\end{array}$ \\
\hline 1450 & Avenida Rio Branco & R Vsc. de Inhaúma & $\begin{array}{r}22^{\circ} 53^{\prime} 55.390 \mathrm{~S} \\
43^{\circ} 10^{\prime} 48.234^{\prime \prime} \mathrm{W}^{\prime \prime}\end{array}$ \\
\hline 1451 & Avenida Rio Branco & Av Pres. Vargas & $\begin{array}{r}22^{\circ} 54^{\prime} 1.858 \mathrm{~S} \\
43^{\circ} 10^{\prime} 45.871^{\prime \prime} \mathrm{W}^{\prime \prime}\end{array}$ \\
\hline 1452 & Avenida Rio Branco & Av Nilo Peçanha & $\begin{array}{r}22^{\circ} 54^{\prime} 14.076 \mathrm{~S} \\
43^{\circ} 10^{\prime} 41.197^{\prime \prime} \mathrm{W}^{\prime \prime}\end{array}$ \\
\hline 1453 & Avenida Rio Branco & Av Alm. Barroso & $\begin{array}{r}22^{\circ} 54 ' 25.713 \mathrm{~S} \\
43^{\circ} 10^{\prime} 36.766^{\prime \prime} \mathrm{W}^{\prime \prime}\end{array}$ \\
\hline 1454 & Avenida Rio Branco & R da Conceição & $\begin{array}{r}22^{\circ} 54^{\prime} 35.029 \mathrm{~S} \\
43^{\circ} 10^{\prime} 33.215^{\prime \prime} \mathrm{W}^{\prime \prime}\end{array}$ \\
\hline 1455 & Avenida Rio Branco & Av Pres. Wilson & $\begin{array}{r}22^{\circ} 54^{\prime} 43.507 \mathrm{~S} \\
43^{\circ} 10^{\prime} 29.984^{\prime \prime} \mathrm{W}^{\prime \prime}\end{array}$ \\
\hline 1456 & Avenida Rio Branco & Av Beira Mar & $\begin{array}{r}22^{\circ} 54^{\prime} 48.927 \mathrm{~S} \\
43^{\circ} 10^{\prime} 27.900^{\prime \prime} \mathrm{W}^{\prime \prime}\end{array}$ \\
\hline 1457 & Avenida Atlântica & Av Rnh. Elizabeth da Bélgica & $\begin{array}{r}22^{\circ} 59^{\prime} 7.335 \mathrm{~S} \\
43^{\circ} 11^{\prime} 20.389^{\prime \prime} \mathrm{W}^{\prime \prime}\end{array}$ \\
\hline 1458 & Avenida Atlântica & R Miguel Lemos & $\begin{array}{r}22^{\circ} 58^{\prime} 52.765 \mathrm{~S} \\
43^{\circ} 11^{\prime} 22.629^{\prime \prime} \mathrm{W}^{\prime \prime}\end{array}$ \\
\hline 1459 & Avenida Atlântica & R Bolivar & $\begin{array}{r}22^{\circ} 58^{\prime} 37.814 \mathrm{~S} \\
43^{\circ} 11^{\prime} 17.967^{\prime \prime} \mathrm{W}^{\prime \prime}\end{array}$ \\
\hline 1460 & Avenida Atlântica & R Figueiredo Magalhães & $\begin{array}{r}22^{\circ} 58^{\prime} 26.044 \mathrm{~S} \\
43^{\circ} 11^{\prime} 10.714^{\prime \prime} \mathrm{W}^{\prime \prime}\end{array}$ \\
\hline
\end{tabular}




\begin{tabular}{|c|c|c|c|}
\hline ordem & corredor & endereco & coordenadas \\
\hline 1461 & Avenida Atlântica & R Siqueira Campos & $\begin{array}{r}22^{\circ} 58^{\prime} 17.016 \mathrm{~S} \\
43^{\circ} 11^{\prime} 2.088^{\prime \prime} \mathrm{W}^{\prime \prime}\end{array}$ \\
\hline 1462 & Avenida Atlântica & Av Prca. Isabel & $\begin{array}{r}22^{\circ} 58^{\prime} 3.663 \mathrm{~S} \\
43^{\circ} 10^{\prime} 42.694^{\prime \prime} \mathrm{W}^{\prime \prime}\end{array}$ \\
\hline 1463 & Avenida Atlântica & Pça Alm. Júlio de Noronha & $\begin{array}{r}22^{\circ} 57^{\prime} 48.513 \mathrm{~S} \\
43^{\circ} 10^{\prime} 9.801 " \mathrm{~W}^{\prime \prime}\end{array}$ \\
\hline 1464 & Avenida Atlântica & Av Prca. Isabel & $\begin{array}{r}22^{\circ} 57^{\prime} 53.964 \mathrm{~S} \\
43^{\circ} 10^{\prime} 24.648^{\prime \prime} \mathrm{W}\end{array}$ \\
\hline 1465 & Avenida Atlântica & R Siqueira Campos & $\begin{array}{r}22^{\circ} 58^{\prime} 3.075 \mathrm{~S} \\
43^{\circ} 10^{\prime} 43.332^{\prime \prime} \mathrm{W}^{\prime \prime}\end{array}$ \\
\hline 1466 & Avenida Atlântica & R Figueiredo Magalhães & $\begin{array}{r}22^{\circ} 58^{\prime} 16.197 \mathrm{~S} \\
43^{\circ} 11^{\prime} 2.565^{\prime \prime} \mathrm{W}^{\prime \prime}\end{array}$ \\
\hline 1467 & Avenida Atlântica & R Bolivar & $\begin{array}{r}22^{\circ} 58^{\prime} 25.523 \mathrm{~S} \\
43^{\circ} 11^{\prime} 11.5111^{\prime \prime}\end{array}$ \\
\hline 1468 & Avenida Atlântica & R Miguel Lemos & $\begin{array}{r}22^{\circ} 58^{\prime} 37.654 \mathrm{~S} \\
43^{\circ} 11^{\prime} 18.846^{\prime \prime} \mathrm{W}^{\prime \prime}\end{array}$ \\
\hline 1469 & Avenida Atlântica & Av Rnh. Elizabeth da Bélgica & $\begin{array}{r}22^{\circ} 58^{\prime} 52.897 \mathrm{~S} \\
43^{\circ} 11^{\prime} 23.527^{\prime \prime} \mathrm{W}^{\prime \prime}\end{array}$ \\
\hline 1470 & Avenida Atlântica & R Joaquim Nabuco & $\begin{array}{r}22^{\circ} 59^{\prime} 5.968 \mathrm{~S} \\
43^{\circ} 11^{\prime} 21.729^{\prime \prime} \mathrm{W}^{\prime \prime}\end{array}$ \\
\hline 1471 & Avenida Ayrton Senna & R Pref. Duldício Cardoso & $\begin{array}{r}23^{\circ} 0^{\prime} 25.993 \mathrm{~S} \\
43^{\circ} 21^{\prime} 57.758^{\prime \prime} \mathrm{W}^{\prime \prime}\end{array}$ \\
\hline 1472 & Avenida Ayrton Senna & Av Juan Manoel Fangio & $\begin{array}{r}22^{\circ} 59^{\prime} 52.689 \mathrm{~S} \\
43^{\circ} 21^{\prime} 52.512^{\prime \prime} \mathrm{W}^{\prime \prime}\end{array}$ \\
\hline 1473 & Avenida Ayrton Senna & Av Nelson Mufarrej & $\begin{array}{r}22^{\circ} 59^{\prime} 22.598 \mathrm{~S} \\
43^{\circ} 21^{\prime} 55.592^{\prime \prime} \mathrm{W}^{\prime \prime}\end{array}$ \\
\hline 1474 & Avenida Ayrton Senna & Jacarepaguá & $\begin{array}{r}22^{\circ} 58^{\prime} 5.963 \mathrm{~S} \\
43^{\circ} 21^{\prime} 29.835^{\prime \prime} \mathrm{W}^{\prime \prime}\end{array}$ \\
\hline 1475 & Avenida Ayrton Senna & Ln Amarela & $\begin{array}{r}22^{\circ} 57^{\prime} 36.964 \mathrm{~S} \\
43^{\circ} 21^{\prime} 26.923^{\prime \prime W "}\end{array}$ \\
\hline 1476 & Avenida Ayrton Senna & Av Emb. Abelardo Bueno & $\begin{array}{r}22^{\circ} 57^{\prime} 49.816 \mathrm{~S} \\
43^{\circ} 21^{\prime} 26.226^{\prime \prime} \mathrm{W}^{\prime \prime}\end{array}$ \\
\hline 1477 & Avenida Ayrton Senna & Av das Américas & $\begin{array}{r}22^{\circ} 59^{\prime} 12.712 \mathrm{~S} \\
43^{\circ} 21^{\prime} 57.986^{\prime \prime} \mathrm{W}^{\prime \prime}\end{array}$ \\
\hline 1478 & Avenida Ayrton Senna & Av Lúcio Costa & $\begin{array}{r}23^{\circ} 0{ }^{\prime} 25.708 \mathrm{~S} \\
43^{\circ} 21^{\prime} 58.412^{\prime \prime} \mathrm{W}^{\prime \prime}\end{array}$ \\
\hline 1479 & $\begin{array}{l}\text { Avenida Ayrton Senna - pista } \\
\text { central }\end{array}$ & Jacarepaguá & $\begin{array}{r}22^{\circ} 58^{\prime} 58.544 \mathrm{~S} \\
43^{\circ} 21^{\prime} 55.930^{\prime \prime} \mathrm{W}^{\prime \prime}\end{array}$ \\
\hline 1480 & $\begin{array}{l}\text { Avenida Ayrton Senna - pista } \\
\text { central }\end{array}$ & Av das Américas & $\begin{array}{r}22^{\circ} 59^{\prime} 3.022 \mathrm{~S} \\
43^{\circ} 21^{\prime} 57.076^{\prime \prime} \mathrm{W}^{\prime \prime}\end{array}$ \\
\hline 1481 & Avenida Trinta e um de Março & R Fr. Caneca & $\begin{array}{r}22^{\circ} 54^{\prime} 59.406 \mathrm{~S} \\
43^{\circ} 11^{\prime} 38.885^{\prime \prime} \mathrm{W}^{\prime \prime}\end{array}$ \\
\hline 1482 & Avenida Trinta e um de Março & Av Pres. Vargas & $\begin{array}{r}22^{\circ} 54^{\prime} 35.983 \mathrm{~S} \\
43^{\circ} 11^{\prime} 47.020^{\prime \prime} \mathrm{W}^{\prime \prime}\end{array}$ \\
\hline
\end{tabular}




\begin{tabular}{|c|c|c|c|}
\hline ordem & corredor & endereco & coordenadas \\
\hline 1483 & Avenida Trinta e um de Março & R S. Pedro & $\begin{array}{r}22^{\circ} 54^{\prime} 17.176 \mathrm{~S} \\
43^{\circ} 11^{\prime} 54.062^{\prime \prime} \mathrm{W}^{\prime \prime}\end{array}$ \\
\hline 1484 & Avenida Trinta e um de Março & Av Pres. Vargas & $\begin{array}{r}22^{\circ} 54^{\prime} 16.949 \mathrm{~S} \\
43^{\circ} 11^{\prime} 54.520^{\prime \prime} \mathrm{W}^{\prime \prime}\end{array}$ \\
\hline 1485 & Avenida Trinta e um de Março & R Fr. Caneca & $\begin{array}{r}22^{\circ} 54^{\prime} 36.236 \mathrm{~S} \\
43^{\circ} 11^{\prime} 47.338^{\prime \prime} \mathrm{W}^{\prime \prime}\end{array}$ \\
\hline 1486 & Avenida Trinta e um de Março & Tun Sta. Bárbara & $\begin{array}{r}22^{\circ} 54 ' 59.653 \mathrm{~S} \\
43^{\circ} 11^{\prime} 39.181^{\prime \prime W "}\end{array}$ \\
\hline 1487 & Túnel Santa Bárbara & R Alm. Alexandrino & $\begin{array}{r}22^{\circ} 55^{\prime} 22.123 \mathrm{~S} \\
43^{\circ} 11^{\prime} 30.744^{\prime \prime} \mathrm{W}^{\prime \prime}\end{array}$ \\
\hline 1488 & Túnel Santa Bárbara & Vd Eng. Noronha & $\begin{array}{r}22^{\circ} 55^{\prime} 40.590 \mathrm{~S} \\
43^{\circ} 11^{\prime} 17.468^{\prime \prime} \mathrm{W}^{\prime \prime}\end{array}$ \\
\hline 1489 & Túnel Santa Bárbara & R Alm. Alexandrino & $\begin{array}{r}22^{\circ} 55^{\prime} 40.590 \mathrm{~S} \\
43^{\circ} 11^{\prime} 17.468^{\prime \prime} \mathrm{W}^{\prime \prime}\end{array}$ \\
\hline 1490 & Túnel Santa Bárbara & Av Trinta e Um de Março & $\begin{array}{r}22^{\circ} 55^{\prime} 22.123 \mathrm{~S} \\
43^{\circ} 11^{\prime} 30.744^{\prime \prime} \mathrm{W}^{\prime \prime}\end{array}$ \\
\hline 1491 & Rua Pinheiro Machado & Vd Jardel Filho & $\begin{array}{r}22^{\circ} 56^{\prime} 2.132 \mathrm{~S} \\
43^{\circ} 11^{\prime} 4.546^{\prime \prime} \mathrm{W}^{\prime \prime}\end{array}$ \\
\hline 1492 & Rua Pinheiro Machado & R Álvares Chaves & $\begin{array}{r}22^{\circ} 566^{\prime} 5.748 \mathrm{~S} \\
43^{\circ} 11^{\prime} 3.584 " 4^{\prime \prime}\end{array}$ \\
\hline 1493 & Rua Pinheiro Machado & R Muniz Barreto & $\begin{array}{r}22^{\circ} 56^{\prime} 19.528 \mathrm{~S} \\
43^{\circ} 10^{\prime} 59.838^{\prime \prime} \mathrm{W}^{\prime \prime}\end{array}$ \\
\hline 1494 & Rua Pinheiro Machado & Pça Chaim Weizmann & $\begin{array}{r}22^{\circ} 56^{\prime} 30.524 \mathrm{~S} \\
43^{\circ} 10^{\prime} 55.939^{\prime \prime} \mathrm{W}^{\prime \prime}\end{array}$ \\
\hline 1495 & Rua Pinheiro Machado & R Paissandu & $\begin{array}{r}22^{\circ} 56^{\prime} 22.290 \mathrm{~S} \\
43^{\circ} 10^{\prime} 58.748^{\prime \prime} \mathrm{W}^{\prime \prime}\end{array}$ \\
\hline 1496 & Rua Pinheiro Machado & R Eng. Moacir Reis & $\begin{array}{r}22^{\circ} 56^{\prime} 10.252 \mathrm{~S} \\
43^{\circ} 11^{\prime} 1.786^{\prime \prime} \mathrm{W}^{\prime \prime}\end{array}$ \\
\hline 1497 & Rua Pinheiro Machado & $\mathrm{R}$ das Laranjeiras & $\begin{array}{r}22^{\circ} 56^{\prime} 2.894 \mathrm{~S} \\
43^{\circ} 11^{\prime} 3.367^{\prime \prime} \mathrm{W}^{\prime \prime}\end{array}$ \\
\hline 1498 & Avenida Amaro Cavalcanti & R Luís Carlos & $\begin{array}{r}22^{\circ} 53^{\prime} 55.360 \mathrm{~S} \\
43^{\circ} 16^{\prime} 52.723^{\prime \prime} \mathrm{W}^{\prime \prime}\end{array}$ \\
\hline 1499 & Avenida Amaro Cavalcanti & Ln Amarela & $\begin{array}{r}22^{\circ} 53^{\prime} 44.591 \mathrm{~S} \\
43^{\circ} 17^{\prime} 35.222^{\prime \prime} \mathrm{W}^{\prime \prime}\end{array}$ \\
\hline 1500 & Avenida Amaro Cavalcanti & R Dois de Fevereiro & $\begin{array}{r}22^{\circ} 53^{\prime} 44.826 \mathrm{~S} \\
43^{\circ} 18^{\prime} 3.695^{\prime \prime} \mathrm{W}^{\prime \prime}\end{array}$ \\
\hline 1501 & Avenida Amaro Cavalcanti & R Pompílio de Albuquerque & $\begin{array}{r}22^{\circ} 53^{\prime} 44.952 \mathrm{~S} \\
43^{\circ} 18^{\prime} 5.998^{\prime \prime} \mathrm{W}^{\prime \prime}\end{array}$ \\
\hline 1502 & Avenida Amaro Cavalcanti & R Dois de Fevereiro & $\begin{array}{r}22^{\circ} 53^{\prime} 44.952 \mathrm{~S} \\
43^{\circ} 18^{\prime} 5.998^{\prime \prime} \mathrm{W}^{\prime \prime}\end{array}$ \\
\hline 1503 & Avenida Amaro Cavalcanti & R Vinte e Quatro de Maio & $\begin{array}{r}22^{\circ} 53^{\prime} 55.360 \mathrm{~S} \\
43^{\circ} 16^{\prime} 52.723^{\prime \prime} \mathrm{W}^{\prime \prime}\end{array}$ \\
\hline 1504 & Avenida Almirante Barroso & Av Rio Branco & $\begin{array}{r}22^{\circ} 54^{\prime} 29.958 \mathrm{~S} \\
43^{\circ} 10^{\prime} 38.914^{\prime \prime} \mathrm{W}^{\prime \prime}\end{array}$ \\
\hline
\end{tabular}




\begin{tabular}{|c|c|c|c|}
\hline ordem & corredor & endereco & coordenadas \\
\hline 1505 & Avenida Almirante Barroso & Av Pres. Antônio Carlos & $\begin{array}{r}22^{\circ} 54^{\prime} 27.045 \mathrm{~S} \\
43^{\circ} 10^{\prime} 29.595^{\prime \prime} \mathrm{W}\end{array}$ \\
\hline 1506 & Avenida Almirante Barroso & Av Rio Branco & $\begin{array}{r}22^{\circ} 54^{\prime} 26.466 \mathrm{~S} \\
43^{\circ} 10^{\prime} 29.763^{\prime \prime} "\end{array}$ \\
\hline 1507 & Avenida Almirante Barroso & Av República do Chile & $\begin{array}{r}22^{\circ} 54^{\prime} 29.451 \mathrm{~S} \\
43^{\circ} 10^{\prime} 38.793^{\prime \prime} \mathrm{W}^{\prime \prime}\end{array}$ \\
\hline 1508 & Avenida Armando Lombardi & Av das Américas & $\begin{array}{r}23^{\circ} 0 ' 25.859 \mathrm{~S} \\
43^{\circ} 18^{\prime} 19.230^{\prime \prime} \mathrm{W}^{\prime \prime}\end{array}$ \\
\hline 1509 & Avenida Armando Lombardi & R Cel. Eurico de Souza G Filho & $\begin{array}{r}23^{\circ} 0^{\prime} 22.266 \mathrm{~S} \\
43^{\circ} 19^{\prime} 0.166^{\prime \prime} \mathrm{W}^{\prime \prime}\end{array}$ \\
\hline 1510 & Avenida Armando Lombardi & Av Afonso de Taunay & $\begin{array}{r}23^{\circ} 0^{\prime} 23.252 \mathrm{~S} \\
43^{\circ} 18^{\prime} 56.361^{\prime \prime} \mathrm{W}^{\prime \prime}\end{array}$ \\
\hline 1511 & Avenida Armando Lombardi & R Pedro Bolato & $\begin{array}{r}23^{\circ} 0^{\prime} 25.710 \mathrm{~S} \\
43^{\circ} 18^{\prime} 33.155^{\prime \prime} \mathrm{W}^{\prime \prime}\end{array}$ \\
\hline 1512 & Avenida Armando Lombardi & Av Min. Ivan Lins & $\begin{array}{r}23^{\circ} 0^{\prime} 26.314 \mathrm{~S} \\
43^{\circ} 18^{\prime} 20.665^{\prime \prime} \mathrm{W}^{\prime \prime}\end{array}$ \\
\hline 1513 & $\begin{array}{l}\text { Avenida Embaixador Abelardo } \\
\text { Bueno }\end{array}$ & Estr Canal Arroio Pavuna & $\begin{array}{r}22^{\circ} 58 ' 23.701 \mathrm{~S} \\
43^{\circ} 22^{\prime} 16.464^{\prime \prime} \mathrm{W}^{\prime \prime}\end{array}$ \\
\hline 1514 & $\begin{array}{l}\text { Avenida Embaixador Abelardo } \\
\text { Bueno }\end{array}$ & Av Salvador Allende & $\begin{array}{r}22^{\circ} 58^{\prime} 22.667 \mathrm{~S} \\
43^{\circ} 23^{\prime} 25.878^{\prime \prime} \mathrm{W}^{\prime \prime}\end{array}$ \\
\hline 1515 & $\begin{array}{l}\text { Avenida Embaixador Abelardo } \\
\text { Bueno }\end{array}$ & Av Ayrton Senna & $\begin{array}{r}22^{\circ} 58^{\prime} 23.326 \mathrm{~S} \\
43^{\circ} 23^{\prime} 25.880^{\prime \prime} \mathrm{W}^{\prime \prime}\end{array}$ \\
\hline 1516 & Avenida Cesário de Melo & Pça Sta. Cruz & $\begin{array}{r}22^{\circ} 56^{\prime} 8.427 \mathrm{~S} \\
43^{\circ} 39^{\prime} 59.367^{\prime \prime} \mathrm{W}^{\prime \prime}\end{array}$ \\
\hline 1517 & Avenida Cesário de Melo & R Câmara & $\begin{array}{r}22^{\circ} 55^{\prime} 52.466 \mathrm{~S} \\
43^{\circ} 39^{\prime} 22.542^{\prime \prime} \mathrm{W}^{\prime \prime}\end{array}$ \\
\hline 1518 & Avenida Cesário de Melo & Estr de Santa Eugênia & $\begin{array}{r}22^{\circ} 55^{\prime} 10.133 \mathrm{~S} \\
43^{\circ} 38^{\prime} 28.929^{\prime \prime} \mathrm{W}^{\prime \prime}\end{array}$ \\
\hline 1519 & Avenida Cesário de Melo & R Balaton & $\begin{array}{r}22^{\circ} 54^{\prime} 59.818 \mathrm{~S} \\
43^{\circ} 37^{\prime} 53.855^{\prime \prime} \mathrm{W}^{\prime \prime}\end{array}$ \\
\hline 1520 & Avenida Cesário de Melo & Estr da Paciência & $\begin{array}{r}22^{\circ} 54^{\prime} 57.096 \mathrm{~S} \\
43^{\circ} 37^{\prime} 44.504^{\prime \prime} \mathrm{W}^{\prime \prime}\end{array}$ \\
\hline 1521 & Avenida Cesário de Melo & Av Farroupilha & $\begin{array}{r}22^{\circ} 54^{\prime} 51.260 \mathrm{~S} \\
43^{\circ} 36^{\prime} 4.813^{\prime \prime} \mathrm{W}^{\prime \prime}\end{array}$ \\
\hline 1522 & Avenida Cesário de Melo & Estr do Monteiro & $\begin{array}{r}22^{\circ} 54^{\prime} 25.558 \mathrm{~S} \\
43^{\circ} 34^{\prime} 12.946^{\prime \prime} \mathrm{W}^{\prime \prime}\end{array}$ \\
\hline 1523 & Avenida Cesário de Melo & R Augusto de Vasconcelos & $\begin{array}{r}22^{\circ} 54^{\prime} 27.889 \mathrm{~S} \\
43^{\circ} 33^{\prime} 51.760^{\prime \prime} \mathrm{W}^{\prime \prime}\end{array}$ \\
\hline 1524 & Avenida Cesário de Melo & R Olinda Ellis & $\begin{array}{r}22^{\circ} 54^{\prime} 26.660 \mathrm{~S} \\
43^{\circ} 33^{\prime} 42.541^{\prime \prime} \mathrm{W}\end{array}$ \\
\hline 1525 & Avenida Cesário de Melo & Estr do Cabuçu & $\begin{array}{r}22^{\circ} 54^{\prime} 19.232 \mathrm{~S} \\
43^{\circ} 33^{\prime} 29.291^{\prime \prime} \mathrm{W}^{\prime \prime}\end{array}$ \\
\hline 1526 & Avenida Cesário de Melo & R Artur Rios & $\begin{array}{r}22^{\circ} 54^{\prime} 13.683 \mathrm{~S} \\
43^{\circ} 33^{\prime} 13.749^{\prime \prime} \mathrm{W}\end{array}$ \\
\hline
\end{tabular}




\begin{tabular}{|c|c|c|c|}
\hline ordem & corredor & endereco & coordenadas \\
\hline 1527 & Avenida Cesário de Melo & Estr da Caroba & $\begin{array}{r}22^{\circ} 53^{\prime} 54.603 \mathrm{~S} \\
43^{\circ} 32^{\prime} 56.185^{\prime \prime} \mathrm{W}^{\prime \prime}\end{array}$ \\
\hline 1528 & Avenida Cesário de Melo & R Campo Grande & $\begin{array}{r}22^{\circ} 53^{\prime} 55.568 \mathrm{~S} \\
43^{\circ} 32^{\prime} 56.980^{\prime \prime} \mathrm{W}^{\prime \prime}\end{array}$ \\
\hline 1529 & Avenida Cesário de Melo & R Xavier Marques & $\begin{array}{r}22^{\circ} 54^{\prime} 4.804 \mathrm{~S} \\
43^{\circ} 33^{\prime} 0.407^{\prime \prime} \mathrm{W}^{\prime \prime}\end{array}$ \\
\hline 1530 & Avenida Cesário de Melo & Av Maria Teresa & $\begin{array}{r}22^{\circ} 54^{\prime} 26.927 \mathrm{~S} \\
43^{\circ} 33^{\prime} 51.768^{\prime \prime} \mathrm{W}^{\prime \prime}\end{array}$ \\
\hline 1531 & Avenida Cesário de Melo & R Cap. Lafay & $\begin{array}{r}22^{\circ} 54^{\prime} 32.236 \mathrm{~S} \\
43^{\circ} 34^{\prime} 43.717^{\prime \prime} \mathrm{W}^{\prime \prime}\end{array}$ \\
\hline 1532 & Avenida Cesário de Melo & Estr da Paciência & $\begin{array}{r}22^{\circ} 54^{\prime} 54.183 \mathrm{~S} \\
43^{\circ} 36^{\prime} 21.774^{\prime \prime} "\end{array}$ \\
\hline 1533 & Avenida Cesário de Melo & R Felipe Cardoso & $\begin{array}{r}22^{\circ} 55^{\prime} 51.901 \mathrm{~S} \\
43^{\circ} 39^{\prime} 22.896^{\prime \prime} "\end{array}$ \\
\hline 1534 & Avenida das Nações Unidas & Pça Nicarágua & $\begin{array}{r}22^{\circ} 56^{\prime} 32.204 \mathrm{~S} \\
43^{\circ} 10^{\prime} 41.386^{\prime \prime} \mathrm{W}^{\prime \prime}\end{array}$ \\
\hline 1535 & Avenida das Nações Unidas & R Prf. Álvaro Rodrigues & $\begin{array}{r}22^{\circ} 56^{\prime} 42.549 \mathrm{~S} \\
43^{\circ} 10^{\prime} 54.182^{\prime \prime} \mathrm{W}^{\prime \prime}\end{array}$ \\
\hline 1536 & Avenida das Nações Unidas & Av Inf-d. Henrique & $\begin{array}{r}22^{\circ} 56^{\prime} 40.138 \mathrm{~S} \\
43^{\circ} 10^{\prime} 52.447 " 7^{\prime \prime}\end{array}$ \\
\hline 1537 & Avenida de Santa Cruz & R Artur Rios & $\begin{array}{r}22^{\circ} 53^{\prime} 37.968 \mathrm{~S} \\
43^{\circ} 32^{\prime} 11.885^{\prime \prime} \mathrm{W}^{\prime \prime}\end{array}$ \\
\hline 1538 & Avenida de Santa Cruz & Estr do Pré & $\begin{array}{r}22^{\circ} 53^{\prime} 39.502 \mathrm{~S} \\
43^{\circ} 32^{\prime} 5.879^{\prime \prime} \mathrm{W}^{\prime \prime}\end{array}$ \\
\hline 1539 & Avenida de Santa Cruz & R Marmiari & $\begin{array}{r}22^{\circ} 52^{\prime} 52.256 \mathrm{~S} \\
43^{\circ} 30^{\prime} 42.176^{\prime \prime} \mathrm{W}^{\prime \prime}\end{array}$ \\
\hline 1540 & Avenida de Santa Cruz & $\mathrm{R}$ da Feira & $\begin{array}{r}22^{\circ} 52^{\prime} 55.735 \mathrm{~S} \\
43^{\circ} 28^{\prime} 57.195^{\prime \prime} \mathrm{W}^{\prime \prime}\end{array}$ \\
\hline 1541 & Avenida de Santa Cruz & R Br. de Capanema & $\begin{array}{r}22^{\circ} 52^{\prime} 35.000 \mathrm{~S} \\
43^{\circ} 28^{\prime} 18.909^{\prime \prime} \mathrm{W}^{\prime \prime}\end{array}$ \\
\hline 1542 & Avenida de Santa Cruz & Pça Pe. Miguel & $\begin{array}{r}22^{\circ} 52^{\prime} 40.886 \mathrm{~S} \\
43^{\circ} 26^{\prime} 23.376^{\prime \prime} \mathrm{W}^{\prime \prime}\end{array}$ \\
\hline 1543 & Avenida de Santa Cruz & R Mal. Soares Andréia & $\begin{array}{r}22^{\circ} 52^{\prime} 41.923 \mathrm{~S} \\
43^{\circ} 25^{\prime} 50.789^{\prime \prime} \mathrm{W}^{\prime \prime}\end{array}$ \\
\hline 1544 & Avenida de Santa Cruz & Av Pontalina & $\begin{array}{r}22^{\circ} 52^{\prime} 43.622 \mathrm{~S} \\
43^{\circ} 25^{\prime} 34.518^{\prime \prime} \mathrm{W}^{\prime \prime}\end{array}$ \\
\hline 1545 & Avenida de Santa Cruz & R Piraquiara & $\begin{array}{r}22^{\circ} 52^{\prime} 43.740 \mathrm{~S} \\
43^{\circ} 25^{\prime} 25.488^{\prime \prime} \mathrm{W}^{\prime \prime}\end{array}$ \\
\hline 1546 & Avenida de Santa Cruz & R Ubatuba & $\begin{array}{r}22^{\circ} 52^{\prime} 35.096 \mathrm{~S} \\
43^{\circ} 26^{\prime} 56.075^{\prime \prime} \mathrm{W}^{\prime \prime}\end{array}$ \\
\hline 1547 & Avenida de Santa Cruz & R Boiobi & $\begin{array}{r}22^{\circ} 52^{\prime} 31.867 \mathrm{~S} \\
43^{\circ} 27^{\prime} 53.739^{\prime \prime} \mathrm{W}^{\prime \prime}\end{array}$ \\
\hline 1548 & Avenida de Santa Cruz & R Urucum & $\begin{array}{r}22^{\circ} 52^{\prime} 42.515 \mathrm{~S} \\
43^{\circ} 28^{\prime} 30.113^{\prime \prime} \mathrm{W}^{\prime \prime}\end{array}$ \\
\hline
\end{tabular}




\begin{tabular}{|c|c|c|c|}
\hline ordem & corredor & endereco & coordenadas \\
\hline 1549 & Avenida de Santa Cruz & R Zopiro Goulart & $\begin{array}{r}22^{\circ} 52^{\prime} 56.241 \mathrm{~S} \\
43^{\circ} 29^{\prime} 7.831^{\prime \prime} \mathrm{W}^{\prime \prime}\end{array}$ \\
\hline 1550 & Avenida de Santa Cruz & Estr do Lameirão & $\begin{array}{r}22^{\circ} 52^{\prime} 47.259 \mathrm{~S} \\
43^{\circ} 30^{\prime} 25.250^{\prime \prime} \mathrm{W}^{\prime \prime}\end{array}$ \\
\hline 1551 & Avenida de Santa Cruz & Av Joaquim Magalhães & $\begin{array}{r}22^{\circ} 53 ' 21.489 \mathrm{~S} \\
43^{\circ} 31^{\prime} 22.913^{\prime \prime} \mathrm{W}^{\prime \prime}\end{array}$ \\
\hline 1552 & Avenida de Santa Cruz & R Artur Rios & $\begin{array}{r}22^{\circ} 53^{\prime} 33.697 \mathrm{~S} \\
43^{\circ} 31^{\prime} 56.742^{\prime \prime} \mathrm{W}^{\prime \prime}\end{array}$ \\
\hline 1553 & Avenida de Santa Cruz & R Cabiúna & $\begin{array}{r}22^{\circ} 53^{\prime} 37.968 \mathrm{~S} \\
43^{\circ} 32^{\prime} 11.885^{\prime \prime} \mathrm{W}^{\prime \prime}\end{array}$ \\
\hline 1554 & Avenida Delfim Moreira & R Vsc. de Albuquerque & $\begin{array}{r}22^{\circ} 59^{\prime} 19.874 \mathrm{~S} \\
43^{\circ} 13^{\prime} 40.409^{\prime \prime} \mathrm{W}^{\prime \prime}\end{array}$ \\
\hline 1555 & Avenida Delfim Moreira & Av Bartolomeu Mitre & $\begin{array}{r}22^{\circ} 59^{\prime} 15.325 \mathrm{~S} \\
43^{\circ} 13^{\prime} 30.768^{\prime \prime} \mathrm{W}^{\prime \prime}\end{array}$ \\
\hline 1556 & Avenida Delfim Moreira & Av Vieira Souto & $\begin{array}{r}22^{\circ} 59^{\prime} 11.977 \mathrm{~S} \\
43^{\circ} 13^{\prime} 9.137^{\prime \prime W "}\end{array}$ \\
\hline 1557 & Avenida Delfim Moreira & Av Bartolomeu Mitre & $\begin{array}{r}22^{\circ} 59^{\prime} 11.531 \mathrm{~S} \\
43^{\circ} 13^{\prime} 9.063^{\prime \prime} \mathrm{W}^{\prime \prime}\end{array}$ \\
\hline 1558 & Avenida Delfim Moreira & R Vsc. de Albuquerque & $\begin{array}{r}22^{\circ} 59^{\prime} 18.716 \mathrm{~S} \\
43^{\circ} 13^{\prime} 40.454^{\prime \prime} \mathrm{W}^{\prime \prime}\end{array}$ \\
\hline 1559 & Avenida Epitácio Pessoa & R Aníbal de Mendonça & $\begin{array}{r}22^{\circ} 58^{\prime} 49.642 \mathrm{~S} \\
43^{\circ} 12^{\prime} 47.964 " 4^{\prime \prime}\end{array}$ \\
\hline 1560 & Avenida Epitácio Pessoa & Vd Augusto Frederico Schmidt & $\begin{array}{r}22^{\circ} 58^{\prime} 49.932 \mathrm{~S} \\
43^{\circ} 12^{\prime} 22.316^{\prime \prime} \mathrm{W}^{\prime \prime}\end{array}$ \\
\hline 1561 & Avenida Epitácio Pessoa & R Fr. Veloso & $\begin{array}{r}22^{\circ} 58^{\prime} 21.650 \mathrm{~S} \\
43^{\circ} 12^{\prime} 29.219^{\prime \prime} \mathrm{W}^{\prime \prime}\end{array}$ \\
\hline 1562 & Avenida Epitácio Pessoa & Vd Eng. Humberto Vital B de Mello & $\begin{array}{r}22^{\circ} 57^{\prime} 46.979 \mathrm{~S} \\
43^{\circ} 12^{\prime} 14.023^{\prime \prime} \mathrm{W}^{\prime \prime}\end{array}$ \\
\hline 1563 & Avenida Epitácio Pessoa & Vd Eng. Humberto Vital B de Mello & $\begin{array}{r}22^{\circ} 57^{\prime} 48.162 \mathrm{~S} \\
43^{\circ} 12^{\prime} 15.195^{\prime \prime} \mathrm{W}^{\prime \prime}\end{array}$ \\
\hline 1564 & Avenida Epitácio Pessoa & Vd Augusto Frederico Schmidt & $\begin{array}{r}22^{\circ} 58^{\prime} 28.197 \mathrm{~S} \\
43^{\circ} 12^{\prime} 26.573^{\prime \prime} \mathrm{W}^{\prime \prime}\end{array}$ \\
\hline 1565 & Avenida Epitácio Pessoa & Av Borges de Medeiros & $\begin{array}{r}22^{\circ} 58^{\prime} 49.997 \mathrm{~S} \\
43^{\circ} 12^{\prime} 26.022^{\prime \prime} \mathrm{W}^{\prime \prime}\end{array}$ \\
\hline 1566 & Avenida General Justo & Av Beira Mar & $\begin{array}{r}22^{\circ} 54^{\prime} 42.422 \mathrm{~S} \\
43^{\circ} 10^{\prime} 12.798^{\prime \prime} \mathrm{W}^{\prime \prime}\end{array}$ \\
\hline 1567 & Avenida General Justo & Trevo Édson & $\begin{array}{r}22^{\circ} 54^{\prime} 41.222 \mathrm{~S} \\
43^{\circ} 10^{\prime} 8.591^{\prime \prime} \mathrm{W}^{\prime \prime}\end{array}$ \\
\hline 1568 & Avenida General Justo & Vevd da Perimetral & $\begin{array}{r}22^{\circ} 54^{\prime} 35.398 \mathrm{~S} \\
43^{\circ} 10^{\prime} 5.624^{\prime \prime} \mathrm{W}^{\prime \prime}\end{array}$ \\
\hline 1569 & Avenida General Justo & Trevo Édson & $\begin{array}{r}22^{\circ} 54^{\prime} 34.705 \mathrm{~S} \\
43^{\circ} 10^{\prime} 6.158^{\prime \prime} \mathrm{W}^{\prime \prime}\end{array}$ \\
\hline 1570 & Avenida General Justo & Av Beira Mar & $\begin{array}{r}22^{\circ} 54^{\prime} 40.536 \mathrm{~S} \\
43^{\circ} 10^{\prime} 8.508^{\prime \prime} \mathrm{W}^{\prime \prime}\end{array}$ \\
\hline
\end{tabular}




\begin{tabular}{|c|c|c|c|}
\hline ordem & corredor & endereco & coordenadas \\
\hline 1571 & Avenida General Justo & Trevo Édson & $\begin{array}{r}22^{\circ} 54^{\prime} 41.436 \mathrm{~S} \\
43^{\circ} 10^{\prime} 10.449^{\prime \prime} \mathrm{W}^{\prime \prime}\end{array}$ \\
\hline 1572 & Avenida General Justo & Av Inf-d. Henrique & $\begin{array}{r}22^{\circ} 54^{\prime} 41.825 \mathrm{~S} \\
43^{\circ} 10^{\prime} 12.659^{\prime \prime} \mathrm{W}^{\prime \prime}\end{array}$ \\
\hline 1573 & Avenida Infante Dom Henrique & Av Gen. Justo & $\begin{array}{r}22^{\circ} 55^{\prime} 46.383 \mathrm{~S} \\
43^{\circ} 10^{\prime} 21.323^{\prime \prime} \mathrm{W}^{\prime \prime}\end{array}$ \\
\hline 1574 & Avenida Infante Dom Henrique & Pça Cuauhtémoque & $\begin{array}{r}22^{\circ} 55^{\prime} 24.341 \mathrm{~S} \\
43^{\circ} 10^{\prime} 16.491 " 1^{\prime \prime}\end{array}$ \\
\hline 1575 & Avenida Infante Dom Henrique & Av das Nações Unidas & $\begin{array}{r}22^{\circ} 56^{\prime} 32.118 \mathrm{~S} \\
43^{\circ} 10^{\prime} 20.208^{\prime \prime} \mathrm{W}^{\prime \prime}\end{array}$ \\
\hline 1576 & Avenida Infante Dom Henrique & Tun do Pasmado & $\begin{array}{r}22^{\circ} 56^{\prime} 58.599 \mathrm{~S} \\
43^{\circ} 10^{\prime} 49.859^{\prime \prime} \mathrm{W}^{\prime \prime}\end{array}$ \\
\hline 1577 & Avenida Maracanã & R Uruguai & $\begin{array}{r}22^{\circ} 55^{\prime} 53.049 \mathrm{~S} \\
43^{\circ} 14^{\prime} 32.947^{\prime \prime} \mathrm{W}^{\prime \prime}\end{array}$ \\
\hline 1578 & Avenida Maracanã & R S. Francisco Xavier & $\begin{array}{r}22^{\circ} 55^{\prime} 23.624 \mathrm{~S} \\
43^{\circ} 14^{\prime} 9.706^{\prime \prime} \mathrm{W}^{\prime \prime}\end{array}$ \\
\hline 1579 & Avenida Maracanã & Av Pres. Castelo Branco & $\begin{array}{r}22^{\circ} 54^{\prime} 47.844 \mathrm{~S} \\
43^{\circ} 13^{\prime} 38.456^{\prime \prime} \mathrm{W}^{\prime \prime}\end{array}$ \\
\hline 1580 & Avenida Maracanã & R Teixeira Soares & $\begin{array}{r}22^{\circ} 54^{\prime} 38.981 \mathrm{~S} \\
43^{\circ} 13^{\prime} 26.124^{\prime \prime} \mathrm{W}^{\prime \prime}\end{array}$ \\
\hline 1581 & Avenida Maracanã & R S. Francisco Xavier & $\begin{array}{r}22^{\circ} 54^{\prime} 51.067 \mathrm{~S} \\
43^{\circ} 13^{\prime} 41.789^{\prime \prime} \mathrm{W}^{\prime \prime}\end{array}$ \\
\hline 1582 & Avenida Maracanã & R Br. de Mesquita & $\begin{array}{r}22^{\circ} 55^{\prime} 9.698 \mathrm{~S} \\
43^{\circ} 14^{\prime} 2.653^{\prime \prime W " W "}\end{array}$ \\
\hline 1583 & Avenida Maracanã & R Uruguai & $\begin{array}{r}22^{\circ} 55^{\prime} 38.490 \mathrm{~S} \\
43^{\circ} 14^{\prime} 20.646^{\prime \prime} \mathrm{W}^{\prime \prime}\end{array}$ \\
\hline 1584 & Avenida Maracanã & R Dr. Octavio Kelly & $\begin{array}{r}22^{\circ} 55^{\prime} 52.821 \mathrm{~S} \\
43^{\circ} 14^{\prime} 33.348^{\prime \prime} \mathrm{W}^{\prime \prime}\end{array}$ \\
\hline 1585 & Avenida Nelson Cardoso & R André Rocha & $\begin{array}{r}22^{\circ} 55^{\prime} 2.165 \mathrm{~S} \\
43^{\circ} 21^{\prime} 47.190^{\prime \prime} \mathrm{W}^{\prime \prime}\end{array}$ \\
\hline 1586 & Avenida Nelson Cardoso & Estr do Tindiba & $\begin{array}{r}22^{\circ} 55^{\prime} 13.370 \mathrm{~S} \\
43^{\circ} 22^{\prime} 7.391^{\prime \prime} \mathrm{W}^{\prime \prime}\end{array}$ \\
\hline 1587 & Avenida Nelson Cardoso & R André Rocha & $\begin{array}{r}22^{\circ} 55^{\prime} 13.370 \mathrm{~S} \\
43^{\circ} 22^{\prime} 7.391^{\prime \prime} \mathrm{W}^{\prime \prime}\end{array}$ \\
\hline 1588 & Avenida Nelson Cardoso & R Cândido Benício & $\begin{array}{r}22^{\circ} 55^{\prime} 2.165 \mathrm{~S} \\
43^{\circ} 21^{\prime} 47.190^{\prime \prime} \mathrm{W}^{\prime \prime}\end{array}$ \\
\hline 1589 & $\begin{array}{l}\text { Avenida Repórter Nestor } \\
\text { Moreira }\end{array}$ & Av das Nações Unidas & $\begin{array}{r}22^{\circ} 56^{\prime} 57.905 \mathrm{~S} \\
43^{\circ} 10^{\prime} 44.231^{\prime \prime} \mathrm{W}^{\prime \prime}\end{array}$ \\
\hline 1590 & Avenida Salvador Allende & Av das Américas & $\begin{array}{r}23^{\circ} 0{ }^{\prime} 24.588 \mathrm{~S} \\
43^{\circ} 26^{\prime} 14.325^{\prime \prime} \mathrm{W}^{\prime \prime}\end{array}$ \\
\hline 1591 & Avenida Salvador Allende & Av Emb. Abelardo Bueno & $\begin{array}{r}22^{\circ} 59^{\prime} 26.010 \mathrm{~S} \\
43^{\circ} 25^{\prime} 7.874^{\prime \prime} \mathrm{W}^{\prime \prime}\end{array}$ \\
\hline 1592 & Avenida Salvador Allende & Estr dos Bandeirantes & $\begin{array}{r}22^{\circ} 57^{\prime} 58.364 \mathrm{~S} \\
43^{\circ} 23^{\prime} 47.238^{\prime \prime} \mathrm{W}^{\prime \prime}\end{array}$ \\
\hline
\end{tabular}




\begin{tabular}{|c|c|c|c|}
\hline ordem & corredor & endereco & coordenadas \\
\hline 1593 & Avenida Salvador Allende & Av Olof Palme & $\begin{array}{r}22^{\circ} 58^{\prime} 57.162 \mathrm{~S} \\
43^{\circ} 24^{\prime} 39.284^{\prime \prime} \mathrm{W}^{\prime \prime}\end{array}$ \\
\hline 1594 & Avenida Salvador Allende & Av das Américas & $\begin{array}{r}22^{\circ} 59^{\prime} 43.060 \mathrm{~S} \\
43^{\circ} 25^{\prime} 25.898^{\prime \prime} \mathrm{W}^{\prime \prime}\end{array}$ \\
\hline 1595 & Avenida Venceslau Brás & Av Pasteur & $\begin{array}{r}22^{\circ} 57^{\prime} 6.724 \mathrm{~S} \\
43^{\circ} 10^{\prime} 31.645^{\prime \prime} \mathrm{W}^{\prime \prime}\end{array}$ \\
\hline 1596 & Avenida Vieira Souto & R Joaquim Nabuco & $\begin{array}{r}22^{\circ} 59^{\prime} 15.200 \mathrm{~S} \\
43^{\circ} 11^{\prime} 43.300^{\prime \prime} \mathrm{W}^{\prime \prime}\end{array}$ \\
\hline 1597 & Avenida Vieira Souto & Av Epitácio Pessoa & $\begin{array}{r}22^{\circ} 59^{\prime} 10.969 \mathrm{~S} \\
43^{\circ} 12^{\prime} 20.323^{\prime \prime} \mathrm{W}^{\prime \prime}\end{array}$ \\
\hline 1598 & Avenida Vieira Souto & Av Delfim Moreira & $\begin{array}{r}22^{\circ} 59^{\prime} 10.056 \mathrm{~S} \\
43^{\circ} 12^{\prime} 55.956^{\prime \prime} \mathrm{W}^{\prime \prime}\end{array}$ \\
\hline 1599 & Avenida Vieira Souto & Av Epitácio Pessoa & $\begin{array}{r}22^{\circ} 59^{\prime} 10.542 \mathrm{~S} \\
43^{\circ} 12^{\prime} 56.597^{\prime \prime} \mathrm{W}^{\prime \prime}\end{array}$ \\
\hline 1600 & Avenida Vieira Souto & R Joaquim Nabuco & $\begin{array}{r}22^{\circ} 59^{\prime} 11.387 \mathrm{~S} \\
43^{\circ} 12^{\prime} 20.969^{\prime \prime} "\end{array}$ \\
\hline 1601 & Avenida Vieira Souto & Av Francisco Bhering & $\begin{array}{r}22^{\circ} 59^{\prime} 15.561 \mathrm{~S} \\
43^{\circ} 11^{\prime} 43.389^{\prime \prime} \mathrm{W}^{\prime \prime}\end{array}$ \\
\hline 1602 & Estrada dos Bandeirantes & R Octacílio Novais & $\begin{array}{r}22^{\circ} 55^{\prime} 30.609 \mathrm{~S} \\
43^{\circ} 22^{\prime} 25.571^{\prime \prime W}\end{array}$ \\
\hline 1603 & Estrada dos Bandeirantes & R André Rocha & $\begin{array}{r}22^{\circ} 55^{\prime} 40.404 \mathrm{~S} \\
43^{\circ} 22^{\prime} 24.756^{\prime \prime} \mathrm{W}^{\prime \prime}\end{array}$ \\
\hline 1604 & Estrada dos Bandeirantes & R Cunha Moreira & $\begin{array}{r}22^{\circ} 55^{\prime} 55.677 \mathrm{~S} \\
43^{\circ} 22^{\prime} 23.312^{\prime \prime} \mathrm{W}^{\prime \prime}\end{array}$ \\
\hline 1605 & Estrada dos Bandeirantes & R José de Lima & $\begin{array}{r}22^{\circ} 56^{\prime} 36.213 \mathrm{~S} \\
43^{\circ} 22^{\prime} 21.154^{\prime \prime} \mathrm{W}^{\prime \prime}\end{array}$ \\
\hline 1606 & Estrada dos Bandeirantes & $\mathrm{R}$ do Castor & $\begin{array}{r}22^{\circ} 57^{\prime} 9.334 \mathrm{~S} \\
43^{\circ} 22^{\prime} 29.763^{\prime \prime} \mathrm{W}^{\prime \prime}\end{array}$ \\
\hline 1607 & Estrada dos Bandeirantes & Estr de Curicica & $\begin{array}{r}22^{\circ} 57^{\prime} 35.344 \mathrm{~S} \\
43^{\circ} 23^{\prime} 21.169^{\prime \prime} \mathrm{W}\end{array}$ \\
\hline 1608 & Estrada dos Bandeirantes & Camorim & $\begin{array}{r}22^{\circ} 58^{\prime} 5.957 \mathrm{~S} \\
43^{\circ} 24^{\prime} 48.835^{\prime \prime} \mathrm{W}^{\prime \prime}\end{array}$ \\
\hline 1609 & Estrada dos Bandeirantes & Estr Benvindo de Novais & $\begin{array}{r}22^{\circ} 59^{\prime} 10.164 \mathrm{~S} \\
43^{\circ} 25^{\prime} 54.721^{\prime \prime} \mathrm{W}^{\prime \prime}\end{array}$ \\
\hline 1610 & Estrada dos Bandeirantes & Av das Américas & $\begin{array}{r}22^{\circ} 58^{\prime} 41.706 \mathrm{~S} \\
43^{\circ} 29^{\prime} 33.187^{\prime \prime W}\end{array}$ \\
\hline 1611 & Estrada dos Bandeirantes & Estr Benvindo de Novais & $\begin{array}{r}22^{\circ} 58^{\prime} 41.706 \mathrm{~S} \\
43^{\circ} 29^{\prime} 33.187^{\prime \prime W}\end{array}$ \\
\hline 1612 & Estrada dos Bandeirantes & Estr Arroio Pavuna & $\begin{array}{r}22^{\circ} 57^{\prime} 44.643 \mathrm{~S} \\
43^{\circ} 23^{\prime} 58.822^{\prime \prime} \mathrm{W}^{\prime \prime}\end{array}$ \\
\hline 1613 & Estrada dos Bandeirantes & Estr Mal. Miguel S M de Morais & $\begin{array}{r}22^{\circ} 56^{\prime} 42.634 \mathrm{~S} \\
43^{\circ} 22^{\prime} 19.047^{\prime \prime W}\end{array}$ \\
\hline 1614 & Estrada dos Bandeirantes & R André Rocha & $\begin{array}{r}22^{\circ} 55^{\prime} 56.688 \mathrm{~S} \\
43^{\circ} 22^{\prime} 22.787^{\prime \prime} \mathrm{W}^{\prime \prime}\end{array}$ \\
\hline
\end{tabular}




\begin{tabular}{|c|c|c|c|}
\hline ordem & corredor & endereco & coordenadas \\
\hline 1615 & Estrada dos Bandeirantes & Pça da Taquara & $\begin{array}{r}22^{\circ} 55^{\prime} 30.609 \mathrm{~S} \\
43^{\circ} 22^{\prime} 25.571^{\prime \prime} \mathrm{W}^{\prime \prime}\end{array}$ \\
\hline 1616 & Avenida dos Democraticos & Ln Amarela & $\begin{array}{r}22^{\circ} 52^{\prime} 38.563 \mathrm{~S} \\
43^{\circ} 15^{\prime} 21.786 " 6^{\prime \prime}\end{array}$ \\
\hline 1617 & Avenida dos Democraticos & Av Itaoca & $\begin{array}{r}22^{\circ} 52^{\prime} 9.702 \mathrm{~S} \\
43^{\circ} 15^{\prime} 30.813^{\prime \prime} \mathrm{W}^{\prime \prime}\end{array}$ \\
\hline 1618 & Avenida dos Democraticos & Pça Dezenove de Novembro & $\begin{array}{r}22^{\circ} 52^{\prime} 0.501 \mathrm{~S} \\
43^{\circ} 15^{\prime} 24.092^{\prime \prime} \mathrm{W}^{\prime \prime}\end{array}$ \\
\hline 1619 & Avenida dos Democraticos & Av Itaoca & $\begin{array}{r}22^{\circ} 52^{\prime} 3.004 \mathrm{~S} \\
43^{\circ} 15^{\prime} 27.342^{\prime \prime} \mathrm{W}^{\prime \prime}\end{array}$ \\
\hline 1620 & Avenida dos Democraticos & Ln Amarela & $\begin{array}{r}22^{\circ} 52^{\prime} 9.702 \mathrm{~S} \\
43^{\circ} 15^{\prime} 30.813^{\prime \prime} \mathrm{W}^{\prime \prime}\end{array}$ \\
\hline 1621 & Avenida Geremario Dantas & R Araguaia & $\begin{array}{r}22^{\circ} 56^{\prime} 19.310 \mathrm{~S} \\
43^{\circ} 20^{\prime} 43.349^{\prime \prime} \mathrm{W}^{\prime \prime}\end{array}$ \\
\hline 1622 & Avenida Geremario Dantas & Ln Amarela & $\begin{array}{r}22^{\circ} 56^{\prime} 18.324 \mathrm{~S} \\
43^{\circ} 20^{\prime} 54.098^{\prime \prime} \mathrm{W}^{\prime \prime}\end{array}$ \\
\hline 1623 & Avenida Geremario Dantas & Estr do Pau Ferro & $\begin{array}{r}22^{\circ} 55^{\prime} 44.426 \mathrm{~S} \\
43^{\circ} 21^{\prime} 14.541^{\prime \prime} \mathrm{W}^{\prime \prime}\end{array}$ \\
\hline 1624 & Avenida Geremario Dantas & R Lopo Saraiva & $\begin{array}{r}22^{\circ} 55^{\prime} 33.870 \mathrm{~S} \\
43^{\circ} 21^{\prime} 23.865^{\prime \prime} \mathrm{W}^{\prime \prime}\end{array}$ \\
\hline 1625 & Avenida Geremario Dantas & R Alexandre Ramos & $\begin{array}{r}22^{\circ} 55^{\prime} 24.261 \mathrm{~S} \\
43^{\circ} 21^{\prime} 40.886^{\prime \prime} \mathrm{W}^{\prime \prime}\end{array}$ \\
\hline 1626 & Avenida Geremario Dantas & R Henriqueta & $\begin{array}{r}22^{\circ} 55^{\prime} 14.430 \mathrm{~S} \\
43^{\circ} 21^{\prime} 37.103^{\prime \prime} \mathrm{W}^{\prime \prime}\end{array}$ \\
\hline 1627 & Avenida Geremario Dantas & R Cândido Benício & $\begin{array}{r}22^{\circ} 55^{\prime} 6.136 \mathrm{~S} \\
43^{\circ} 21^{\prime} 39.243^{\prime \prime} \mathrm{W}^{\prime \prime}\end{array}$ \\
\hline 1628 & Avenida Geremario Dantas & R Henriqueta & $\begin{array}{r}22^{\circ} 55^{\prime} 6.136 \mathrm{~S} \\
43^{\circ} 21^{\prime} 39.243^{\prime \prime} \mathrm{W}^{\prime \prime}\end{array}$ \\
\hline 1629 & Avenida Geremario Dantas & R Piatã & $\begin{array}{r}22^{\circ} 55^{\prime} 14.339 \mathrm{~S} \\
43^{\circ} 21^{\prime} 37.512^{\prime \prime} \mathrm{W}^{\prime \prime}\end{array}$ \\
\hline 1630 & Avenida Geremario Dantas & R Lopo Saraiva & $\begin{array}{r}22^{\circ} 55^{\prime} 29.235 \mathrm{~S} \\
43^{\circ} 21^{\prime} 34.897^{\prime \prime W "}\end{array}$ \\
\hline 1631 & Avenida Geremario Dantas & Estr do Tindiba & $\begin{array}{r}22^{\circ} 55^{\prime} 33.870 \mathrm{~S} \\
43^{\circ} 21^{\prime} 23.865^{\prime \prime} \mathrm{W}^{\prime \prime}\end{array}$ \\
\hline 1632 & Avenida Geremario Dantas & Estr do Pau Ferro & $\begin{array}{r}22^{\circ} 55^{\prime} 43.081 \mathrm{~S} \\
43^{\circ} 21^{\prime} 16.283^{\prime \prime} \mathrm{W}^{\prime \prime}\end{array}$ \\
\hline 1633 & Avenida Geremario Dantas & R Benevente & $\begin{array}{r}22^{\circ} 55^{\prime} 44.426 \mathrm{~S} \\
43^{\circ} 21^{\prime} 14.541^{\prime \prime} \mathrm{W}\end{array}$ \\
\hline 1634 & Avenida Geremario Dantas & Estr dos Três Rios & $\begin{array}{r}22^{\circ} 56^{\prime} 19.310 \mathrm{~S} \\
43^{\circ} 20^{\prime} 43.349^{\prime \prime} \mathrm{W}\end{array}$ \\
\hline 1635 & Avenida Geremario Dantas & Estr de Jacarepaguá & $\begin{array}{r}22^{\circ} 56^{\prime} 25.409 \mathrm{~S} \\
43^{\circ} 20^{\prime} 36.289^{\prime \prime} \mathrm{W}^{\prime \prime}\end{array}$ \\
\hline 1636 & Avenida Niemeyer & Av Pref. Mendes de Morais & $\begin{array}{r}22^{\circ} 59^{\prime} 21.079 \mathrm{~S} \\
43^{\circ} 13^{\prime} 39.791 " 1^{\prime \prime}\end{array}$ \\
\hline
\end{tabular}




\begin{tabular}{|c|c|c|c|}
\hline ordem & corredor & endereco & coordenadas \\
\hline 1637 & Avenida Niemeyer & Av Delfim Moreira & $\begin{array}{r}22^{\circ} 59^{\prime} 23.377 \mathrm{~S} \\
43^{\circ} 13^{\prime} 39.619^{\prime \prime} \mathrm{W}^{\prime \prime}\end{array}$ \\
\hline 1638 & Avenida Vital Brasil & Tun Antônio Rebouças & $\begin{array}{r}22^{\circ} 55^{\prime} 56.697 \mathrm{~S} \\
43^{\circ} 12^{\prime} 34.442^{\prime \prime} \mathrm{W}^{\prime \prime}\end{array}$ \\
\hline 1639 & Avenida Vital Brasil & Vd Saint Hilaire & $\begin{array}{r}22^{\circ} 57^{\prime} 28.259 \mathrm{~S} \\
43^{\circ} 12^{\prime} 16.168^{\prime \prime} \mathrm{W}^{\prime \prime}\end{array}$ \\
\hline 1640 & Avenida Vital Brasil & Tun André Rebouças & $\begin{array}{r}22^{\circ} 57^{\prime} 27.678 \mathrm{~S} \\
43^{\circ} 12^{\prime} 15.607 " \mathrm{~W}^{\prime \prime}\end{array}$ \\
\hline 1641 & Avenida Vital Brasil & Vevd Eng. Freyssinet & $\begin{array}{r}22^{\circ} 55^{\prime} 56.639 \mathrm{~S} \\
43^{\circ} 12^{\prime} 34.146^{\prime \prime} \mathrm{W}^{\prime \prime}\end{array}$ \\
\hline 1642 & Estrada da Gávea & R Gen. Olímpio Mourão Filho & $\begin{array}{r}22^{\circ} 59^{\prime} 34.007 \mathrm{~S} \\
43^{\circ} 15^{\prime} 18.526^{\prime \prime} "\end{array}$ \\
\hline 1643 & Estrada da Gávea & Estr Lagoa Barra & $\begin{array}{r}22^{\circ} 59^{\prime} 46.902 \mathrm{~S} \\
43^{\circ} 15^{\prime} 39.014^{\prime \prime} \mathrm{W}^{\prime \prime}\end{array}$ \\
\hline 1644 & Estrada do Galeão & Av Vinte de Janeiro & $\begin{array}{r}22^{\circ} 49^{\prime} 42.113 \mathrm{~S} \\
43^{\circ} 14^{\prime} 7.765^{\prime \prime} \mathrm{W}^{\prime \prime}\end{array}$ \\
\hline 1645 & Estrada do Galeão & Estr das Canárias & $\begin{array}{r}22^{\circ} 49^{\prime} 18.696 \mathrm{~S} \\
43^{\circ} 13^{\prime} 45.673^{\prime \prime} \mathrm{W}^{\prime \prime}\end{array}$ \\
\hline 1646 & Estrada do Galeão & R Luiz Belart & $\begin{array}{r}22^{\circ} 48^{\prime} 44.769 \mathrm{~S} \\
43^{\circ} 13^{\prime} 9.378^{\prime \prime} \mathrm{W}^{\prime \prime}\end{array}$ \\
\hline 1647 & Estrada do Galeão & R Colina & $\begin{array}{r}22^{\circ} 48^{\prime} 19.131 \mathrm{~S} \\
43^{\circ} 12^{\prime} 31.015^{\prime \prime} \mathrm{W}^{\prime \prime}\end{array}$ \\
\hline 1648 & Estrada do Galeão & Av Cel. Luiz de Oliveira Sampaio & $\begin{array}{r}22^{\circ} 48^{\prime} 26.774 \mathrm{~S} \\
43^{\circ} 11^{\prime} 50.602^{\prime \prime} \mathrm{W}^{\prime \prime}\end{array}$ \\
\hline 1649 & Estrada do Galeão & Av Mto. Paulo e Silva & $\begin{array}{r}22^{\circ} 48^{\prime} 30.220 \mathrm{~S} \\
43^{\circ} 11^{\prime} 46.775^{\prime \prime} \mathrm{W}^{\prime \prime}\end{array}$ \\
\hline 1650 & Estrada do Galeão & Estr das Canárias & $\begin{array}{r}22^{\circ} 48^{\prime} 36.813 \mathrm{~S} \\
43^{\circ} 12^{\prime} 58.493^{\prime \prime} \mathrm{W}^{\prime \prime}\end{array}$ \\
\hline 1651 & Estrada do Galeão & Av Vinte de Janeiro & $\begin{array}{r}22^{\circ} 49^{\prime} 25.847 \mathrm{~S} \\
43^{\circ} 13^{\prime} 54.350^{\prime \prime} \mathrm{W}^{\prime \prime}\end{array}$ \\
\hline 1652 & Estrada do Galeão & Av Pres. João Goulart & $\begin{array}{r}22^{\circ} 49^{\prime} 37.934 \mathrm{~S} \\
43^{\circ} 14^{\prime} 5.015^{\prime \prime} \mathrm{W}^{\prime \prime}\end{array}$ \\
\hline 1653 & Estrada do Galeão & Av Brg. Trompowski & $\begin{array}{r}22^{\circ} 49^{\prime} 59.593 \mathrm{~S} \\
43^{\circ} 14^{\prime} 29.636^{\prime \prime} \mathrm{W}^{\prime \prime}\end{array}$ \\
\hline 1654 & Praia do Flamengo & Av Beira Mar & $\begin{array}{r}22^{\circ} 55^{\prime} 48.742 \mathrm{~S} \\
43^{\circ} 10^{\prime} 26.829^{\prime \prime} \mathrm{W}^{\prime \prime}\end{array}$ \\
\hline 1655 & Praia do Flamengo & Pça Cuauhtémoque & $\begin{array}{r}22^{\circ} 55^{\prime} 51.926 \mathrm{~S} \\
43^{\circ} 10^{\prime} 27.679^{\prime \prime} \mathrm{W}^{\prime \prime}\end{array}$ \\
\hline 1656 & Praia do Flamengo & Av Oswaldo Cruz & $\begin{array}{r}22^{\circ} 56^{\prime} 18.188 \mathrm{~S} \\
43^{\circ} 10^{\prime} 25.350^{\prime \prime} \mathrm{W}^{\prime \prime}\end{array}$ \\
\hline 1657 & Rua Humaitá & R Vsc. de Silva & $\begin{array}{r}22^{\circ} 57^{\prime} 34.894 \mathrm{~S} \\
43^{\circ} 12^{\prime} 5.599^{\prime \prime} \mathrm{W}^{\prime \prime}\end{array}$ \\
\hline 1658 & Rua Humaitá & R Prf. Abelardo Lobo & $\begin{array}{r}22^{\circ} 57^{\prime} 33.279 \mathrm{~S} \\
43^{\circ} 12^{\prime} 4.236^{\prime \prime} \mathrm{W}^{\prime \prime}\end{array}$ \\
\hline
\end{tabular}




\begin{tabular}{|c|c|c|c|}
\hline ordem & corredor & endereco & coordenadas \\
\hline 1659 & Rua Humaitá & R Fr. Veloso & $\begin{array}{r}22^{\circ} 57^{\prime} 36.605 \mathrm{~S} \\
43^{\circ} 12^{\prime} 13.612^{\prime \prime} \mathrm{W}^{\prime \prime}\end{array}$ \\
\hline 1660 & $\begin{array}{l}\text { Avenida Chrisóstomo Pimentel } \\
\text { de Oliveira }\end{array}$ & $\mathrm{Bc}$ do Jagunço & $\begin{array}{r}22^{\circ} 48^{\prime} 50.557 \mathrm{~S} \\
43^{\circ} 22^{\prime} 46.010^{\prime \prime} \mathrm{W}^{\prime \prime}\end{array}$ \\
\hline 1661 & $\begin{array}{l}\text { Avenida Chrisóstomo Pimentel } \\
\text { de Oliveira }\end{array}$ & Via Light & $\begin{array}{r}22^{\circ} 48^{\prime} 57.298 \mathrm{~S} \\
43^{\circ} 23^{\prime} 14.581^{\prime \prime} \mathrm{W}^{\prime \prime}\end{array}$ \\
\hline 1662 & $\begin{array}{l}\text { Avenida Chrisóstomo Pimentel } \\
\text { de Oliveira }\end{array}$ & Estr do Rio do Pau & $\begin{array}{r}22^{\circ} 48^{\prime} 55.891 \mathrm{~S} \\
43^{\circ} 23^{\prime} 18.967^{\prime \prime} \mathrm{W}^{\prime \prime}\end{array}$ \\
\hline 1663 & $\begin{array}{l}\text { Avenida Chrisóstomo Pimentel } \\
\text { de Oliveira }\end{array}$ & R Javatá & $\begin{array}{r}22^{\circ} 49^{\prime} 2.684 \mathrm{~S} \\
43^{\circ} 23^{\prime} 22.998^{\prime \prime} \mathrm{W}^{\prime \prime}\end{array}$ \\
\hline 1664 & $\begin{array}{l}\text { Avenida Chrisóstomo Pimentel } \\
\text { de Oliveira }\end{array}$ & R Itaí & $\begin{array}{r}22^{\circ} 49^{\prime} 8.343 \mathrm{~S} \\
43^{\circ} 23^{\prime} 38.873^{\prime \prime} \mathrm{W}^{\prime \prime}\end{array}$ \\
\hline 1665 & $\begin{array}{l}\text { Avenida Chrisóstomo Pimentel } \\
\text { de Oliveira }\end{array}$ & R José Lourenço & $\begin{array}{r}22^{\circ} 49^{\prime} 18.782 \mathrm{~S} \\
43^{\circ} 23^{\prime} 55.725^{\prime \prime} \mathrm{W}^{\prime \prime}\end{array}$ \\
\hline 1666 & $\begin{array}{l}\text { Avenida Chrisóstomo Pimentel } \\
\text { de Oliveira }\end{array}$ & R Pe. Mário Versé & $\begin{array}{r}22^{\circ} 49^{\prime} 18.782 \mathrm{~S} \\
43^{\circ} 23^{\prime} 55.725^{\prime \prime} \mathrm{W}^{\prime \prime}\end{array}$ \\
\hline 1667 & $\begin{array}{l}\text { Avenida Chrisóstomo Pimentel } \\
\text { de Oliveira }\end{array}$ & R Javatá & $\begin{array}{r}22^{\circ} 49^{\prime} 10.018 \mathrm{~S} \\
43^{\circ} 23^{\prime} 41.511^{\prime \prime} \mathrm{W}^{\prime \prime}\end{array}$ \\
\hline 1668 & $\begin{array}{l}\text { Avenida Chrisóstomo Pimentel } \\
\text { de Oliveira }\end{array}$ & R Cdor. Nogueira & $\begin{array}{r}22^{\circ} 48^{\prime} 54.602 \mathrm{~S} \\
43^{\circ} 22^{\prime} 54.881^{\prime \prime} "\end{array}$ \\
\hline 1669 & Avenida Dom Helder Câmara & Vd de Cascadura & $\begin{array}{r}22^{\circ} 52^{\prime} 54.724 \mathrm{~S} \\
43^{\circ} 19^{\prime} 42.649^{\prime \prime} \mathrm{W}^{\prime \prime}\end{array}$ \\
\hline 1670 & Avenida Dom Helder Câmara & $\mathrm{R}$ da Pedreira & $\begin{array}{r}22^{\circ} 52^{\prime} 55.329 \mathrm{~S} \\
43^{\circ} 19^{\prime} 31.229^{\prime \prime} \mathrm{W}^{\prime \prime}\end{array}$ \\
\hline 1671 & Avenida Dom Helder Câmara & R Eng. Nazareth & $\begin{array}{r}22^{\circ} 53^{\prime} 5.619 \mathrm{~S} \\
43^{\circ} 18^{\prime} 48.338^{\prime \prime} \mathrm{W}^{\prime \prime}\end{array}$ \\
\hline 1672 & Avenida Dom Helder Câmara & Tv Virgínia & $\begin{array}{r}22^{\circ} 53^{\prime} 9.276 \mathrm{~S} \\
43^{\circ} 18^{\prime} 7.907^{\prime \prime} \mathrm{W}^{\prime \prime}\end{array}$ \\
\hline 1673 & Avenida Dom Helder Câmara & R da Abolição & $\begin{array}{r}22^{\circ} 53^{\prime} 7.016 \mathrm{~S} \\
43^{\circ} 18^{\prime} 0.838^{\prime \prime} \mathrm{W}^{\prime \prime}\end{array}$ \\
\hline 1674 & Avenida Dom Helder Câmara & R Alfredo de Sousa Mendes & $\begin{array}{r}22^{\circ} 52^{\prime} 58.241 \mathrm{~S} \\
43^{\circ} 17^{\prime} 46.308^{\prime \prime} \mathrm{W}^{\prime \prime}\end{array}$ \\
\hline 1675 & Avenida Dom Helder Câmara & R Mário Carpenter & $\begin{array}{r}22^{\circ} 52^{\prime} 57.311 \mathrm{~S} \\
43^{\circ} 17^{\prime} 33.363^{\prime \prime} \mathrm{W}^{\prime \prime}\end{array}$ \\
\hline 1676 & Avenida Dom Helder Câmara & Ln Amarela & $\begin{array}{r}22^{\circ} 53^{\prime} 4.262 \mathrm{~S} \\
43^{\circ} 17^{\prime} 27.496^{\prime \prime} \mathrm{W}^{\prime \prime}\end{array}$ \\
\hline 1677 & Avenida Dom Helder Câmara & Av Carlos Lacerda & $\begin{array}{r}22^{\circ} 53^{\prime} 10.402 \mathrm{~S} \\
43^{\circ} 17^{\prime} 20.053^{\prime \prime} \mathrm{W}^{\prime \prime}\end{array}$ \\
\hline 1678 & Avenida Dom Helder Câmara & R Ibiraci & $\begin{array}{r}22^{\circ} 53^{\prime} 11.504 \mathrm{~S} \\
43^{\circ} 17^{\prime} 18.430^{\prime \prime} \mathrm{W}^{\prime \prime}\end{array}$ \\
\hline 1679 & Avenida Dom Helder Câmara & R Cachambi & $\begin{array}{r}22^{\circ} 53^{\prime} 14.941 \mathrm{~S} \\
43^{\circ} 16^{\prime} 57.599^{\prime \prime} \mathrm{W}^{\prime \prime}\end{array}$ \\
\hline 1680 & Avenida Dom Helder Câmara & R Guanacás & $\begin{array}{r}22^{\circ} 52^{\prime} 51.163 \mathrm{~S} \\
43^{\circ} 16^{\prime} 15.945^{\prime \prime} \mathrm{W}^{\prime \prime}\end{array}$ \\
\hline
\end{tabular}




\begin{tabular}{|c|c|c|c|}
\hline ordem & corredor & endereco & coordenadas \\
\hline 1681 & Avenida Dom Helder Câmara & Av dos Democráticos & $\begin{array}{r}22^{\circ} 52^{\prime} 49.342 \mathrm{~S} \\
43^{\circ} 15^{\prime} 31.888^{\prime \prime} \mathrm{W}^{\prime \prime}\end{array}$ \\
\hline 1682 & Avenida Dom Helder Câmara & Vd de Benfica & $\begin{array}{r}22^{\circ} 53^{\prime} 6.973 \mathrm{~S} \\
43^{\circ} 15^{\prime} 8.826^{\prime \prime} \mathrm{W}^{\prime \prime}\end{array}$ \\
\hline 1683 & Avenida Dom Helder Câmara & Av dos Democráticos & $\begin{array}{r}22^{\circ} 53^{\prime} 6.973 \mathrm{~S} \\
43^{\circ} 15^{\prime} 8.826^{\prime \prime} \mathrm{W}^{\prime \prime}\end{array}$ \\
\hline 1684 & Avenida Dom Helder Câmara & R Tamiarana & $\begin{array}{r}22^{\circ} 52^{\prime} 49.342 \mathrm{~S} \\
43^{\circ} 15^{\prime} 31.888^{\prime \prime} \mathrm{W}^{\prime \prime}\end{array}$ \\
\hline 1685 & Avenida Dom Helder Câmara & R Cachambi & $\begin{array}{r}22^{\circ} 52^{\prime} 50.909 \mathrm{~S} \\
43^{\circ} 16^{\prime} 19.104^{\prime \prime} \mathrm{W}^{\prime \prime}\end{array}$ \\
\hline 1686 & Avenida Dom Helder Câmara & R Ibiraci & $\begin{array}{r}22^{\circ} 53^{\prime} 14.366 \mathrm{~S} \\
43^{\circ} 16^{\prime} 58.121^{\prime \prime} \mathrm{W}^{\prime \prime}\end{array}$ \\
\hline 1687 & Avenida Dom Helder Câmara & R Fernão Cardim & $\begin{array}{r}22^{\circ} 53^{\prime} 10.851 \mathrm{~S} \\
43^{\circ} 17^{\prime} 18.281^{\prime \prime} \mathrm{W}^{\prime \prime}\end{array}$ \\
\hline 1688 & Avenida Dom Helder Câmara & Ln Amarela & $\begin{array}{r}22^{\circ} 53^{\prime} 7.758 \mathrm{~S} \\
43^{\circ} 17^{\prime} 23.240^{\prime \prime} \mathrm{W}^{\prime \prime}\end{array}$ \\
\hline 1689 & Avenida Dom Helder Câmara & Pça Brg. Clóvis Travassos & $\begin{array}{r}22^{\circ} 53^{\prime} 1.883 \mathrm{~S} \\
43^{\circ} 17^{\prime} 28.658^{\prime \prime} \mathrm{W}^{\prime \prime}\end{array}$ \\
\hline 1690 & Avenida Dom Helder Câmara & R Alfredo de Sousa Mendes & $\begin{array}{r}22^{\circ} 52^{\prime} 54.901 \mathrm{~S} \\
43^{\circ} 17^{\prime} 34.605^{\prime \prime} \mathrm{W}^{\prime \prime}\end{array}$ \\
\hline 1691 & Avenida Dom Helder Câmara & R da Abolição & $\begin{array}{r}22^{\circ} 52^{\prime} 57.724 \mathrm{~S} \\
43^{\circ} 17^{\prime} 46.435^{\prime \prime} \mathrm{W}^{\prime \prime}\end{array}$ \\
\hline 1692 & Avenida Dom Helder Câmara & R Cerqueira Daltro & $\begin{array}{r}22^{\circ} 53^{\prime} 5.484 \mathrm{~S} \\
43^{\circ} 18^{\prime} 41.722^{\prime \prime} \mathrm{W}^{\prime \prime}\end{array}$ \\
\hline 1693 & Avenida Dom Helder Câmara & R Silva Gomes & $\begin{array}{r}22^{\circ} 52^{\prime} 55.294 \mathrm{~S} \\
43^{\circ} 19^{\prime} 37.911^{\prime \prime} \mathrm{W}^{\prime \prime}\end{array}$ \\
\hline 1694 & Elevado Eng. Freyssinet & R Haddock Lobo & $\begin{array}{r}22^{\circ} 55^{\prime} 27.132 \mathrm{~S} \\
43^{\circ} 12^{\prime} 34.687^{\prime \prime} \mathrm{W}^{\prime \prime}\end{array}$ \\
\hline 1695 & Elevado Eng. Freyssinet & Vevd Prf. Rufino de Almeida Pizarro & $\begin{array}{r}22^{\circ} 54 ' 53.246 \mathrm{~S} \\
43^{\circ} 12^{\prime} 36.434^{\prime \prime} \mathrm{W}^{\prime \prime}\end{array}$ \\
\hline 1696 & Elevado Eng. Freyssinet & R Haddock Lobo & $\begin{array}{r}22^{\circ} 54^{\prime} 53.285 \mathrm{~S} \\
43^{\circ} 12^{\prime} 36.767^{\prime \prime} \mathrm{W}^{\prime \prime}\end{array}$ \\
\hline 1697 & Elevado Eng. Freyssinet & Av Vital Brasil & $\begin{array}{r}22^{\circ} 55^{\prime} 27.234 \mathrm{~S} \\
43^{\circ} 12^{\prime} 35.032^{\prime \prime} \mathrm{W}^{\prime \prime}\end{array}$ \\
\hline 1698 & Avenida Pasteur & R Bartolomeu Portela & $\begin{array}{r}22^{\circ} 57^{\prime} 4.374 \mathrm{~S} \\
43^{\circ} 10^{\prime} 31.133^{\prime \prime W}\end{array}$ \\
\hline 1699 & Avenida Pasteur & Av Rep. Nestor Moreira & $\begin{array}{r}22^{\circ} 57^{\prime} 0.416 \mathrm{~S} \\
43^{\circ} 10^{\prime} 37.095^{\prime \prime} \mathrm{W}^{\prime \prime}\end{array}$ \\
\hline 1700 & Avenida Armando Lombardi & Av das Américas & $\begin{array}{r}23^{\circ} 0^{\prime} 25.859 \mathrm{~S} \\
43^{\circ} 18^{\prime} 19.230^{\prime \prime} \mathrm{W}^{\prime \prime}\end{array}$ \\
\hline 1701 & Avenida Armando Lombardi & R Cel. Eurico de Souza G Filho & $\begin{array}{r}23^{\circ} 0 ' 22.266 \mathrm{~S} \\
43^{\circ} 19^{\prime} 0.166^{\prime \prime} \mathrm{W}^{\prime \prime}\end{array}$ \\
\hline 1702 & Avenida Armando Lombardi & Av Afonso de Taunay & $\begin{array}{r}23^{\circ} 0{ }^{\prime} 23.252 \mathrm{~S} \\
43^{\circ} 18^{\prime} 56.361 " \mathrm{~W}^{\prime \prime}\end{array}$ \\
\hline
\end{tabular}




\begin{tabular}{|c|c|c|c|}
\hline ordem & corredor & endereco & coordenadas \\
\hline 1703 & Avenida Armando Lombardi & R Pedro Bolato & $\begin{array}{r}23^{\circ} 0 ' 25.710 \mathrm{~S} \\
43^{\circ} 18^{\prime} 33.155^{\prime \prime} \mathrm{W}^{\prime \prime}\end{array}$ \\
\hline 1704 & Avenida Armando Lombardi & Av Min. Ivan Lins & $\begin{array}{r}23^{\circ} 0 ' 26.314 \mathrm{~S} \\
43^{\circ} 18^{\prime} 20.665^{\prime \prime} \mathrm{W}^{\prime \prime}\end{array}$ \\
\hline 1705 & Autoestrada Lagoa-Barra & Av Pref. Mendes de Morais & $\begin{array}{r}23^{\circ} 0^{\prime} 1.653 \mathrm{~S} \\
43^{\circ} 16^{\prime} 23.619^{\prime \prime} \mathrm{W}^{\prime \prime}\end{array}$ \\
\hline 1706 & Autoestrada Lagoa-Barra & R Herbert Moses & $\begin{array}{r}22^{\circ} 59^{\prime} 55.192 \mathrm{~S} \\
43^{\circ} 16^{\prime} 3.695^{\prime \prime} \mathrm{W}^{\prime \prime}\end{array}$ \\
\hline 1707 & Autoestrada Lagoa-Barra & Av Niemeyer & $\begin{array}{r}22^{\circ} 59^{\prime} 44.892 \mathrm{~S} \\
43^{\circ} 15^{\prime} 33.485^{\prime \prime} \mathrm{W}^{\prime \prime}\end{array}$ \\
\hline 1708 & Autoestrada Lagoa-Barra & R Berta Lutz & $\begin{array}{r}22^{\circ} 59^{\prime} 33.695 \mathrm{~S} \\
43^{\circ} 15^{\prime} 8.681^{\prime \prime} \mathrm{W}^{\prime \prime}\end{array}$ \\
\hline 1709 & Autoestrada Lagoa-Barra & Av Pe. Leonel França & $\begin{array}{r}22^{\circ} 58^{\prime} 56.739 \mathrm{~S} \\
43^{\circ} 14^{\prime} 6.307^{\prime \prime} \mathrm{W}^{\prime \prime}\end{array}$ \\
\hline 1710 & Autoestrada Lagoa-Barra & R Alexandre Stockler & $\begin{array}{r}22^{\circ} 58^{\prime} 56.114 \mathrm{~S} \\
43^{\circ} 14^{\prime} 6.078^{\prime \prime} \mathrm{W}^{\prime}\end{array}$ \\
\hline 1711 & Autoestrada Lagoa-Barra & Av Niemeyer & $\begin{array}{r}22^{\circ} 59^{\prime} 32.988 \mathrm{~S} \\
43^{\circ} 15^{\prime} 7.209^{\prime \prime} \mathrm{W}^{\prime \prime}\end{array}$ \\
\hline 1712 & Autoestrada Lagoa-Barra & Estr da Gávea & $\begin{array}{r}22^{\circ} 59^{\prime} 53.932 \mathrm{~S} \\
43^{\circ} 16^{\prime} 2.418^{\prime \prime} \mathrm{W}^{\prime \prime}\end{array}$ \\
\hline 1713 & Autoestrada Lagoa-Barra & Tun S. Conrado & $\begin{array}{r}22^{\circ} 59^{\prime} 58.485 \mathrm{~S} \\
43^{\circ} 16^{\prime} 21.829^{\prime \prime} \mathrm{W}^{\prime \prime}\end{array}$ \\
\hline 1714 & Avenida Bartolomeu Mitre & Av Delfim Moreira & $\begin{array}{r}22^{\circ} 59^{\prime} 13.374 \mathrm{~S} \\
43^{\circ} 13^{\prime} 20.824^{\prime \prime} \mathrm{W}^{\prime \prime}\end{array}$ \\
\hline 1715 & Avenida Bartolomeu Mitre & R Des. Alfredo Russel & $\begin{array}{r}22^{\circ} 59^{\prime} 3.035 \mathrm{~S} \\
43^{\circ} 13^{\prime} 23.416^{\prime \prime} \mathrm{W}^{\prime \prime}\end{array}$ \\
\hline 1716 & Avenida Bartolomeu Mitre & R Mário Ribeiro & $\begin{array}{r}22^{\circ} 58^{\prime} 47.208 \mathrm{~S} \\
43^{\circ} 13^{\prime} 27.585^{\prime \prime} \mathrm{W}^{\prime \prime}\end{array}$ \\
\hline 1717 & Avenida Bartolomeu Mitre & Av Vsc. de Albuquerque & $\begin{array}{r}22^{\circ} 58^{\prime} 38.399 \mathrm{~S} \\
43^{\circ} 13^{\prime} 29.702^{\prime \prime} \mathrm{W}^{\prime \prime}\end{array}$ \\
\hline 1718 & Avenida Bartolomeu Mitre & R Jardim Botânico & $\begin{array}{r}22^{\circ} 58^{\prime} 32.166 \mathrm{~S} \\
43^{\circ} 13^{\prime} 31.972^{\prime \prime} \mathrm{W}^{\prime \prime}\end{array}$ \\
\hline 1719 & Avenida Bartolomeu Mitre & Av Rodrigo Otavio & $\begin{array}{r}22^{\circ} 58^{\prime} 28.814 \mathrm{~S} \\
43^{\circ} 13^{\prime} 34.540^{\prime \prime} \mathrm{W}^{\prime \prime}\end{array}$ \\
\hline 1720 & $\begin{array}{l}\text { Avenida Bartolomeu Mitre - } \\
\text { pista lateral }\end{array}$ & R Mário Ribeiro & $\begin{array}{r}22^{\circ} 58^{\prime} 46.911 \mathrm{~S} \\
43^{\circ} 13^{\prime} 25.932^{\prime \prime} \mathrm{W}^{\prime \prime}\end{array}$ \\
\hline 1721 & Avenida Osvaldo Aranha & R Pará & $\begin{array}{r}22^{\circ} 54^{\prime} 38.886 \mathrm{~S} \\
43^{\circ} 12^{\prime} 52.204^{\prime \prime} \mathrm{W}^{\prime \prime}\end{array}$ \\
\hline 1722 & Avenida Osvaldo Aranha & Av Pres. Castelo Branco & $\begin{array}{r}22^{\circ} 54^{\prime} 36.728 \mathrm{~S} \\
43^{\circ} 13^{\prime} 9.139^{\prime \prime} \mathrm{W}^{\prime \prime}\end{array}$ \\
\hline 1723 & Avenida Padre Leonel Franca & Av Rodrigo Otavio & $\begin{array}{r}22^{\circ} 58^{\prime} 42.071 \mathrm{~S} \\
43^{\circ} 13^{\prime} 35.946^{\prime \prime} \mathrm{W}^{\prime \prime}\end{array}$ \\
\hline 1724 & Avenida Padre Leonel Franca & Estr Lagoa Barra & $\begin{array}{r}22^{\circ} 58^{\prime} 43.854 \mathrm{~S} \\
43^{\circ} 13^{\prime} 43.554^{\prime \prime} \mathrm{W}^{\prime \prime}\end{array}$ \\
\hline
\end{tabular}




\begin{tabular}{|c|c|c|c|}
\hline ordem & corredor & endereco & coordenadas \\
\hline 1725 & Avenida Padre Leonel Franca & R Mário Ribeiro & $\begin{array}{r}22^{\circ} 58^{\prime} 44.481 \mathrm{~S} \\
43^{\circ} 13^{\prime} 43.635^{\prime \prime} \mathrm{W}^{\prime \prime}\end{array}$ \\
\hline 1726 & $\begin{array}{l}\text { Avenida Pres. Castelo Branco - } \\
\text { Radial Oeste }\end{array}$ & Vd Oduvaldo Cozzi & $\begin{array}{r}22^{\circ} 54^{\prime} 37.902 \mathrm{~S} \\
43^{\circ} 13^{\prime} 23.630^{\prime \prime} \mathrm{W}^{\prime \prime}\end{array}$ \\
\hline 1727 & Avenida Rio de Janeiro & Vevd da Perimetral & $\begin{array}{r}22^{\circ} 53 ' 50.533 \mathrm{~S} \\
43^{\circ} 12^{\prime} 42.992^{\prime \prime} \mathrm{W}^{\prime \prime}\end{array}$ \\
\hline 1728 & Avenida Rio de Janeiro & R Eduardo Luíz Lopes & $\begin{array}{r}22^{\circ} 53^{\prime} 44.591 \mathrm{~S} \\
43^{\circ} 12^{\prime} 47.340^{\prime \prime} \mathrm{W}^{\prime \prime}\end{array}$ \\
\hline 1729 & Avenida Rio de Janeiro & R Alm. Mariath & $\begin{array}{r}22^{\circ} 53^{\prime} 35.131 \mathrm{~S} \\
43^{\circ} 12^{\prime} 51.964^{\prime \prime} \mathrm{W}^{\prime \prime}\end{array}$ \\
\hline 1730 & Avenida Rio de Janeiro & Av Brasil & $\begin{array}{r}22^{\circ} 53^{\prime} 23.140 \mathrm{~S} \\
43^{\circ} 12^{\prime} 57.736^{\prime \prime} \mathrm{W}^{\prime \prime}\end{array}$ \\
\hline 1731 & Avenida Rio de Janeiro & Av Rodrigues Alves & $\begin{array}{r}22^{\circ} 53^{\prime} 30.944 \mathrm{~S} \\
43^{\circ} 12^{\prime} 52.595^{\prime \prime} \mathrm{W}^{\prime \prime}\end{array}$ \\
\hline 1732 & Avenida Lúcio Costa & R Condomínio Vivendas da Barra & $\begin{array}{r}23^{\circ} 0^{\prime} 45.273 \mathrm{~S} \\
43^{\circ} 19^{\prime} 9.943^{\prime \prime} \mathrm{W}^{\prime \prime}\end{array}$ \\
\hline 1733 & Avenida Lúcio Costa & Av Ayrton Senna & $\begin{array}{r}23^{\circ} 0{ }^{\prime} 36.589 \mathrm{~S} \\
43^{\circ} 20^{\prime} 42.856^{\prime \prime} \mathrm{W}^{\prime \prime}\end{array}$ \\
\hline 1734 & Avenida Lúcio Costa & Av do Contorno & $\begin{array}{r}23^{\circ} 0{ }^{\prime} 38.937 \mathrm{~S} \\
43^{\circ} 22^{\prime} 12.884^{\prime \prime} \mathrm{W}^{\prime \prime}\end{array}$ \\
\hline 1735 & Avenida Lúcio Costa & Av Pedro Moura & $\begin{array}{r}23^{\circ} 1^{\prime} 20.241 \mathrm{~S} \\
43^{\circ} 26^{\prime} 52.200^{\prime \prime} \mathrm{W}^{\prime \prime}\end{array}$ \\
\hline 1736 & Avenida Lúcio Costa & Av Glaucio Gil & $\begin{array}{r}23^{\circ} 1 ' 24.955 \mathrm{~S} \\
43^{\circ} 27^{\prime} 10.408^{\prime \prime} \mathrm{W}^{\prime \prime}\end{array}$ \\
\hline 1737 & Avenida Lúcio Costa & Av Armando Ribeiro & $\begin{array}{r}23^{\circ} 1^{\prime} 37.162 \mathrm{~S} \\
43^{\circ} 27^{\prime} 49.556^{\prime \prime} \mathrm{W}^{\prime \prime}\end{array}$ \\
\hline 1738 & Avenida Lúcio Costa & Estr do Pontal & $\begin{array}{r}23^{\circ} 11^{\prime} 50.391 \mathrm{~S} \\
43^{\circ} 28^{\prime} 14.736^{\prime \prime} \mathrm{W}^{\prime \prime}\end{array}$ \\
\hline 1739 & Avenida Lúcio Costa & Barra da Tijuca & $\begin{array}{r}23^{\circ} 11^{\prime} 32.590 \mathrm{~S} \\
43^{\circ} 27^{\prime} 33.602^{\prime \prime} \mathrm{W}^{\prime \prime}\end{array}$ \\
\hline 1740 & Avenida Lúcio Costa & Av Ayrton Senna & $\begin{array}{r}23^{\circ} 0{ }^{\prime} 54.995 \mathrm{~S} \\
43^{\circ} 24^{\prime} 35.240^{\prime \prime} \mathrm{W}^{\prime \prime}\end{array}$ \\
\hline 1741 & Avenida Lúcio Costa & Av Érico Veríssimo & $\begin{array}{r}23^{\circ} 0 ' 37.004 \mathrm{~S} \\
43^{\circ} 20^{\prime} 55.968^{\prime \prime} \mathrm{W}^{\prime \prime}\end{array}$ \\
\hline 1742 & Avenida Beira Mar & Av Gen. Justo & $\begin{array}{r}22^{\circ} 54^{\prime} 41.194 \mathrm{~S} \\
43^{\circ} 10^{\prime} 9.058^{\prime \prime} \mathrm{W}^{\prime \prime}\end{array}$ \\
\hline 1743 & Avenida Beira Mar & Av Mal. Câmara & $\begin{array}{r}22^{\circ} 54^{\prime} 39.599 \mathrm{~S} \\
43^{\circ} 10^{\prime} 10.008^{\prime \prime} \mathrm{W}^{\prime \prime}\end{array}$ \\
\hline 1744 & Avenida Beira Mar & Av Pres. Antônio Carlos & $\begin{array}{r}22^{\circ} 54^{\prime} 38.501 \mathrm{~S} \\
43^{\circ} 10^{\prime} 14.317^{\prime \prime} \mathrm{W}^{\prime \prime}\end{array}$ \\
\hline 1745 & Avenida Beira Mar & Pça Itália & $\begin{array}{r}22^{\circ} 54^{\prime} 38.936 \mathrm{~S} \\
43^{\circ} 10^{\prime} 17.636^{\prime \prime} \mathrm{W}^{\prime \prime}\end{array}$ \\
\hline 1746 & Avenida Beira Mar & R do Russel & $\begin{array}{r}22^{\circ} 55^{\prime} 15.798 \mathrm{~S} \\
43^{\circ} 10^{\prime} 25.712^{\prime \prime} \mathrm{W}^{\prime \prime}\end{array}$ \\
\hline
\end{tabular}




\begin{tabular}{|c|c|c|c|}
\hline ordem & corredor & endereco & coordenadas \\
\hline 1747 & Avenida Beira Mar & Praia do Flamengo & $\begin{array}{r}22^{\circ} 55^{\prime} 23.804 \mathrm{~S} \\
43^{\circ} 10^{\prime} 20.516^{\prime \prime} \mathrm{W}^{\prime \prime}\end{array}$ \\
\hline 1748 & Avenida Beira Mar & R do Russel & $\begin{array}{r}22^{\circ} 55^{\prime} 21.647 \mathrm{~S} \\
43^{\circ} 10^{\prime} 20.270^{\prime \prime} \mathrm{W}^{\prime \prime}\end{array}$ \\
\hline 1749 & Avenida Beira Mar & R Teixeira de Freitas & $\begin{array}{r}22^{\circ} 55^{\prime} 4.092 \mathrm{~S} \\
43^{\circ} 10^{\prime} 30.867^{\prime \prime} \mathrm{W}^{\prime \prime}\end{array}$ \\
\hline 1750 & Avenida Beira Mar & Av Rio Branco & $\begin{array}{r}22^{\circ} 54 ' 51.290 \mathrm{~S} \\
43^{\circ} 10^{\prime} 28.818^{\prime \prime} \mathrm{W}^{\prime \prime}\end{array}$ \\
\hline 1751 & Avenida Beira Mar & Av Rio Branco & $\begin{array}{r}22^{\circ} 54^{\prime} 47.791 \mathrm{~S} \\
43^{\circ} 10^{\prime} 26.620^{\prime \prime} \mathrm{W}^{\prime \prime}\end{array}$ \\
\hline 1752 & Avenida Beira Mar & Pça Itália & $\begin{array}{r}22^{\circ} 54^{\prime} 42.925 \mathrm{~S} \\
43^{\circ} 10^{\prime} 22.210^{\prime \prime} \mathrm{W}^{\prime \prime}\end{array}$ \\
\hline 1753 & Avenida Beira Mar & Trevo Édson & $\begin{array}{r}22^{\circ} 54^{\prime} 39.308 \mathrm{~S} \\
43^{\circ} 10^{\prime} 14.735^{\prime \prime} \mathrm{W}^{\prime \prime}\end{array}$ \\
\hline 1754 & Avenida Beira Mar & Av Gen. Justo & $\begin{array}{r}22^{\circ} 54^{\prime} 40.193 \mathrm{~S} \\
43^{\circ} 10^{\prime} 10.266^{\prime \prime} \mathrm{W}^{\prime \prime}\end{array}$ \\
\hline 1755 & Avenida Beira Mar & Av Gen. Justo & $\begin{array}{r}22^{\circ} 54^{\prime} 41.403 \mathrm{~S} \\
43^{\circ} 10^{\prime} 9.528^{\prime \prime} \mathrm{W}^{\prime \prime}\end{array}$ \\
\hline 1756 & Avenida Beira Mar & R Teixeira de Freitas & $\begin{array}{r}22^{\circ} 55^{\prime} 4.271 \mathrm{~S} \\
43^{\circ} 10^{\prime} 31.385^{\prime \prime} \mathrm{W}^{\prime \prime}\end{array}$ \\
\hline 1757 & Avenida Beira Mar & R Teixeira de Freitas & $\begin{array}{r}22^{\circ} 54^{\prime} 53.192 \mathrm{~S} \\
43^{\circ} 10^{\prime} 30.083^{\prime \prime} \mathrm{W}^{\prime \prime}\end{array}$ \\
\hline 1758 & Avenida Beira Mar & Av Rio Branco & $\begin{array}{r}22^{\circ} 54^{\prime} 50.730 \mathrm{~S} \\
43^{\circ} 10^{\prime} 29.161^{\prime \prime} \mathrm{W}^{\prime \prime}\end{array}$ \\
\hline 1759 & Avenida Beira Mar & Av Rio Branco & $\begin{array}{r}22^{\circ} 54^{\prime} 47.472 \mathrm{~S} \\
43^{\circ} 10^{\prime} 27.232^{\prime \prime} \mathrm{W}^{\prime \prime}\end{array}$ \\
\hline 1760 & Avenida Beira Mar & Av Pres. Antônio Carlos & $\begin{array}{r}22^{\circ} 54^{\prime} 42.723 \mathrm{~S} \\
43^{\circ} 10^{\prime} 22.854^{\prime \prime} \mathrm{W}^{\prime \prime}\end{array}$ \\
\hline 1761 & Ponte da Joatinga & R Srg. João de Faria & $\begin{array}{r}23^{\circ} 00^{\prime} 45.377 \mathrm{~S} \\
43^{\circ} 17^{\prime} 56.064^{\prime \prime} \mathrm{W}^{\prime \prime}\end{array}$ \\
\hline 1762 & Ponte da Joatinga & R do Canal & $\begin{array}{r}23^{\circ} 0^{\prime} 47.781 \mathrm{~S} \\
43^{\circ} 17^{\prime} 48.628^{\prime \prime} \mathrm{W}^{\prime \prime}\end{array}$ \\
\hline 1763 & Ponte da Joatinga & R Maria Luísa Pitanga & $\begin{array}{r}23^{\circ} 0^{\prime} 46.753 \mathrm{~S} \\
43^{\circ} 17^{\prime} 41.416^{\prime \prime} \mathrm{W}^{\prime \prime}\end{array}$ \\
\hline 1764 & Ponte da Joatinga & Tun do Joá & $\begin{array}{r}23^{\circ} 0{ }^{\prime} 44.649 \mathrm{~S} \\
43^{\circ} 17^{\prime} 34.102^{\prime \prime} \mathrm{W}^{\prime \prime}\end{array}$ \\
\hline 1765 & Ponte da Joatinga & R Maria Luísa Pitanga & $\begin{array}{r}23^{\circ} 0^{\prime} 44.199 \mathrm{~S} \\
43^{\circ} 17^{\prime} 33.882^{\prime \prime}{ }^{\prime \prime}\end{array}$ \\
\hline 1766 & Ponte da Joatinga & $\mathrm{R}$ do Canal & $\begin{array}{r}23^{\circ} 0^{\prime} 46.302 \mathrm{~S} \\
43^{\circ} 17^{\prime} 41.2711^{\prime \prime}\end{array}$ \\
\hline 1767 & Ponte da Joatinga & R Srg. João de Faria & $\begin{array}{r}23^{\circ} 00^{\prime} 47.429 \mathrm{~S} \\
43^{\circ} 17^{\prime} 48.450^{\prime \prime} \mathrm{W}^{\prime \prime}\end{array}$ \\
\hline 1768 & Ponte da Joatinga & Av Min. Ivan Lins & $\begin{array}{r}23^{\circ} 0^{\prime} 44.607 \mathrm{~S} \\
43^{\circ} 17^{\prime} 56.628^{\prime \prime} \mathrm{W}^{\prime \prime}\end{array}$ \\
\hline
\end{tabular}




\begin{tabular}{|c|c|c|c|}
\hline ordem & corredor & endereco & coordenadas \\
\hline 1769 & Rua Mario Ribeiro & Av Bartolomeu Mitre & $\begin{array}{r}22^{\circ} 58^{\prime} 38.740 \mathrm{~S} \\
43^{\circ} 13^{\prime} 18.273^{\prime \prime} \mathrm{W}^{\prime \prime}\end{array}$ \\
\hline 1770 & Rua Mario Ribeiro & Av Pe. Leonel França & $\begin{array}{r}22^{\circ} 58^{\prime} 41.386 \mathrm{~S} \\
43^{\circ} 13^{\prime} 31.886^{\prime \prime} \mathrm{W}^{\prime \prime}\end{array}$ \\
\hline 1771 & Rua Mario Ribeiro & R Vsc. de Albuquerque & $\begin{array}{r}22^{\circ} 58^{\prime} 42.422 \mathrm{~S} \\
43^{\circ} 13^{\prime} 35.160^{\prime \prime} \mathrm{W}^{\prime \prime}\end{array}$ \\
\hline 1772 & Rua Mario Ribeiro & Av Bartolomeu Mitre & $\begin{array}{r}22^{\circ} 58^{\prime} 41.413 \mathrm{~S} \\
43^{\circ} 13^{\prime} 28.827^{\prime \prime} \mathrm{W}^{\prime \prime}\end{array}$ \\
\hline 1773 & Rua Mario Ribeiro & Av Borges de Medeiros & $\begin{array}{r}22^{\circ} 58^{\prime} 39.459 \mathrm{~S} \\
43^{\circ} 13^{\prime} 19.402^{\prime \prime} \mathrm{W}^{\prime \prime}\end{array}$ \\
\hline 1774 & Túnel do Pasmado & Av Pasteur & $\begin{array}{r}22^{\circ} 57^{\prime} 1.795 \mathrm{~S} \\
43^{\circ} 10^{\prime} 48.151^{\prime \prime} "\end{array}$ \\
\hline 1775 & Túnel do Pasmado & Vd Pedro Álvares Cabral & $\begin{array}{r}22^{\circ} 57^{\prime} 2.901 \mathrm{~S} \\
43^{\circ} 10^{\prime} 47.572^{\prime \prime} \mathrm{W}^{\prime \prime}\end{array}$ \\
\hline 1776 & Túnel do Pasmado & R Bartolomeu Portela & $\begin{array}{r}22^{\circ} 57^{\prime} 6.790 \mathrm{~S} \\
43^{\circ} 10^{\prime} 46.082^{\prime \prime} \mathrm{W}^{\prime \prime}\end{array}$ \\
\hline 1777 & Túnel Zuzu Angel & Estr Lagoa Barra & $\begin{array}{r}22^{\circ} 59^{\prime} 21.680 \mathrm{~S} \\
43^{\circ} 14^{\prime} 40.445^{\prime \prime} \mathrm{W}^{\prime \prime}\end{array}$ \\
\hline 1778 & Túnel Zuzu Angel & R Alexandre Stoclker & $\begin{array}{r}22^{\circ} 59^{\prime} 23.514 \mathrm{~S} \\
43^{\circ} 14^{\prime} 41.239^{\prime \prime} \mathrm{W}^{\prime \prime}\end{array}$ \\
\hline 1779 & Viaduto de Manguinhos & Av Brasil & $\begin{array}{r}22^{\circ} 52^{\prime} 15.636 \mathrm{~S} \\
43^{\circ} 14^{\prime} 46.118^{\prime \prime} \mathrm{W}^{\prime \prime}\end{array}$ \\
\hline 1780 & Viaduto de Manguinhos & Av Bento Ribeiro Dantas & $\begin{array}{r}22^{\circ} 52^{\prime} 12.890 \mathrm{~S} \\
43^{\circ} 14^{\prime} 41.152^{\prime \prime} \mathrm{W}^{\prime \prime}\end{array}$ \\
\hline 1781 & Viaduto de Manguinhos & Av Brasil & $\begin{array}{r}22^{\circ} 52^{\prime} 15.727 \mathrm{~S} \\
43^{\circ} 14^{\prime} 47.163^{\prime \prime} \mathrm{W}^{\prime \prime}\end{array}$ \\
\hline 1782 & Viaduto de Manguinhos & Ln Amarela & $\begin{array}{r}22^{\circ} 52^{\prime} 16.350 \mathrm{~S} \\
43^{\circ} 14^{\prime} 48.359^{\prime \prime} \mathrm{W}^{\prime \prime}\end{array}$ \\
\hline 1783 & Viaduto do Gasômetro & Vevd da Perimetral & $\begin{array}{r}22^{\circ} 53^{\prime} 54.648 \mathrm{~S} \\
43^{\circ} 12^{\prime} 38.765^{\prime \prime} \mathrm{W}^{\prime \prime}\end{array}$ \\
\hline 1784 & Túnel São Conrado & Estr Lagoa Barra & $\begin{array}{r}23^{\circ} 0^{\prime} 12.443 \mathrm{~S} \\
43^{\circ} 16^{\prime} 36.458^{\prime \prime} \mathrm{W}^{\prime \prime}\end{array}$ \\
\hline 1785 & Estrada da Pedra & Estr do Piaí & $\begin{array}{r}22^{\circ} 57^{\prime} 31.148 \mathrm{~S} \\
43^{\circ} 39^{\prime} 0.341^{\prime \prime} \mathrm{W}^{\prime \prime}\end{array}$ \\
\hline 1786 & Estrada da Pedra & R Gen. Alexandre Barreto & $\begin{array}{r}22^{\circ} 57^{\prime} 33.513 \mathrm{~S} \\
43^{\circ} 39^{\prime} 0.199^{\prime \prime} \mathrm{W}^{\prime \prime}\end{array}$ \\
\hline 1787 & Estrada da Pedra & Av Cesário de Melo & $\begin{array}{r}22^{\circ} 56^{\prime} 41.166 \mathrm{~S} \\
43^{\circ} 39^{\prime} 35.704^{\prime \prime} \mathrm{W}^{\prime \prime}\end{array}$ \\
\hline 1788 & Estrada da Gávea & R Gen. Olímpio Mourão Filho & $\begin{array}{r}22^{\circ} 59^{\prime} 34.007 \mathrm{~S} \\
43^{\circ} 15^{\prime} 18.526^{\prime \prime} \mathrm{W}^{\prime \prime}\end{array}$ \\
\hline 1789 & Estrada da Gávea & Estr Lagoa Barra & $\begin{array}{r}22^{\circ} 59^{\prime} 46.902 \mathrm{~S} \\
43^{\circ} 15^{\prime} 39.014^{\prime \prime} \mathrm{W}^{\prime \prime}\end{array}$ \\
\hline 1790 & $\begin{array}{l}\text { Avenida Pres. Castelo Branco - } \\
\text { Radial Oeste }\end{array}$ & Vd Oduvaldo Cozzi & $\begin{array}{r}22^{\circ} 54^{\prime} 37.902 \mathrm{~S} \\
43^{\circ} 13^{\prime} 23.630^{\prime \prime} \mathrm{W}^{\prime \prime}\end{array}$ \\
\hline
\end{tabular}




\begin{tabular}{|r|l|l|r|}
\hline \multicolumn{1}{|c|}{ ordem } & \multicolumn{1}{|c|}{ corredor } & \multicolumn{1}{c|}{ condereco } & $\begin{array}{r}22^{\circ} 54^{\prime} 11.811 \mathrm{~S} \\
43^{\circ} 10^{\prime} 21.954^{\prime \prime} \mathrm{W}^{\prime \prime}\end{array}$ \\
\hline 1791 & Avenida Alfred Agache & Vevd da Perimetral & $22^{\circ} 54^{\prime} 12.213 \mathrm{~S}$ \\
$43^{\circ} 10^{\prime} 22.865^{\prime \prime} \mathrm{W}^{\prime \prime}$ \\
\hline
\end{tabular}

